ALISSON ALVES SARMENTO

UNIÃO DE CHAPAS DE AÇO POR CONFORMAÇÃO A FRIO: ANÁLISE DA RESISTÊNCIA MECÂNICA SOB CARGA MULTIAXIAL 


\section{UNIÃO DE CHAPAS DE AÇO POR CONFORMAÇÃO A FRIO: ANÁLISE DA RESISTÊNCIA MECÂNICA SOB CARGA MULTIAXIAL}

Dissertação apresentada à Escola Politécnica da Universidade de São Paulo para obtenção do título de Mestre em Engenharia Mecânica

Área de Concentração:

Engenharia Mecânica de Projeto e Fabricação

Orientador: Prof. Dr. Gilmar Ferreira Batalha 
Este exemplar foi revisado e alterado em relação à versão original, sob responsabilidade única do autor e com a anuência do seu orientador.

São Paulo, 10 de Fevereiro 2012

Assinatura do autor

Assinatura do orientador

FICHA CATALOGRÁFICA

Sarmento, Alisson Alves

União de chapas de aço por conformação a frio: análise da resistência mecânica sob carga multiaxial / A.A. Sarmento. -ed.rev. -- São Paulo, 2012.

$112 \mathrm{p}$.

Dissertação (Mestrado) - Escola Politécnica da Universidade de São Paulo. Departamento de Engenharia Mecânica.

1. Conformação mecânica 2. Soldagem por ponto 3. Juntas soldadas 4. Aço baixo carbono I. Universidade de São Paulo. Escola Politécnica. Departamento de Engenharia Mecânica II. t. 


\section{DEDICATÓRIA}

Dedico esse trabalho a toda minha família, em especial às minhas avós Dona Chica e Mimosa, e aos meus avos Caboclo e Zé Ferreira (in memoriam). 


\section{AGRADECIMENTOS}

Ao meu orientador Prof. Dr. Gilmar Ferreira Batalha por todo o apoio dado e principalmente pelo conhecimento compartilhado durante a realização desse trabalho.

Aos Professores, Dr. João Telésforo Nobrega de Medeiros e Dr. Éd Claudio Bordinassi, que neste trabalho, deram grandes contribuições.

Aos meus pais, Isabel e Francisco, que sempre me mostraram a importância do conhecimento na vida de um ser humano.

Ao meu irmão Cleber, que foi e sempre será a minha referência de competência acadêmica e profissional.

À minha namorada Danielle, que esteve ao meu lado me apoiando nos momentos conclusivos deste trabalho.

À Escola Politécnica da Universidade de São Paulo, por toda infraestrutura fornecida e também pela oportunidade oferecida.

Ao Instituto Mauá de Tecnologia, pela ajuda na obtenção das imagens dos corpos de prova, tornando possível a realização das análises metalográficas.

À General Motors do Brasil, em especial Antônio Caputo que me apoiou nos estudos. Sinceros agradecimentos também a Rita Binda, Dorisvaldo Bisaio, André Arroio, Alexandre Souza Rodrigues, Mario Passerini, Vinicius Deangelo Chaves e Leandro Fleires.

À empresa TOX Pressotechnik, em especial Leandro de Lemos, Gustavo Shulze e Vanderlei Bastos.

A todas as pessoas que colaboraram na execução e desenvolvimento deste trabalho e que, involuntariamente, foram omitidos. 
“A gravidade explica os movimentos dos planetas, mas não pode explicar quem colocou os planetas em movimento. Deus governa todas as coisas e sabe tudo que é ou que pode ser feito." 


\section{RESUMO}

Este trabalho visou entender e avaliar a resistência mecânica da junção de chapas de aço obtidas pelo processo de União de Chapas por Conformação a Frio (UCCF). Esse processo é conhecido no meio industrial pelo termo em inglês: "clinching" ou "press joining”. O formato de união cilíndrico, também conhecido como "Round”, foi selecionado para unir os corpos de provas. As uniões metálicas ensaiadas foram fabricadas com aço de baixo teor de carbono sem camada superficial de proteção (170MPa de limite de escoamento). O material escolhido é de comum utilização na indústria automotiva. Duas espessuras diferentes foram avaliadas: $0,8 \mathrm{~mm}$ e $1,2 \mathrm{~mm}$. Um completo procedimento foi criado para determinar os parâmetros ideais do processo UCCF baseado nos critérios de falha existentes na literatura e na experiência do fornecedor do equipamento. A união em estudo foi submetida, experimentalmente, a cargas multiaxiais com o auxílio de um dispositivo baseado no ensaio de "Arcan" para possibilitar uma condição de carga combinada, onde foi possível identificar graficamente o comportamento estrutural do corpo de prova em estados de carregamento que variam de tração (normal à superfície do ponto) até cisalhamento (perpendicular à superfície do ponto). Os valores de resistência mecânica encontrados foram de $1,13 \mathrm{kN}$ (mínimo) a $2,55 \mathrm{kN}$ (máximo) para as chapas de aço com espessura de $0,8 \mathrm{~mm}$ e de $1,89 \mathrm{kN}$ (mínimo) e $3,18 \mathrm{kN}$ (máximo) para as chapas de 1,2mm. Um estudo comparativo com Solda Ponto por Resistência Elétrica (SPRE) foi realizado. A UCCF alcançou resultados de 47,68\% dos valores obtidos para a SPRE para chapa com espessura de $0,8 \mathrm{~mm}$ e $37,78 \%$ para chapas de $1,2 \mathrm{~mm}$.

Palavras chave: União de chapas. Conformação mecânica. Clinching. Solda a ponto. Processos de junção. 


\begin{abstract}
The purposes of this work were understand and evaluate cold forming sheet metal joining of steel plates mechanical resistance. This process is well known as clinching or press joining. Round clinching element was selected to be used on all tested specimens due to its industry suitability. The metallic specimens were built on mid carbon steel without zinc coat protection (Yield Stress: 170MPa). This is a common material on automotive industry. Two different thicknesses were evaluated: $0.8 \mathrm{~mm}$ and $1.2 \mathrm{~mm}$. A full procedure to determine ideal clinching parameters was created based on available literature information and clinching supplier know-how. All union technology was experimentally submitted to multiaxial loads using device based on Arcan concept. Joining mechanical behavior curves were plotted from traction (normal to element joint surface) to shear (perpendicular to element joint surface) loads. As a result, $0.8 \mathrm{~mm}$ thickness steel plates achieved load values from $1.13 \mathrm{kN}$ (minimum) to $2.55 \mathrm{kN}$ (maximum), $1.2 \mathrm{~mm}$ thickness steel plates achieved values from $1.89 \mathrm{kN}$ (minimum) e $3.18 \mathrm{kN}$ (maximum). A comparative study was made with Electric Resistance Spot Weld (ERSP). Clinching joining achieved results as $47.68 \%$ and $37.78 \%$ of ERSP loads for $0.8 \mathrm{~mm}$ and $1.2 \mathrm{~mm}$ thickness steel plates respectively.
\end{abstract}

Keywords: Press joining. Clinching. Cold forming. Electric resistance spot weld. Manufacturing process. 


\section{LISTA DE ILUSTRAÇÕES}

Figura 1 - Tendências no desenvolvimento dos métodos de junta ...............................................20

Figura 2 - Vista explodida da carroceria Opel Meriva ${ }^{\circledR}$........................................................... 21

Figura 3 - Custo de processo e investimento de uniões de chapa................................................22

Figura 4 - Processos de Fabricação Mecânica ..............................................................................26

Figura 5 - Seção transversal da junta obtida pelo processo de UCCF.........................................22

Figura 6 - Classificação básica dos elementos de UCCF ......................................................28

Figura 7 - Alguns exemplos de elementos de junta sem material auxiliar ..................................28

Figura 8 - Exemplo de processo de junta com material auxiliar .................................................29

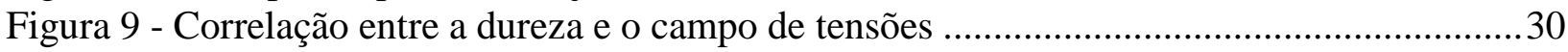

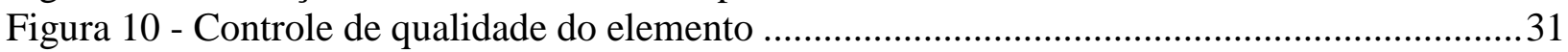

Figura 11 - Análise metalográfica de um Aço St 1203-crs ....................................................... 31

Figura 12 - Seleção de alguns tipos de Ferramenta Padrão pra a UCCF.................................... 32

Figura 13 - Processo de UCCF em único estágio com incisão local ..............................................33

Figura 14 - Processo de UCCF de dois ou múltiplo estágios com incisão local ........................... 34

Figura 15 - Processo de UCCF de único estágio sem incisão local Ferramentas com

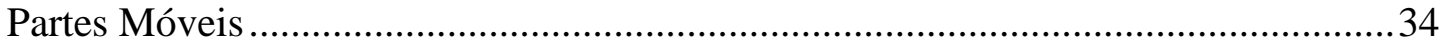

Figura 16 - Processo de UCCF de único estágio sem incisão local Ferramentas sem

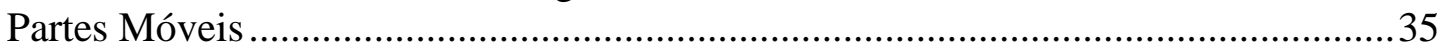

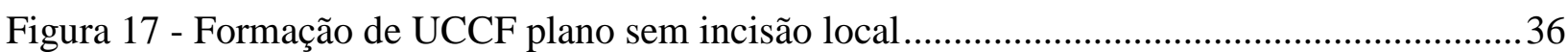

Figura 18 - Aplicação do UCCF plano em uma carroceria automotiva ...................................... 36

Figura 19 - Processo de UCCF plano de múltiplo estágio sem incisão local ............................... 37

Figura 20 - Comparação da área de fixação das chapas nos processo de UCCF .......................... 38

Figura 21 - Comparação dos elementos de UCCF com variação de incisão local e

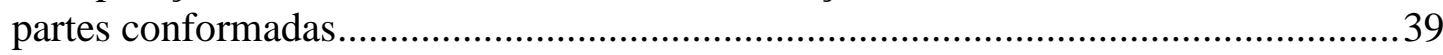

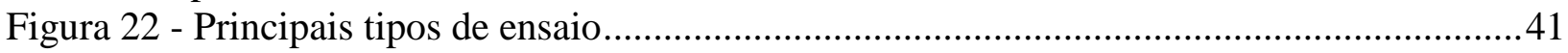

Figura 23 - Gráfico conceitual de descolamento x carga para cisalhamento e tração ...................42

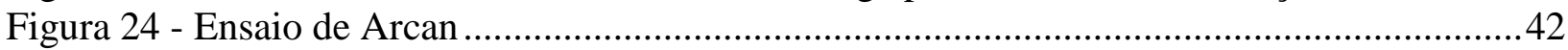

Figura 25 - Fixação do Corpo de Prova no Modelo de Langrand \& Combescure .........................43

Figura 26 - Corpo de prova do modelo de ensaio de Lin ............................................................43

Figura 27 - Dispositivo e corpo de prova do modelo de Lee ....................................................44

Figura 28 - Dimensões dos corpos de prova para ensaio de tração, segundo as normas

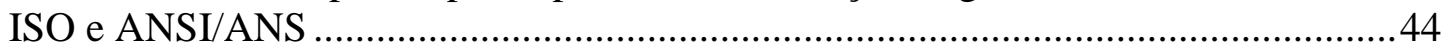

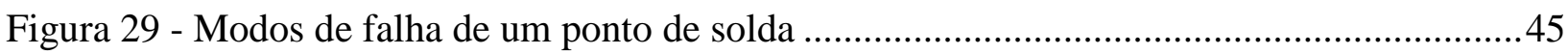

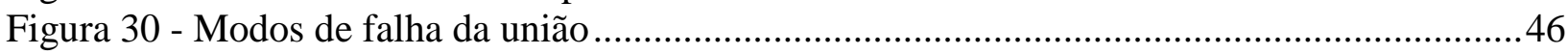

Figura 31 - Parâmetros importantes do ponto de UCCF .........................................................47

Figura 32 - Volumes do ponto da UCCF utilizando ferramentas fixas ...................................... 47

Figura 33 - Representação da função f(r) após a operação de UCCF …….................................48

Figura 34 - Seção da união ótima do estudo realizado .........................................................49

Figura 35 - Etapas da aplicação de carga de um ensaio de cisalhamento por tração ....................50

Figura 36 - Formação da rótula plástica ................................................................................51

Figura 37 - Tensões e cargas na interface do ponto de solda ...................................................51

Figura 38 - Tensões e cargas na ZTA do ponto de solda ........................................................53

Figura 39 - Tensões e esforços no cisalhamento por esforço de tração .....................................53

Figura 40 - Etapas da aplicação de carga de um ensaio de arrancamento......................................55 
Figura 41 - Tensões e esforços no ensaio de arrancamento ..................................................55

Figura 42 - Análise de tensões em volta do ponto de solda .....................................................56

Figura 43 - Forças e momentos atuantes em cargas combinadas ...........................................57

Figura 44 - Comparação entre o modelo geral e o simplificado .................................................58

Figura 45 - Corpos de prova para ensaios de cisalhamento e fadiga:

(a) configuração transversal; (b) configuração longitudinal

Figura 46 - Resultado dos ensaios de cisalhamento:

(a) Curva de carga em relação ao deslocamento;

(b) Ruptura da parte interior do ponto (falha típica)

Figura 47 - Comportamento à fadiga de juntas de UCCF:

(a) e (b) Curva de carga em função do número de ciclos;

(c) e (d) Curva de força máxima em função do fator $\mathrm{R}$

Figura 48 - Proposta de procedimento para determinação da Medida "X" ideal .........................6 63

Figura 49 - Relação de diâmetros de matriz para UCCF........................................................64

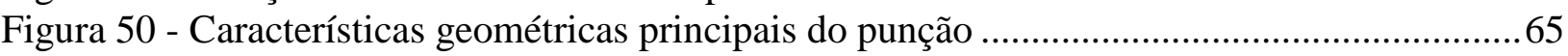

Figura 51 - Características geométricas principais da matriz......................................................66

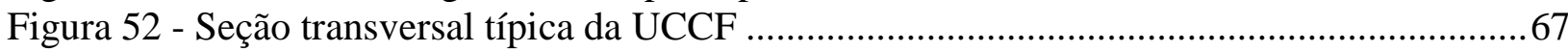

Figura 53 - Análise metalográficas do ponto de $8 \mathrm{~mm}$ com medida "X" de 0,75mm:

(a)Escala de $50 \mu \mathrm{m}$; (b) Escala de $200 \mu \mathrm{m}$

Figura 54 - Corpos de prova para ensaio de tração e cisalhamento ..............................................70

Figura 55 - Procedimento de confecção do corpo de prova de arrancamento...............................71

Figura 56 - Equipamentos utilizados para junção e ensaio dos corpos de prova .........................71

Figura 57 - Carga de prensagem em função da união e do diâmetro do ponto .............................. 72

Figura 58 - Ensaio de cisalhamento e arrancamento .................................................................. 72

Figura 59 - Gráfico de resistência do ponto de $6 \mathrm{~mm}$ para a chapa de $0,8 \mathrm{~mm}$............................. 73

Figura 60 - Gráfico de resistência do ponto de $8 \mathrm{~mm}$ para a chapa de $0,8 \mathrm{~mm}$............................ 73

Figura 61 - Gráfico de resistência do ponto de $6 \mathrm{~mm}$ para a chapa de $1,2 \mathrm{~mm}$............................74

Figura 62 - Gráfico de resistência do ponto de $8 \mathrm{~mm}$ para a chapa de $1,2 \mathrm{~mm}$..............................74

Figura 63 - Gráfico para determinação da medida $X_{\text {ideal }}$ do ponto de $8 \mathrm{~mm}$ para chapa

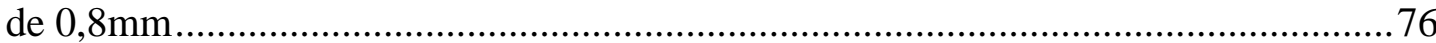

Figura 64 - Gráfico para determinação da medida $\mathrm{X}_{\text {ideal }}$ do ponto de 8mm para chapa

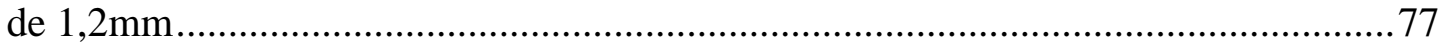

Figura 65 - Espinha de peixe do ensaio de tração ........................................................................ 79

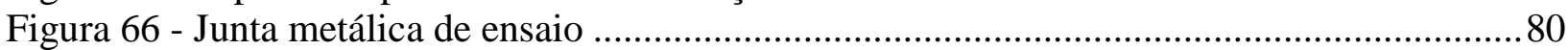

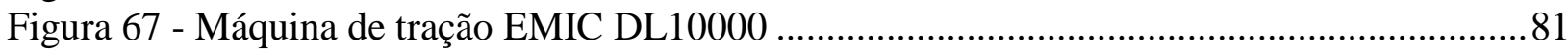

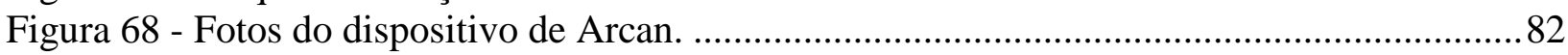

Figura 69 - Etapas do ensaio de tração multiaxial...................................................................... 84

Figura 70 - Procedimento para fixação do corpo de prova no dispositivo de Arcan ....................85

Figura 71 - Resultado do ensaio de Arcan para chapa de 0,8mm unido pelo processo de UCCF

Figura 72 - Resultado do ensaio de Arcan para chapa de 1,2 unido pelo processo de $\mathrm{UCCF}$

Figura 73 - Cisalhamento da parte interna do ponto sem separação total do corpo de prova.

Figura 74 - Cisalhamento da parte interna do ponto com separação total do corpo de prova.

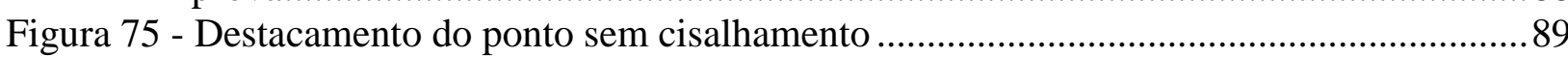

Figura 76 - Rigidez do ponto em diferentes configurações angulares de ensaio .........................89

Figura 77 - Relação do tipo de falha com a configuração da carga na UCCF 
Figura 78 - MSPP tipo "C"

Figura 79 - Comparação dos resultados das diferentes configurações angulares em relação à espessura e tipo de processo de solda:

(a) SPRE espessura $0,80 \mathrm{~mm}$; (b) SPRE espessura $1,20 \mathrm{~mm}$

Figura 80 - Comparação dos resultados das diferentes configurações angulares em relação à espessura e tipo de processo de união:

(a) UCCF espessura $0,8 \mathrm{~mm}$; (b) UCCF espessura $1,2 \mathrm{~mm}$;

(c) SPRE espessura $0,8 \mathrm{~mm}$; (d) SPRE espessura $1,2 \mathrm{~mm}$

Figura 81 - Comparação dos valores de resistência entre UCCF e SPRE

Figura 82 - Relação de resistência entre as tecnologias de UCCF e SPRE em função dos ângulos de ensaio e espessura de chapa. 


\section{LISTA DE TABELAS}

Tabela 1 - Aplicação da UCCF na indústria

Tabela 2 - Combinação de ferramentas estudadas para a determinação da medida " $X$ ".

Diâmetro da matriz $8,0 \mathrm{~mm}$

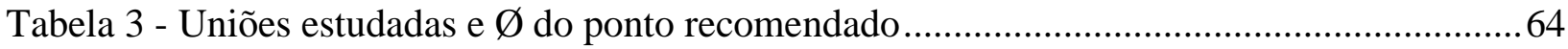

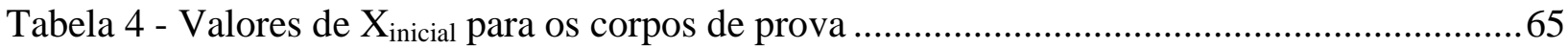

Tabela 5 - Sequência de avaliação da combinação punção/matriz..............................................66

Tabela 6 - Tipos mais comuns de falha na união de chapas por UCCF ....................................68

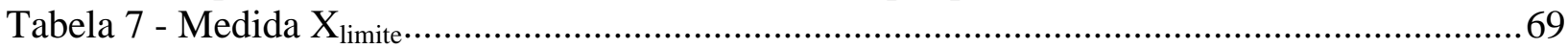

Tabela 8 - Amostragem dos corpos de prova para determinação da medida " $X$ " ideal ................70

Tabela 9 - Diâmetros reais dos pontos de solda .................................................................. 78

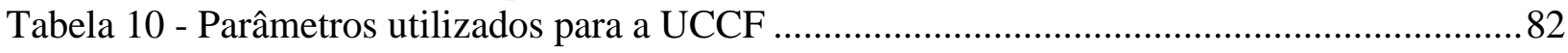

Tabela 11 - Matriz de ensaios de comparação entre UCCF e SPRE .......................................... 83

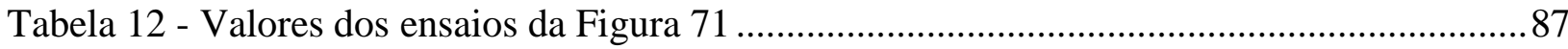

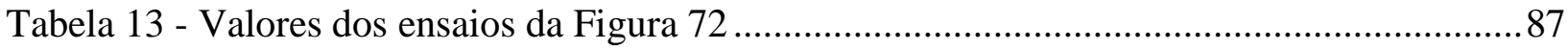

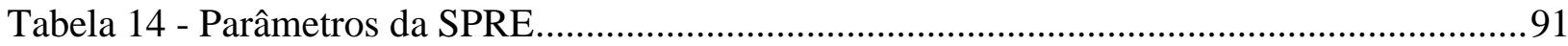

Tabela 15 - Valores médios de carga máxima das diferentes configurações angulares

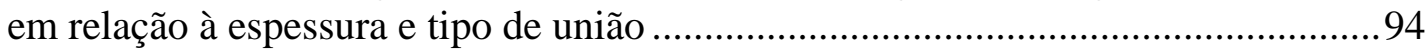

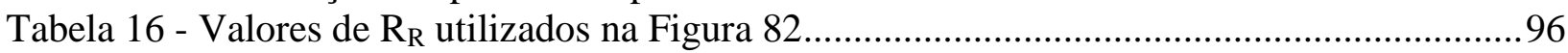




\section{LISTA DE ABREVIATURAS E SIGLAS}

$\begin{array}{ll}\text { AWS } & \text { American Welding Society } \\ \text { BFF } & \text { Bobina Forjada a Frio } \\ \text { BH } & \text { Bake Hardening } \\ \text { BIW } & \text { Body in White } \\ \text { DIN } & \text { Deutsches Institut Fur Normung } \\ \text { DP } & \text { Dual Phase } \\ \text { EEP } & \text { Estampagem Extra Profunda } \\ \text { HV } & \text { Unidade de medida da dureza Vickers } \\ \text { ISO } & \text { International Organization for Standardization } \\ \text { IWU } & \text { Institut Werkzeugmaschinen und Umformtechnik } \\ \text { MSPP } & \text { Máquina de Solda a Ponto Portátil } \\ \text { PHS } & \text { Press Hardness Steel } \\ \text { SPRE } & \text { Solda Ponto por Resistência Elétrica } \\ \text { UCCF } & \text { União de Chapas por Conformação a Frio } \\ \text { ZTA } & \text { Zona Termicamente Afetada }\end{array}$




\section{LISTA DE SÍMBOLOS}

\begin{tabular}{|c|c|c|}
\hline Símbolo & Descrição & Unidade \\
\hline d & Diâmetro & $\mathrm{mm}$ \\
\hline $\mathbf{F}$ & Força aplicada & $\mathrm{N}$ \\
\hline $\mathbf{F}_{\text {fmax }}$ & Força máxima aplicada no ensaio à fadiga & $\mathrm{N}$ \\
\hline $\mathbf{F}_{\text {fmin }}$ & Força de alívio aplicada no ensaio à fadiga & $\mathrm{N}$ \\
\hline $\mathbf{K}_{\mathbf{P x y}}$ & Fator de correção para aços de baixo carbono & ad. \\
\hline $\mathbf{L}_{\text {crítica }}$ & Largura crítica do corpo de prova & $\mathrm{mm}$ \\
\hline $\mathbf{L}_{\mathbf{p}}$ & Comprimento da ponta do punção & $\mathrm{mm}$ \\
\hline $\mathbf{M}_{\mathbf{X}}$ & Momento aplicado no eixo X & $\mathrm{Nm}$ \\
\hline $\mathbf{M}_{\mathbf{Y}}$ & Momento aplicado no eixo Y & $\mathrm{Nm}$ \\
\hline $\mathbf{M}_{\mathbf{Z}}$ & Momento aplicado no eixo Z & $\mathrm{Nm}$ \\
\hline $\mathbf{P}$ & Componente da força aplicada normal à face & $\mathrm{N}$ \\
\hline $\mathbf{P}_{\mathbf{f}}$ & Carga de falha do ponto de solda & $\mathrm{N}$ \\
\hline $\mathbf{P}_{\mathbf{m}}$ & Profundidade do canal da matriz & $\mathrm{mm}$ \\
\hline $\mathbf{P}_{\text {máx }}$ & Carga máxima até a falha em um ensaio uniaxial de tração & $\mathrm{N}$ \\
\hline $\mathbf{P}_{\mathbf{X}}$ & Carga aplicada paralela ao eixo X & $\mathrm{N}$ \\
\hline $\mathbf{P}_{\mathbf{Y}}$ & Carga aplicada paralela ao eixo $\mathrm{Y}$ & $\mathrm{N}$ \\
\hline $\mathbf{P}_{\mathbf{Z}}$ & Carga aplicada paralela ao eixo $\mathrm{Z}$ & $\mathrm{N}$ \\
\hline $\mathbf{R}_{\mathbf{f}}$ & Relação de carga do ensaio de fadiga & ad. \\
\hline $\mathbf{R}_{\mathbf{R}}$ & Relação de resistência & ad. \\
\hline $\mathbf{R}_{\mathbf{S}}$ & Força de resistência do corpo de prova de SPRE & $\mathrm{N}$ \\
\hline $\mathbf{R}_{\mathbf{U}}$ & Força de resistência do corpo de prova de UCCF & $\mathrm{N}$ \\
\hline $\mathbf{S}_{\mathbf{y M B}}$ & Tensão de escoamento do metal base & $\mathrm{MPa}$ \\
\hline $\mathbf{t}$ & Espessura da chapa & $\mathrm{mm}$ \\
\hline $\mathbf{t}_{\mathbf{N}}$ & Espessura do "pescoço" do ponto & $\mathrm{mm}$ \\
\hline $\mathbf{t}_{\mathbf{U}}$ & Dimensão do travamento do ponto & $\mathrm{mm}$ \\
\hline $\mathbf{V}$ & Componente da força aplicada tangente à face & $\mathrm{N}$ \\
\hline $\mathbf{V}_{\mathbf{A}}$ & Volume interno superior do elemento de UCCF & $\mathrm{m}^{3}$ \\
\hline $\mathbf{V}_{\mathrm{A} 1}$ & Volume de material deslocado do elemento de UCCF & $\mathrm{m}^{3}$ \\
\hline
\end{tabular}




\begin{tabular}{|c|c|}
\hline $\mathbf{V}_{\mathbf{B}}$ & Volume inferior do elemento de UCCF \\
\hline $\mathbf{X}$ & Espessura da base do elemento de UCCF \\
\hline $\mathbf{X}_{\mathbf{a}}$ & $\begin{array}{l}\text { Espessura de maior resistência ao arrancamento do elemento } \\
\text { de UCCF }\end{array}$ \\
\hline $\mathbf{X}_{\mathbf{c}}$ & $\begin{array}{l}\text { Espessura de maior resitência ao cisalhamento do elemento } \\
\text { de UCCF }\end{array}$ \\
\hline $\mathbf{X}_{\text {ideal }}$ & Espessura ideal do elemento clinching \\
\hline $\mathbf{X}_{\text {inicial }}$ & Espessura inicial da base do elemento clinching \\
\hline $\mathbf{w}$ & Largura do corpo de prova \\
\hline$\alpha$ & Ângulo \\
\hline$\alpha_{c}$ & Conicidade da ponta do punção \\
\hline$\alpha_{p}$ & Ângulo da ponta do punção \\
\hline$\sigma_{\mathbf{E}}$ & Tensão equivalente \\
\hline$\sigma_{\text {eINT }}$ & Tensão resultante na interface \\
\hline$\sigma_{\text {eZTA }}$ & Tensão equivalente na zona termicamente afetada \\
\hline$\sigma_{\mathbf{f}}$ & Tensão de falha do ponto de solda \\
\hline$\sigma_{\mathbf{I}}$ & Tensão normal à interface \\
\hline$\sigma_{\text {MAX }}$ & Valor máximo de tensão \\
\hline$\sigma_{\mathbf{V}}$ & Tensão tangente à interface \\
\hline$\tau$ & Tensão de cisalhamento \\
\hline$\tau_{\mathbf{f}}$ & Tensão de cisalhamento de falha do ponto \\
\hline$\tau_{\max }$ & Tensão de cisalhamento máximo \\
\hline$\tau_{\mathbf{V}}$ & Tensão de cisalhamento na parede do cilindro da SPRE \\
\hline$\tau_{\mathbf{P}}$ & Tensão de cisalhamento na parede do cilindro da SPRE \\
\hline$\emptyset_{\mathbf{p}}$ & Diâmetro da ponta do punção \\
\hline$\varnothing_{\mathrm{m}}$ & Diâmetro do canal da matriz \\
\hline
\end{tabular}




\section{SUMÁRIO}

1 INTRODUÇÃO .........................................................................................................19

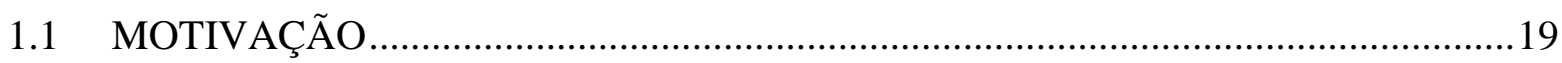

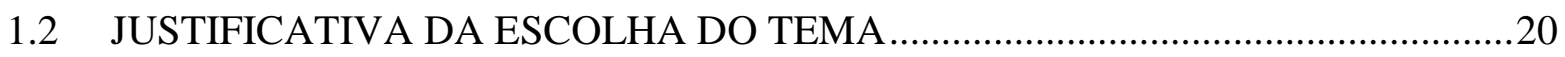

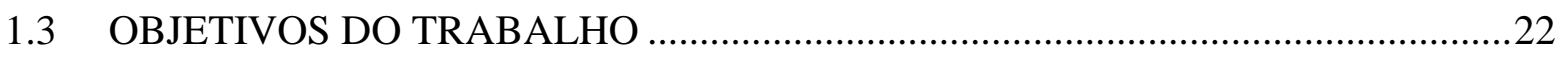

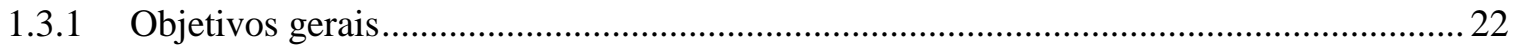

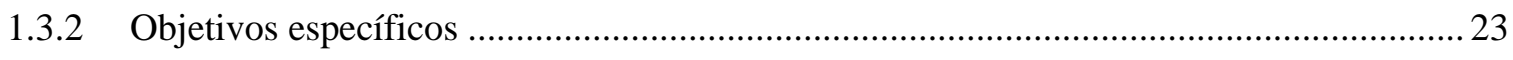

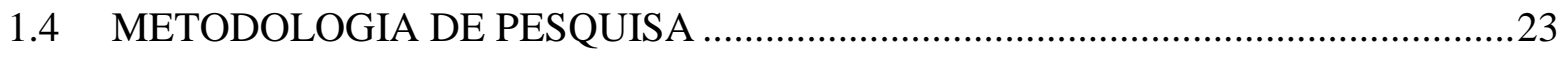

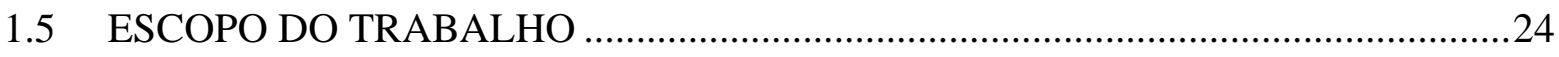

2 REVISÃO DA LITERATURA _........................................................................25

2.1 FUNDAMENTOS DA UNIÃO DE CHAPAS POR CONFORMAÇÃO A FRIO .....25

2.1.1 Classificação dos processos de junção ...........................................................................2

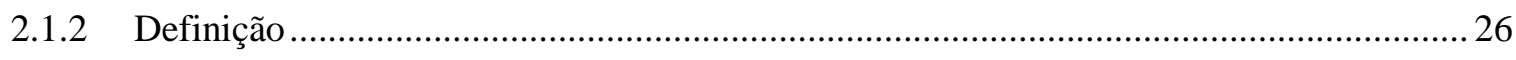

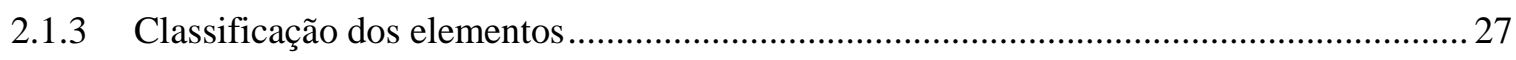

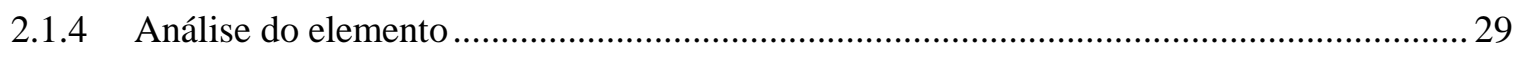

2.1.5 Combinação de ferramentas padrão utilizadas no processo ............................................... 32

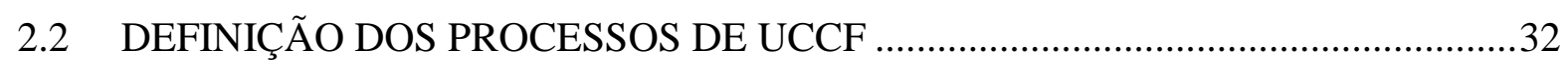

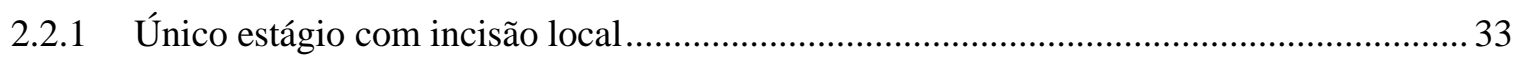

2.2.2 Dois estágios ou múltiplos estágios com incisão local.........................................................33

2.2.3 Único estágio sem incisão local (Ferramenta com partes móveis)........................................34

2.2.4 Único estágio sem incisão local (Ferramenta sem partes móveis) .......................................35

2.2.5 Formação do elemento plano sem incisão local.................................................................. 35

2.2.6 Sistema para fixar e soltar as peças ............................................................................... 37

2.3 COMPARAÇÃO DOS ELEMENTOS DE UCCF COM VARIAÇÃO DE INCISÃO LOCAL E PARTES CONFORMADAS .................................................38

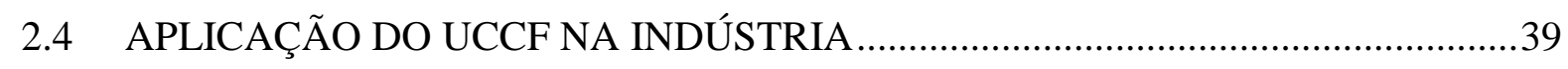

2.5 MODELOS DE RESISTÊNCIA MECÂNICA PARA UCCF E SPRE …………….....41

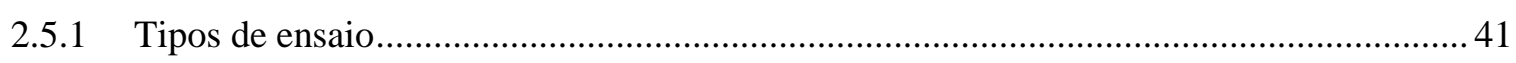

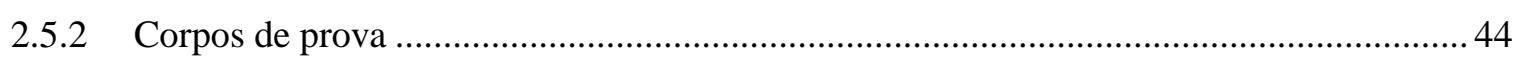

2.5.3 Principais parâmetros do elemento de UCCF ……………………………………..... 46

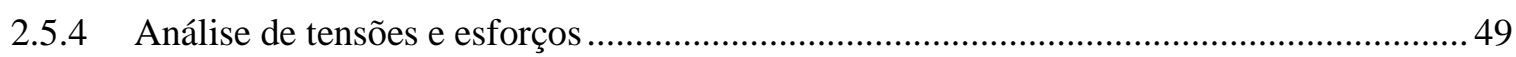

2.5.4.1 Cisalhamento por esforço de tração......................................................................50 


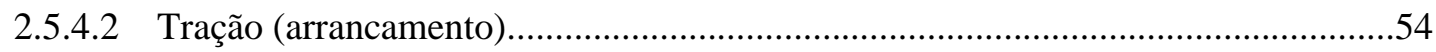

2.5.4.3 Esforços combinados de cisalhamento e tração (arrancamento)...............................56

2.5.4.4 Resistência mecânica da UCCF à carga estática de cisalhamento e fadiga..............59

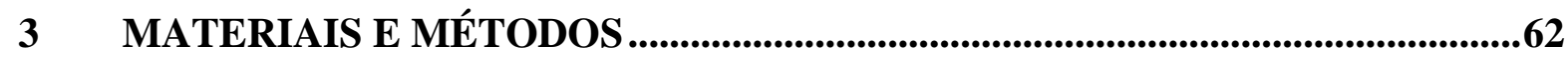

3.1 DETERMINAÇÃO DOS PARÂMETROS DA UCCF ............................................62

3.1.1 Procedimento de ensaio para determinação dos parâmetros ideais de união ...................... 62

3.1.2 Determinação da Medida " $X$ " ideal para a união de chapas de aço ................................... 64

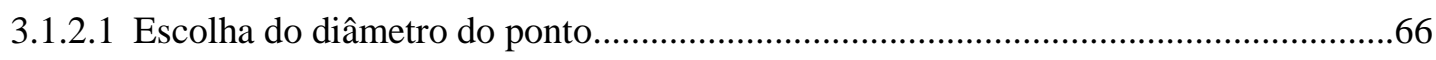

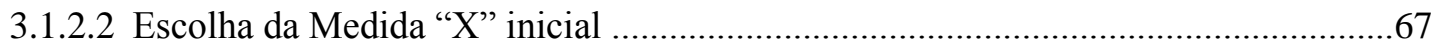

3.1.2.3 Escolha do punção e matriz.....................................................................................67

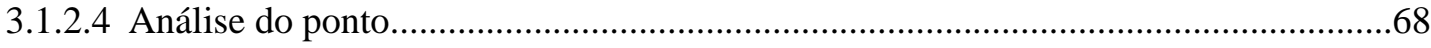

3.1.2.5 Redução da medida "X" até o ponto crítico de resistência do punção .........................71

3.1.2.6 Confecção dos corpos de prova..................................................................................

3.1.2.7 Ensaio de cisalhamento e destacamento...................................................................73

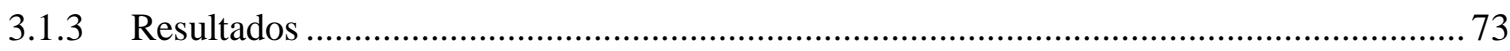

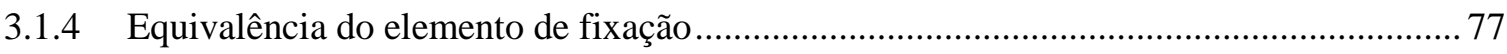

3.2 ANÁLISE DA RESISTÊNCIA MECÂNICA DA UCCF SOB CARGA

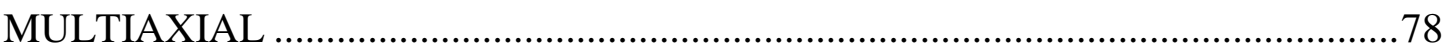

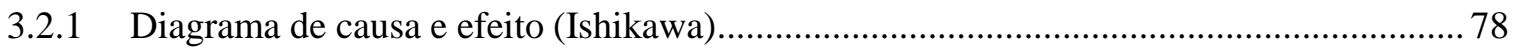

3.2.2 Condições gerais de ensaio para análise da UCCF sob carga multiaxial ...........................79

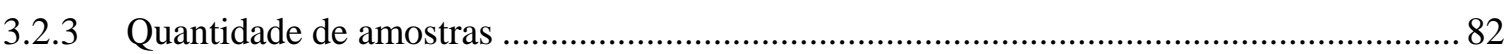

4 RESULTADOS E DISCUSSÕES .......................................................................86

4.1 RESULTADO DO ENSAIO DE ARCAN PARA UCCF ........................................86

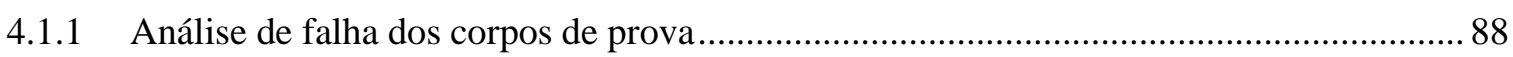

4.2 ANÁLISE COMPARATIVA DA RESISTÊNCIA MECÂNICA DA UCCF

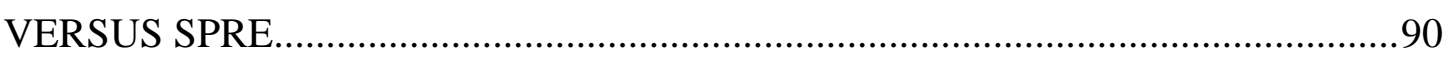

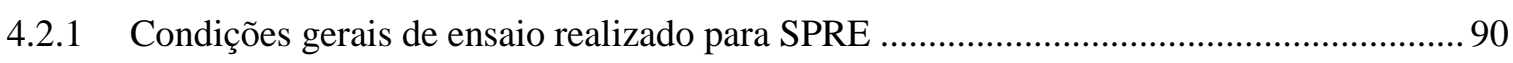

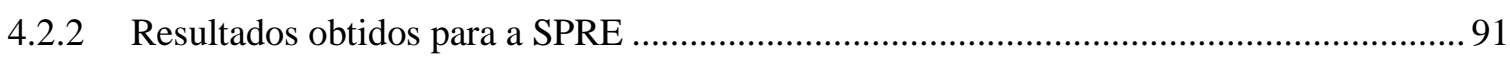

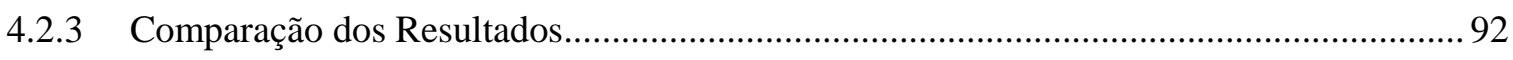

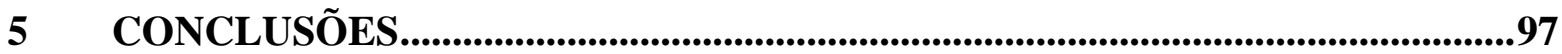

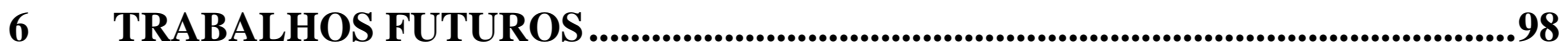

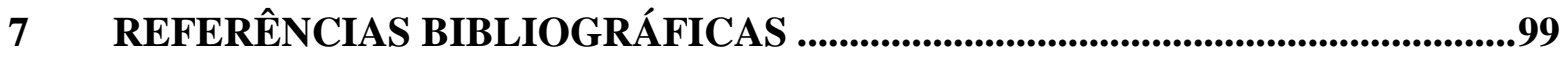




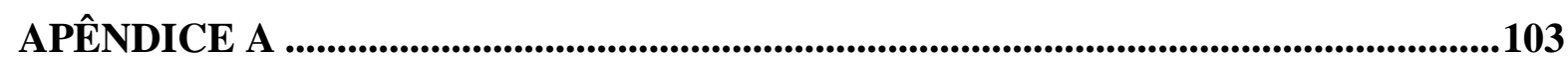

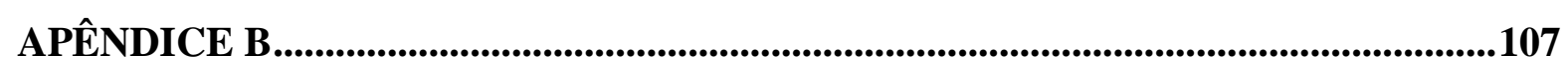

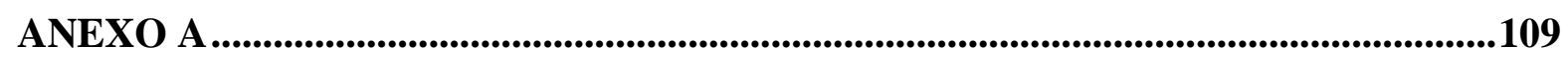

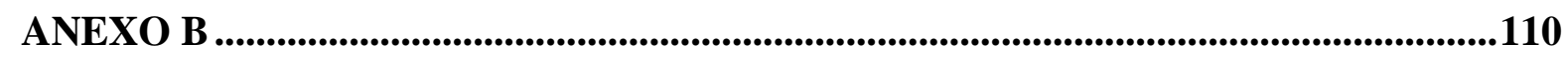

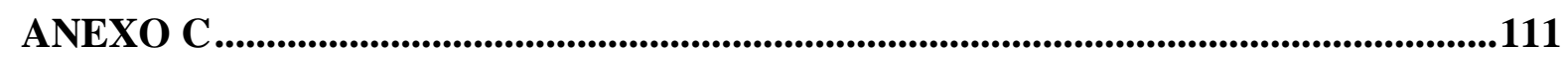

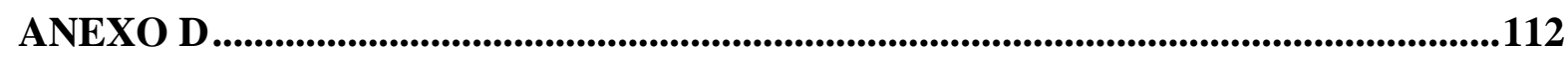




\section{INTRODUÇÃO}

\subsection{MOTIVAÇÃO}

O avanço tecnológico aliado à competitividade do mercado de bens de consumo incentivam as indústrias a aperfeiçoar seus produtos e processos produtivos em busca de alternativas que viabilizem um equilíbrio entre custo e beneficio sem prejudicar a qualidade de seus produtos. A tecnologia empregada no produto e seu processo é um fator importantíssimo e o mesmo pode ser determinante como um diferencial no mercado, seja por custos ou característica do produto (PORTER, 1991).

Atualmente, devido ao avanço tecnológico, existe uma grande variedade de materiais que podem ser utilizados na fabricação de um determinado produto. A escolha correta do material deve estar vinculada ao tipo de processo de união aos quais os componentes serão submetidos. A carroceria de um veículo automotivo é um exemplo, onde o custo do processo bem como o comportamento mecânico da união são fatores fundamentais que devem ser determinados na fase do desenvolvimento do projeto.

O gráfico da Figura 1 ilustra as tendências de utilização dos métodos de junta na indústria automobilística (união de carrocerias de produção em série). É possível notar, analisando-se o gráfico, que em 2003, o Instituto alemão de Fraunhofer projetou uma forte tendência de aumento na utilização do processo de União de Chapas por Conformação a Frio (UCCF) até o ano de 2010. É importante ressaltar que o gráfico foi preparado sem levar em conta os princípios de design específicos, tais como construção em aço, alumínio espaçoframe ou design multi-material. $\mathrm{O}$ apelo ambiental significativo aliado à versatilidade oriunda do processo de UCCF, que permite, inclusive, a união de diferentes tipos de materias, tais como o aço, o alumínio e polímeros, foram fatores decisivos na elaboração dessas curvas de tendência. No entanto, o que se observa atualmente é que o uso da Solda a Ponto por Resistência Elétrica (SPRE) ainda tem sido o processo dominante no seguimento automotivo, influenciado, em grande parte, pelos elevados custos dos metais mais leves, como é o caso do alumínio e dos aços de alta resistência. 


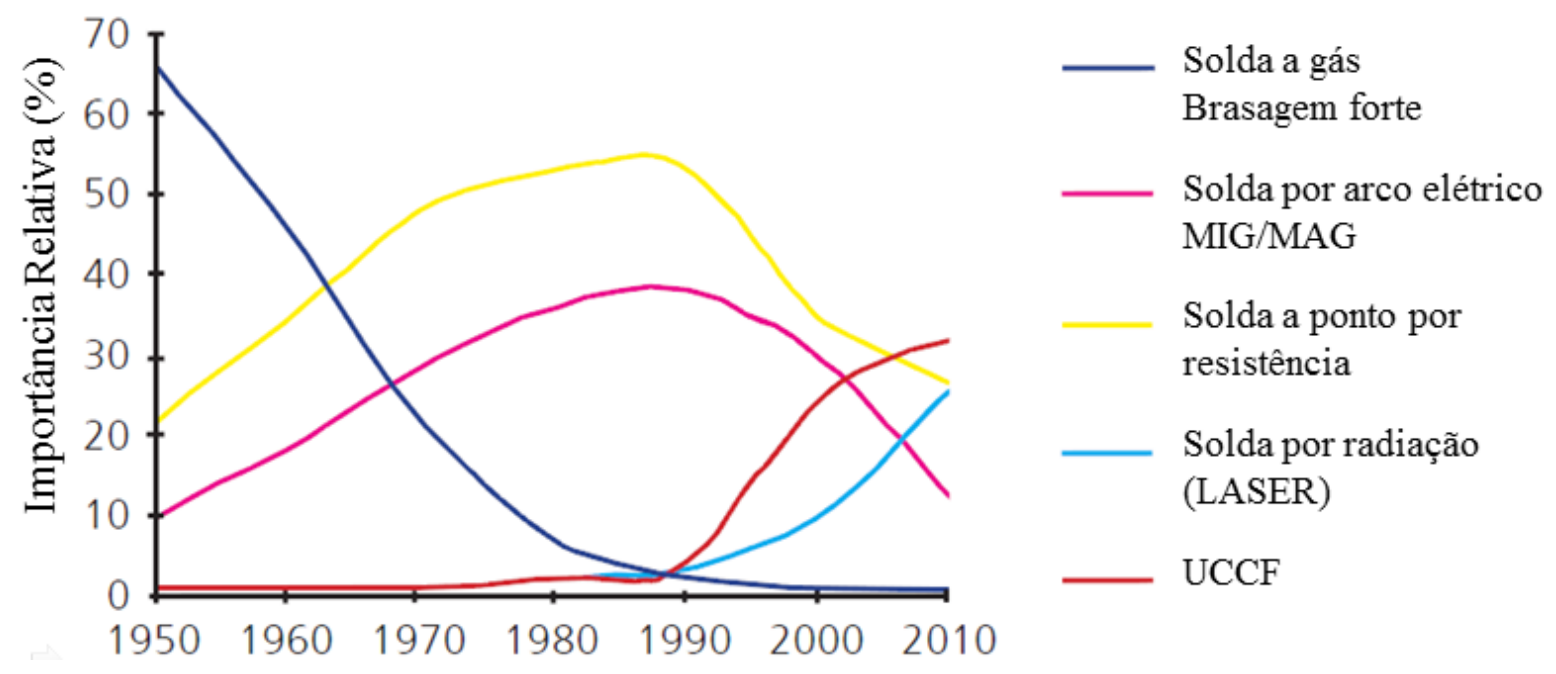

Figura 1 - Tendências no desenvolvimento dos métodos de junta (IWU, 2003)

\subsection{JUSTIFICATIVA DA ESCOLHA DO TEMA}

O processo de UCCF pode ser utilizado em vários produtos em diversas aplicações. No exemplo da carroceria automotiva, as premissas básicas de desenvolvimento são: atendimento aos requisitos legais referentes à segurança veicular e satisfação do consumidor. Abaixo é possível observar as características que mais agregam valor na visão do consumidor com relação à carroceria bem como as ações que devem ser perseguidas pelo engenheiro no desenvolvimento do produto para alcançar tais requisitos.

- Economia de combustível - redução de massa;

- Rapidez na resposta do veículo à energia fornecida pelo motor - redução de massa;

- Estabilidade e melhora na resposta da suspensão - elevação da rigidez torsional;

- Chapas externas menos sensíveis à deformação oriunda de pequenos impactos adição de mantas estruturais locais, aumento da espessura de chapas, adição de formas e/ou troca de matéria-prima;

- Segurança aos ocupantes em caso de colisão - melhoria da distribuição das cargas oriundas do impacto, substituição de matéria prima e adição de reforços;

- Baixo ruído - melhoria no comportamento aerodinâmico; 
Nota-se que a redução de massa da carroceria é uma das premissas principais de projeto. A busca por esse objetivo pela indústria automobilística gerou novas tecnologias e novos conceitos de carroceria. A Figura 2 mostra o tipo mais comum de carroceria fabricada atualmente no mundo e, é possível observar os diferentes tipos de aço utilizado.

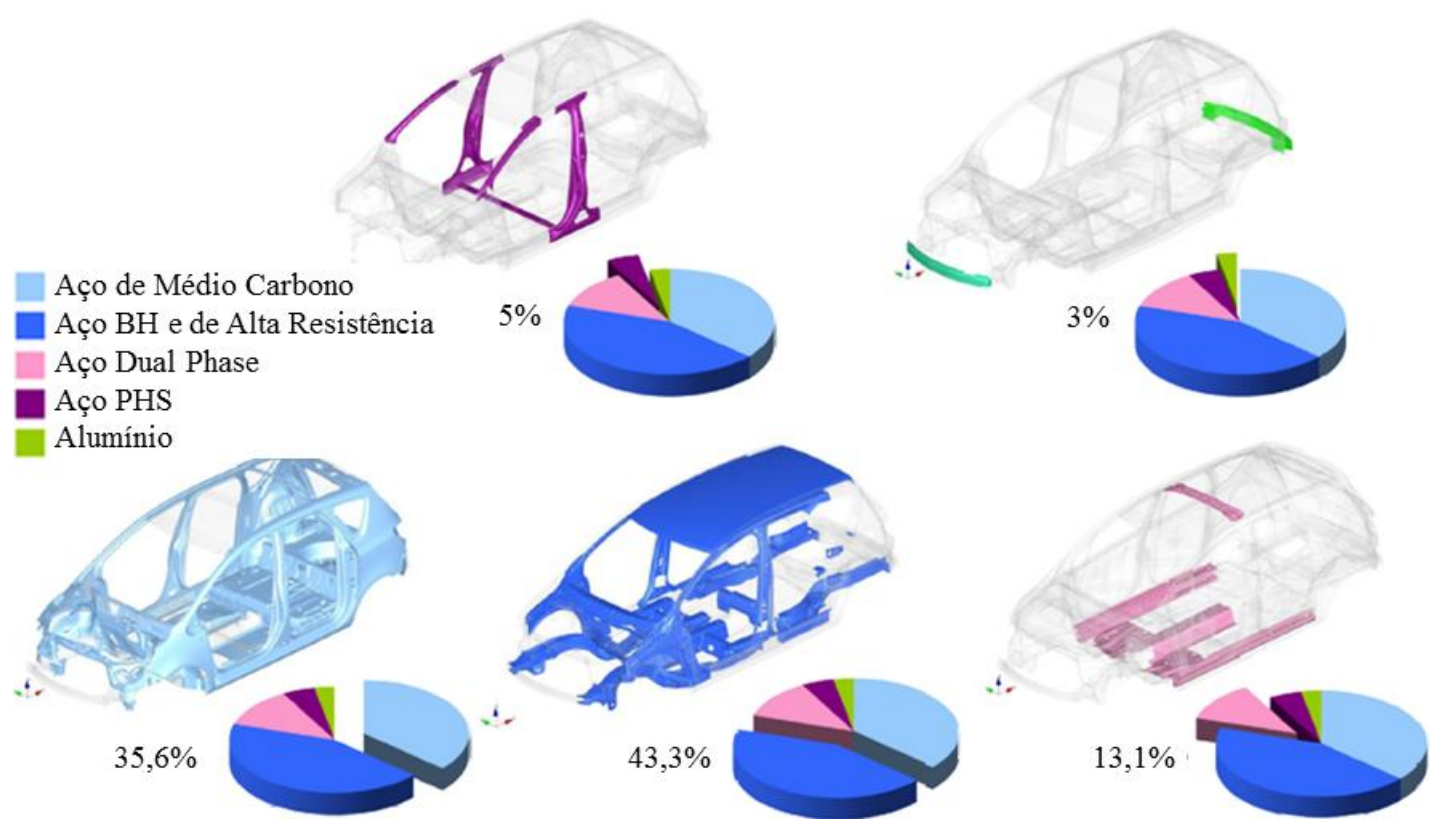

Figura 2 - Vista explodida da carroceria Opel Meriva ${ }^{\circledR}$ (FREIJE et al, 2010)

A escolha do processo de união dos componentes da carroceria é tão importante quanto à escolha do material. O processo de UCCF tem sido uma alternativa bastante utilizada por apresentar características peculiares tais como: baixo impacto ambiental, processo limpo em termos de emissão de poluentes químicos e sonoros, versatilidade na união de componentes compostos por diferentes materiais e confiabilidade no processo.

Neste trabalho, a SPRE foi a união escolhida como base de comparação na análise do comportamento da UCCF por se tratar da união mais utilizada atualmente na indústria automotiva.

Um estudo realizado por Ali (2005) comparou nove tipos de tecnologia de união de chapas. Aspectos como corrosão, resistência às cargas estáticas e dinâmicas, qualidade visual da união, possibilidade de união de diferentes materiais, custo de processo e investimento, foram considerados com base em três produtos: máquina de lavar, painel de energia elétrica e armário.

O resultado da análise de custo das uniões pode ser visto no gráfico da Figura 3. Notase que o processo de UCCF, utilizando o formato cilíndrico (Figura 7), foi o que apresentou o 
menor custo de processo (euro/metro) entre as uniões estudadas. $\mathrm{O}$ valor de investimento não destoa da maioria dos processos. Destaque para a solda a laser que apresentou valores relativamente altos tanto no processo quanto no investimento. $\mathrm{O}$ detalhamento dos custos pode ser encontrado no Anexo A do presente trabalho.

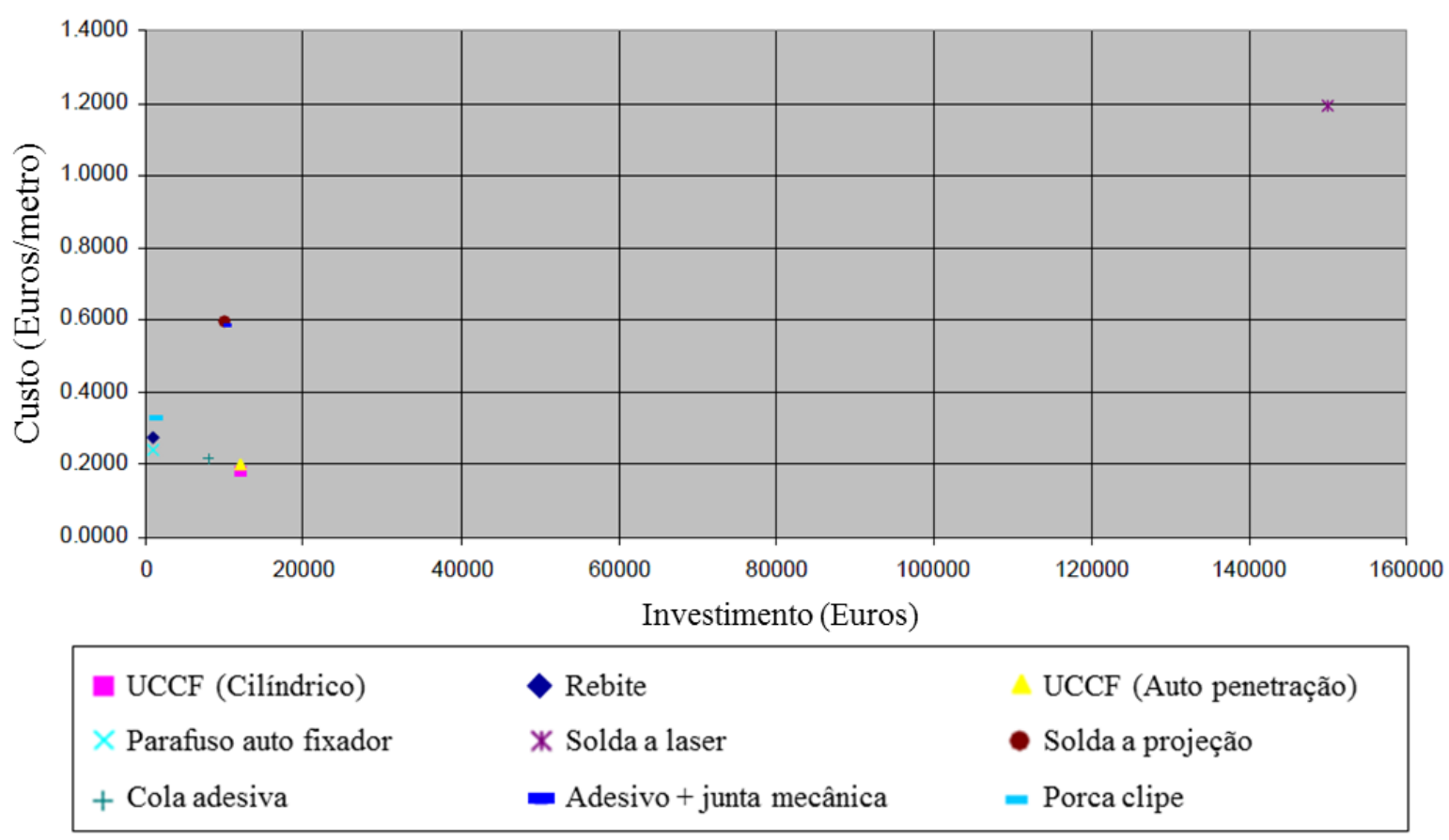

Figura 3 - Custo de processo e investimento de uniões de chapa (ALI, 2005).

\subsection{OBJETIVOS DO TRABALHO}

\subsubsection{Objetivos gerais}

1. Realizar ensaios de resistência mecânica, sob carga multiaxial, da união de chapas de aço por conformação a frio;

2. Entender e avaliar a resistência mecânica da junção de chapas de aço obtidas pelo processo de UCCF. 


\subsubsection{Objetivos específicos}

1. Determinar os parâmetros de processo da UCCF para obtenção do elemento de união que suporta a maior carga possível para um dado material.

2. Efetuar análise comparativa de resistência mecânica entre as tecnologias de UCCF e SPRE.

\subsection{METODOLOGIA DE PESQUISA}

A Metodologia é a explicação detalhada e exata de toda ação desenvolvida no método (caminho) do trabalho de pesquisa. Pesquisa nada mais é que a procura por respostas para indagações propostas.

De uma forma mais filosófica, "pesquisa" é a atividade básica das ciências na sua indagação e descoberta da realidade. É uma atitude e uma prática teórica de constante busca que define um processo intrinsecamente inacabado e permanente. "É uma atividade de aproximação sucessiva da realidade que nunca se esgota, fazendo uma combinação particular entre teoria e dados" (MINAYO, 1993).

Dentre as metodologias para se detalhar as pesquisas, uma delas é classificar a pesquisa quanto à forma de abordagem ao problema, podendo ser quantitativa ou qualitativa.

Pesquisa Quantitativa considera que todos os parâmetros podem ser quantificados em números de modo a classificá-la e analisá-la. Para esta forma de pesquisa são requeríveis recursos estatísticos, como percentagem, média, moda, mediana, desvio-padrão, coeficiente de correlação, análise de regressão, etc.

Pesquisa Qualitativa considera que o mundo real e o sujeito possuem uma relação dinâmica, isto é, o mundo objetivo e o subjetivo estão associados e não podem ser traduzir em números. A interpretação dos fenômenos e a atribuição de significados estão presentes neste tipo de pesquisa. Não requer uso de ferramentas estatísticas e o ambiente natural é a fonte direta de coleta de dados, sendo o pesquisador seu instrumento-chave. É descritiva. Os pesquisadores tendem a analisar seus dados indutivamente. O processo e seu significado são os focos principais de abordagem. 
Para Bryman (1989), procedimento de pesquisa é a orientação geral da investigação, e esta orientação fornece uma estrutura dentro das quais os dados são coletados e analisados. Segundo Filippine (1997), Fernandes (1999), Berto \& Nakano (1999; 2000), os procedimentos de pesquisa utilizados em Engenharia são: Pesquisa de avaliação “survey”, Experimental, Pesquisa-ação, Teórico-conceitual e Estudo de caso.

Neste trabalho a metodologia que mais se aplica é a experimental. De acordo com Bryman (1989), este procedimento de pesquisa é mais indicado para abordagens quantitativas. A pesquisa experimental é geralmente relacionada com experimentos controlados em laboratórios, modelagens matemáticas e simulações computacionais.

\subsection{ESCOPO DO TRABALHO}

No Capítulo 1, são apresentadas as motivações, justificativas e objetivos para o presente trabalho, incluindo a metodologia de pesquisa aplicada.

O Capítulo 2 traz a revisão da literatura. Os fundamentos, processos e modelos de resistência da UCCF são tratados também neste capítulo.

O Capítulo 3 refere-se aos materiais e métodos.

No Capitulo 4 são apresentados e discutidos os resultados obtidos. Uma análise comparativa também é realizada.

O Capítulo 5 traz as conclusões finais.

O Capítulo 6 sugere alguns trabalhos futuros como forma de avançar no estudo realizado.

No Capitulo 7, as referências bibliográficas.

Os Apêndices bem como os Anexos podem ser encontrados ao final do trabalho. 


\section{REVISÃO DA LITERATURA}

\subsection{FUNDAMENTOS DA UNIÃO DE CHAPAS POR CONFORMAÇÃO A FRIO}

Os tópicos seguintes mostram o posicionamento da UCCF entre os processos de junção existentes na fabricação mecânica. As definições de processo e do elemento de união também são apresentadas.

\subsubsection{Classificação dos processos de junção}

Segundo Batalha (2003), junção é a ligação permanente ou uma colocação em contato de duas ou mais peças com uma determinada forma geométrica ou até mesmo de peças com material sem forma definida, em um processo no qual a composição local é alterada e misturada como um todo.

Uma multiplicidade de materiais completamente distintos e suas possíveis combinações, tais como metais, plásticos, madeira, têxteis ou papel, que podem ser empregados como peças a serem submetidas a um processo de junção, que pode ser tanto direto, através de soldagem, brasagem e conformação, quanto sob a ação de elementos de adicionais de fixação e junção, através de parafusos, adesivos, rebites e anéis de cravação.

O processo de UCCF pode ser observado na Figura 4 no quadrante "Junção por conformação" - DIN 8593 Parte 5. 


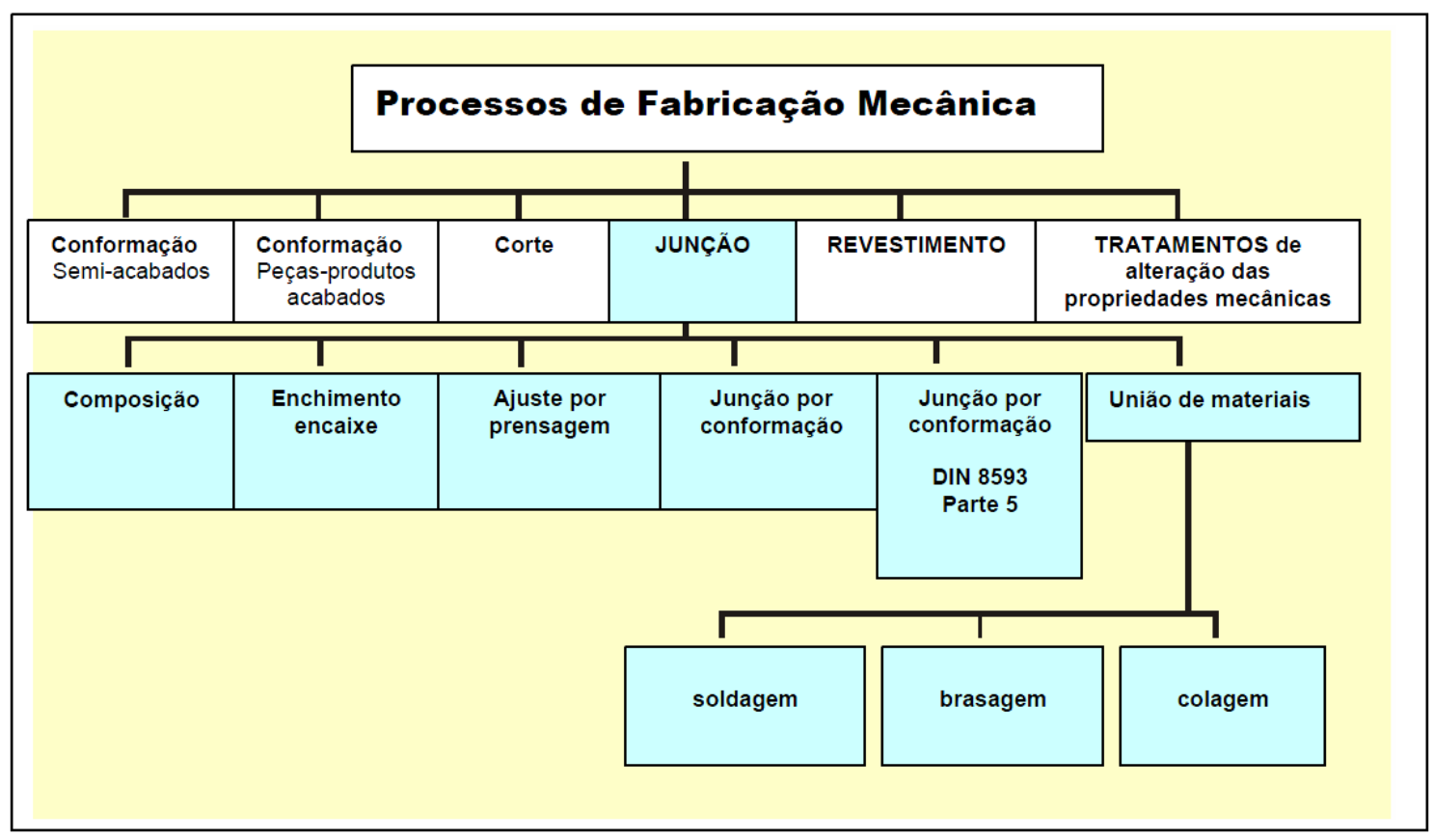

Figura 4 - Processos de Fabricação Mecânica (Batalha, 2003)

\subsubsection{Definição}

Segundo Carboni et al (2006), o processo de UCCF, basicamente, tem como princípio o travamento mecânico entre dois ou mais componentes, compostos pelo mesmo ou por diferentes materiais, por intermédio da deformação plástica, a qual é imposta por uma ferramenta constituída por um material mais duro que os materiais da junta. A somatória das espessuras das chapas pode chegar a $6,0 \mathrm{~mm}$, sendo possível unir até mesmo chapas já pintadas sem necessidade de preparação prévia de superfície.

Comparado com outras tecnologias de união, o processo de UCCF é rápido, de fácil automação e recomendado para processos de alta produtividade. Não provoca aquecimento, radiações nocivas, fagulha ou luz, entretanto requer o uso de equipamentos de segurança. $\mathrm{O}$ rebite normalmente requer furação, a cola adesiva requer limpeza e controle da rugosidade da superfície a ser unida. A preparação da junta frequentemente é necessária para o processo de solda a arco. Não há necessidade de pós-processo para a UCCF devido à ausência de fluxo térmico que durante um processo de união causa tensões residuais

A tecnologia de UCCF é relativamente nova, tendo sido a primeira patente para esse processo emitida em 1897 (VARIS; LEPISTÖ, 2003). Entretanto, a sua utilização industrial 
em larga escala foi iniciada na década de 80. Apenas em 1987 foram fabricadas as primeiras máquinas de UCCF pela TOX ${ }^{\circledR}$.

A Figura 5 mostra seções transversais do elemento de junta cilíndrico realizado pelo processo de UCCF.

No elemento ocorre o encruamento do material devido à deformação plástica imposta pela ferramenta. $\mathrm{O}$ encruamento aumenta a resistência do material da chapa nos locais onde o ponto é mais solicitado (não há fatores que causam concentração de tensão em torno do elemento). Não há alteração na composição química do material.

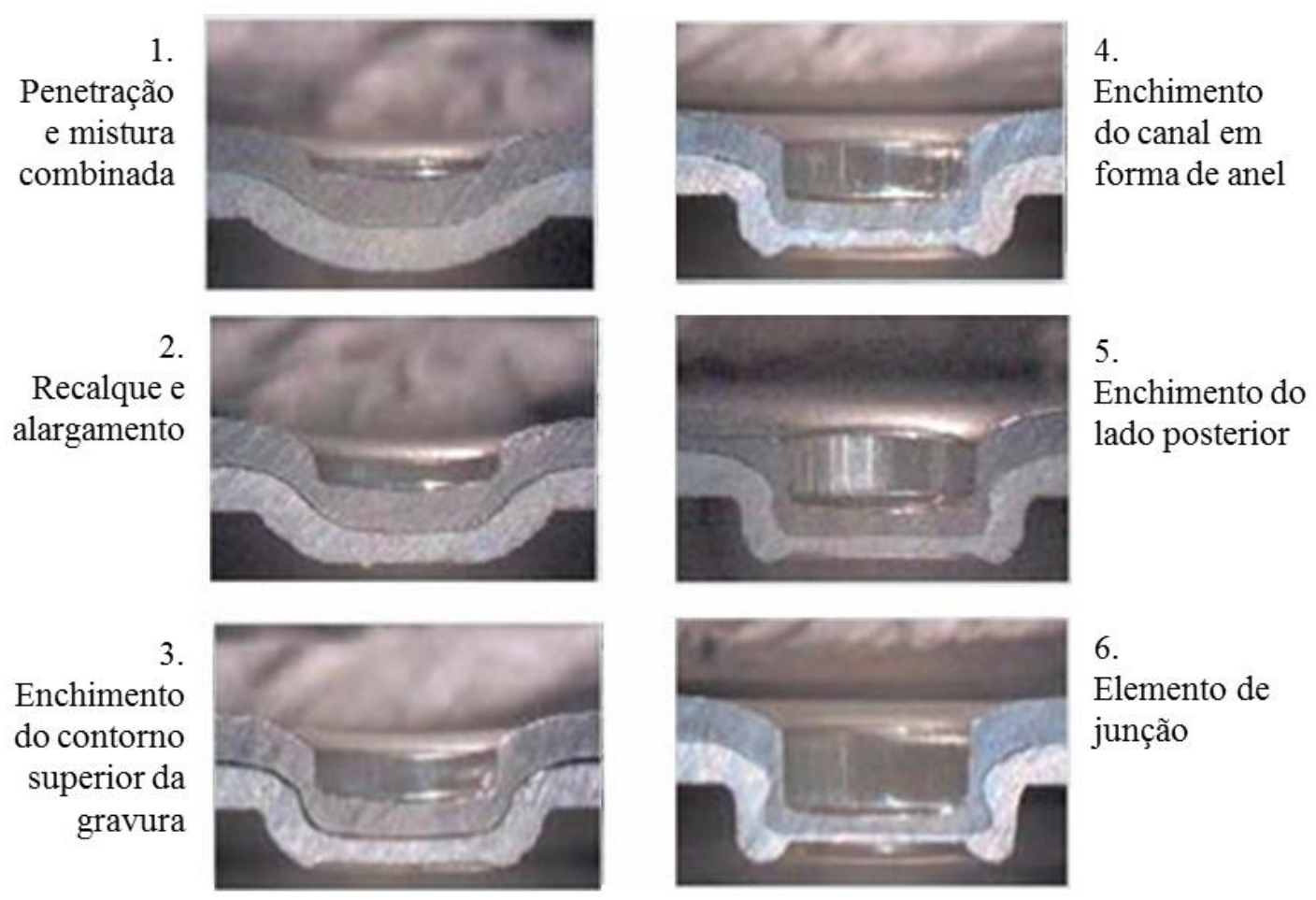

Figura 5 - Seção transversal da junta obtida pelo processo de UCCF (TOX, 2011a)

\subsubsection{Classificação dos elementos}

Várias construções e tipos de elementos de UCCF têm sido desenvolvidos desde o início da utilização industrial deste processo. Alguns dos elementos mais utilizados são ilustrados na Figura 6, onde é possível observar, de forma genérica, o desmembramento dos tipos de elemento. 
$\mathrm{Na}$ categoria classificada como "Sem Material Auxiliar", não existe a adição de elementos de fixação durante o processo de junção: a união é formada apenas pelo travamento mecânicos das chapas. O formato das juntas pode ser visualizado na Figura 7.

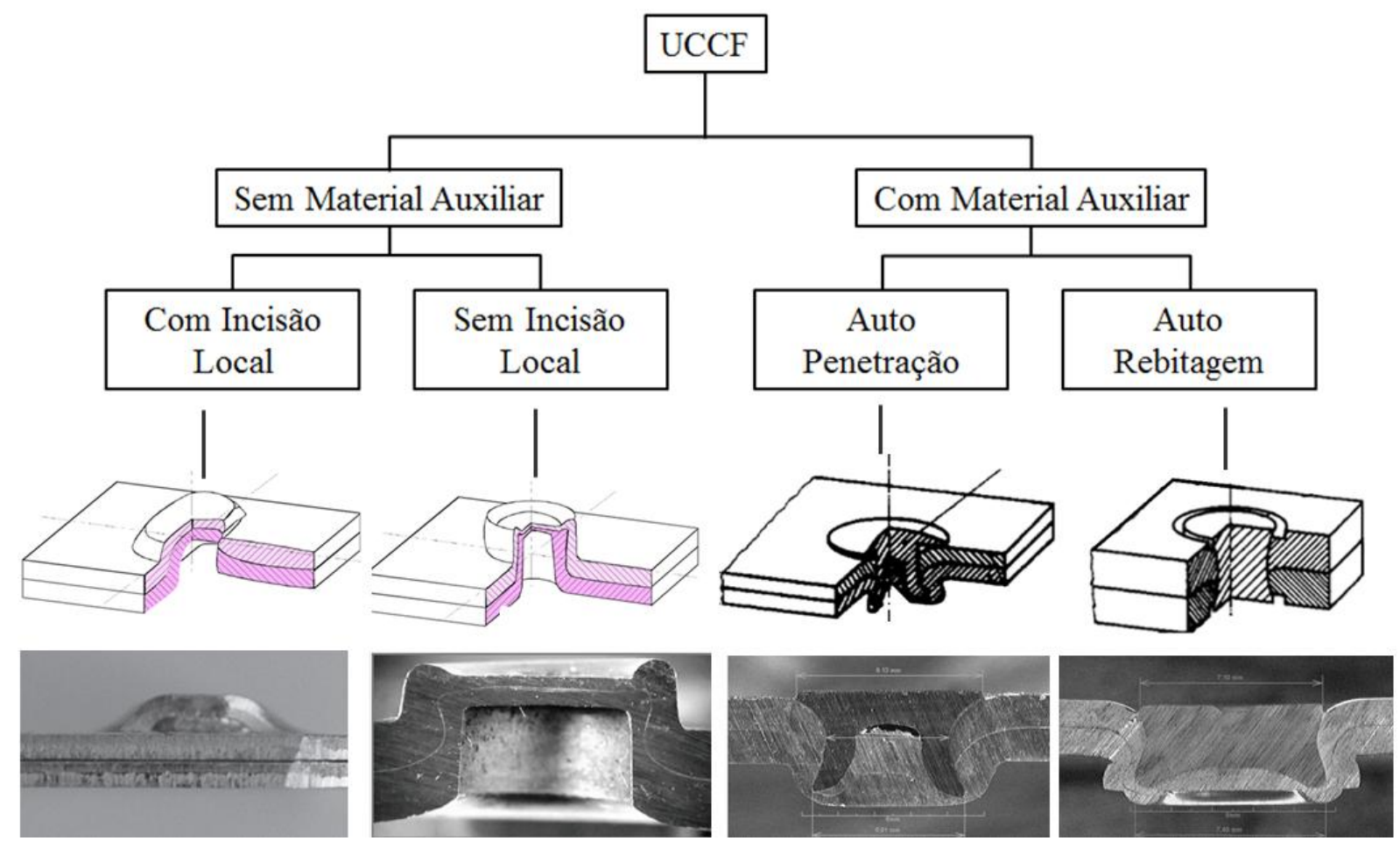

Figura 6 - Classificação básica dos elementos de UCCF (Adaptado de Gao \& Budde, 1994)

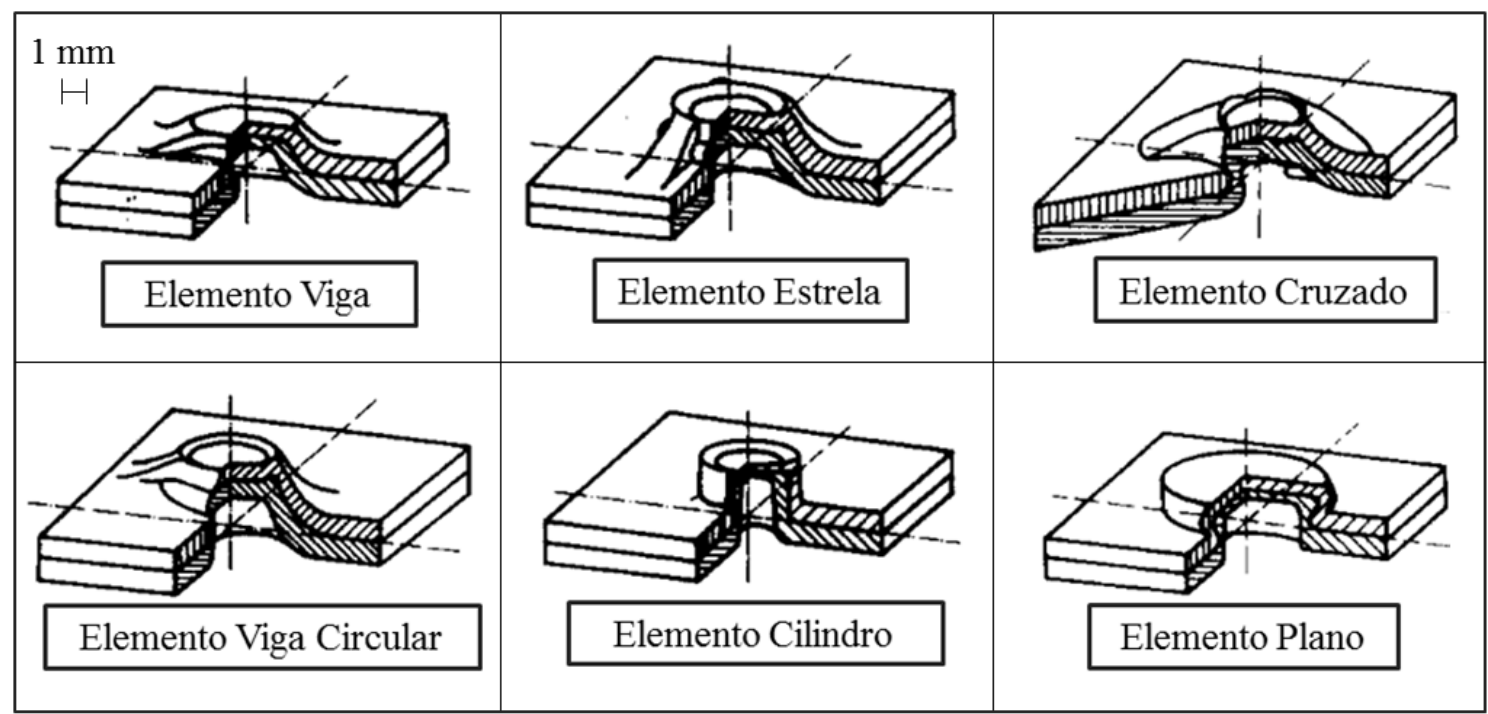

Figura 7 - Alguns exemplos de elementos de junta sem material auxiliar

(Adaptado de Gao \& Budde, 1994) 
$\mathrm{Na}$ categoria classificada como "Com Material Auxiliar", existe a adição de um elemento de fixação que pode ser feito tanto pelo processo de autopenetração quanto por autorebitagem (Figura 8).
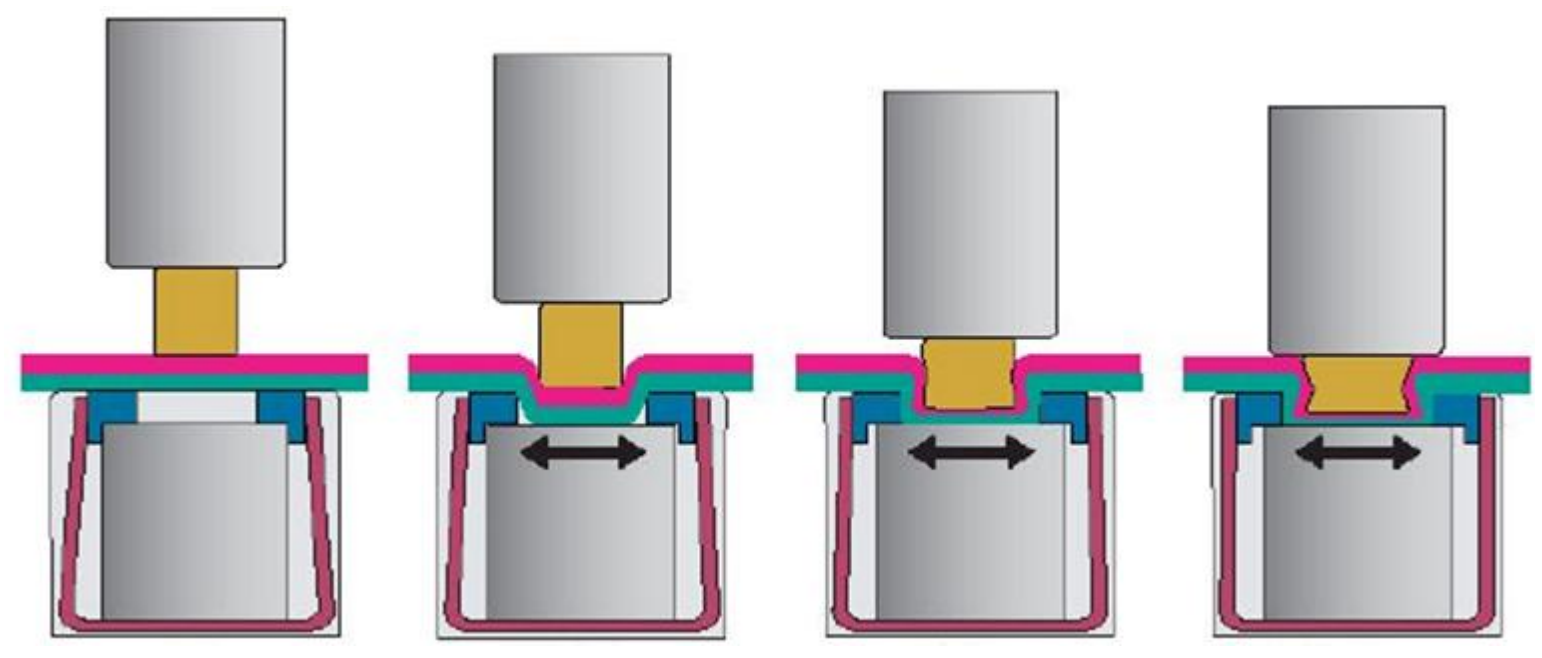

Figura 8 - Exemplo de processo de junta com material auxiliar (TOX, [entre 2000 e 2011])

Baseado no processo de UCCF, Carter (2010) criou e patenteou um novo método de união de chapas utilizando a fricção entre o punção e a chapa ao final do processo de conformação. Esse processo denominado pelo autor no termo em inglês "clinching-assisted friction" é recomendado para união de chapas de materiais frágeis. Segundo o mesmo autor, o método permite a execução da união com menor risco de trincas devido à combinação de estampagem não profunda com a fusão dos materiais.

\subsubsection{Análise do elemento}

No elemento de UCCF ocorre o encruamento do material devido à deformação plástica, havendo um aumento de resistência do material da chapa devido ao encruamento. A resistência também é aumentada nos locais onde o ponto é mais solicitado e não existem fatores que causam concentração de tensão em torno do elemento. Uma análise de dureza foi realizada por Mucha (2011) no elemento de junta, o resultado pode ser observado na Figura 9.

A especificação do material do elemento está descrita a seguir:

- Material: chapa de aço H320LA steel; 
- Dureza inicial: 93/110 HV 0.1;

- Espessura da chapa: 2,00mm;

- Dimensão "X": 1.65mm;

- Diâmetro do ponto: $8,00 \mathrm{~mm}$.

A Figura 9 mostra a dureza medida em duas linhas do elemento de UCCF, observa-se também o campo de tensões obtido pela análise de conformação mecânica pelo método de elementos finitos. Os níveis de tensão variam de azul (menor) para o vermelho (maior). Notase que existe relação entre o nível de tensão e a dureza do material. Outro ponto relevante é o fato de não existir tensão na região em torno do elemento, sendo assim, não há alteração de propriedade mecânica nessa região.

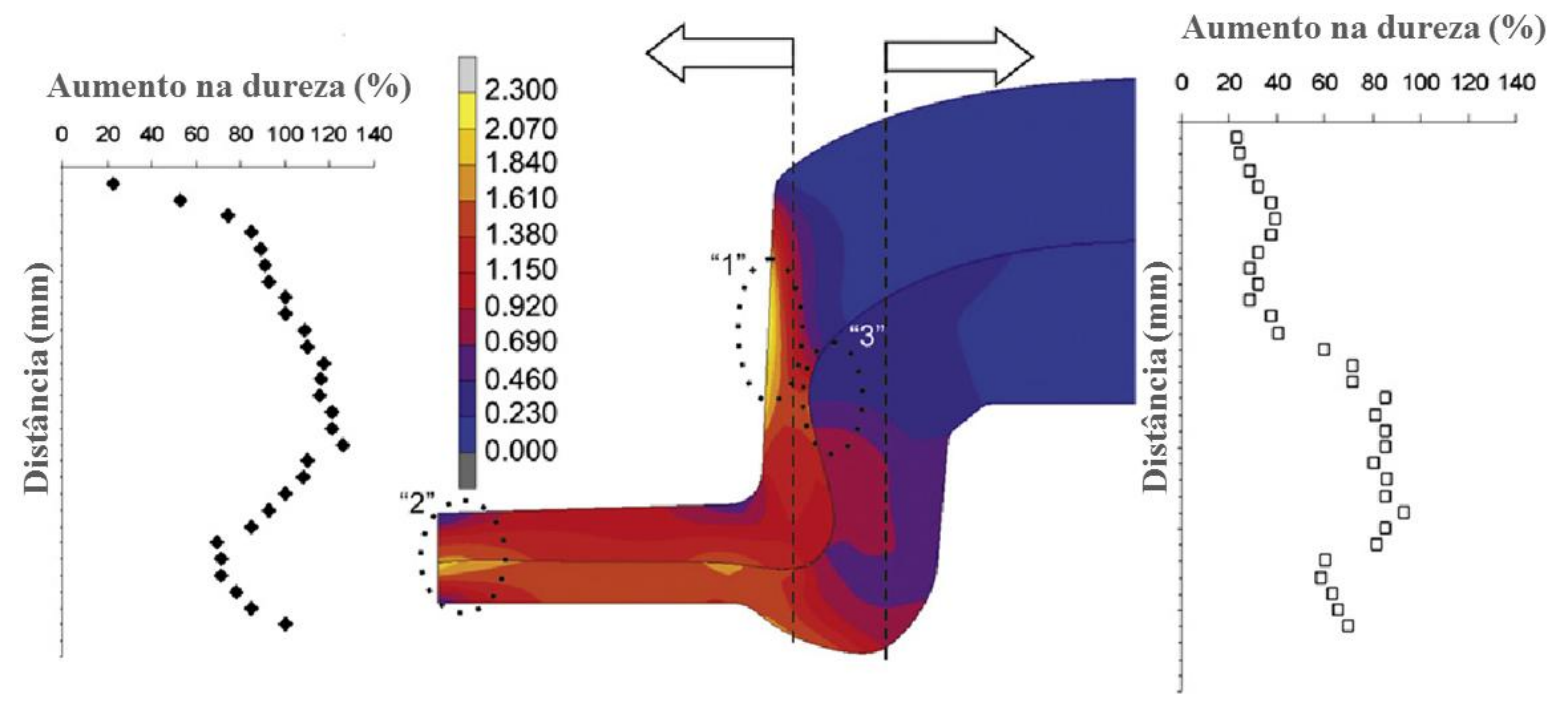

Figura 9 - Correlação entre a dureza e o campo de tensões (MUCHA, 2011)

As dimensões $X, t_{N}$ e $t_{U}$ (Figura 10a), mencionadas por Coppieters at al. (2011), têm relação com a resistência do ponto ao cisalhamento e destacamento. A cota "X" representa a espessura da base do ponto, $t_{N}$, a espessura do "pescoço" e $t_{U}$ a dimensão do travamento mecânico. A medida " $X$ " pode ser facilmente medida através de um equipamento denominado especímetro (Figura 10b), tornando-se um eficiente meio de controle de qualidade. O controle estatístico de processo (CEP), mostrado na Figura 10c, permite o monitoramento de $100 \%$ dos pontos de forma automática, segura e confiável. O princípio de funcionamento é baseado na medição da carga de prensagem do ponto e a verificação da medida "X. 


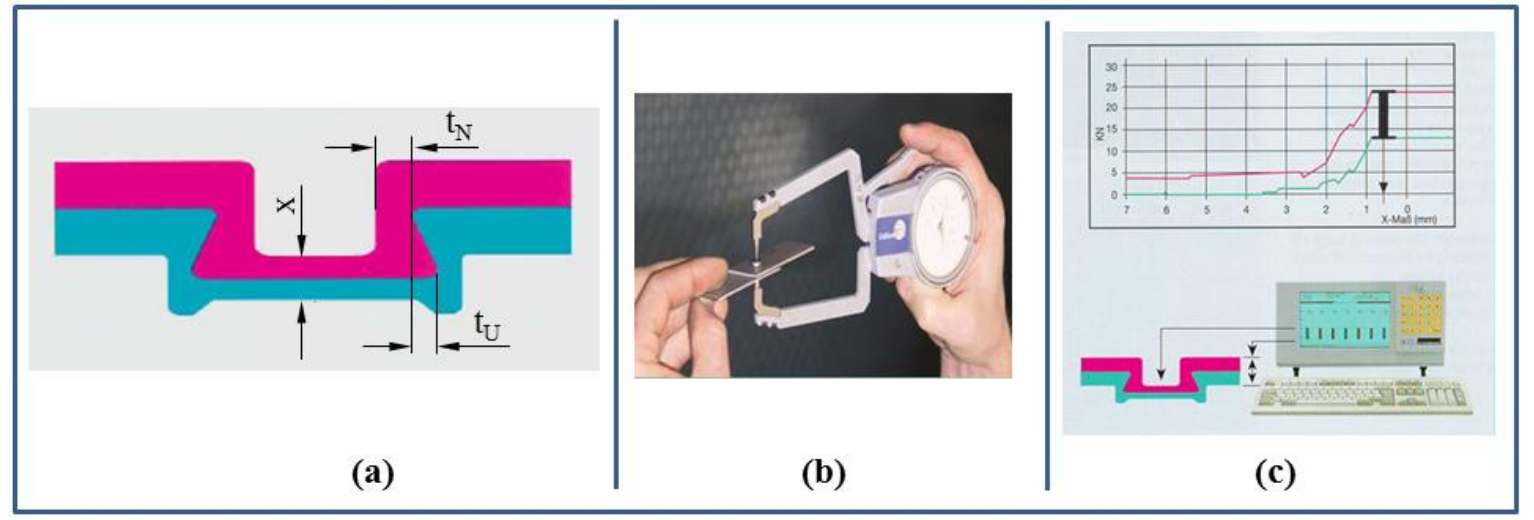

Figura 10 - Controle de qualidade do elemento (TOX, [entre 2000 e 2011])

Na Figura 11 é possível observar o efeito do encruamento na microestrutura do material. Mesmo com um aumento relativamente baixo, nota-se a existência de regiões mais escuras, onde houve uma maior solicitação de tensão (Figura 9).

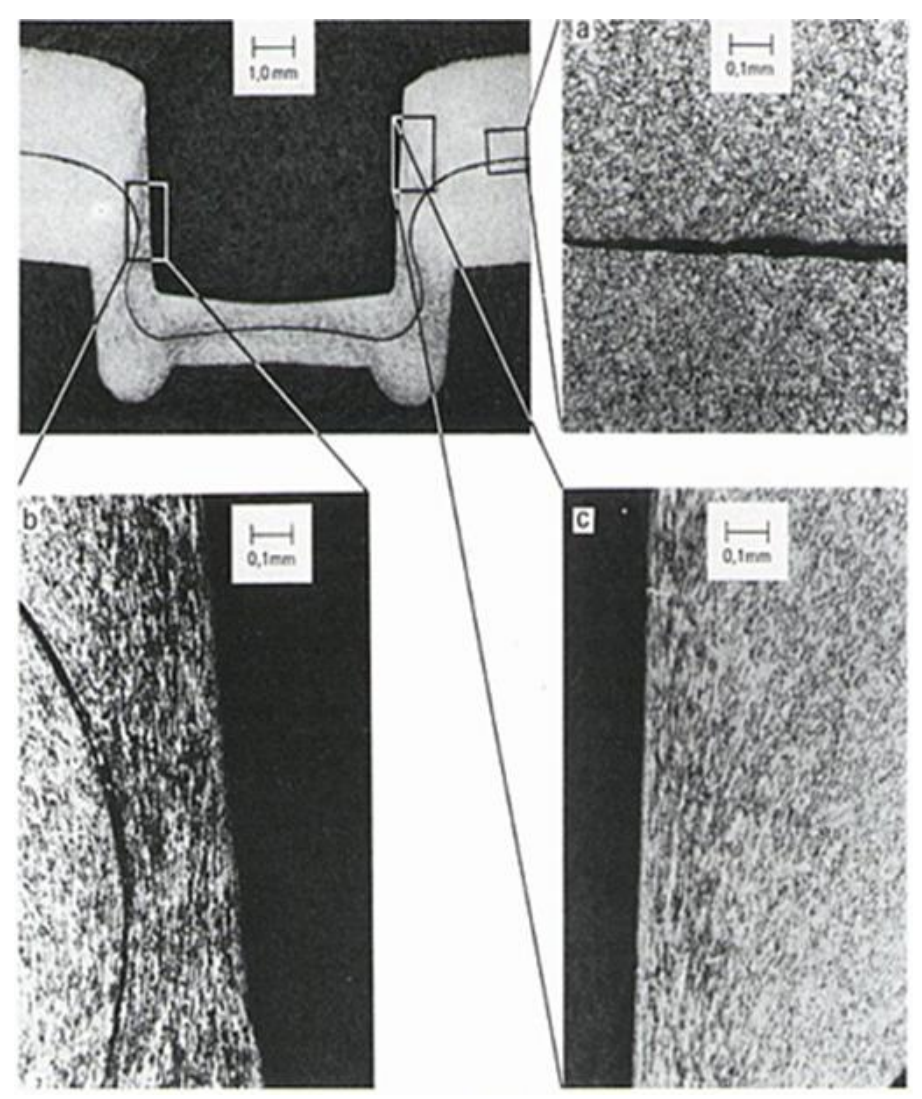

Figura 11 - Análise metalográfica de um Aço St 1203 -crs ${ }^{1}$ 


\subsubsection{Combinação de ferramentas padrão utilizadas no processo}

A seleção das ferramentas padrão para a UCCF baseado na incisão e/ou processo de formação ilustra o estado da arte para os métodos de fixação mecânica (Figura 12).

A resistência mecânica obtida da junta depende, entre outros fatores, do tipo de ferramenta utilizada. O processo individual também contribui significativamente. Esses processos estão sendo constantemente aprimorados.

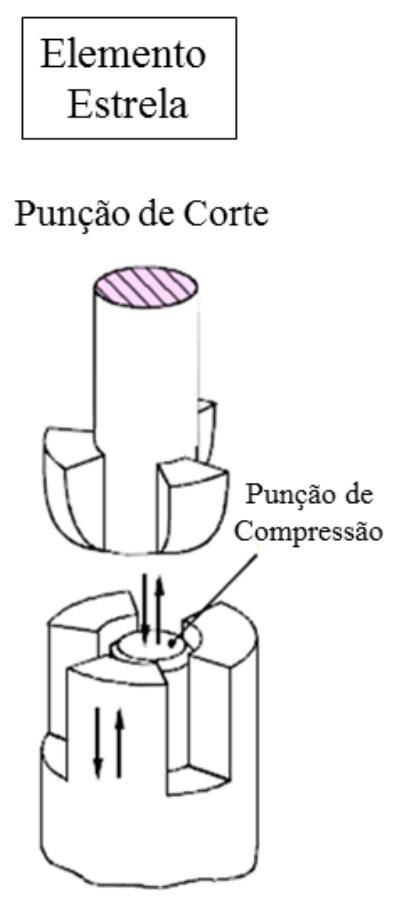

Matriz de Corte
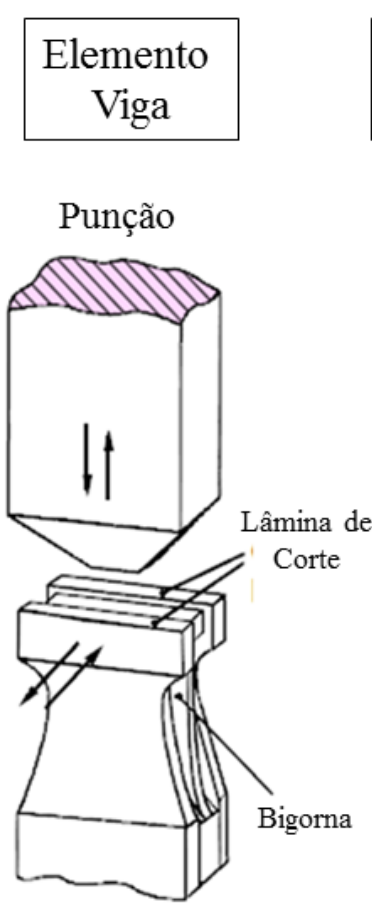

Matriz de Corte
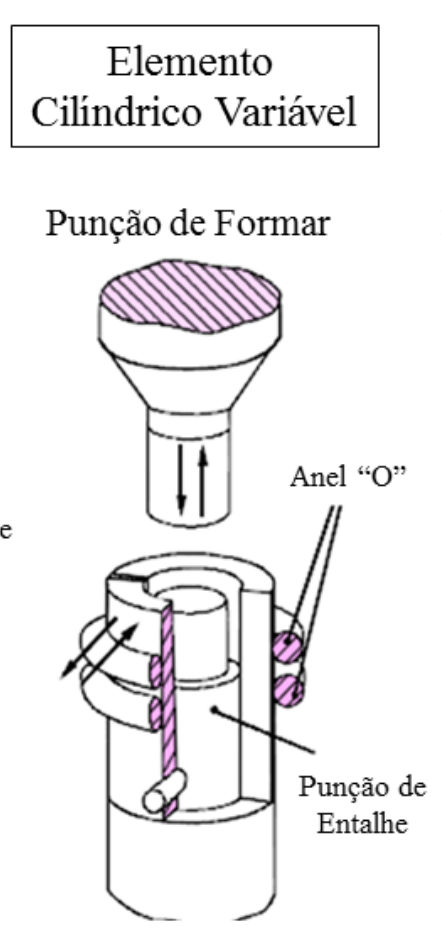

Matriz de Formar

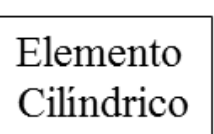

Punção de Formar
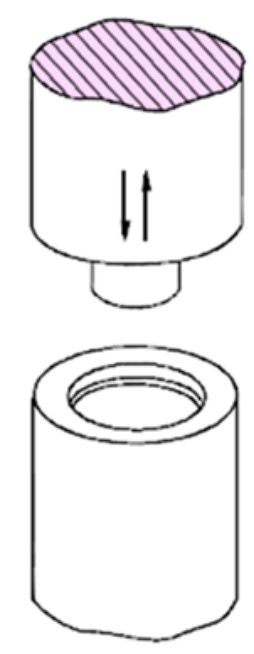

Matriz de Formar

Figura 12 - Seleção de alguns tipos de Ferramenta Padrão pra a UCCF (DIN8593)

\subsection{DEFINIÇÃO DOS PROCESSOS DE UCCF}

Baseado na norma DIN 8593, parte 5, é possível caracterizar o processo de UCCF de acordo com a cinemática dos componentes da ferramenta (simples ou múltiplo estágio) ou pela forma da junta (com ou sem incisão local). 


\subsection{1 Único estágio com incisão local}

A UCCF com incisão local cria uma junta permanente sob ações combinadas de cisalhamento. O punção é responsável por cortar a chapa e deforma-la até o batente representado pela matriz, que por sua vez comprime, juntamente com o punção, exercendo esforço de compressão e provocando o achatamento do elemento de tal maneira que é criada uma forma da junta quase totalmente travada. Uma representação esquemática do processo e da junta pode ser observada na Figura 13.

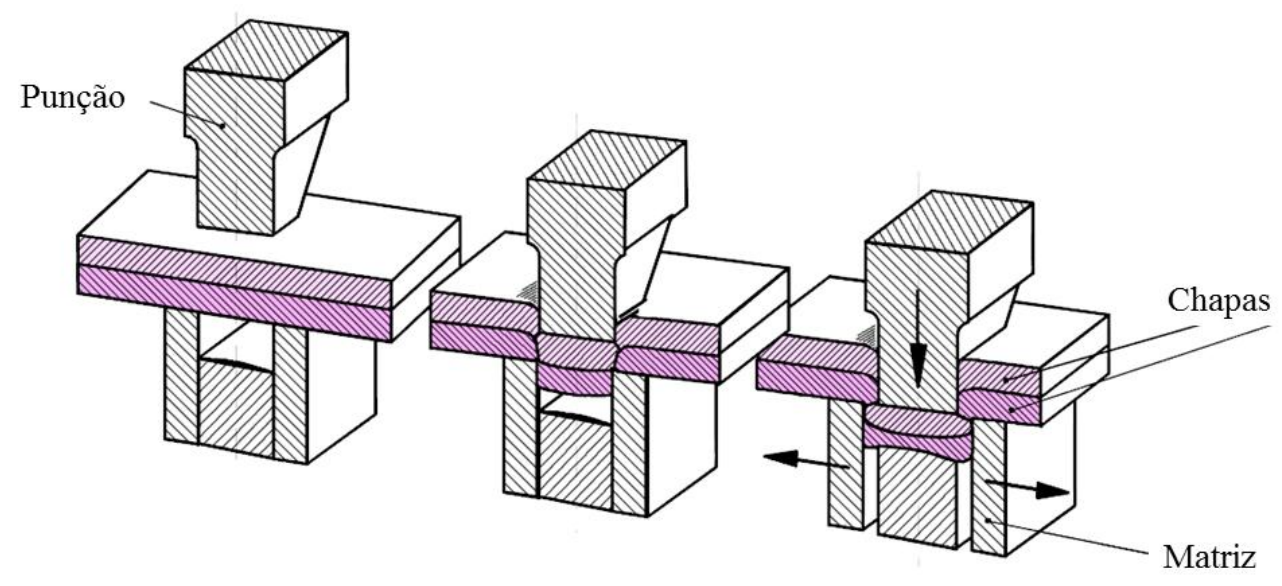

Figura 13 - Processo de UCCF em único estágio com incisão local (DIN8593)

\subsubsection{Dois estágios ou múltiplos estágios com incisão local}

O elemento de junção obtido pelo processo de UCCF de dois estágios ou múltiplos estágios com incisão local é criado sob ação de movimentações sucessivas dos componentes da ferramenta.

Esse processo não tem sido muito bem sucedido até o presente momento devido à maior complexidade da técnica de alinhamento, embora seja muito parecido com o processo de simples estágio mostrado anteriormente. Uma representação esquemática do processo e da junta pode ser observada na Figura 14. 


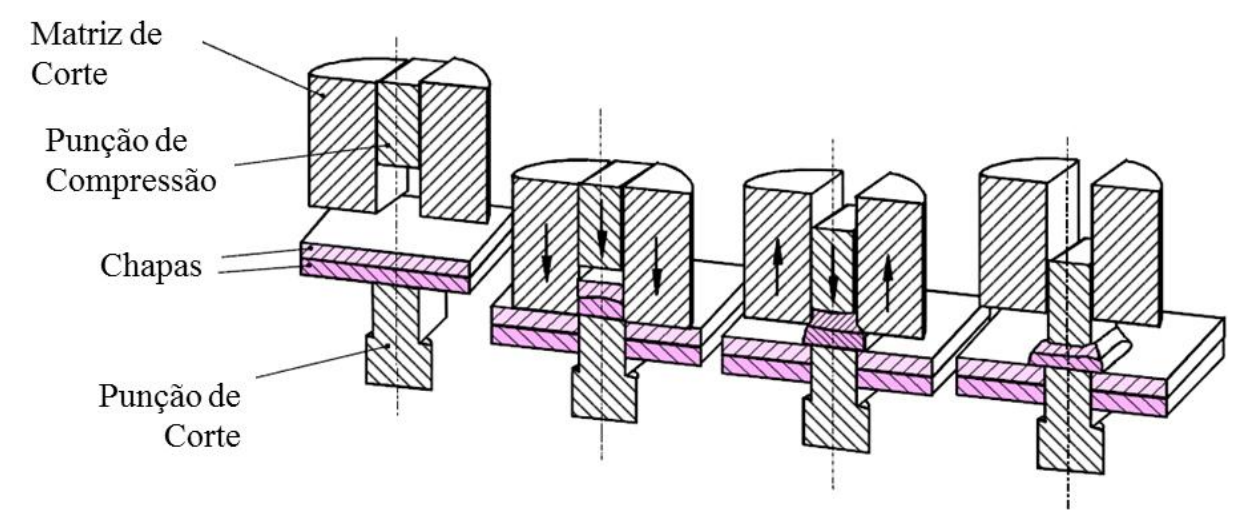

Figura 14 - Processo de UCCF de dois ou múltiplo estágios com incisão local (DIN8593)

\subsection{3 Único estágio sem incisão local (Ferramenta com partes móveis)}

No processo de UCCF sem incisão local, a operação de cravamento (onde a região fixada é limitada pela penetração) é seguida pelo processo de compressão a frio (onde o volume de material deslocado é achatado pela compressão) direcionando para uma junta travada quase estática formada pelo fluxo de material (extrusão de impacto), Figura 15.

O material deslocado da junta, relevante para o comportamento mecânico, é formado pela característica de fluxo de variações dos materiais na matriz e nos lados do punção.

As lamelas da matriz são resistentes e servem para absorver a variação de espessura de chapas, muito comum na indústria, principalmente em construção de carrocerias automotivas.

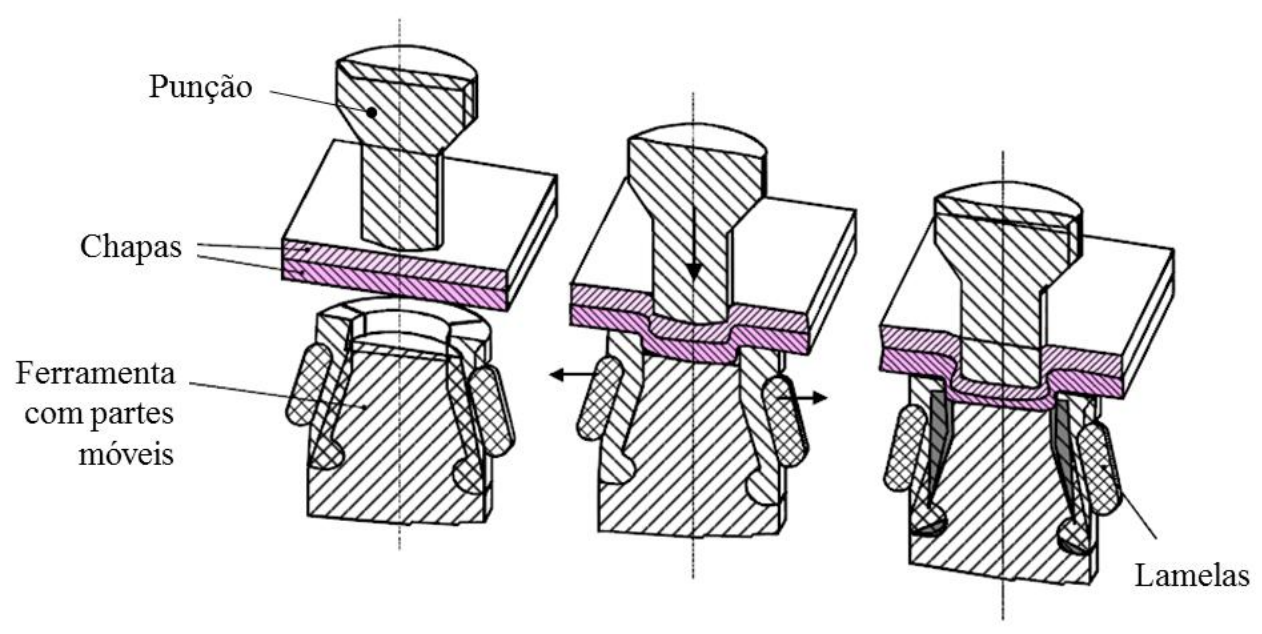

Figura 15 - Processo de UCCF de único estágio sem incisão local

(Ferramenta com Partes Móveis), (DIN8593) 


\subsection{4 Único estágio sem incisão local (Ferramenta sem partes móveis)}

Sistemas de ferramenta com e sem movimentação de partes têm sido projetadas para o processo de UCCF de simples estágio sem incisão local. Durante o processo de simples estágio com matriz de partes móveis, a característica do fluxo de deformação das partes a serem unidas é causada pela sujeição das chapas. Por outro lado, no processo de simples estágio sem partes móveis, o anel estriado da ferramenta força o material a se deformar plasticamente dentro da cavidade da matriz (Figura 16).

A vantagem da ferramenta sem partes móveis é o desgaste desprezível dos componentes móveis. As lamelas, presentes no processo com partes móveis, podem quebrar por desgaste ou por falha na operação, tornando o ponto menos resistente. O processo sem partes móveis não absorve grandes variações de espessura de chapa.

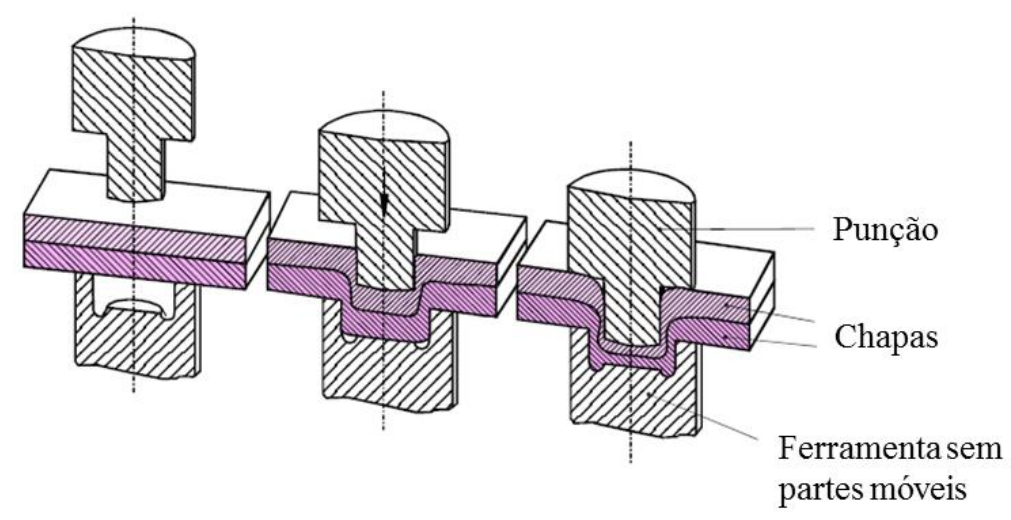

Figura 16 - Processo de UCCF de único estágio sem incisão local (Ferramenta sem Partes Móveis), (DIN8593)

\subsubsection{Formação do elemento plano sem incisão local}

Novas variações dos processos de UCCF estão sendo desenvolvidos constantemente. O princípio básico, entretanto, permanece o mesmo. O processo mostrado na Figura 17 permite aplainar a sobressalência da chapa, através de uma segunda operação. 


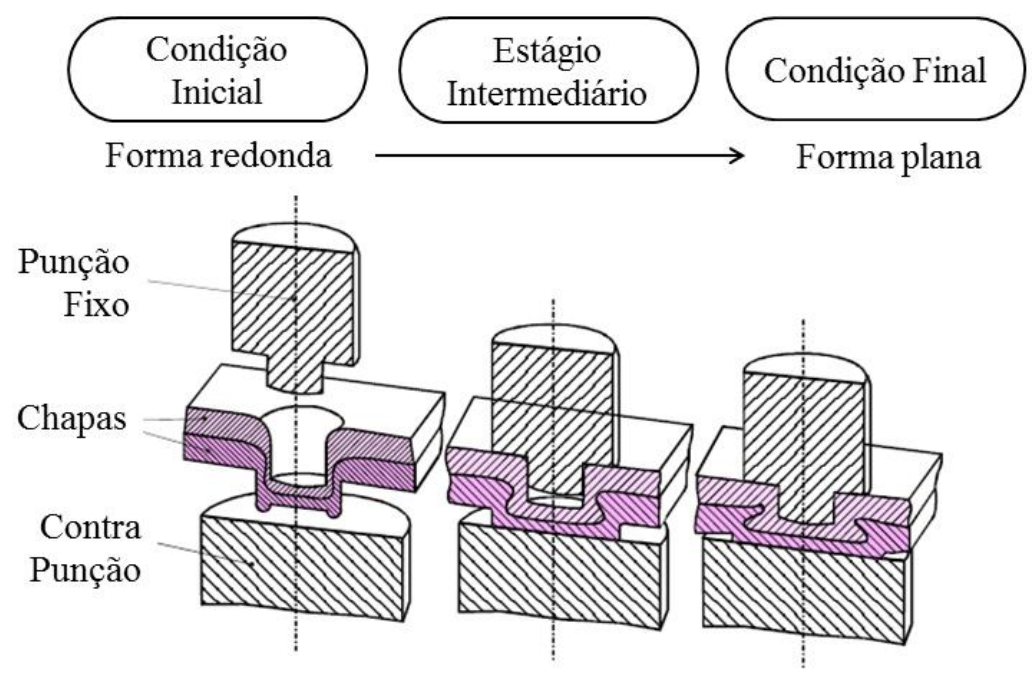

Figura 17 - Formação de UCCF plano sem incisão local (DIN8593)

Esse processo é útil para permitir a montagem de alguns componentes na face da chapa onde o elemento está presente, como se pode ver na Figura 18 uma aplicação desse processo em uma carroceria automotiva. O flange plano da carroceria permite a montagem da vedação de borracha de vedação da porta. Outro ponto relevante é a melhoria no aspecto visual da região.

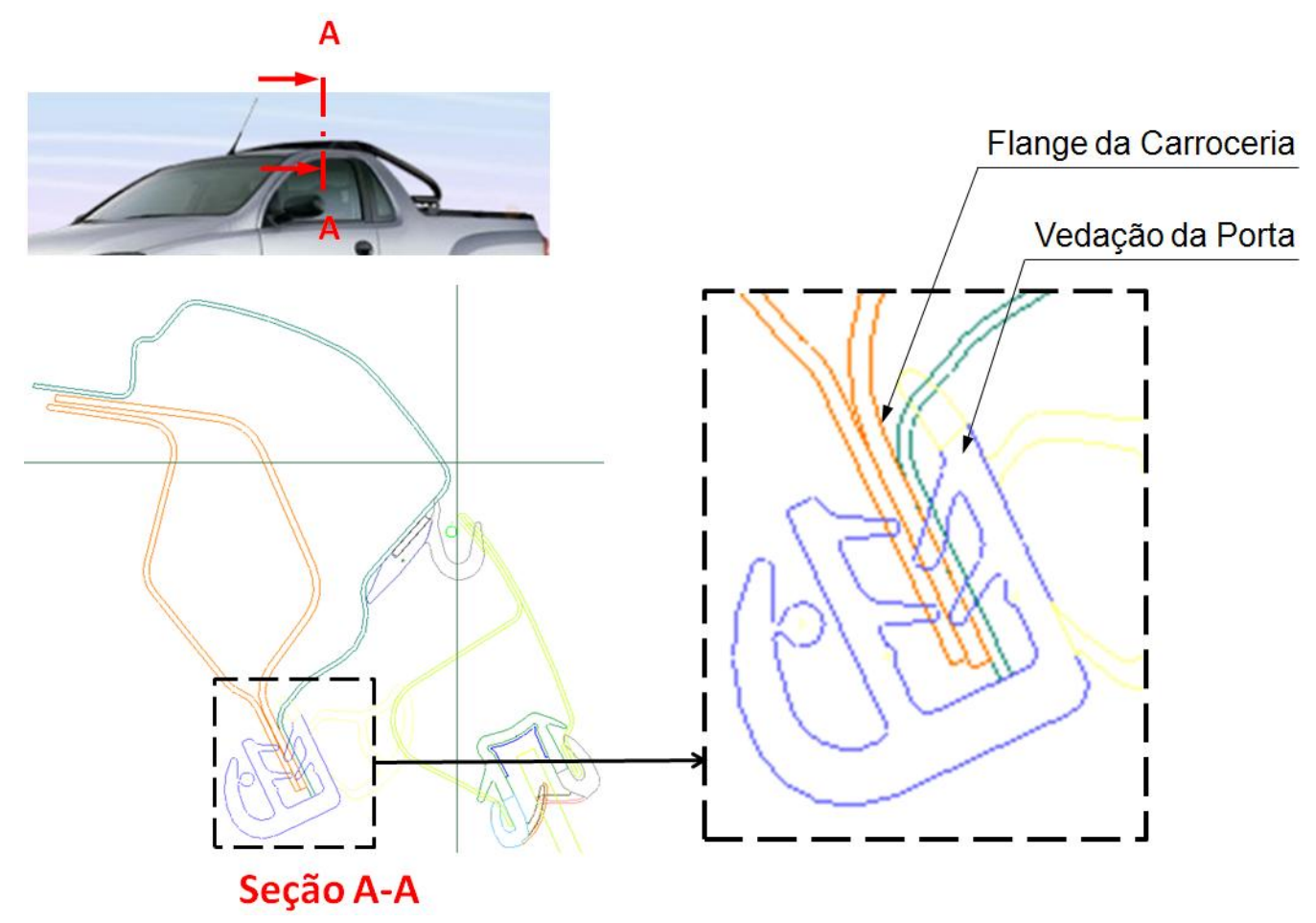

Figura 18 - Aplicação do UCCF plano em uma carroceria automotiva 
Similar ao processo com incisão local é possível, em dois ou mais estágios consecutivos, produzir-se uma união plana (Figura 19).

O processo de duplo estágio ou o múltiplo estágio utiliza aproximadamente $20 \%$ menos energia em comparação ao de único estágio devido ao fato dos estágios de penetração e compressão (achatamento) ocorrerem em estágios consecutivos.

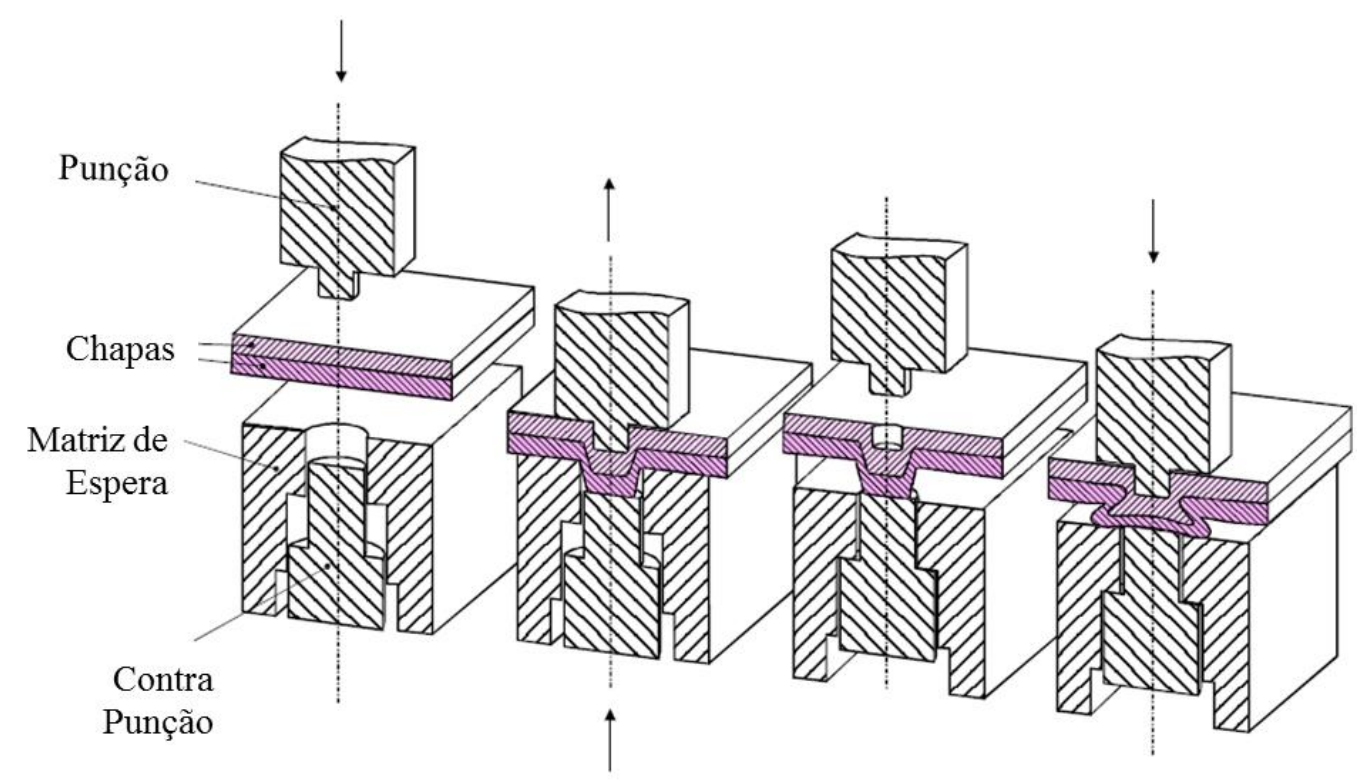

Figura 19 - Processo de UCCF plano de múltiplo estágio sem incisão local (DIN8593)

\subsubsection{Sistema para fixar e soltar as peças}

Um sistema confiável de fixação, pré-requisito na produção de componentes com alta qualidade, precisa grampear as peças alinhadas de tal forma que durante o processo não cause o movimento da posição relativa do elemento da junta com relação.

Um sistema de fixação apropriado pode ser usado para segurar as partes unidas, bem como soltar as peças finalizadas das ferramentas.

Apenas nos casos de UCCF, sistemas de fixação precisam ser também adaptados para o uso apropriado do punção de rebitagem.

Na Figura 20, é possível observar-se que a área de fixação para o processo com incisão local é maior do que a área do processo sem incisão local. 


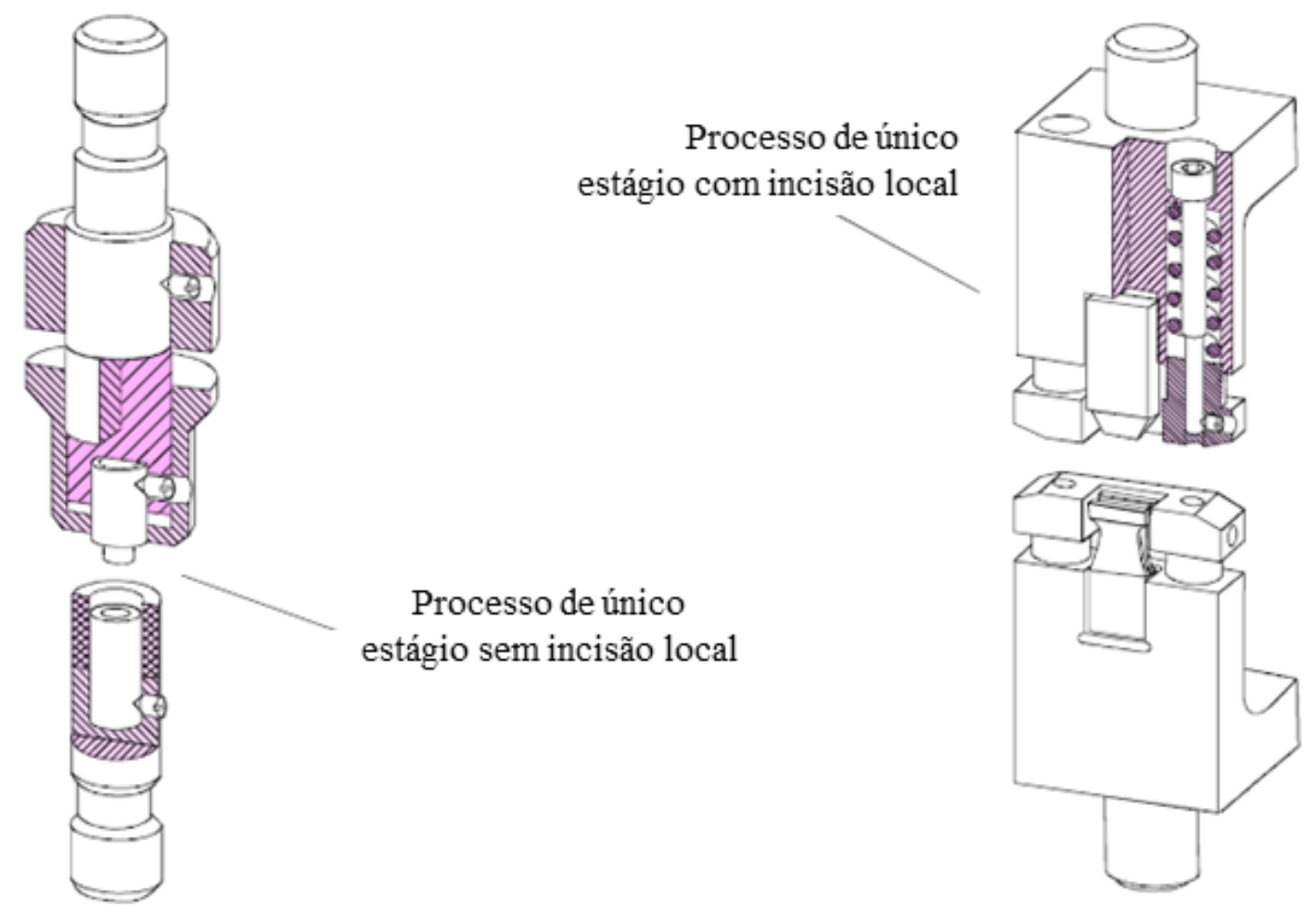

Figura 20 - Comparação da área de fixação das chapas nos processo de UCCF - (DIN8593)

\subsection{COMPARAÇÃO DOS ELEMENTOS DE UCCF COM VARIAÇÃO DE INCISÃO LOCAL E PARTES CONFORMADAS}

A incisão do elemento de união é um parâmetro controlável no processo produtivo. A Figura 21 mostra a influência do cisalhamento em relação a alguns aspectos de processo. Quanto maior o cisalhamento, maior será, em relação ao elemento cilíndrico, a formação de rebarba e o efeito da geometria no comportamento mecânico. Já o controle da ferramenta e a influência da superfície unida (em contato), em relação à resistência mecânica, são menores. 


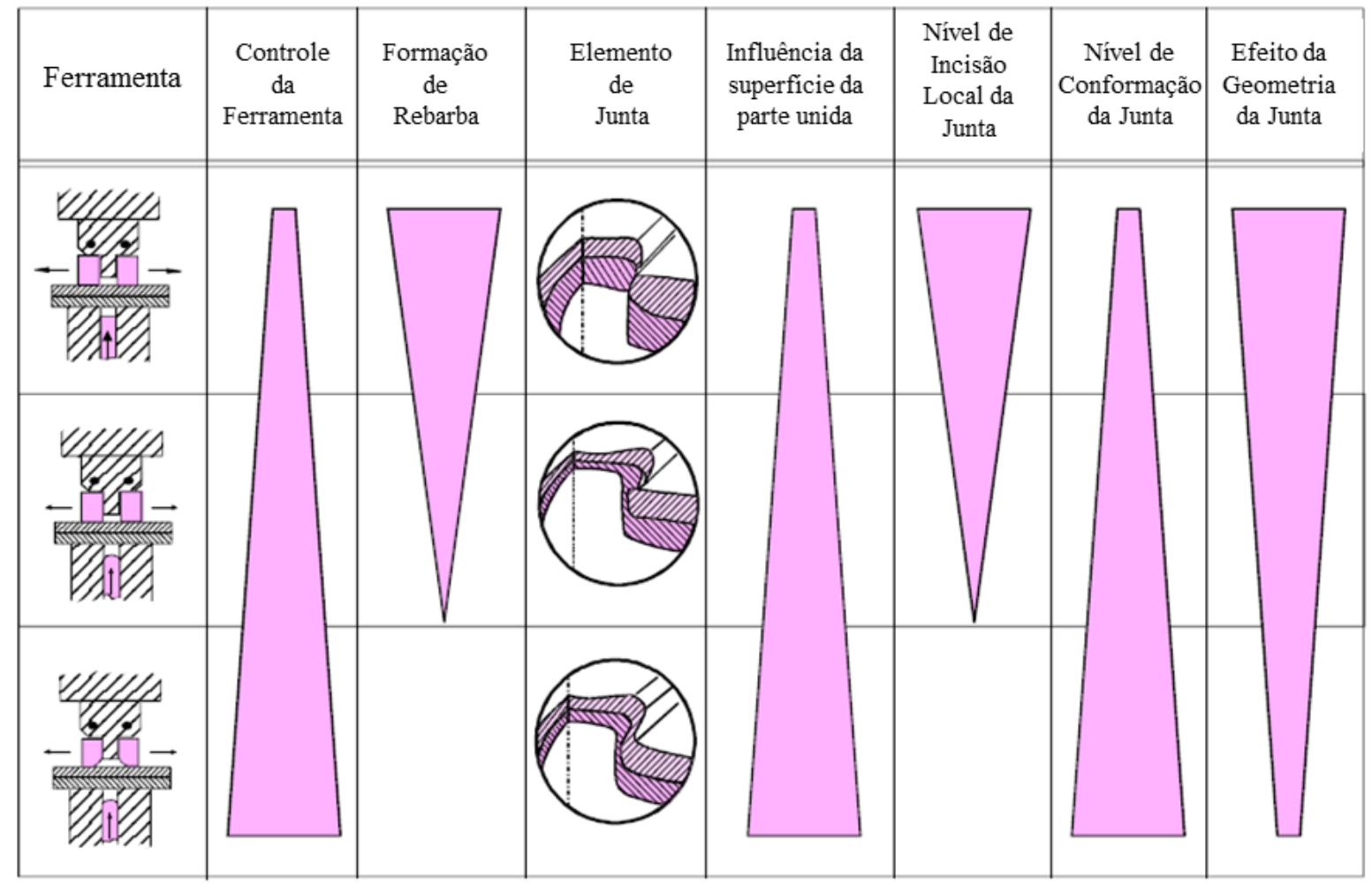

Figura 21 - Comparação dos elementos de UCCF com variação de incisão local e partes conformadas (DIN8593)

\subsection{APLICAÇÃO DO UCCF NA INDÚSTRIA}

São diversas as aplicações da UCCF na indústria. Um resumo das aplicações pode ser encontrado na Tabela 1. A pesquisa foi feita com base nas informações encontradas em páginas virtuais dos fabricantes de equipamentos de UCCF. 
Tabela 1 - Aplicação da UCCF na indústria

\begin{tabular}{|c|c|c|c|}
\hline Fabricante & Produtos & $\begin{array}{c}\text { Área de } \\
\text { aplicação }\end{array}$ & $\begin{array}{l}\text { Componentes } \\
\text { em produção }\end{array}$ \\
\hline \multirow{4}{*}{ ATTEXOR } & & Automotivo & $\begin{array}{l}\text { Tela térmica, mecanismo do levantador } \\
\text { de vidro, tampa dianteira e traseira }\end{array}$ \\
\hline & & $\begin{array}{l}\text { Construção } \\
\text { Civil }\end{array}$ & Portão industriais e andaimes \\
\hline & & $\begin{array}{c}\text { Linha } \\
\text { Branca }\end{array}$ & $\begin{array}{l}\text { Estrutura de fogões, máquina de lavar } \\
\text { roupa, secadoras e contatos elétricos }\end{array}$ \\
\hline & & Térmico & $\begin{array}{l}\text { Base de painéis solares, estrutura dos } \\
\text { filtros dos ventiladores e perfil do } \\
\text { fixador de dutos }\end{array}$ \\
\hline \multirow[t]{4}{*}{ BTM } & & Automotivo & $\begin{array}{l}\text { Cinta do tanque de combustível, } \\
\text { estrutura do teto solar, protetor } \\
\text { térmciso do escapamento, suporte do } \\
\text { pedal de freio, tampa dianteira, tudo de } \\
\text { ar condicionado, ajustador do braço da } \\
\text { direção, travessas de teto, suporte da } \\
\text { bateria e juntas }\end{array}$ \\
\hline & & $\begin{array}{c}\text { Linha } \\
\text { Branca }\end{array}$ & $\begin{array}{l}\text { Secadora, lavadora de roupa e louça, } \\
\text { refrigerador, micoondas }\end{array}$ \\
\hline & & Térmico & $\begin{array}{l}\text { Gabinete de forno, duto galvanizado e } \\
\text { ventilador }\end{array}$ \\
\hline & & $\begin{array}{l}\text { Construção } \\
\text { Civil }\end{array}$ & $\begin{array}{l}\text { Treliça de aço, luminária de teto, portão } \\
\text { de garagem e painel elétrico }\end{array}$ \\
\hline \multirow{2}{*}{ ECHOLD } & & Automotivo & $\begin{array}{l}\text { Mecanismo de levantador de vidro e } \\
\text { tampa dianteira }\end{array}$ \\
\hline & & $\begin{array}{l}\text { Construção } \\
\text { Civil }\end{array}$ & $\begin{array}{l}\text { Estojo para itens de laboratório e linha } \\
\text { branca, dispositivos de segurança para } \\
\text { fluxo de aquecedores de gás }\end{array}$ \\
\hline \multirow{3}{*}{ TOX } & & Automotivo & $\begin{array}{l}\text { Estrutura e trilho de banco, freio de } \\
\text { estacionamento, tampa dianteira, tampa } \\
\text { traseira, estrutura do levantador de } \\
\text { vidro, coxim do motor }\end{array}$ \\
\hline & & $\begin{array}{l}\text { Linha } \\
\text { branca }\end{array}$ & $\begin{array}{l}\text { Gabinete de máquina de lavar roupa, } \\
\text { gabinete de ar condicionado, base de } \\
\text { microondas, gabinete de } \\
\text { freezer/refrigerador }\end{array}$ \\
\hline & & Diversos & $\begin{array}{l}\text { Ventilador, encosto de assento, chassis } \\
\text { de computador, componente eletrônico }\end{array}$ \\
\hline
\end{tabular}

Fonte: Adaptado das informações disponíveis pelos fabricantes por meio de catálogo ${ }^{2}$

\footnotetext{
${ }^{2}$ ATTEXOR: <http://www.clinchsystems.com/> - Todos os acessos feitos em 26 out. 2011.

BTM: <http://www.clinching.co.uk/>

ECKHOLD: 〈http://www.eckold.com/en-us/productsforsheetmetalworking/kraftformer/kraftformerkf665.aspx>

TOX: <http://www.tox-br.com/pt/pagina-inicial.html>
} 


\subsection{MODELOS DE RESISTÊNCIA MECÂNICA PARA UCCF E SPRE}

Na literatura existem diversos tipos diferentes de ensaio de resistência aplicado à união de chapas. Este capítulo visa mostra-los, relatando as características de cada um.

\subsubsection{Tipos de ensaio}

O ensaio de cisalhamento por tração (tensile-shear lap test) é o mais comum devido à simplicidade. Existem também os ensaios de arrancamento (pull-out test) e o arrancamento com flange (coach peel test). Esses três ensaios são os mais utilizados (Figura 22).

As setas indicam o vetor de força aplicado nos corpos de prova em cada tipo de ensaio. É possível também visualizar a deformação característica desses corpos nos ensaios por meio de representação gráfica baseado no método de elementos finitos.

Cisalhamento por Tração

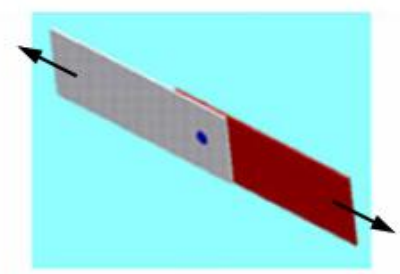

Arrancamento

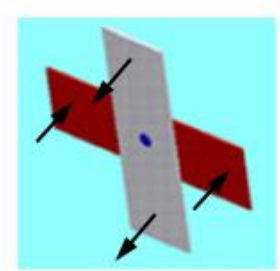

Arrancamento com flange

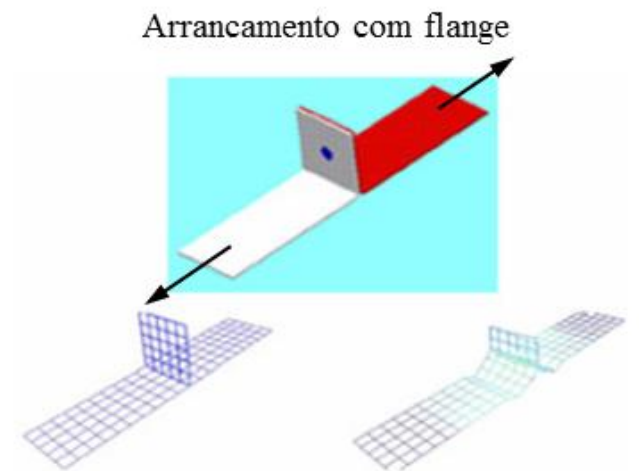

Figura 22 - Principais tipos de ensaio. (LANGRAND; COMBESCURE, 2004) 
Cada ensaio avalia um tipo de carga isoladamente, o que na prática não acontece no ponto de união, pois o mesmo sofre diversas cargas combinadas. Segundo Lee et al. (1998) negligenciar os efeitos de cargas combinadas poderá resultar em falhas prematuras nas regiões do ponto por subestimar esse tipo de carga. As duas cargas mais importantes no ponto são o cisalhamento causado por tração e o arrancamento (tração) causado pela força normal ao ponto. Na Figura 23 pode-se observar a carga máxima suportada em ambos os ensaios separadamente, a carga de tração (arrancamento) é sempre menor que o de cisalhamento por volta de $20 \%$.

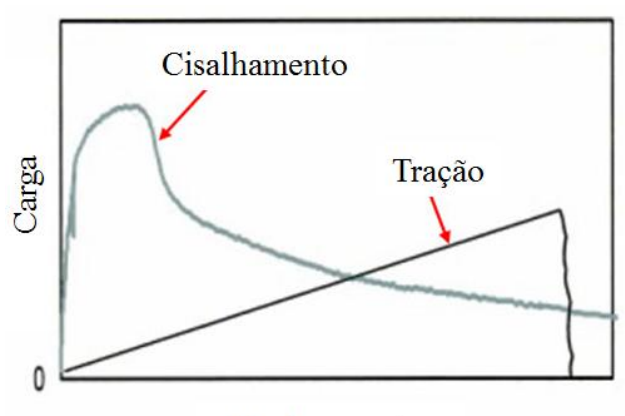

Deslocamento

Figura 23 - Gráfico conceitual de descolamento x carga para cisalhamento e tração (LEE et al, 1998)

O ensaio de Arcan apresentado por Lagrand e Combescure (2004) possibilita testar o elemento de união através de cargas combinadas variando de tração pura (arrancamento) na condição de $0^{\circ}$ e cisalhamento puro na condição de $90^{\circ}$ (Figura 24). O dispositivo permite um ajuste angular com acréscimo de $15^{\circ}$. Os dados obtidos por esse ensaio fornece ao avaliador um panorama completo do comportamento da união.
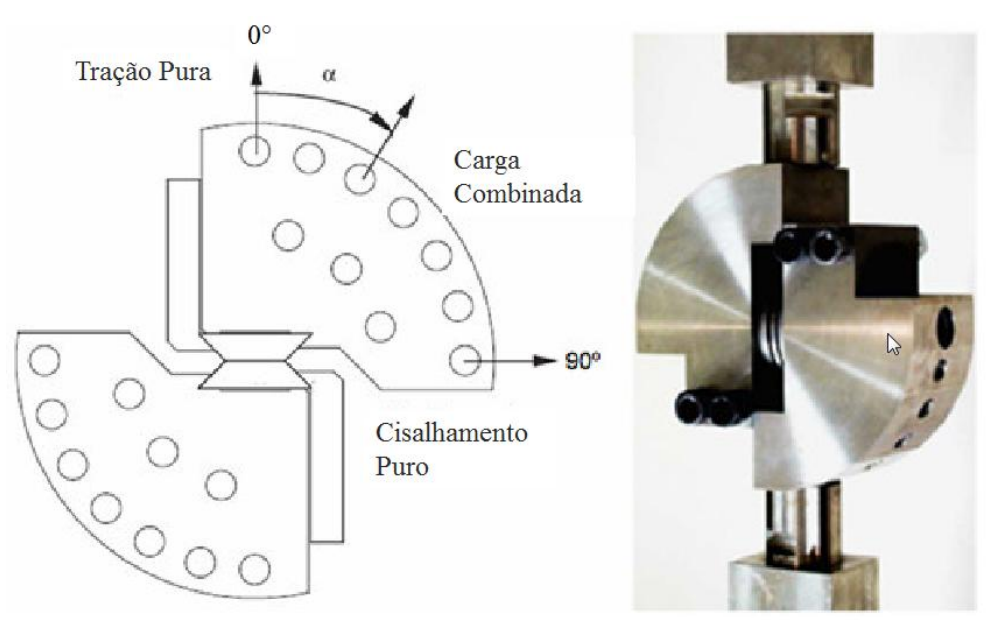

Figura 24 - Ensaio de Arcan (LANGRAND; COMBESCURE, 2004) 
O modelo de Langrand \& Combescure (2004) possibilita aplicar a carga diretamente na união estudada. Esse tipo de ensaio é complexo, pois requer uma brasagem feita em um forno à temperatura de aproximadamente $635^{\circ} \mathrm{C}$ (Figura 25). A base do dispositivo deve ser usinada após cada ensaio. Os efeitos da soldagem do corpo de prova no dispositivo não foram estudados pelo autor.
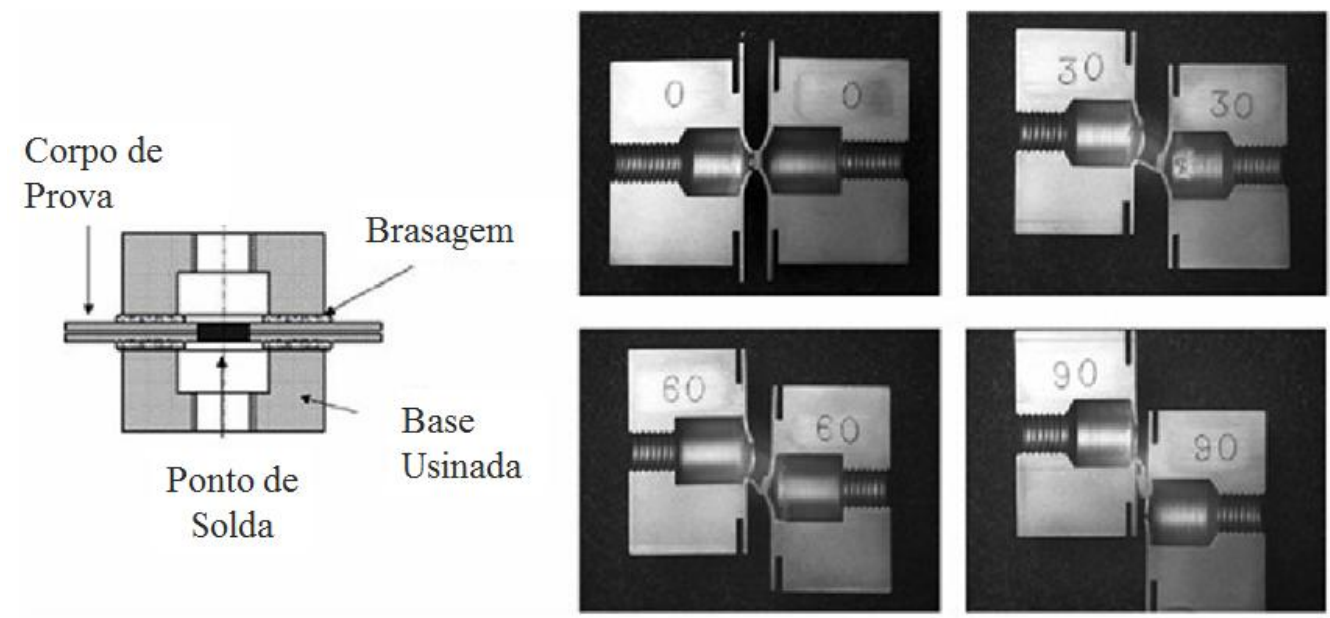

Figura 25 - Fixação do Corpo de Prova no Modelo de Langrand \& Combescure

(LANGRAND; COMBESCURE, 2004)

Lin et al. (2002) foi apresentaram um modelo de ensaio com cargas combinadas que elimina os problemas do modelo de Langrand e Combescure (2004), contudo esse modelo está sujeito a problemas com dimensões dos corpos de prova. A maior dificuldade que esse modelo mostra é o corpo de prova do tipo copo-quadrado que recai no mesmo complicador citado no modelo anterior de encarecer o ensaio pela complexidade de construção (Figura 26).

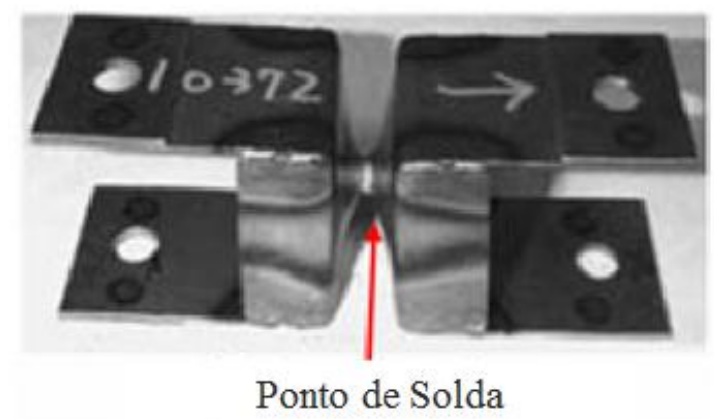

Figura 26 - Corpo de prova do modelo de ensaio de Lin. (LIN et al., 2002) 
Baseado no modelo de Arcan, Lee et al. (1998) projetaram um corpo de prova em formato "U”, simples de ser construído e apresentaram resultados de ensaios similares aos demais modelos.

Vale lembrar que ele também está sujeito a problemas de dimensões do corpo de provas como no modelo de Lin et al. (2002). Na Figura 27 pode-se ver o dispositivo e o corpo de provas.

O modelo de Lee et al (1998) foi utilizado como base para a construção do dispositivo de ensaio dos corpos de prova de unidos pelo processo de UCCF.
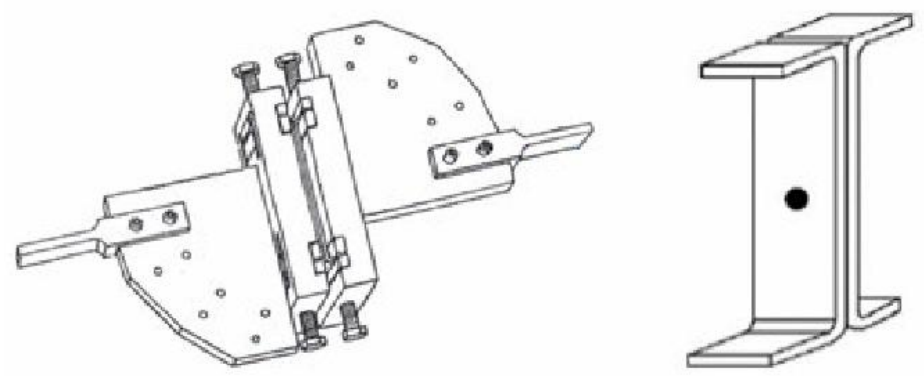

Figura 27 - Dispositivo e corpo de prova do modelo de Lee. (LEE et al., 1998)

\subsubsection{Corpos de prova}

Existem variadas normas para determinação da dimensão do corpo de prova para ensaios de tração. Os modelos de corpos de prova mostrados na Figura 28 são referenciados pelas normas ANSI/AWS e ISO.

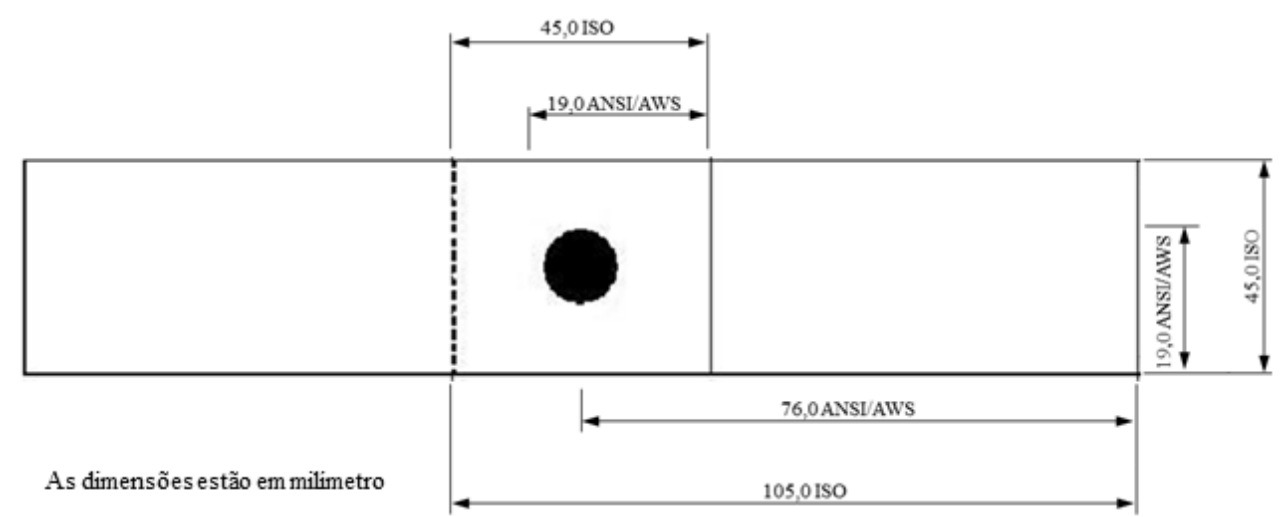

Figura 28 - Dimensões dos corpos de prova para ensaio de tração, segundo as normas ISO e ANSI/ANS (ZHOU et al, 1999) 
Zhou et al (1999) estudaram os modos de falha em ensaios estáticos, constatando a existência de cinco diferentes modos, conforme mostrado na Figura 29a e Figura 29b. As falhas "A" e B" constituem evidência que os corpos de prova se romperam antes do elemento de união. Sendo assim, não é possível observar a resistência máxima do elemento de fixação.

O desejável é que ocorra a falha do elemento ensaiado e não do corpo de prova (Figura 29c, Figura 29d e Figura 29e. Para isso, é importante determinar a largura mínima do corpo de prova.

Modos de falha indesejáveis
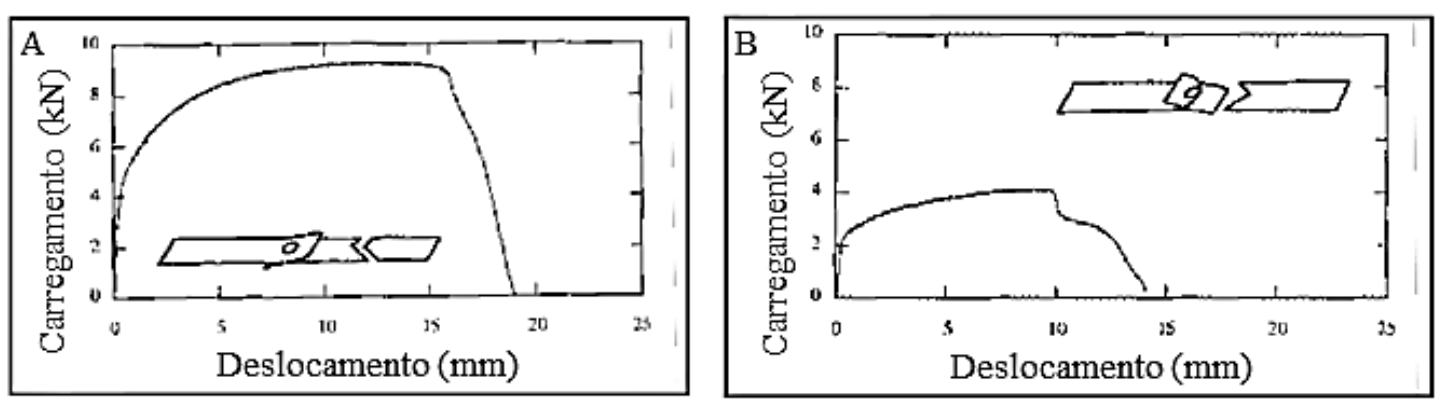

Modos de falha desejáveis
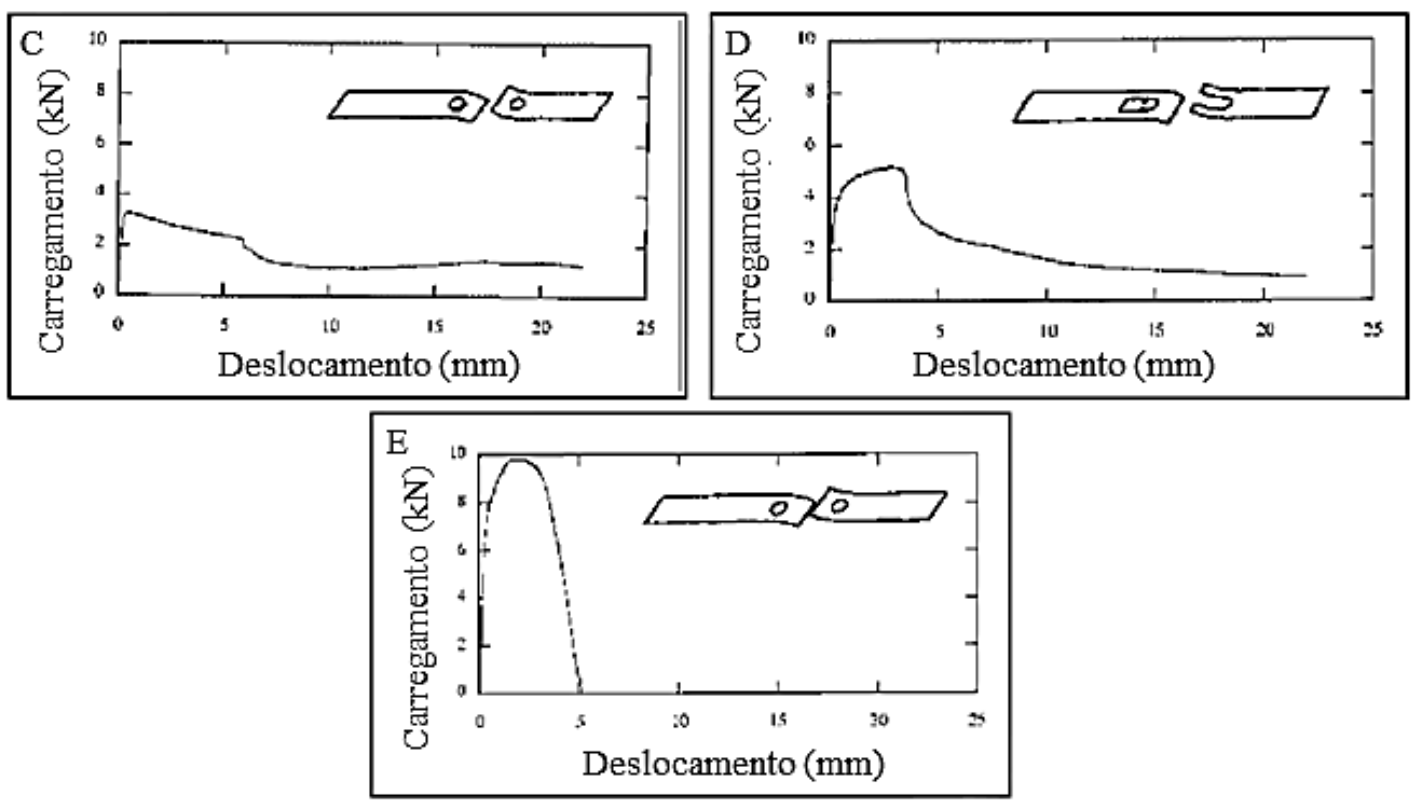

Figura 29 - Modos de falha de um ponto de solda. (ZHOU et al, 1999)

$L_{\text {CRÍTICA }}=13,404+(18,598 \times t)$ 


\subsubsection{Principais parâmetros do elemento de UCCF}

Estudos baseados no método de elementos finitos têm sido realizados por pesquisadores no objetivo de entender melhor a influência da geometria do elemento de união no comportamento mecânico.

Segundo Varis e Lepistö (2003), no geral, três modos de falha têm sido observados quando a união é carregada. Dois deles são mostrados na Figura 30. No modo A, as folhas são deformadas e a união se abre em decorrência da tensão. Tipicamente, um baixo afinamento da base da união (conhecido como medida "X", Figura 10a ) não produz um bom travamento das chapas.

No segundo modo, B, ilustrado na Figura 30, não há material suficiente no pescoço da união, a carga resultará na falha nessa região. Existem duas razões aparentes para a falha B: folga pequena entre punção e matriz ou penetração muito profunda do punção na matriz.

O terceiro modo de falha $\mathrm{C}$ é a combinação dos modos $\mathrm{A}$ e B. Nesse modo um dos lados da junta falha, o outro lado é deformado ainda nesse primeiro estágio. Consequentemente, as chapas são separadas sem ocorrência de fratura.
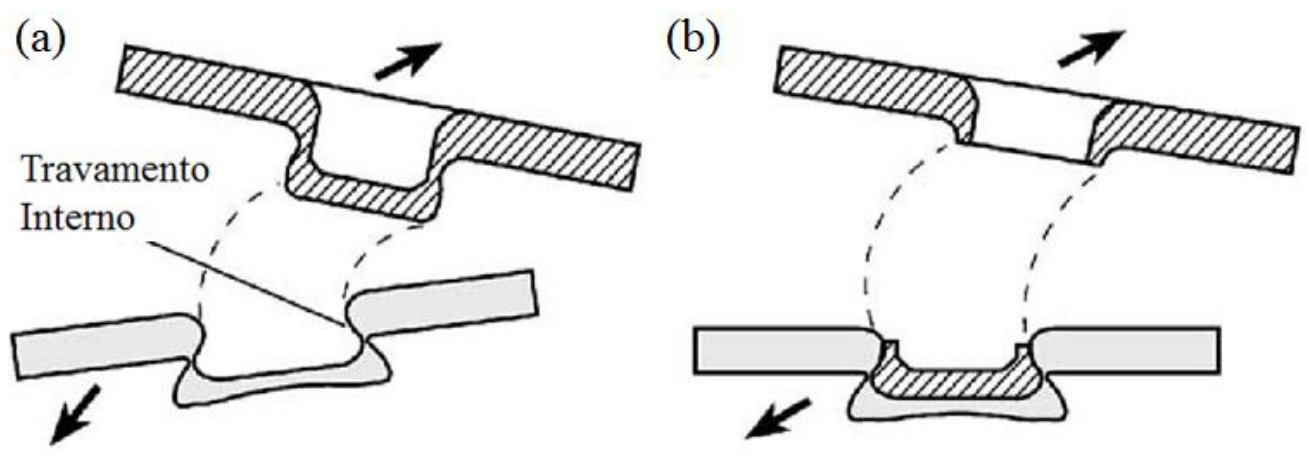

Figura 30 - Modos de falha da união (VARIS; LEPISTÖ, 2003)

Atualmente, a indústria automobilística atua na fase de desenvolvimento do produto junto com o fornecedor dos equipamentos de UCCF para determinar os parâmetros da união. O fornecedor possui um banco de dados contendo os parâmetros do equipamento para algumas combinações mais comuns. Para outras combinações, essa determinação é feita de forma experimental.

No sentido de reduzir o número de amostras para determinação da união ótima, Varis e Lepistö (2003), estabeleceram alguns parâmetros importantes (Figura 31). 


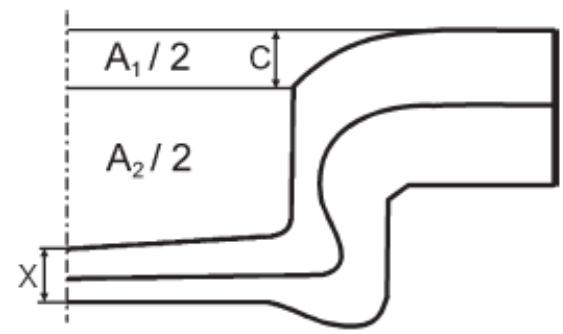

Figura 31 - Parâmetros importantes do ponto de UCCF (VARIS; LEPISTÖ, 2003)

A Figura 32 mostra a seção da união de UCCF dividida em dois estágios. O Volume $V_{A 1}$ depende da deformação do punção e o Volume $V_{A}$ é basicamente o deslocamento de material para o Volume inferior $V_{B}$. Combinando os volumes $V_{A}$ e $V_{B}$, juntamente a medida "X" assumindo o total preenchimento da matriz é possível determinar que:

$V_{A}(\mathrm{X})=V_{B}$

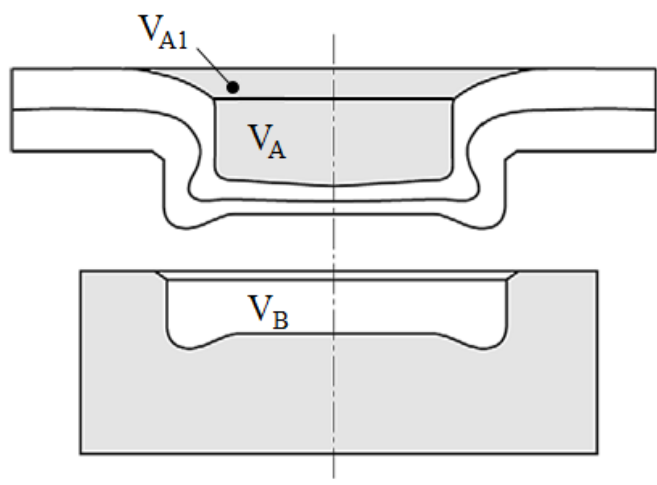

Figura 32 - Volumes do ponto da UCCF utilizando ferramentas fixas (VARIS; LEPISTÖ, 2003)

O modelamento matemático para o volume $V_{A 1}$ pode ser encontrado na equação 3 .

$V_{A 1}=\int_{r 2}^{r 1} \pi r^{2} f(r) d r$

A função $f(r)$ foi determinada utilizando-se as ferramentas de modelamento matemático, tendo como base de dados, o perfil geométrico apresentado na Figura 33.

$f(r)=3,523-1,348 r+0,129 r^{2}$ 


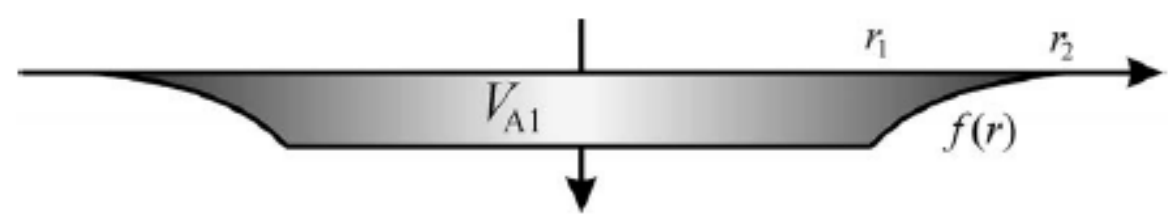

Figura 33 - Representação da função f(r) após a operação de UCCF (VARIS; LEPISTÖ, 2003)

Os valores de volume do punção e as dimensões de diâmetro da matriz foram colocados em uma planilha eletrônica para determinação dos possíveis valores da medida "X". O campo de valores encontrado foi de $0,4 \mathrm{~mm}<\mathrm{X}<$ profundidade da matriz.

O procedimento descrito acima foi ensaiado utilizando como ferramenta uma matriz de diâmetro de 8,0 mm. O material utilizado foi a chapa de aço galvanizado (espessura de 1,0 $\mathrm{mm}$ ) com limite de ruptura na ordem de 550MPa. Um total de 49 combinações foram ensaiadas (Tabela 2), desse montante apenas 12 obtiveram resultados satisfatórios.

$O$ valor de $X=0,6 \mathrm{~mm}$ foi o que obteve melhor resultados nos ensaios de tração. Portanto foi definido como o a dimensão ótima para o ensaio em questão.

Tabela 2 - Combinação de ferramentas estudadas para a determinação da medida " $X$ ". Diâmetro da matriz $8,0 \mathrm{~mm}$

\begin{tabular}{llllllll}
\hline $\begin{array}{l}\text { Diâmetro do } \\
\text { Punção }(\mathrm{mm})\end{array}$ & \multicolumn{7}{l}{ Profundidade da matriz $(\mathrm{mm})$} \\
\cline { 2 - 7 } & 0.8 & 1.0 & 1.2 & 1.4 & 1.6 & 1.8 & 2.0 \\
\hline & $1.19^{\mathrm{a}}$ & $0.84^{\mathrm{b}}$ & 0.50 & $0.17^{\mathrm{a}}$ & $-0.16^{\mathrm{a}}$ & $-0.47^{\mathrm{a}}$ & $-0.78^{\mathrm{a}}$ \\
4.8 & $1.22^{\mathrm{a}}$ & $0.91^{\mathrm{b}}$ & 0.61 & $0.32^{\mathrm{a}}$ & $0.04^{\mathrm{a}}$ & $-0.24^{\mathrm{a}}$ & $-0.52^{\mathrm{a}}$ \\
5.0 & $1.25^{\mathrm{a}}$ & $0.98^{\mathrm{b}}$ & 0.72 & 0.46 & $0.21^{\mathrm{a}}$ & $-0.04^{\mathrm{a}}$ & $-0.28^{\mathrm{a}}$ \\
5.2 & $1.28^{\mathrm{a}}$ & $1.05^{\mathrm{a}}$ & 0.82 & $\underline{0.60}$ & $0.38^{\mathrm{a}}$ & $0.16^{\mathrm{a}}$ & $-0.06^{\mathrm{a}}$ \\
5.4 & $1.32^{\mathrm{a}}$ & $1.12^{\mathrm{a}}$ & $0.92^{\mathrm{a}}$ & 0.72 & 0.53 & $0.33^{\mathrm{a}}$ & $0.15^{\mathrm{a}}$ \\
5.6 & $1.35^{\mathrm{a}}$ & $1.18^{\mathrm{a}}$ & $1.00^{\mathrm{b}}$ & 0.83 & 0.66 & $0.50^{\mathrm{c}, \mathrm{d}}$ & $0.33^{\mathrm{a}}$ \\
5.8 & $1.39^{\mathrm{a}}$ & $1.24^{\mathrm{a}}$ & $1.09^{\mathrm{b}}$ & 0.94 & 0.79 & $0.65^{\mathrm{c}, \mathrm{d}}$ & $0.51^{\mathrm{b}}$ \\
\hline
\end{tabular}

${ }^{\text {a }}$ Criterio $(0,4<\mathrm{X}<$ profundidade da matriz) não preenchindo

${ }^{\mathrm{b}}$ Falha no processo (trincas/má formação)

c Inspeção visual não aprovada

${ }^{\mathrm{d}}$ Falha no teste de tração

Fonte: Varis e Lepistö (2003)

A Figura 34a mostra a metade de uma seção da combinação ótima ( $\mathrm{X}=0,6 \mathrm{~mm})$. $\mathrm{O}$ material foi completamente preenchido na matriz. Não houve separação das chapas. A base da chapa continuou plana sem deformações e o estiramento do pescoço da união foi limitado. 


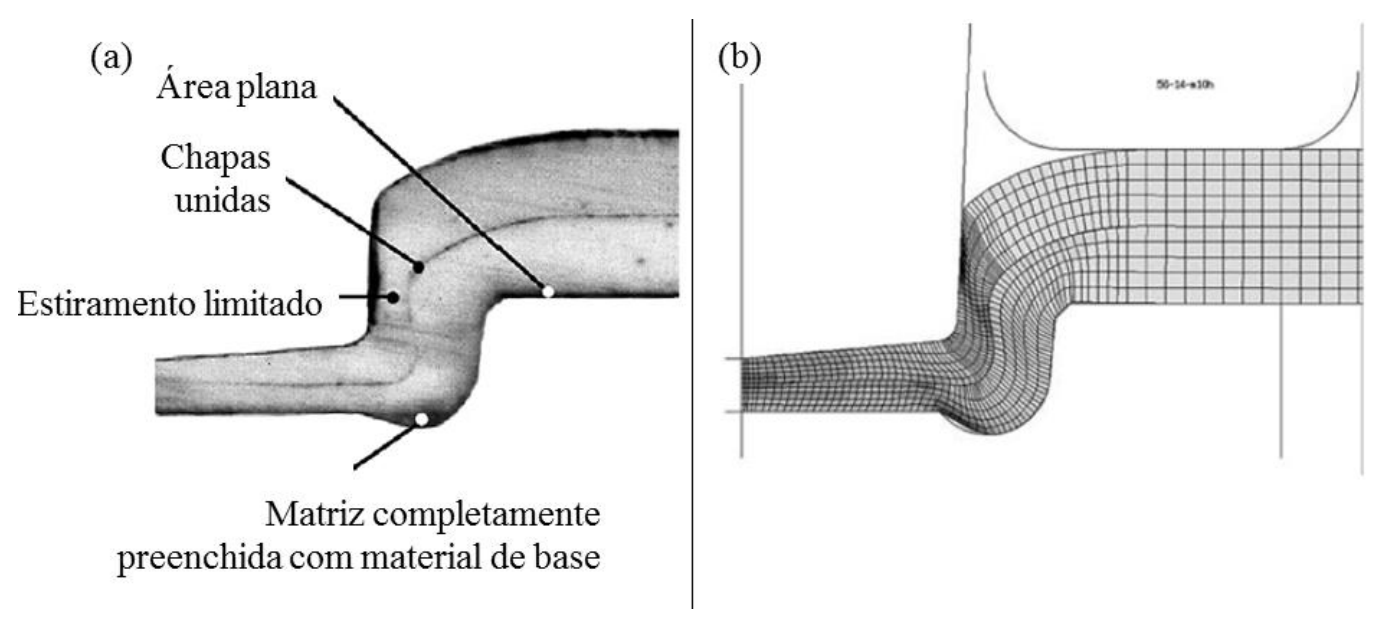

Figura 34 - Seção da união ótima do estudo realizado (VARIS; LEPISTÖ, 2003)

Em posse de todos os dados obtidos pelos ensaios que foram realizados baseados nas equações, Varis e Lepistö (2003) desenvolveram um método em elementos finitos para calcular a medida " $X$ ” ideal para cada combinação de união para ferramenta fixa (Figura 34b).

Nesse procedimento é possível verificar virtualmente o preenchimento do volume da matriz, a deformação na área entre o esticador e a base da matriz, o estiramento do pescoço pode também ser apontado e, por fim, o afastamento das chapas.

\subsubsection{Análise de tensões e esforços}

Nas análises de tensões e esforços são mostrados os modelos que estudam o cisalhamento e a tração (arrancamento) da junção separadamente e, em seguida, os modelos com efeito simultâneo e combinado dos esforços.

\subsubsection{Cisalhamento por esforço de tração}

Nas análises de cisalhamentos por esforços de tração são apresentados dois modelos de análise de tensões e esforços ou cargas de falha. O primeiro será o modelo clássico de Vandenbossche (1977) e, o segundo, será o modelo de Chao (2003). 
Antes de estudar os modelos, é importante entender como a junção, que no caso é um ponto de solda por resistência, se comporta durante a carga inicial até a sua falha. Na Figura 35 são mostradas as etapas da carga na junção.

Na etapa "a", os corpos de prova não estão sob carga. Logo, em seguida, em "b", a carga começa a ser aplicada e ocorre o fenômeno da rótula plástica que será explicado posteriormente. Em “c”, ocorrem reduções de espessuras na ZTA, principalmente na direção da carga, caracterizando a proximidade da falha. Na fase "d", ocorre o início da falha.

O fenômeno da rótula plástica ocorre devido ao desalinhamento das chapas na direção da carga aplicada. Apesar de o desalinhamento ser muito pequeno, é possível observar na Figura 36 que ele é suficiente para provocar um momento fletor que deforma os corpos de prova e resulta no ângulo a para forçar um alinhamento dos esforços.

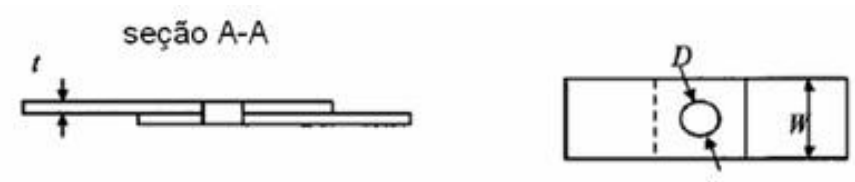

(a)

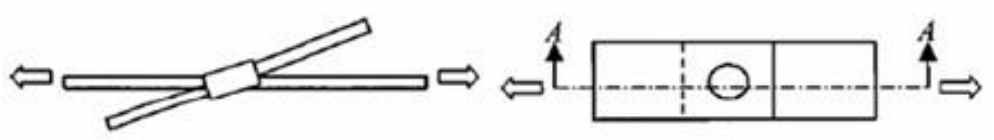

(b)

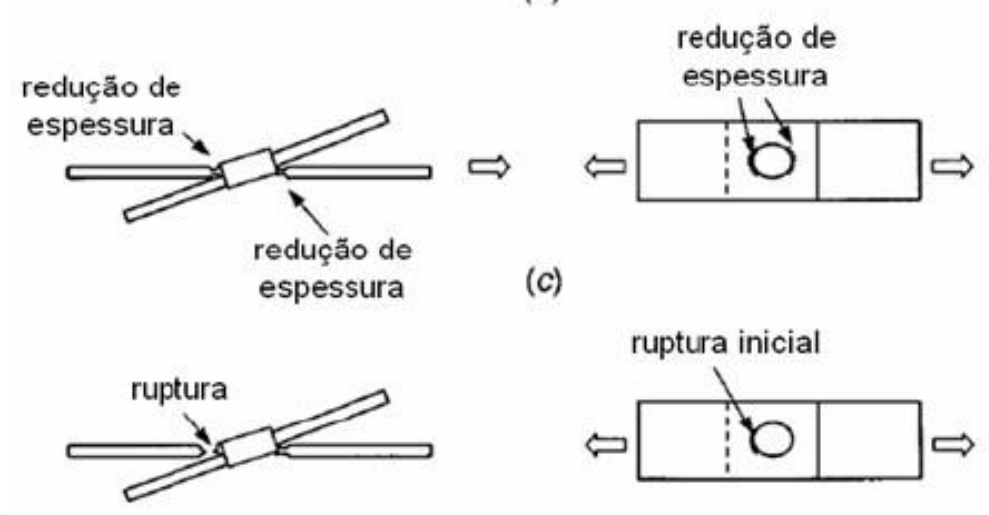

(d)

Figura 35 - Etapas da aplicação de carga de um ensaio de cisalhamento por tração (CHAO, 2003) 


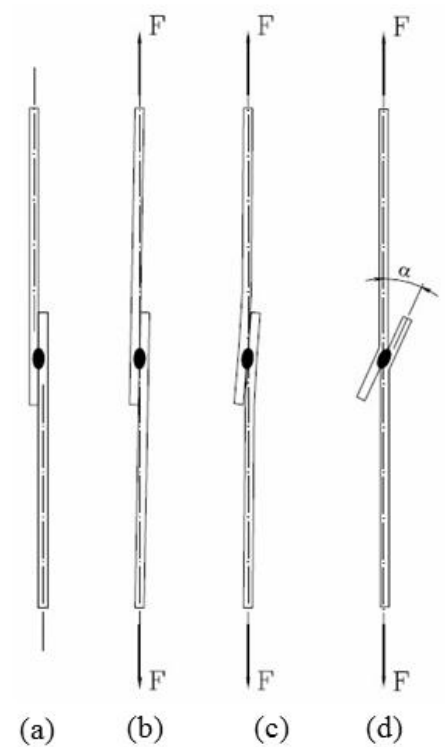

Figura 36 - Formação da rótula plástica (VANDENBOSSCHE, 1977)

Vandenbossche (1977) estudou um modelo de falha na interface da junção de aços de alta resistência. É importante observar que o modelo parte do princípio que o efeito da deformação plástica já resultou na rotação do ponto de solda, causada pela formação da rótula plástica. Com a formação da rótula plástica, apenas tensões de tração e cisalhamento estão atuando (Figura 37).
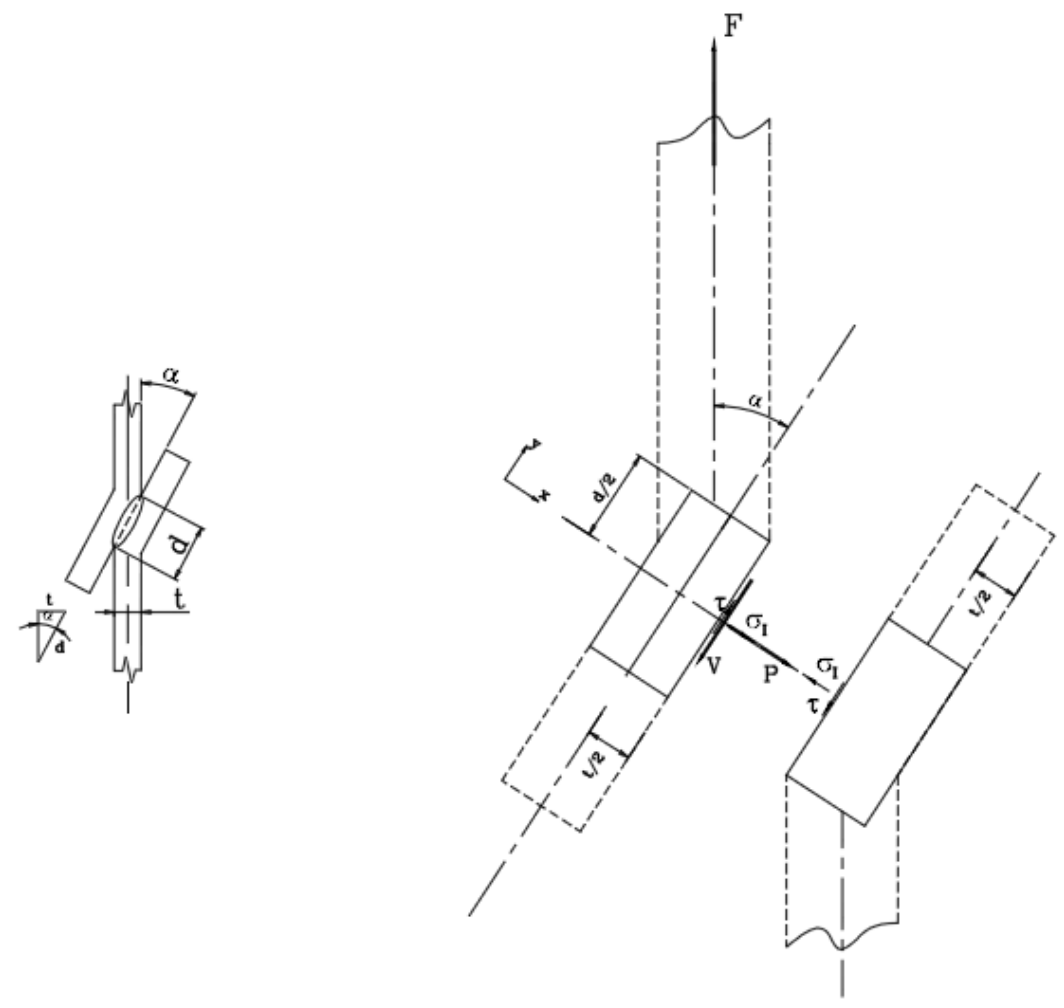

Figura 37 - Tensões e cargas na interface do ponto de solda (VANDENBOSSCHE, 1977) 
O esforço atuante pode ser decomposto em duas direções (Figura 37), uma normal ao ponto $\mathrm{P}$, e outra, a carga de cisalhamento $\mathrm{V}$, dado por:

$$
\begin{aligned}
& P=F \times \operatorname{sen}(\propto) \\
& V=F \times \cos (\propto)
\end{aligned}
$$

Onde: $\alpha=\operatorname{arcsen}\left(\frac{t}{d}\right)$

Como o modelo apresenta tensões de cisalhamento atuando juntamente com tensões de tração, Vandenbossche (1977) utilizou a teoria da tensão equivalente de Von Mises.

$$
\sigma_{e}=\sqrt{\left(\sigma^{2}+3 \times \tau^{2}\right)}
$$

Onde $\sigma_{\boldsymbol{e}}$ é a tensão equivalente, $\boldsymbol{\sigma}$ é a tensão de tração atuando na interface do ponto de solda e $\boldsymbol{\tau}$ é a tensão de cisalhamento atuando na interface do ponto de solda. A equação final para cálculo da tensão equivalente na interface do ponto de solda é:

$$
\sigma_{e I N T}=\frac{3 \times S_{y M B} \times w \times t}{2 \times d^{2}}
$$

Onde $\boldsymbol{\sigma}_{\boldsymbol{e I N T}}$ é a tensão equivalente na interface do ponto de solda, $\boldsymbol{S}_{\boldsymbol{y} \boldsymbol{M B}}$ é a tensão de escoamento do metal base, $\boldsymbol{w}$ é a largura do corpo de prova, $\boldsymbol{t}$ a espessura e $\boldsymbol{d}$ é o diâmetro do ponto de solda. Vandenbossche (1977) também desenvolveu um modelo de falha para tensões na ZTA, onde as tensões e cargas são mostradas na Figura 38. Como também existem tensões de tração e cisalhamento a teoria da tensão equivalente de Von Mises foi utilizada nesse modelo, equação (8). A equação final para o cálculo da tensão equivalente na ZTA do ponto de solda é:

$$
\sigma_{e Z T A}=\left(\frac{S_{y M B} \times w \times t}{2 \times d^{2}}\right) \times\left(\frac{d}{t}+\frac{1}{2}\right)
$$

Onde $\boldsymbol{\sigma}_{\boldsymbol{e Z T A}}$ é a tensão equivalente na ZTA do ponto de solda. 
O modelo de Chao (2003) estuda as tensões e o modo de falha na ZTA. Devido à complexidade existente nas variáveis envolvidas Chao (2003) não estudou um modelo para tensões e modo de falha na interface do ponto de solda, considerando no modelo o ponto de solda como um cilindro rígido. Vale lembrar que a falha na interface classifica o ponto de solda como ruim, sendo assim estudar a interface do ponto de solda não é considerado como uma prioridade. A Figura 39 mostra as tensões e esforços considerados no modelo de Chao (2003) para ensaios de cisalhamento por esforço de tração.

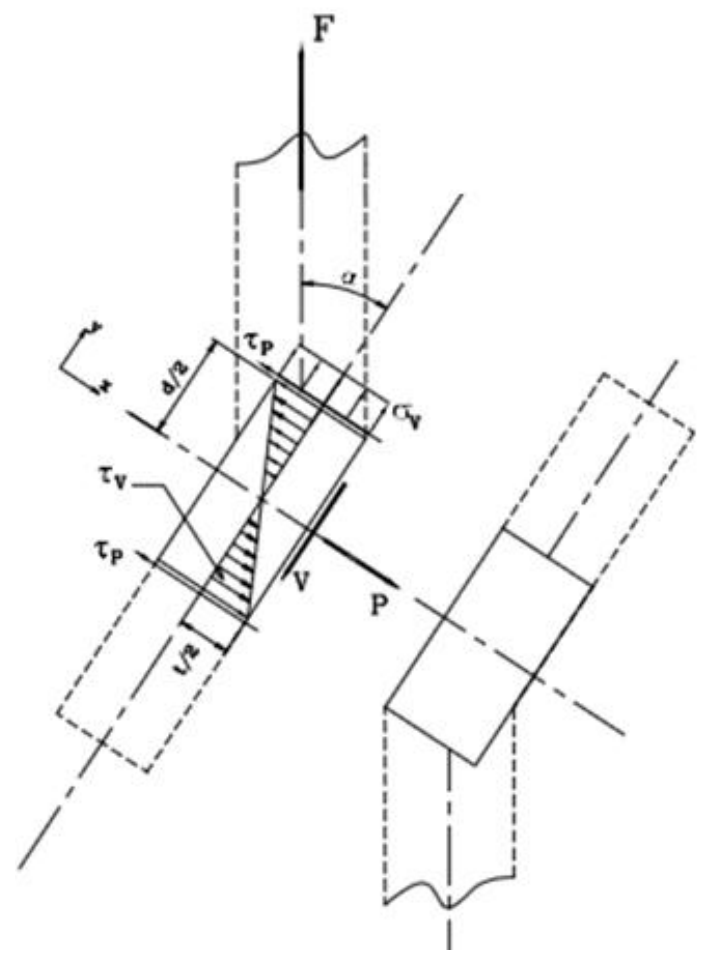

Figura 38 - Tensões e cargas na ZTA do ponto de solda (VANDENBOSSCHE, 1977)
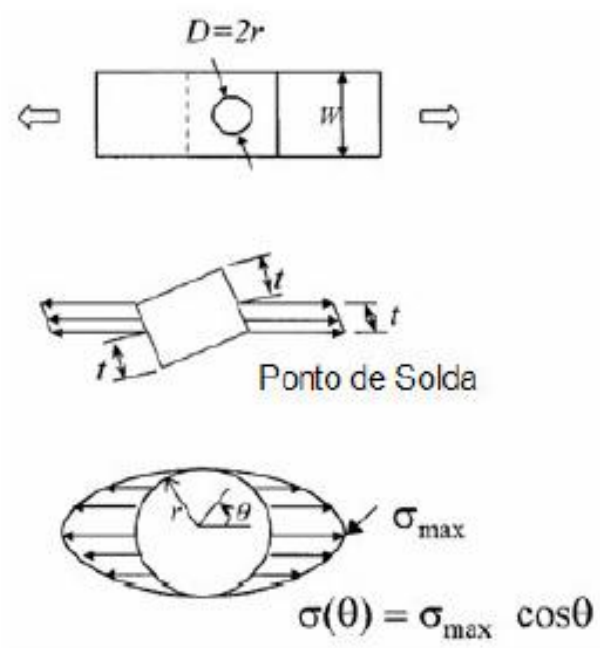

Figura 39 - Tensões e esforços no cisalhamento por esforço de tração (CHAO, 2003) 
É importante notar que a tensão máxima fica no centro do ponto de solda, na direção da carga aplicada. Como o modelo considera o ponto de solda como um corpo rígido, a falha ocorre por tensões de tração entre o ponto de solda e a ZTA. A equação a seguir mostra o modelo de Chao (2003):

$\sigma_{f}=\frac{P_{f}}{0,785 \times t \times d}$

Onde $\boldsymbol{\sigma}_{\boldsymbol{f}}$ é a tensão de falha do ponto de solda, $\boldsymbol{P}_{\boldsymbol{f}}$ é a carga de falha do ponto de solda, t é a espessura do material base e d é o diâmetro do ponto de solda. Falha, nesse caso, quer dizer tensão ou esforço máximo (ou de pico) suportado pela junção.

\subsubsection{Tração (arrancamento)}

No modelo de Chao (2003) para ensaio de tração ou arrancamento, foi estudado o ensaio com os corpos de prova dispostos perpendicularmente entre si, formando uma espécie de "cruz" com dimensões iguais. Esse modelo considera apenas as tensões e modo de falha na ZTA pelos mesmos motivos do modelo de cisalhamento por tração, e o ponto de solda é considerado como um cilindro de corpo rígido.

A Figura 40 mostra as etapas de aplicação da carga até a falha do ponto de solda. Na etapa "a", os corpos de prova não possuem carga. Na etapa "b", os corpos de prova sofrem a aplicação de carga e ocorre a deformação de ambos. Em "c", é representada a falha, que nesse ensaio é caracterizada pelo destacamento na região da ZTA do ponto de solda em uma das chapas.

A Figura 41 mostra as tensões atuantes do ponto de solda. 
(a)
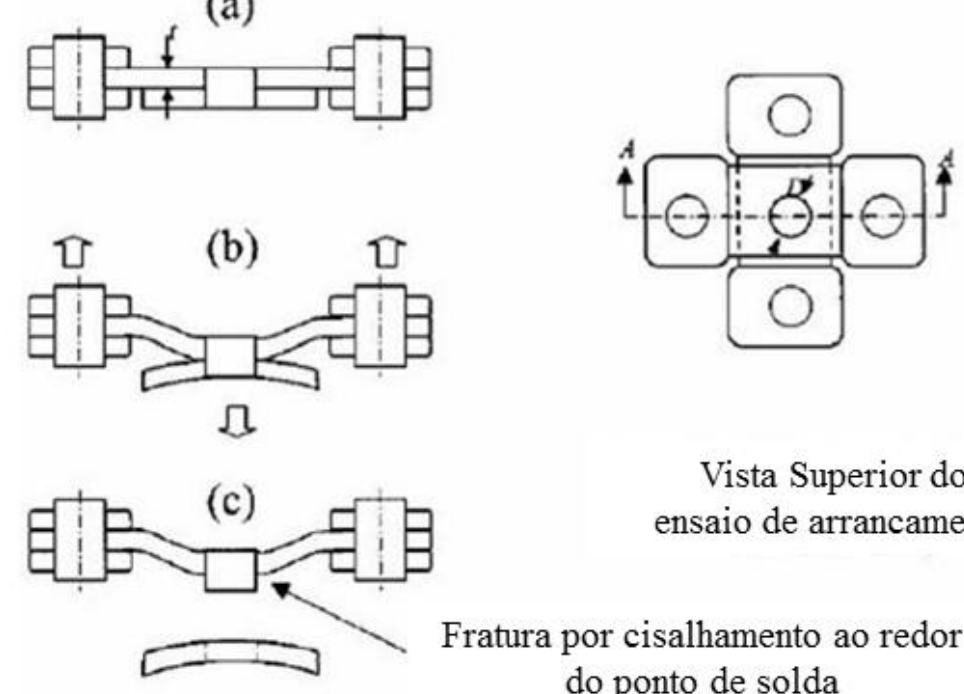

Fratura por cisalhamento ao redor do ponto de solda

Figura 40 - Etapas da aplicação de carga de um ensaio de arrancamento (CHAO, 2003)

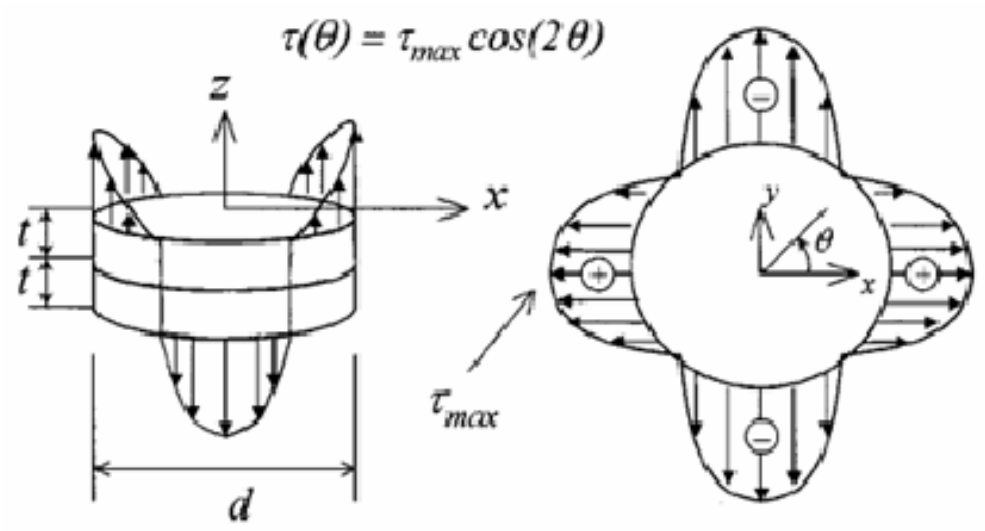

Figura 41 - Tensões e esforços no ensaio de arrancamento (CHAO, 2003)

É importante notar que o ponto de solda sofre esforços e tensões de tração, porém, no modelo, ele é considerado um corpo rígido e, como a falha ocorre na ZTA, os esforços e tensões atuantes na falha da junção são de cisalhamento. Existem quatro picos de tensão máxima, sendo duas na chapa superior e duas na inferior, sempre na posição central ao ponto de solda e na direção da carga. A equação abaixo expressa o modelo de Chao (2003) para cálculo da tensão de cisalhamento no ensaio de arrancamento:

$\tau_{f}=\frac{P_{f}}{t \times d}$ 
Onde $\boldsymbol{\tau}_{\boldsymbol{f}}$ é a tensão de falha do ponto de solda, $\boldsymbol{P}_{\boldsymbol{f}}$ é a carga de falha do ponto de solda, $\boldsymbol{t}$ é a espessura do material base e $\boldsymbol{d}$ é o diâmetro do ponto de solda. Falha, nesse caso, quer dizer tensão ou esforço máximo (ou de pico) suportado pela junção.

\subsubsection{Esforços combinados de cisalhamento e tração (arrancamento)}

Para esforços combinados, serão mostrados dois modelos analíticos, o de Lin et al. (2002), para esforços relativos, e o de Chao (2003), para tensões. Ambos os modelos focam o estudo de esforços e tensões na ZTA por motivos previamente explicados, e o critério de Von Mises foi empregado devido à atuação simultânea de tensões de tração e cisalhamento. Ensaios com cargas combinadas são muito difíceis de serem estudados e, por esse motivo, existe pouco material disponível sobre o assunto. Lin et al. (2003) desenvolveram um modelo de elementos finitos, demonstrando que existe uma grande diferença de tensão em volta do ponto de solda, sendo a área de maior tensão a porção de $50 \%$, na direção da aplicação de carga, como mostra a Figura 42, onde a área mais escura representa tensões maiores. No modelo de Lin et al. (2003), todos os esforços e momentos foram previamente considerados para construção da análise (Figura 43).

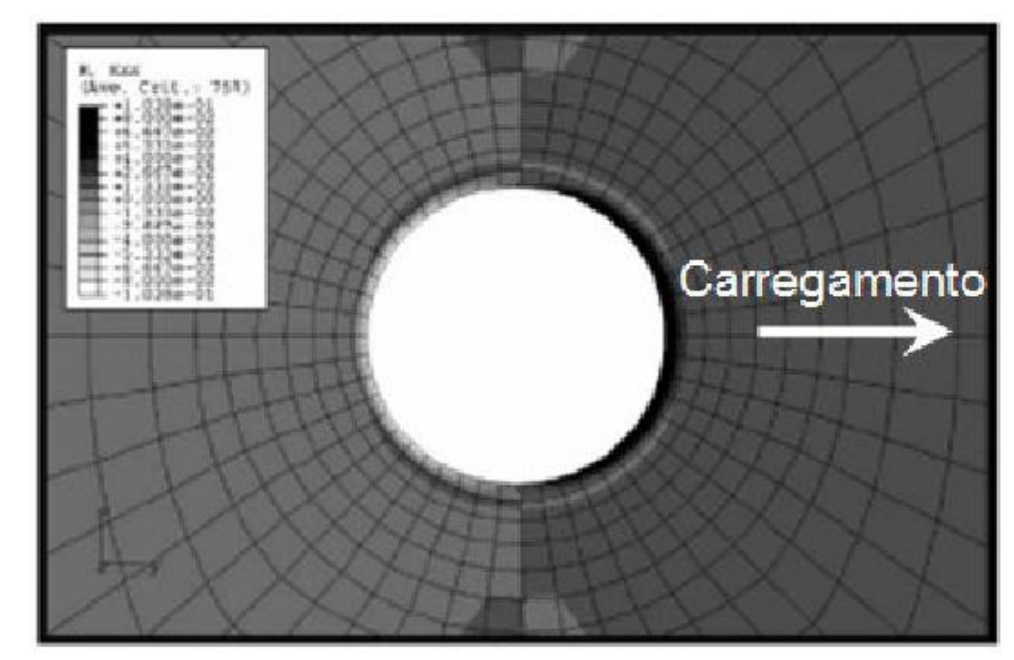

Figura 42 - Análise de tensões em volta do ponto de solda (LIN et al., 2003) 


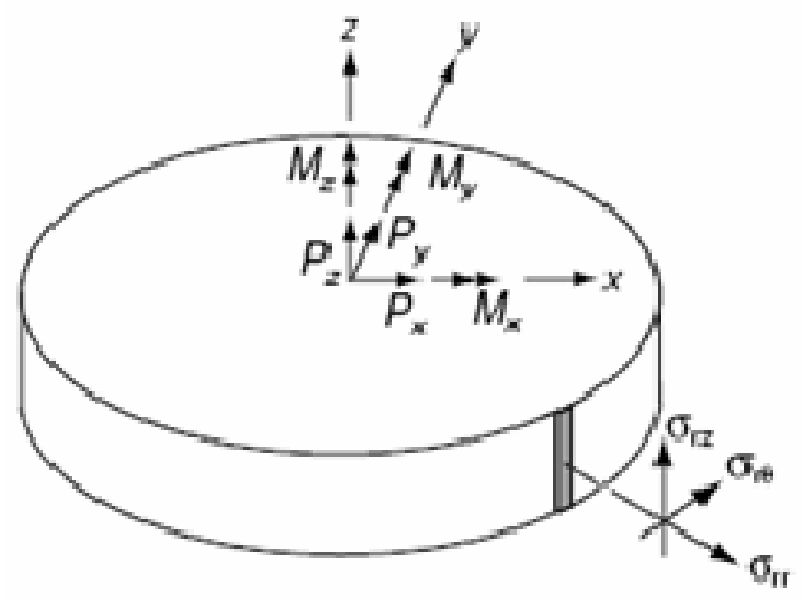

Figura 43 - Forças e momentos atuantes em cargas combinadas. (LIN et al., 2003)

Lin et al (2003), a principio, desenvolveram um modelo altamente complexo que abrange diferentes combinações e direções de cargas, o que gera esforços em condições diferentes aos encontrados nos ensaios físicos. Para facilitar os estudos, os autores propõem dois modelos, sendo um geral e, o outro, simplificado, onde as forças atuantes são $P_{x}, P_{z}, M_{x}$ e $\mathrm{M}_{\mathrm{y}} . \boldsymbol{P}_{\boldsymbol{x}}$ é a carga de cisalhamento por tração e $\boldsymbol{P}_{z}$ é a carga de tração (arrancamento). Para as equações simplificadas é considerado $\boldsymbol{P}_{\boldsymbol{y}}=0$ e $\boldsymbol{M}_{z}=0$.

O primeiro modelo desenvolveu a equação geral:

$\frac{1}{3} \times\left(K_{P x y} \times \overline{\boldsymbol{P}_{\boldsymbol{x}}}\right)+\left[\alpha \overline{\boldsymbol{P}_{\boldsymbol{z}}}+K_{P x y} \times \overline{\boldsymbol{P}_{\boldsymbol{x}}}\left(\frac{4 \times t}{\pi \times d}\right)\right]^{2}+\left[(1-\propto) \overline{\boldsymbol{P}_{\mathbf{z}}}\right]^{2}$

Onde:

$\boldsymbol{t}$ é a espessura da chapa e $\boldsymbol{d}$ o diâmetro do ponto de solda.

$\boldsymbol{K}_{\boldsymbol{P} x y}$ é um fator de correção, cujo valor assume 1,11 para aços de baixo carbono.

$\overline{\boldsymbol{P}_{\boldsymbol{x}}}=\frac{\boldsymbol{P} \boldsymbol{x}}{\boldsymbol{P}_{\boldsymbol{m a ́ x}}}$, onde $\boldsymbol{P}_{\boldsymbol{m} a ́ x}$ é a carga máxima até a falha em um ensaio uniaxial de tração (arrancamento). 
$\overline{\boldsymbol{P}_{\boldsymbol{z}}}=\frac{\boldsymbol{P} \boldsymbol{z}}{\boldsymbol{P}_{\boldsymbol{m a ́ x}}}$, onde $\boldsymbol{P}_{\boldsymbol{m} a ́ x}$ é a carga máxima até a falha em um ensaio uniaxial de tração (arrancamento).

$\propto=\frac{\boldsymbol{P}}{\boldsymbol{P}_{\mathbf{z}}}$, onde $\boldsymbol{P}$ é a carga resultante aplicada no corpo de prova, sendo assim, $\alpha=1$ para um ensaio uniaxial de arrancamento e $\alpha=0,5$ para um ensaio com cargas de cisalhamento e tração com valores iguais.

O segundo modelo desenvolveu a equação geral simplificada:

$$
\left(1-2 \propto+2 \propto^{2}\right){\overline{\boldsymbol{P}_{z}}}^{2}+\left[\frac{1}{3}+\left(\frac{4 \times t}{\pi \times d}\right)^{2}\right] \times\left(K_{P x y} \times \overline{\boldsymbol{P}_{x}}\right)^{2}=1
$$

O valor de $\boldsymbol{K}_{\boldsymbol{P x y}}$, nesse caso, muda para 1,25, o restante dos componentes da equação são exatamente os mesmos que a equação geral (13).

A complexidade do modelo resultou nas equações (13) e (14). Para cada aplicação, eles sugerem que deve ser estudado o modelo que melhor se encaixa, pois os autores não deixam clara a relação do primeiro modelo com o segundo. Lin et al. (2003) recomendam que seja usada primeiramente a equação simplificada (14) para eventuais estudos em chapas de baixo carbono. Caso os dados obtidos apresentem resultados divergentes, é necessário utilizar a equação (13). A Figura 44 mostra uma comparação entre ambos.
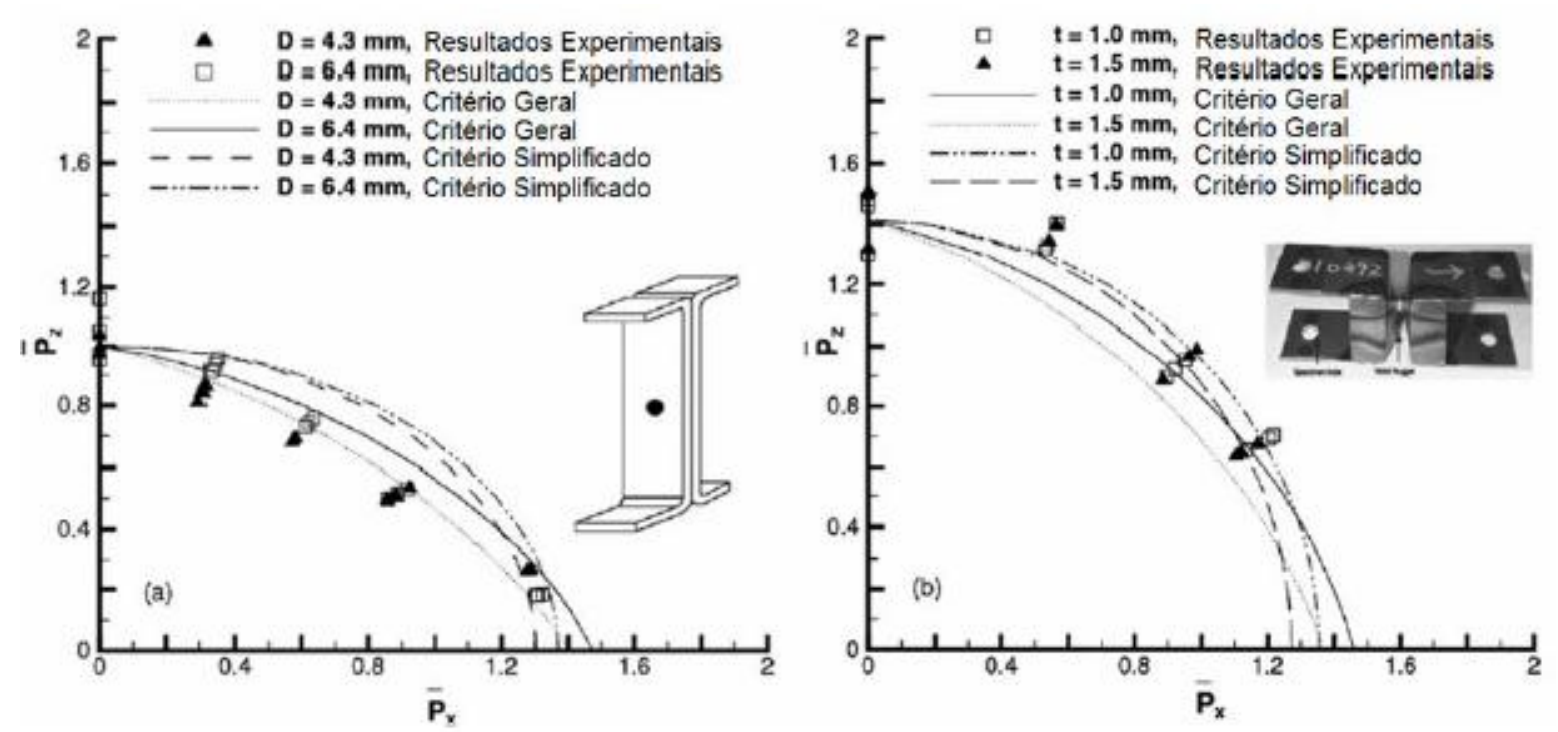

Figura 44 - Comparação entre o modelo geral e o simplificado (LIN et al., 2003) 
Para testar a aplicação do modelo foram usados os dados obtidos em experimentos de Lee et al. (1998) com o corpo de prova em forma de "U" e o de Lin et al. (2002) com o corpo de provas do tipo copo-quadrado. Para os dados obtidos no ensaio de Lee et al. (1998) o modelo geral foi o que melhor representou os resultados, sendo assim a equação (10) é a recomendada para esse modelo de ensaio. Já para os resultados no ensaio de Lin et al. (2002), o modelo simplificado saiu-se melhor, sendo então recomendada a equação (11) para esse modelo de ensaio.

Para o modelo de Chao (2003), são apresentadas duas equações para o cálculo de tensões, cada uma usa um critério para equivalência devido à atuação de esforços e tensões de cisalhamento e tração.

$$
\begin{gathered}
\sigma_{f}=\sqrt{1,623\left(\frac{P_{x}}{t \times d}\right)^{2}+3\left(\frac{P_{z}}{t \times d}\right)^{2}} \\
\sigma_{f}=\sqrt{1,623\left(\frac{P_{x}}{t \times d}\right)^{2}+4\left(\frac{P_{z}}{t \times d}\right)^{2}}
\end{gathered}
$$

Onde $\boldsymbol{\sigma}_{\mathrm{f}}$ é a tensão de ruptura, $\boldsymbol{P}_{\boldsymbol{x}}$ a carga de cisalhamento, e $\boldsymbol{P}_{z}$ a carga de tração (arrancamento), $\boldsymbol{t}$ é a espessura da chapa e $\boldsymbol{d}$ é o diâmetro do ponto de solda. A equação (15) usa o critério de Von Mises para equivalência, enquanto a equação (16) usa Tresca. Diferenciam-se as duas equações na ponderação até $16 \%$ maior que o critério de Tresca atribui à carga de tração (arrancamento), Pz.

\subsubsection{Resistência mecânica da UCCF à carga estática de cisalhamento e fadiga}

Um estudo foi realizado por Carboni (2006) no intuito de entender o comportamento mecânico de junções de chapas de aço unidas pelo processo de conformação a frio. A análise foi realizada submetendo-se os corpos de prova à carga estática de cisalhamento (ensaio de lap shear) e à carga dinâmica (ensaio de fadiga). Duas configurações de corpos de prova de aço comum $\left(\mathrm{F}_{\mathrm{e}} \mathrm{PO}_{2}\right.$ - zincado) foram construídos conforme Figura 45. 

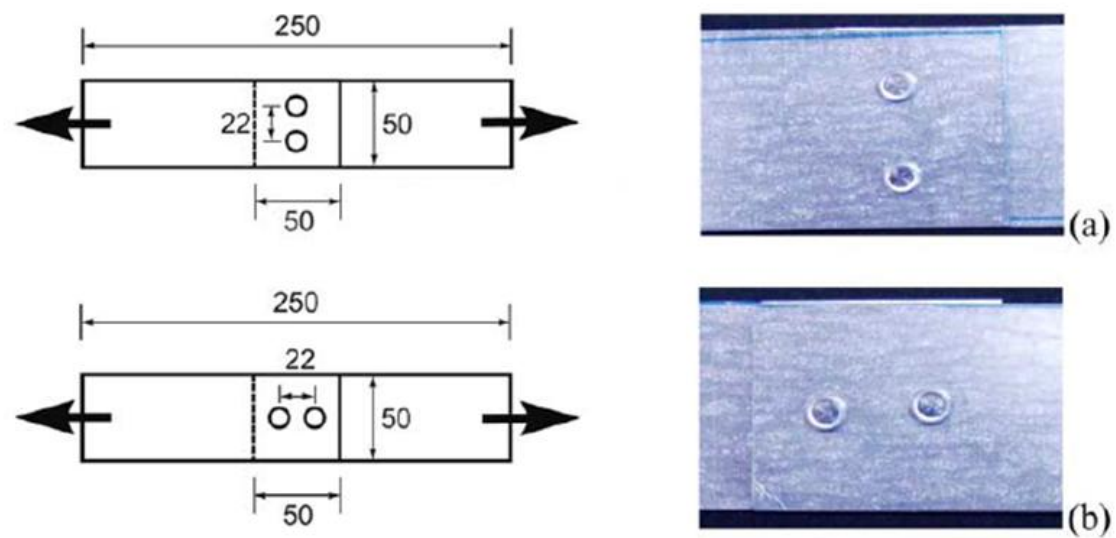

Figura 45 - Corpos de prova para ensaios de cisalhamento e fadiga: (a) configuração transversal;

(b) configuração longitudinal (CARBONI et al 2006)

Os ensaios de tração foram realizados com três corpos de prova, na configuração da Figura 45a, e dois, na configuração da Figura 45b. O resultado pode ser visto no gráfico da Figura 46a, com desvio padrão de $0,16 \mathrm{kN}$.

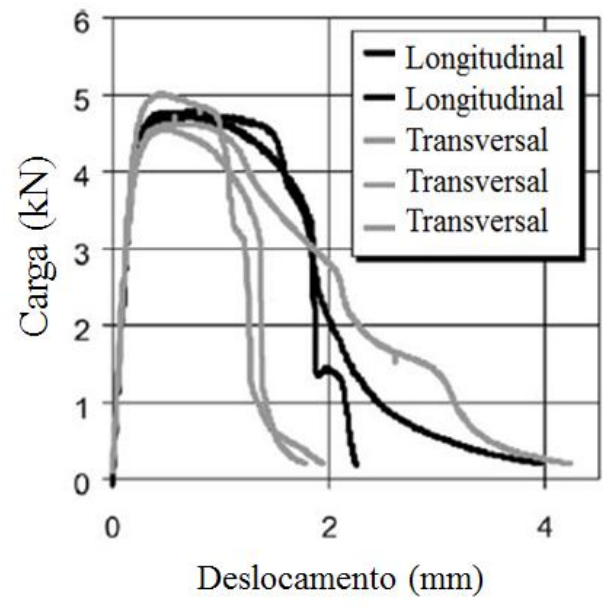

(a)

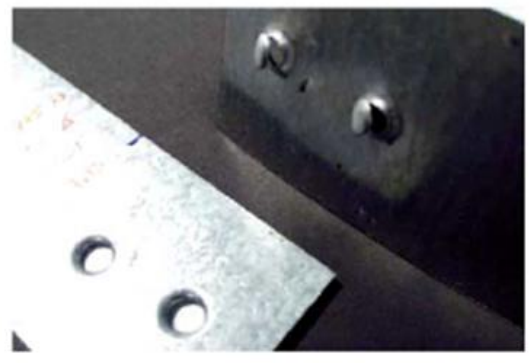

(b)

Figura 46 - Resultado dos ensaios de cisalhamento: (a) Curva de carga em relação ao deslocamento; (b) Ruptura da parte interior do ponto (falha típica) (CARBONI et al. 2006)

O comportamento dos corpos de prova à fadiga pode ser observado nos gráficos da Figura 47. $\mathrm{O}$ fator $\mathrm{R}_{\mathrm{f}}$ é a relação de carga do ensaio de fadiga descrito na equação 17. Quanto mais próximo do valor "0", maior é a diferença entre a carga aplicada $\left(\mathrm{F}_{\mathrm{fmax}}\right)$ e a carga de alívio $\left(\mathrm{F}_{\text {fmin }}\right)$, tornando, assim, mais severo o carregamento. Os pontos em branco são referentes aos ensaios que foram interrompidos por ultrapassar o número de ciclos de $10^{7}$. 
$R_{f}=\frac{R_{f \min }}{R_{f \max }}$

Pode-se observar nos gráficos (a) e (b) da Figura 47, os pontos de ruptura dos corpos de prova unidos por 2 elementos de UCCF na direção longitudinal e transversal. A distribuição dos pontos é similar, o que mostra que a distribuição (transversal ou longitudinal) não influencia significativamente no comportamento à fadiga dos corpos de prova. Entretanto, a disposição longitudinal alcançou valores de resistência maiores, conforme gráficos (c) e (d) da mesma figura. É possível também observar que o limite de força para resistência à fadiga é $2,25 \mathrm{kN}$ para a configuração longitudinal e $2,50 \mathrm{kN}$ para a configuração transversal. Esses valores representam cerca de $50 \%$ da carga de ruptura obtidas por Carboni et al (2006) no ensaio de cisalhamento. Segundo o autor, a carga de fadiga limite para SPRE é entre 30-40\%, o que mostra uma melhor estabilidade da UCCF às cargas dinâmicas.

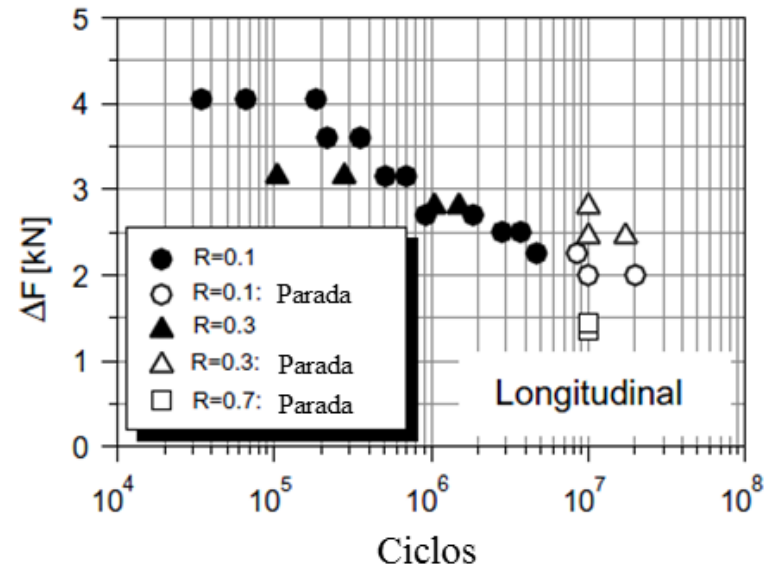

(a)

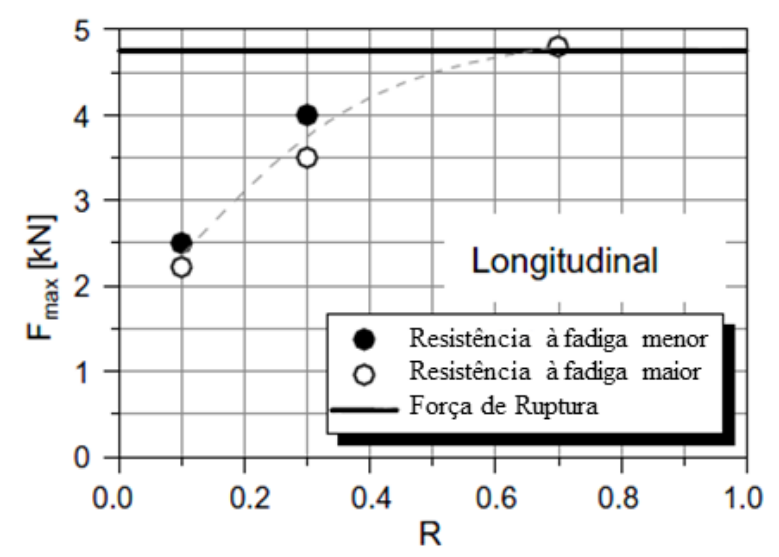

(c)

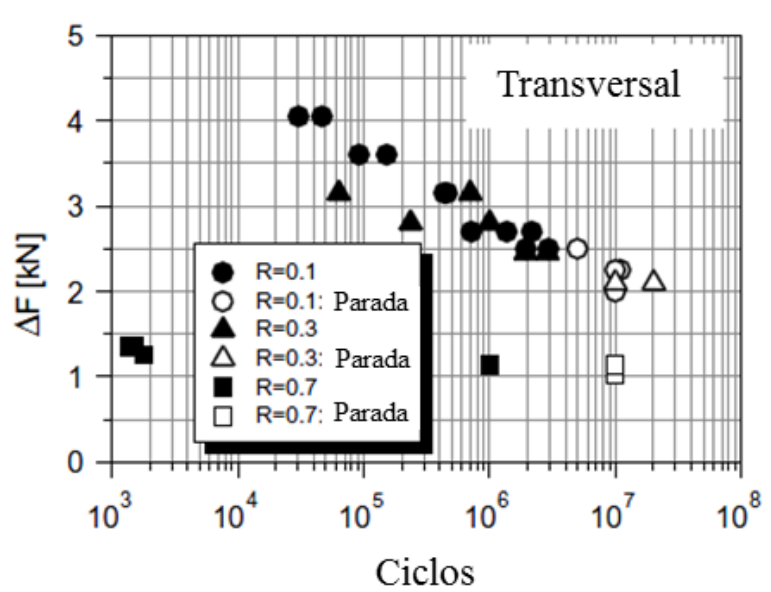

(b)

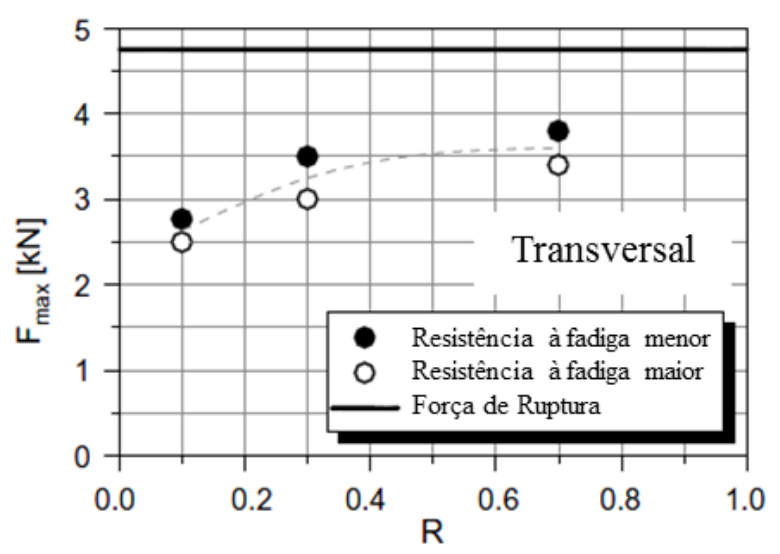

(d)

Figura 47 - Comportamento à fadiga de juntas de UCCF (a) e (b) Curva de carga em função do número de ciclos; (c) e (d) Curva de força máxima em função do fator R (CARBONI et al, 2006) 


\section{MATERIAIS E MÉTODOS}

O capítulo anterior mostrou uma variedade de técnicas visando a obtenção da resistência mecânica de elementos de união.

O modelo de Lee et al (1998) baseado no ensaio de Arcan foi escolhido para ser utilizado nos ensaios do presente trabalho. Tal dispositivo permite a realização dos ensaios de resistência mecânica sob carga multiaxial do elemento de união de chapas em uma máquina de tração comum. Para tornar possível a comparação entre a tecnologia de UCCF e SPRE, uma bateria de ensaios foi realizada para determinação dos parâmetros mais resistentes do elemento de união para ambos os processos. O diagrama de Ishikawa ajudou a evidenciar as possíveis causas de uma má correlação de dados entre os valores obtidos pelo ensaio realizado por Kavamura (2007) e os dados que serão obtidos neste trabalho.

\subsection{DETERMINAÇÃO DOS PARÂMETROS DA UCCF}

Este capítulo apresenta toda a parte experimental do trabalho referente à determinação dos parâmetros ideais da união estudada. O tipo de UCCF denominado Round (Elemento cilindro da Figura 7) foi o escolhido para realização dos ensaios por ser o mais versátil, além de ser o mais utilizado na indústria em geral (VARIS, 2001).

\subsubsection{Procedimento de ensaio para determinação dos parâmetros ideais de união}

Características como: tipo de material e espessura das chapas, tipo de solicitação da junta, área disponível para receber o ponto, esforço de prensagem do punção, diâmetro do ponto e a espessura do ponto (Medida "X") são os principais parâmetros a serem analisados na determinação de um ponto resistente e robusto.

Este trabalho utilizou os equipamentos da fabricante TOX $^{\circledR}$ para confecção dos corpos de prova. Esse fabricante controla, basicamente, a qualidade do ponto em função da Medida "X". 
Vários procedimentos podem ser encontrados na literatura para a determinação da Medida " $X$ " ideal de uma união baseado na análise de elementos finitos. No Capítulo 2.5.3 foi mostrado uma completa análise feita por Varis e Lepistö (2003). Segundo os autores citados, a análise de elementos finitos ajuda a reduzir a quantidade de ensaios necessários para a determinação da Medida " $X$ " ideal, porém a necessidade do ensaio físico é fundamental para garantir a integridade da união, haja vista que o processo de elementos finitos não contempla todas as variáveis existentes no processo físico. O procedimento para determinação da Medida " $\mathrm{X}$ " é algo não difundido na literatura, pois trata-se de "know-how" dos fornecedores de equipamento de UCCF que indicam aos clientes e pesquisadores a Medida " $X$ " ideal para um dado tipo de união.

A criação de um procedimento de ensaio prático para obtenção da Medida " $X$ " mais resistente aos esforços multiaxiais foi um grande desafio, pois exigiu uma profunda pesquisa das variáveis de processo que influenciam na resistência da união. Tal procedimento foi baseado nos critérios de falha existentes na literatura e na experiência do fornecedor do equipamento de UCCF. O fluxograma mostrado na Figura 48 mostra todos os passos realizados. O detalhamento de cada processo será feito no próximo capítulo utilizando como exemplo os corpos de prova designados para este trabalho.

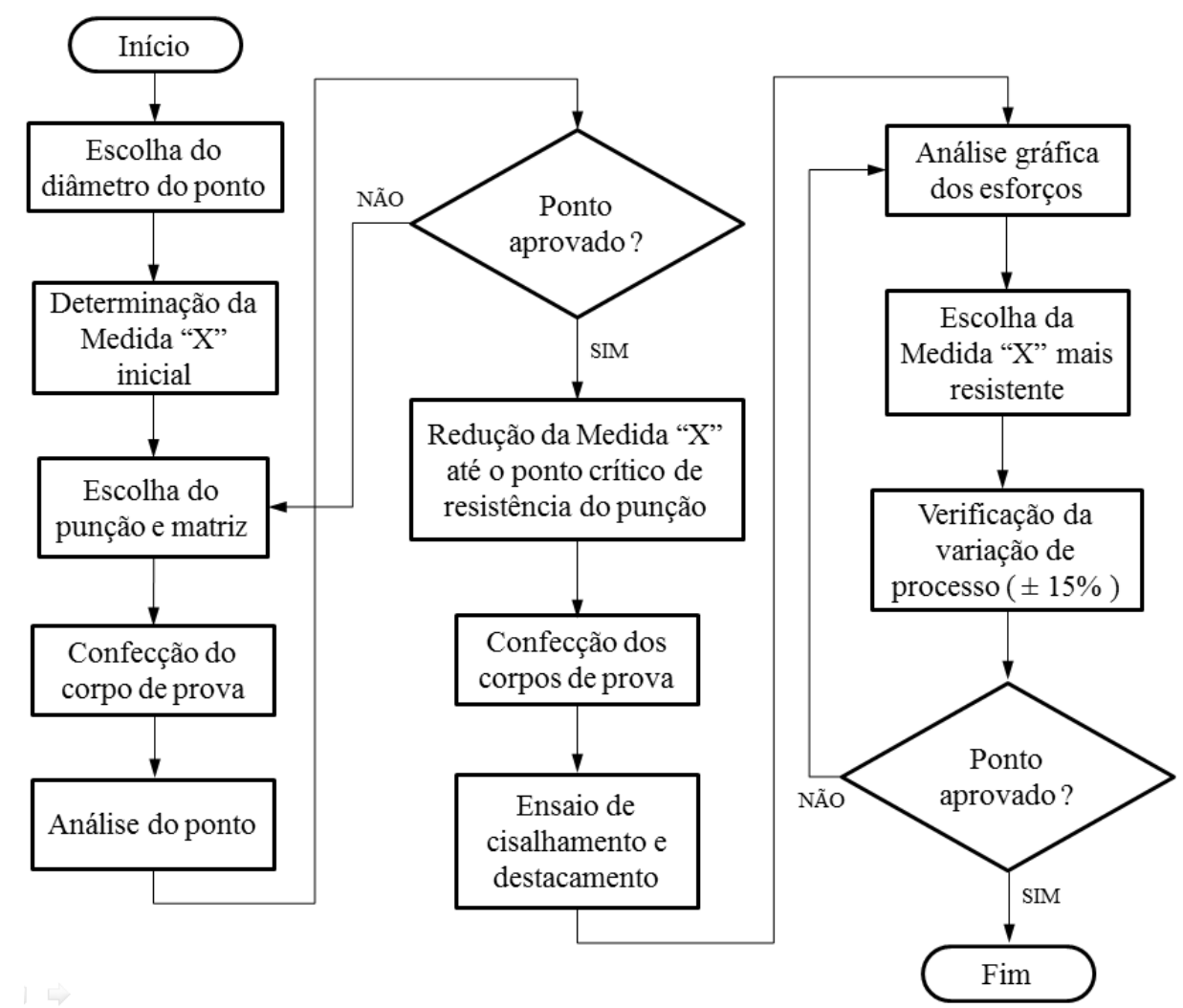

Figura 48 - Proposta de procedimento para determinação da Medida " $\mathrm{X}$ ” ideal 


\subsubsection{Determinação da Medida " $X$ " ideal para a união de chapas de aço}

O material utilizado para confecção dos corpos de prova é a chapa de aço comum EMS.ME.1508 BFF EEP (EMS.ME.1508, 1996), sem revestimento, utilizada na indústria automotiva, com as espessuras de $0,80 \mathrm{~mm}$ e $1,20 \mathrm{~mm}$. A especificação completa do material pode ser visto no Anexo B.

3.1.2.1 Escolha do diâmetro do ponto

O catálogo do fabricante (Anexo C) recomenda os pontos de diâmetros de $6 \mathrm{~mm}$ e $8 \mathrm{~mm}$ para o material escolhido (Tabela 3 ).

Tabela 3 - Uniões estudadas e $\varnothing$ do ponto recomendado

\begin{tabular}{lcccc}
\hline \multirow{2}{*}{ União } & Material & $\begin{array}{c}\text { Espessura da } \\
\text { Chapa 1 } \\
(\mathrm{mm})\end{array}$ & $\begin{array}{c}\text { Espessura da } \\
\text { Chapa 2 } \\
(\mathrm{mm})\end{array}$ & $\begin{array}{c}\varnothing \text { do Ponto } \\
\text { recomendado } \\
(\mathrm{mm})\end{array}$ \\
\hline 1 & Aço EMS.ME.1508 BFF EEP & 0,80 & 0,80 & 6 e 8 \\
\cline { 1 - 5 } 2 & 1,20 & 1,20 & 6 e 8 \\
\hline
\end{tabular}

O diâmetro do ponto (Figura 49) é determinado pela matriz da ferramenta.

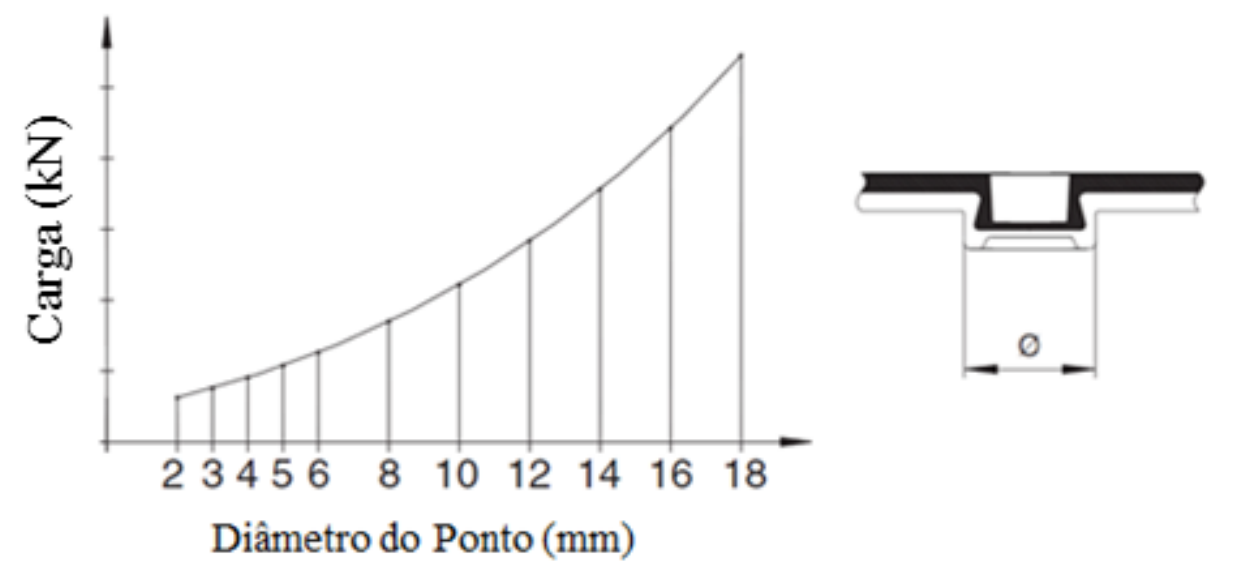

Figura 49 - Relação de diâmetros de matriz para UCCF (TOX, 2011b) 


\subsubsection{Escolha da Medida " $X$ " inicial}

$\mathrm{X}_{\text {inicial }}=1 / 2$ espessura da chapa de maior espessura. Os valores de $X_{\text {inicial }}$ podem ser vistos na Tabela 4:

Tabela 4 - Valores de $\mathrm{X}_{\text {inicial }}$ para os corpos de prova

\begin{tabular}{|c|c|c|c|c|}
\hline União & Material & $\begin{array}{c}\text { Espessura d } \\
\text { Chapa } 1 \\
(\mathrm{~mm})\end{array}$ & $\begin{array}{c}\text { Espessura da } \\
\text { Chapa } 2 \\
(\mathrm{~mm})\end{array}$ & $\begin{array}{l}X_{\text {inicial }} \\
(\mathrm{mm})\end{array}$ \\
\hline 1 & \multirow{2}{*}{ Aço EMS.ME.1508 BFF EEP } & 0,80 & 0,80 & 0,40 \\
\hline 2 & & 1,20 & 1,20 & 0,60 \\
\hline
\end{tabular}

\subsubsection{Escolha do punção e matriz}

As características principais do punção são: Comprimento da ponta $\left(\mathrm{L}_{\mathrm{p}}\right)$, diâmetro da ponta $\left(\emptyset_{\mathrm{p}}\right)$, ângulo ponta $\left(\alpha_{\mathrm{p}}\right)$, conicidade da ponta $\left(\alpha_{\mathrm{c}}\right)$ e material. Uma representação detalhada do punção pode ser observada na Figura 50.

A matriz tem como características: diâmetro interno $\left(\emptyset_{\mathrm{m}}\right)$, profundidade da cavidade $\left(\mathrm{P}_{\mathrm{m}}\right)$ e material (Figura 51). De todos as características apresentadas, apenas os valores de $\emptyset_{\mathrm{p}}$, $\mathrm{L}_{\mathrm{p}}, \emptyset_{\mathrm{m}}$ e $\mathrm{P}_{\mathrm{m}}$ foram autorizados para serem divulgados pela empresa $\mathrm{TOX}^{\circledR}$.

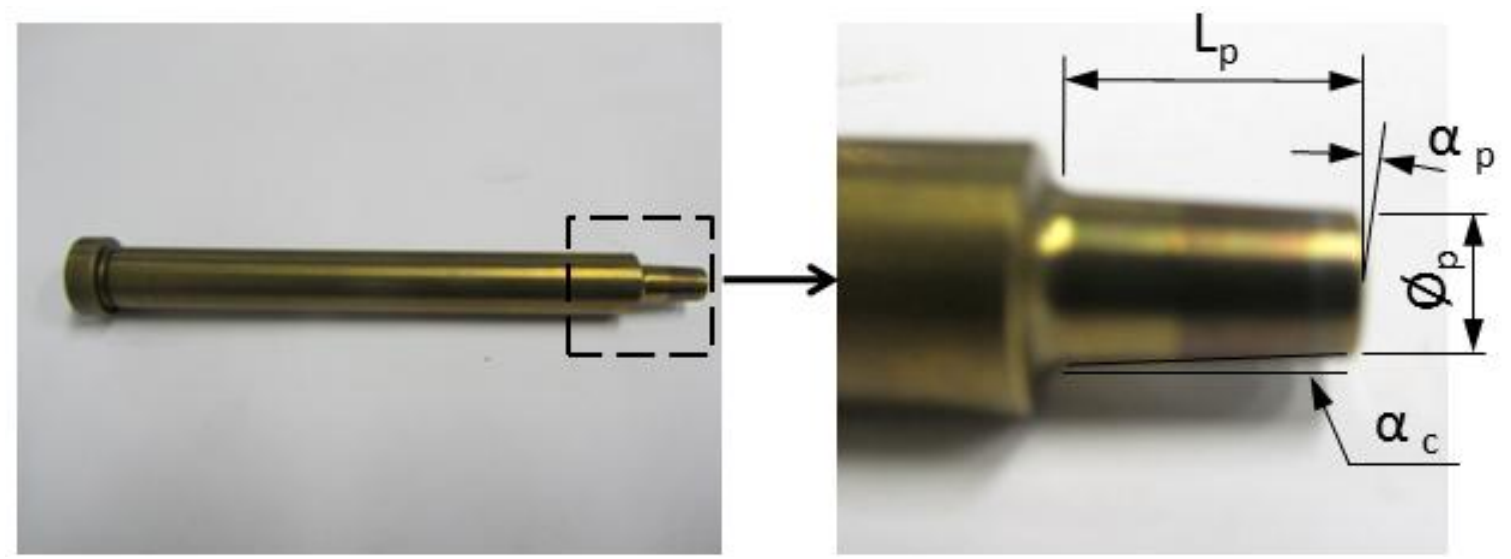

Figura 50 - Características geométricas principais do punção 


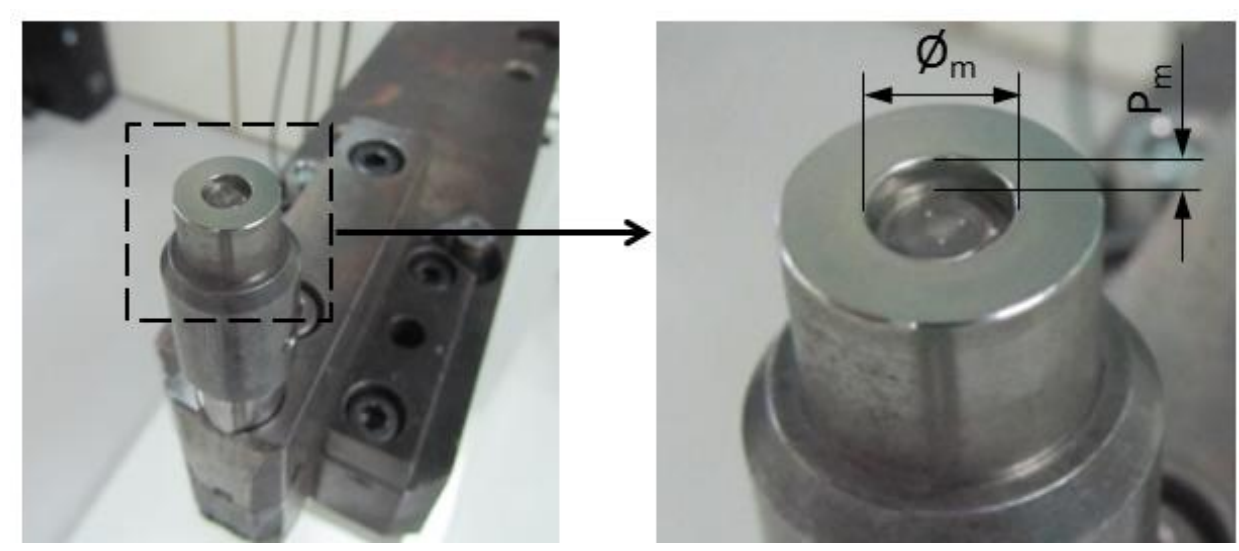

Figura 51 - Características geométricas principais da matriz

Na Tabela 5 é possível identificar a sequência utilizada na seleção do punção e matriz. Para cada jogo "punção / matriz" selecionado foi feito a análise visual do ponto.

Tabela 5 - Sequência de avaliação da combinação punção/matriz

\begin{tabular}{|c|c|c|c|c|c|c|c|c|c|c|c|}
\hline & & \multicolumn{2}{|c|}{ Combinação 1} & \multicolumn{2}{|c|}{ Combinação 2} & \multicolumn{2}{|c|}{ Combinação 3} & \multicolumn{2}{|c|}{ Combinação 4} & \multicolumn{2}{|c|}{ Combinação Final } \\
\hline União & $\begin{array}{c}\varnothing \text { do Ponto } \\
\text { recomendado } \\
\mathrm{mm}\end{array}$ & $\begin{array}{c}\text { Punção } \\
\left(\emptyset_{\mathrm{p}} / \mathrm{L}_{\mathrm{p}}\right) \\
\mathrm{mm}\end{array}$ & $\begin{array}{c}\text { Matriz } \\
\left(\varnothing_{\mathrm{m}} / \mathrm{P}_{\mathrm{m}}\right) \\
\mathrm{mm}\end{array}$ & $\begin{array}{c}\text { Punção } \\
\left(\emptyset_{\mathrm{p}} / \mathrm{L}_{\mathrm{p}}\right) \\
\mathrm{mm}\end{array}$ & $\begin{array}{c}\text { Matriz } \\
\left(\emptyset_{\mathrm{m}} / \mathrm{P}_{\mathrm{m}}\right) \\
\mathrm{mm}\end{array}$ & $\begin{array}{c}\text { Punção } \\
\left(\varnothing_{\mathrm{p}} / \mathrm{L}_{\mathrm{p}}\right) \\
\text { mm }\end{array}$ & $\begin{array}{c}\text { Matriz } \\
\left(\emptyset_{\mathrm{m}} / \mathrm{P}_{\mathrm{m}}\right) \\
\mathrm{mm}\end{array}$ & $\begin{array}{c}\text { Punção } \\
\left(\emptyset_{\mathrm{p}} / \mathrm{L}_{\mathrm{p}}\right) \\
\mathrm{mm}\end{array}$ & $\begin{array}{c}\text { Matriz } \\
\left(\emptyset_{\mathrm{m}} / \mathrm{P}_{\mathrm{m}}\right) \\
\mathrm{mm}\end{array}$ & $\begin{array}{c}\text { Punção } \\
\left(\emptyset_{\mathrm{p}} / \mathrm{L}_{\mathrm{p}}\right) \\
\text { mm }\end{array}$ & $\begin{array}{c}\text { Matriz } \\
\left(\emptyset_{\mathrm{m}} / \mathrm{P}_{\mathrm{m}}\right) \\
\mathrm{mm}\end{array}$ \\
\hline \multirow{2}{*}{1} & 6,00 & $4,4 / 100$ & $6,0 / 1,2$ & $4,2 / 100$ & $6,0 / 1,2$ & - & - & - & - & $4,2 / 100$ & $6,0 / 1,2$ \\
\hline & 8,00 & $5,6 / 100$ & $8,0 / 1,6$ & $5,8 / 100$ & $8,0 / 1,6$ & $5,8 / 100$ & $8,0 / 1,6$ & $5,8 / 100$ & $8,0 / 1,4$ & $5,6 / 100$ & $8,0 / 1,6$ \\
\hline \multirow[b]{2}{*}{2} & & $4,0 /$ & $0 / 1,2$ & $4,0 / 1$ & $6,0 / 1,2$ & - & - & - & - & $4,0 / 100$ & $6,0 / 1,2$ \\
\hline & 8,00 & $5,2 / 100$ & $8,0 / 1,6$ & $5,4 / 100$ & $8,0 / 1,6$ & $5,2 / 100$ & $8,0 / 1,4$ & $5,2 / 100$ & $8,0 / 1,6$ & $5,2 / 100$ & $8,0 / 1,6$ \\
\hline
\end{tabular}

\subsubsection{Análise do ponto}

Esse processo consiste na verificação visual prévia do ponto. Uma seção transversal é realizada no ponto para verificação. A necessidade de utilização de microscópio depende da acuidade visual do técnico e, geralmente se faz necessária para verificação de pontos menores que $4 \mathrm{~mm}$ de diâmetro. Não existem parâmetros pré-definidos para uma união ideal, porém algumas características devem ser fortemente observadas. A seção transversal de uma união ideal típica é mostrada na Figura 52. Os pontos principais de observação da união são:

- Área de ancoragem;

- Área de formação do pescoço; 
- Espessura da medida ' $X$ ';

- Área de contato entre as chapas;

- Formação de trincas;

- Centralidade do ponto.

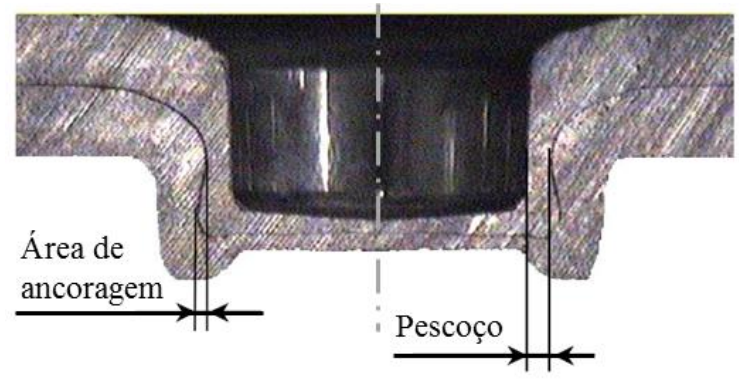

Figura 52 - Seção transversal típica da UCCF (TOX, [entre 2000 e 2011])

Alguns problemas podem ocorrer na união quando um conjunto punção / matriz não é devidamente selecionado. Na Tabela 6, pode-se observar os tipos mais comuns de falha do ponto. A análise metalográfica feita no ponto mostra áreas mais escuras na base do ponto e próximo ao pescoço. As áreas circundadas em azul (Figura 53) sofreram maiores esforços de compressão e, possivelmente, obtiveram aumento de dureza. Observa-se também que não há espaço entre as chapas, o que caracteriza uma boa junção. Apenas um dos lados foi mostrado para melhorar a definição da imagem. O reagente químico utilizado nas análises metalográficas foi Nital $4 \%$.

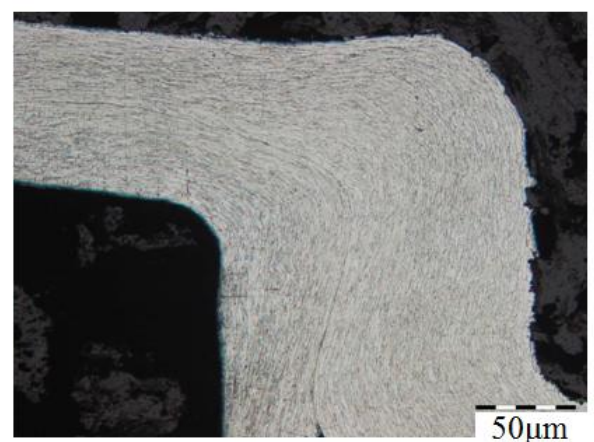

(a)

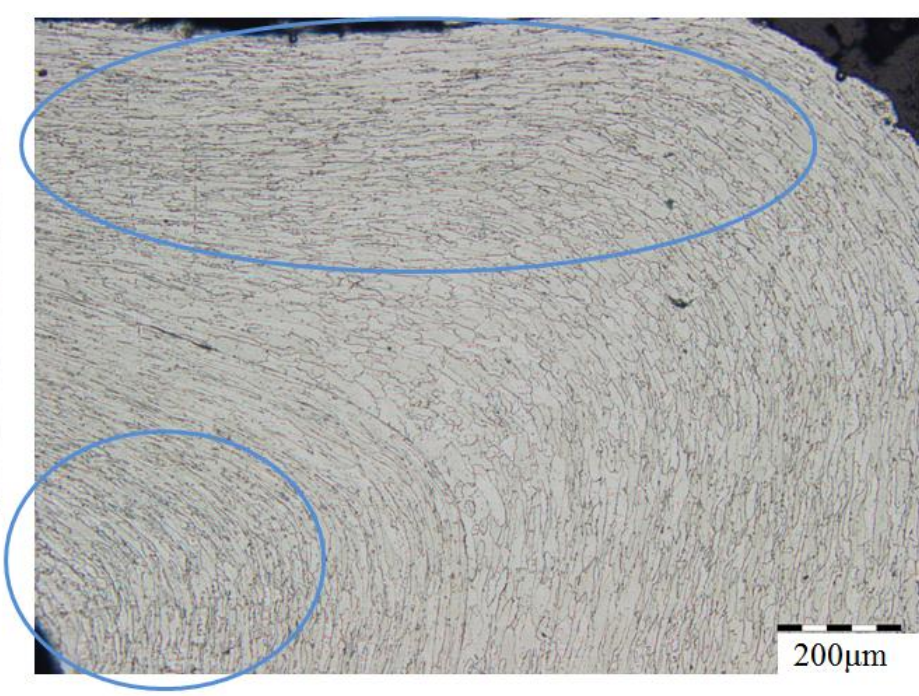

(b)

Figura 53 - Análise metalográficas do ponto de $8 \mathrm{~mm}$ com medida "X" de 0,75mm:

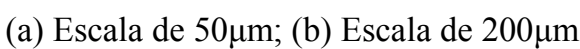


Tabela 6 - Tipos mais comuns de falha na união de chapas por UCCF

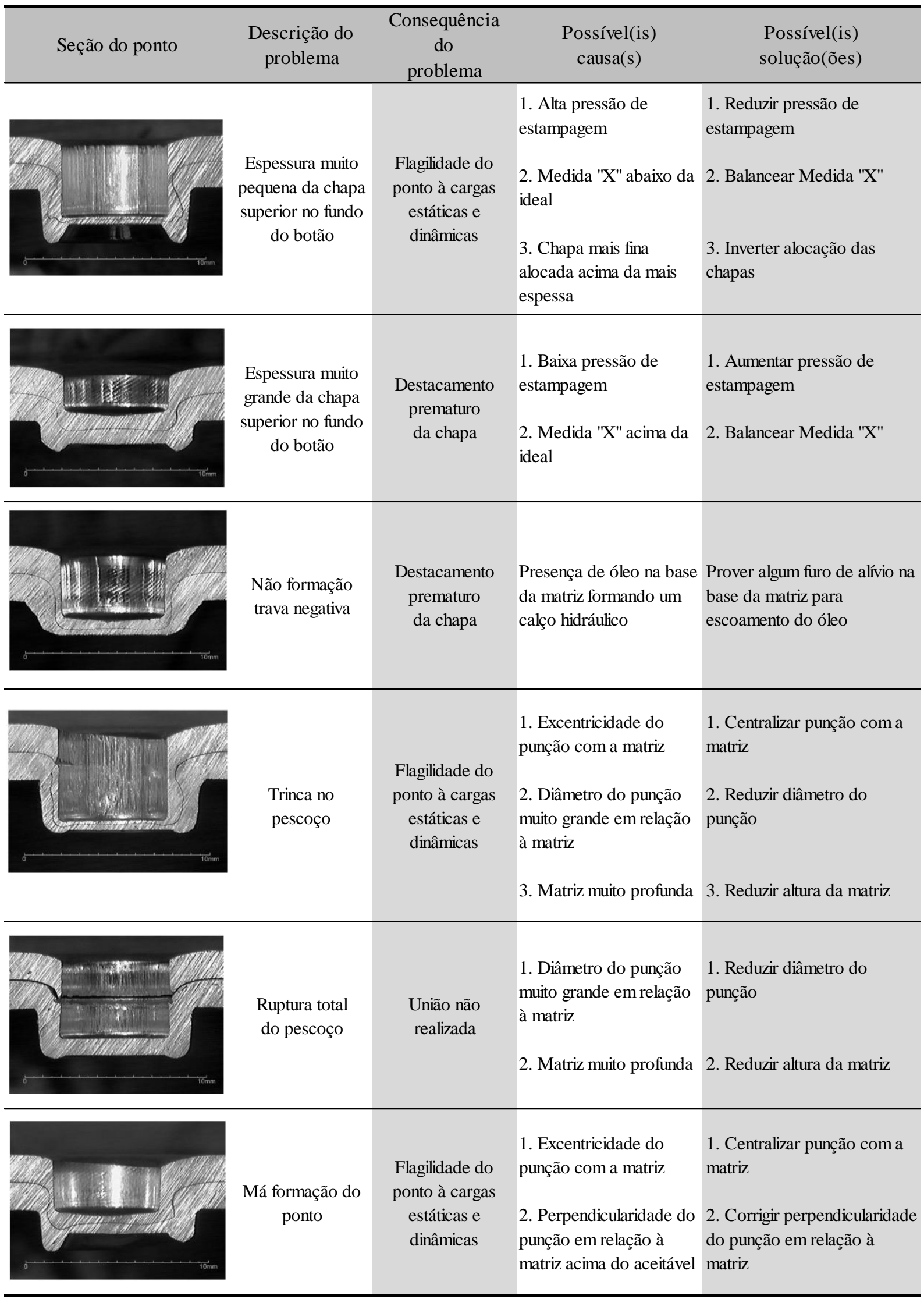

Fonte adaptada de: TOX, [entre 2000 e 2011] 
3.1.2.5 Redução da medida " $\mathrm{X}$ " até o ponto crítico de resistência do punção

O fabricante $\mathrm{TOX}^{\circledR}$ do equipamento de UCCF fornece uma tabela com a carga máxima que o punção resiste, conforme Tabela 7. No procedimento proposto será reduzida a medida "X" até próximo do limite. A medida selecionada será nomeada de $\mathrm{X}_{\text {limite. Nesta }}$ mesma tabela, pode-se verificar as medidas encontradas para os corpos de prova em questão. A medida de $\mathrm{X}_{\text {imite }}$ para os pontos de $8 \mathrm{~mm}$ foram determinados antes do alcance da carga limite recomendada pelo fato dos pontos apresentarem deformidades.

Tabela 7 - Medida $\mathrm{X}_{\text {limite }}$

\begin{tabular}{|c|c|c|c|c|c|c|}
\hline \multirow[b]{2}{*}{ União } & \multicolumn{3}{|c|}{ Combinação Final } & \multirow[b]{2}{*}{$\begin{array}{c}\mathrm{X}_{\text {limite }} \\
(\mathrm{mm})\end{array}$} & \multirow[b]{2}{*}{$\begin{array}{c}\text { Carga } \\
\text { Medida } \\
(\mathrm{kN})\end{array}$} & \multirow[b]{2}{*}{$\begin{array}{c}\text { Carga Máxima } \\
\text { Recomendada } \\
(\mathrm{kN})\end{array}$} \\
\hline & $\begin{array}{l}\varnothing \text { do Ponto } \\
\text { recomendado } \\
(\mathrm{mm})\end{array}$ & $\begin{array}{c}\text { Punção } \\
\text { ( Øp / Lp) } \\
\text { mm }\end{array}$ & $\begin{array}{c}\text { Matriz } \\
\left(\begin{array}{l}\emptyset \mathrm{m} / \mathrm{Pm}) \\
\mathrm{mm}\end{array}\right.\end{array}$ & & & \\
\hline \multirow{2}{*}{1} & 6,00 & $4,2 / 100$ & $6,0 / 1,2$ & 0,25 & 51 & 55 \\
\hline & 8,00 & $5,6 / 100$ & $8,0 / 1,6$ & 0,35 & 73 & 98 \\
\hline \multirow{2}{*}{2} & 6,00 & $4,0 / 100$ & $6,0 / 1,2$ & 0,45 & 50 & 52 \\
\hline & 8,00 & $5,2 / 100$ & $8,0 / 1,6$ & 0,60 & 62 & 84 \\
\hline
\end{tabular}

\subsubsection{Confecção dos corpos de prova}

Foi utilizado o padrão de corpos de prova da TOX $^{\circledR}$ (Figura 54). Os ensaios mostraram que todos os corpos de prova atenderam os critérios de falha mostrados na Figura 29a e Figura 29b. Tal critério determina que o corpo de prova deve ser resistente o suficiente para não romper/falhar, sendo assim possível avaliar a resistência do ponto.

Um total de 180 corpos de prova foram confeccionados para determinação da medida "X" ideal para a união de chapas $\mathrm{N}^{\circ} 1$ e $\mathrm{N}^{\circ} 2$. Na Tabela 8 , pode-se verificar a quantidade de corpos bem como a variação da medida "X", que foi definida com o incremento de $0,05 \mathrm{~mm}$ a partir da medida $\mathrm{X}_{\text {limite }}$ definida na Tabela 7. Definido os valores da medida "X", o processo de preparação dos corpos de prova pode ser iniciado. 


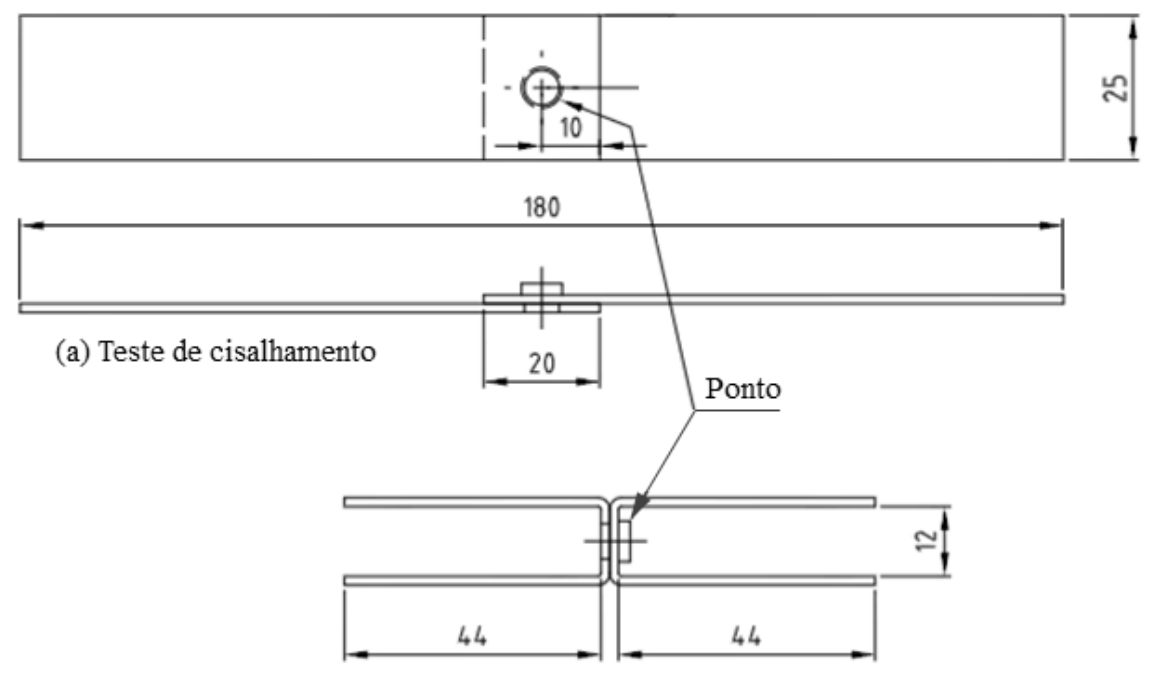

(b) Teste de arrancamento

Figura 54 - Corpos de prova para ensaio de tração e cisalhamento (TOX, [entre 2000 e 2011])

Tabela 8 - Amostragem dos corpos de prova para determinação da medida "X" ideal

\begin{tabular}{|c|c|c|c|c|c|c|c|c|c|c|c|c|c|c|c|c|c|}
\hline \multirow{2}{*}{ União } & \multirow{2}{*}{$\begin{array}{l}\varnothing \text { do Ponto } \\
\text { recomendado } \\
(\mathrm{mm})\end{array}$} & \multirow{2}{*}{$\begin{array}{c}\text { Tipo de } \\
\text { Solicitação }\end{array}$} & \multicolumn{15}{|c|}{ Medida "X" (mm) } \\
\hline & & & 0,25 & 0,30 & 0,35 & 0,40 & 0,45 & 0,50 & 0,55 & 0,60 & 0,65 & 0,70 & 0,75 & 0,80 & 0,85 & 0,90 & 0,95 \\
\hline \multirow{4}{*}{1} & \multirow{2}{*}{6,00} & Cisalhan & 3 & 3 & 3 & 3 & 3 & 3 & 3 & 3 & 3 & - & - & - & - & - & - \\
\hline & & Arrancamento & 3 & 3 & 3 & 3 & 3 & 3 & 3 & 3 & 3 & - & - & - & - & - & - \\
\hline & \multirow{2}{*}{8,00} & Cisalhamento & - & - & 3 & 3 & 3 & 3 & 3 & 3 & 3 & - & - & - & - & - & - \\
\hline & & Arrancamento & - & - & 3 & 3 & 3 & 3 & 3 & 3 & 3 & - & - & - & - & - & - \\
\hline \multirow{4}{*}{2} & \multirow{2}{*}{6,00} & Cisalhamento & - & - & - & - & 3 & 3 & 3 & 3 & 3 & 3 & 3 & - & - & - & - \\
\hline & & Arrancamento & - & - & - & - & 3 & 3 & 3 & 3 & 3 & 3 & 3 & - & - & - & - \\
\hline & \multirow{2}{*}{8,00} & Cisalhamento & - & - & - & - & - & - & - & - & 3 & 3 & 3 & 3 & 3 & 3 & 3 \\
\hline & & Arrancamento & - & - & - & - & - & - & - & - & 3 & 3 & 3 & 3 & 3 & 3 & 3 \\
\hline
\end{tabular}

A confecção dos corpos de prova da Figura 55a é relativamente simples. O blanque da chapa é cortada em uma guilhotina na dimensão de $25 \mathrm{~mm}$ x $100 \mathrm{~mm}$ formando as chapas planas que serão posteriormente unidas. A centralização dos pontos no corpo de prova foi garantida pela indicação existente na prensa, reduzindo a variação dimensional de localização do ponto.

Para o ensaio de arrancamento foi utilizado o corpo de prova da Figura 54b. O procedimento de confecção exige mais cuidado. Primeiramente, as chapas planas são cortadas na dimensão de $25 \mathrm{~mm}$ x 100mm (mesma dimensão do corpo de prova anterior).

O conjunto formado pelas duas chapas (Figura 55a) é dobrado com o auxílio do dispositivo mostrado na Figura 55b. O resultado final pode ser observado na Figura 55c. 


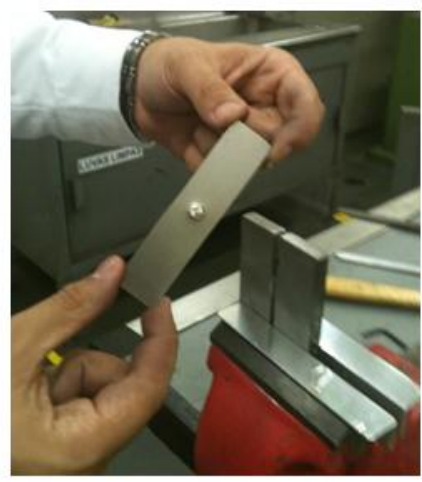

(a)

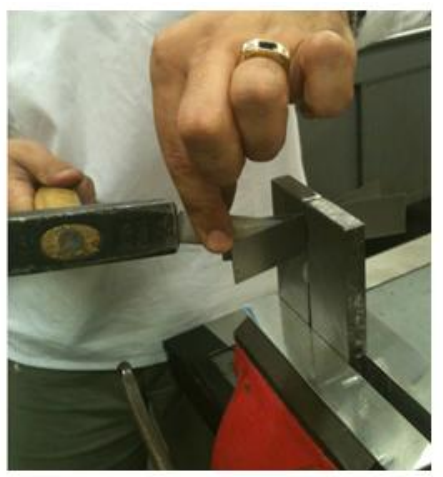

(b)

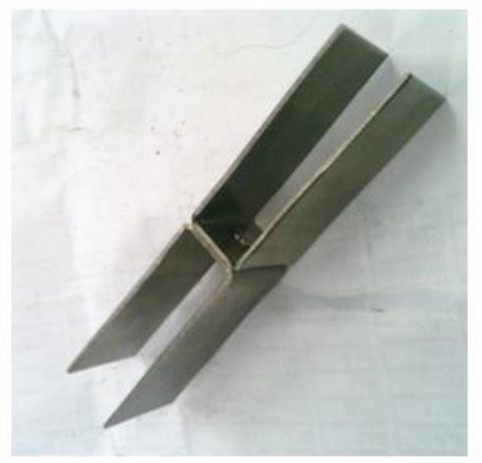

(c)

Figura 55- Procedimento de confecção do corpo de prova de arrancamento

\subsubsection{Ensaio de cisalhamento e destacamento}

Todos os corpos de prova e os ensaios foram realizados no laboratório da TOX $^{\circledR}$ em Joinville. Foi utilizado uma prensa TOX ${ }^{\circledR}$ Modelo CEU de 150kN (Figura 56a); máquina de tração LLOYD ${ }^{\circledR}$, Modelo LR10k com resolução de 0,1 Newton (Figura 56b); Instrumento de medição da marca Kroeplin ${ }^{\circledR}$ Modelo CMT85, escala de 0-17mm, com resolução de 0,01mm (Figura 56c) e para cortar a seção transversal foi utilizado a máquina de corte da marca Brillant ${ }^{\circledR}$ Modelo 200 (Figura 56d).

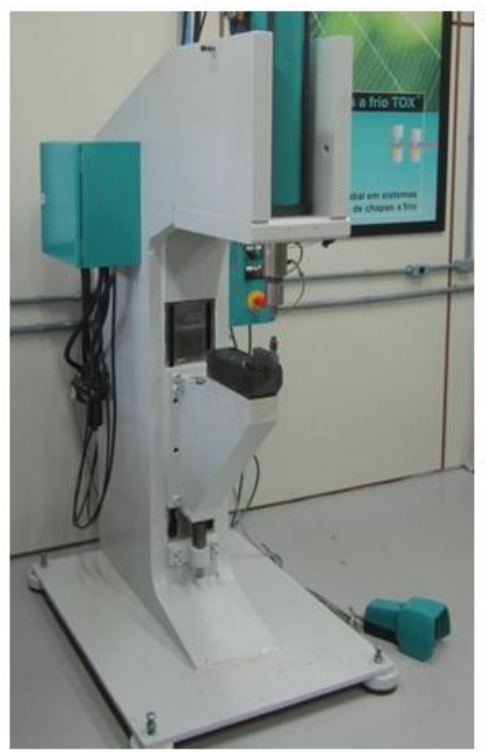

(a)

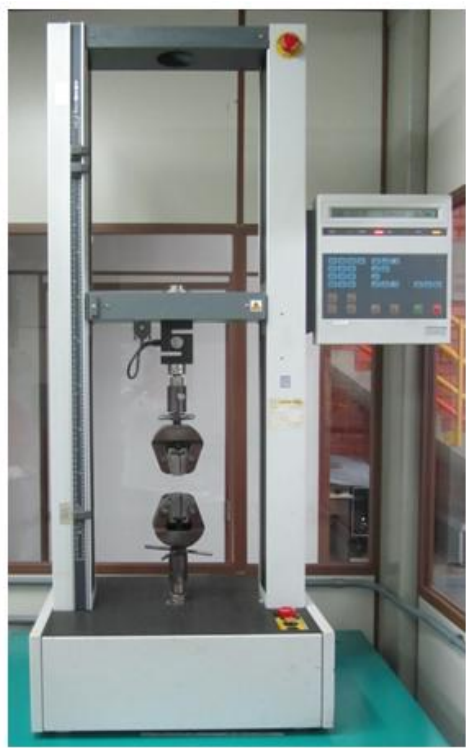

(b)

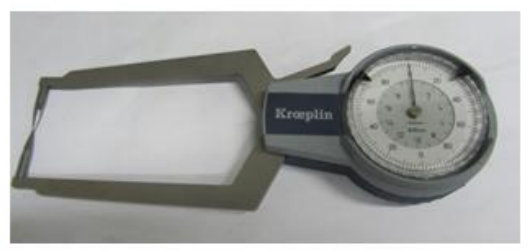

(c)

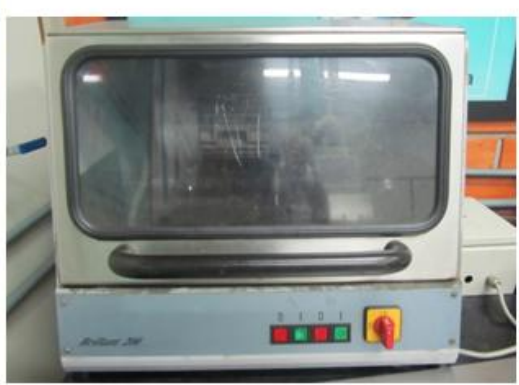

(d)

Figura 56 - Equipamentos utilizados para junção e ensaio dos corpos de prova 
O gráfico mostrado na Figura 57 mostra a carga de prensagem em cada união.

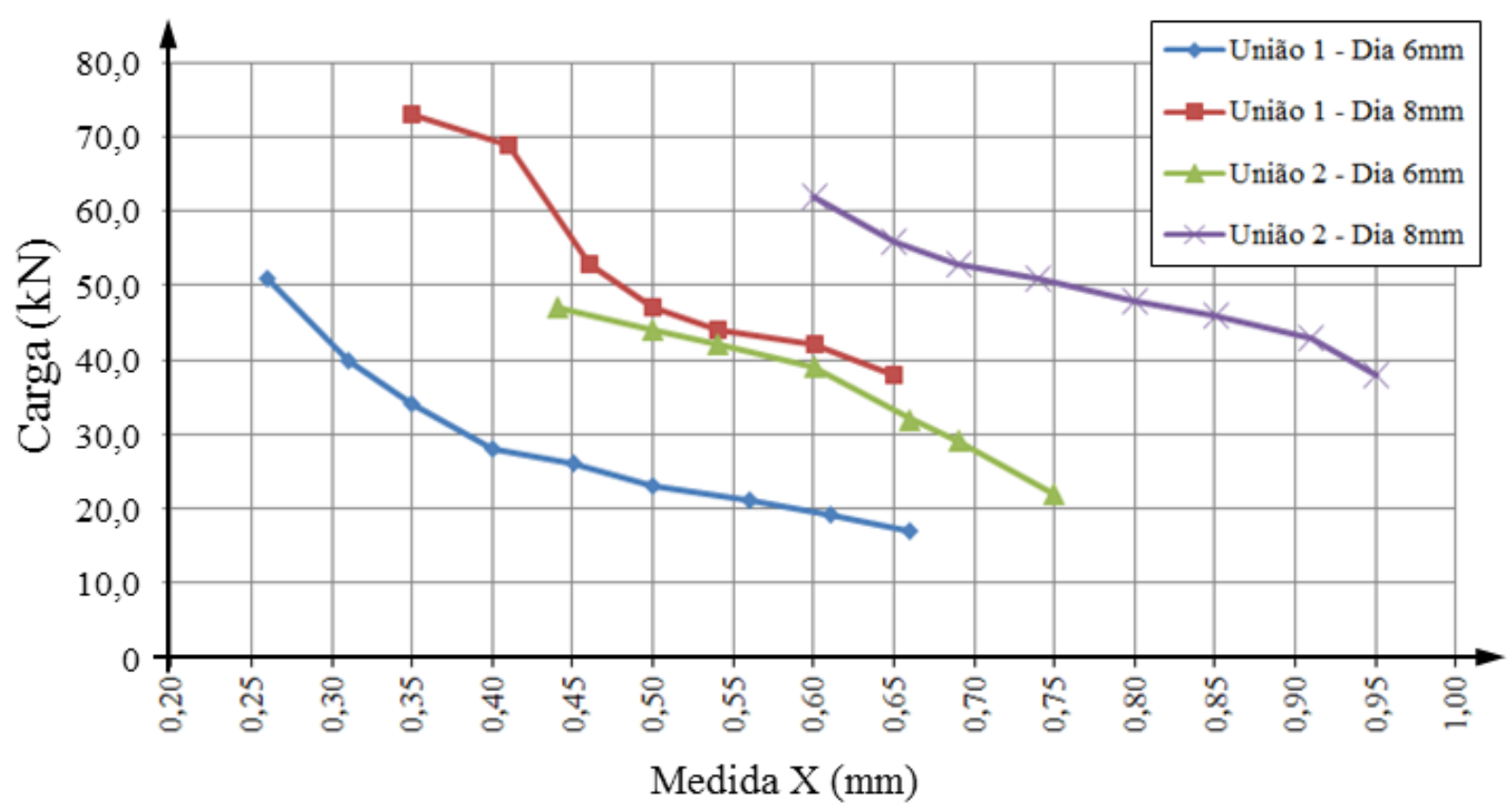

Figura 57 - Carga de prensagem em função da união e do diâmetro do ponto

Os ensaios de cisalhamento (Figura 58a) e de arrancamento (Figura 58b) foram realizados com velocidade de deslocamento de $5 \mathrm{~mm} / \mathrm{min}$ seguindo a recomendação de condição quase estática definida por Lin et al. (2003) e Lee et al.(1998). A temperatura do laboratório foi mantida em $23^{\circ} \mathrm{C}$ durante os ensaios.

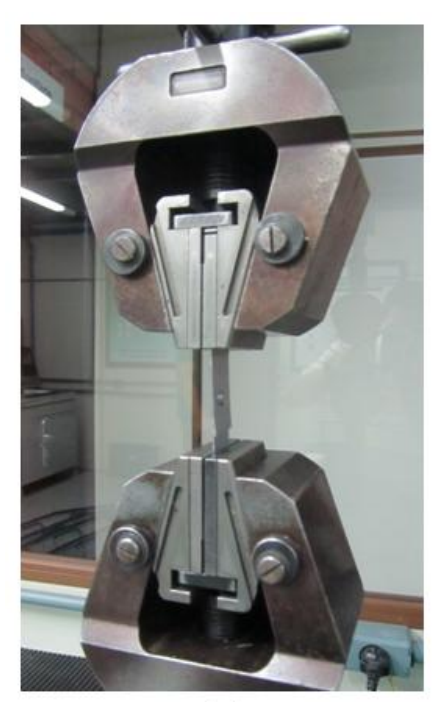

(a)

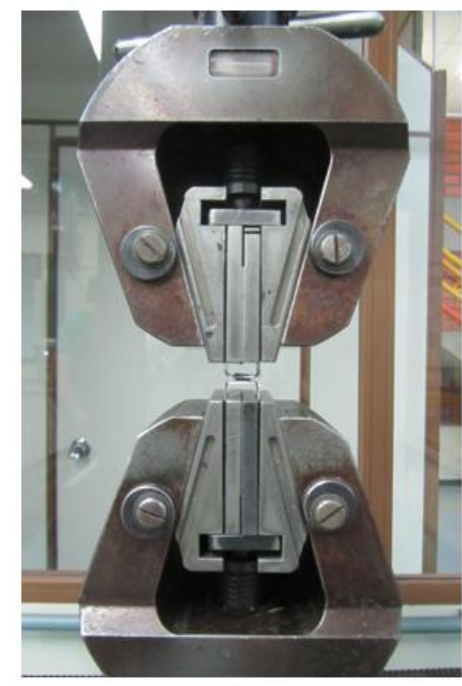

(b)

Figura 58 - Ensaio de cisalhamento e arrancamento 


\subsubsection{Resultados}

Os resultados dos ensaios de destacamento e cisalhamento podem ser verificados pelos gráficos das Figura 59 à Figura 62. Cada ponto contido no gráfico refere-se à média do valor obtido para três corpos de prova. As tabelas contendo os valores de resistência para cada corpo de prova podem ser encontradas no Apêndice A. Curvas de tendência foram traçadas em todos os gráficos para auxiliar na determinação do ponto de maior resistência.

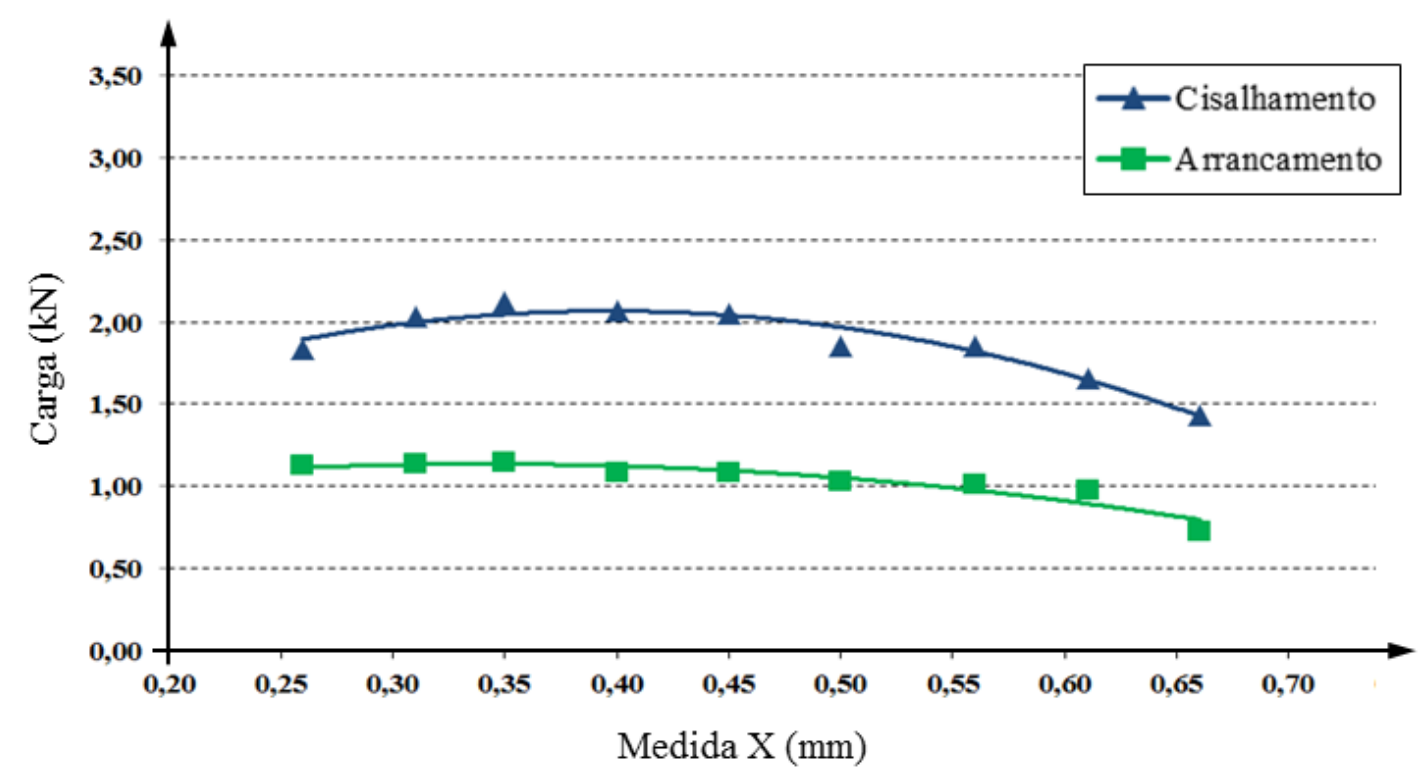

Figura 59 - Gráfico de resistência do ponto de $6 \mathrm{~mm}$ para a chapa de $0,8 \mathrm{~mm}$

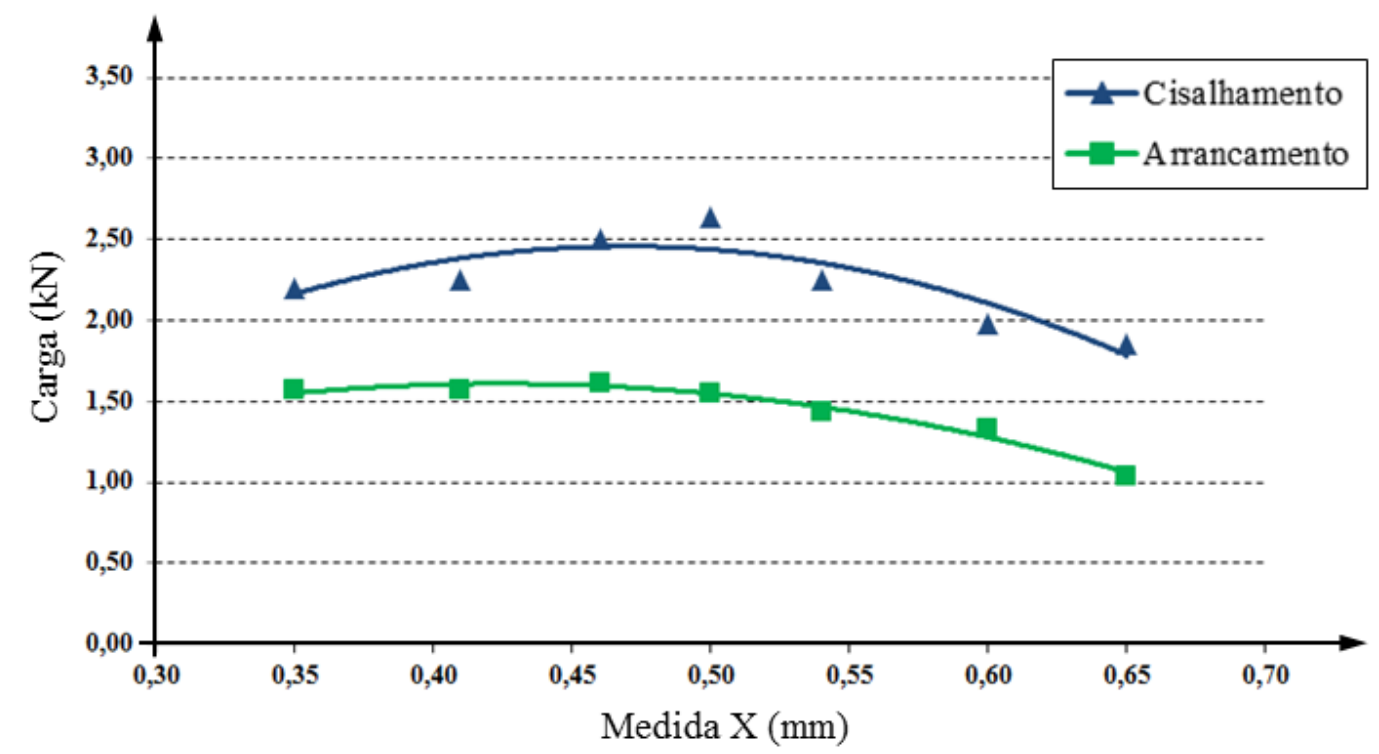

Figura 60 - Gráfico de resistência do ponto de $8 \mathrm{~mm}$ para a chapa de $0,8 \mathrm{~mm}$ 


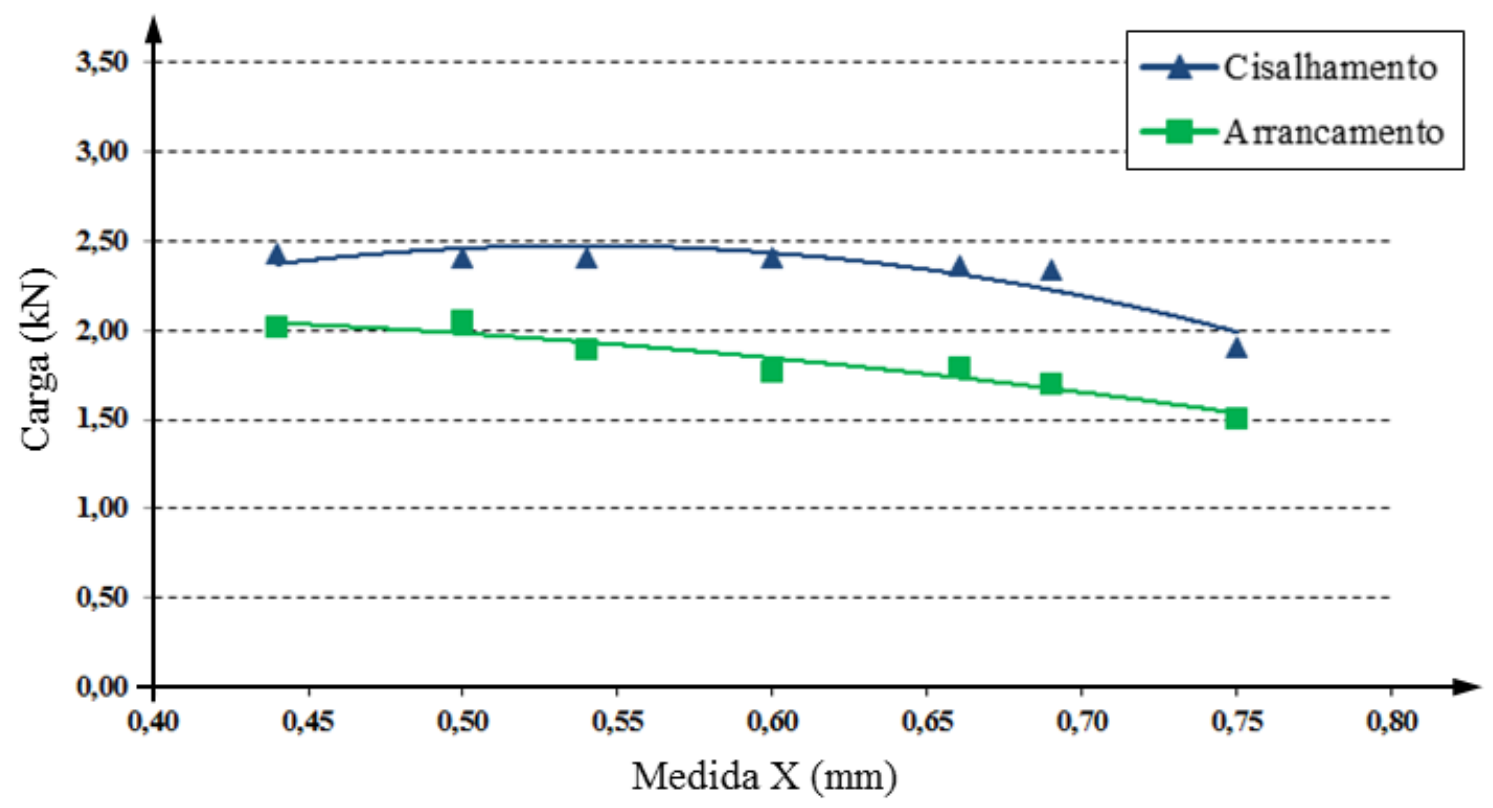

Figura 61 - Gráfico de resistência do ponto de $6 \mathrm{~mm}$ para a chapa de 1,2mm

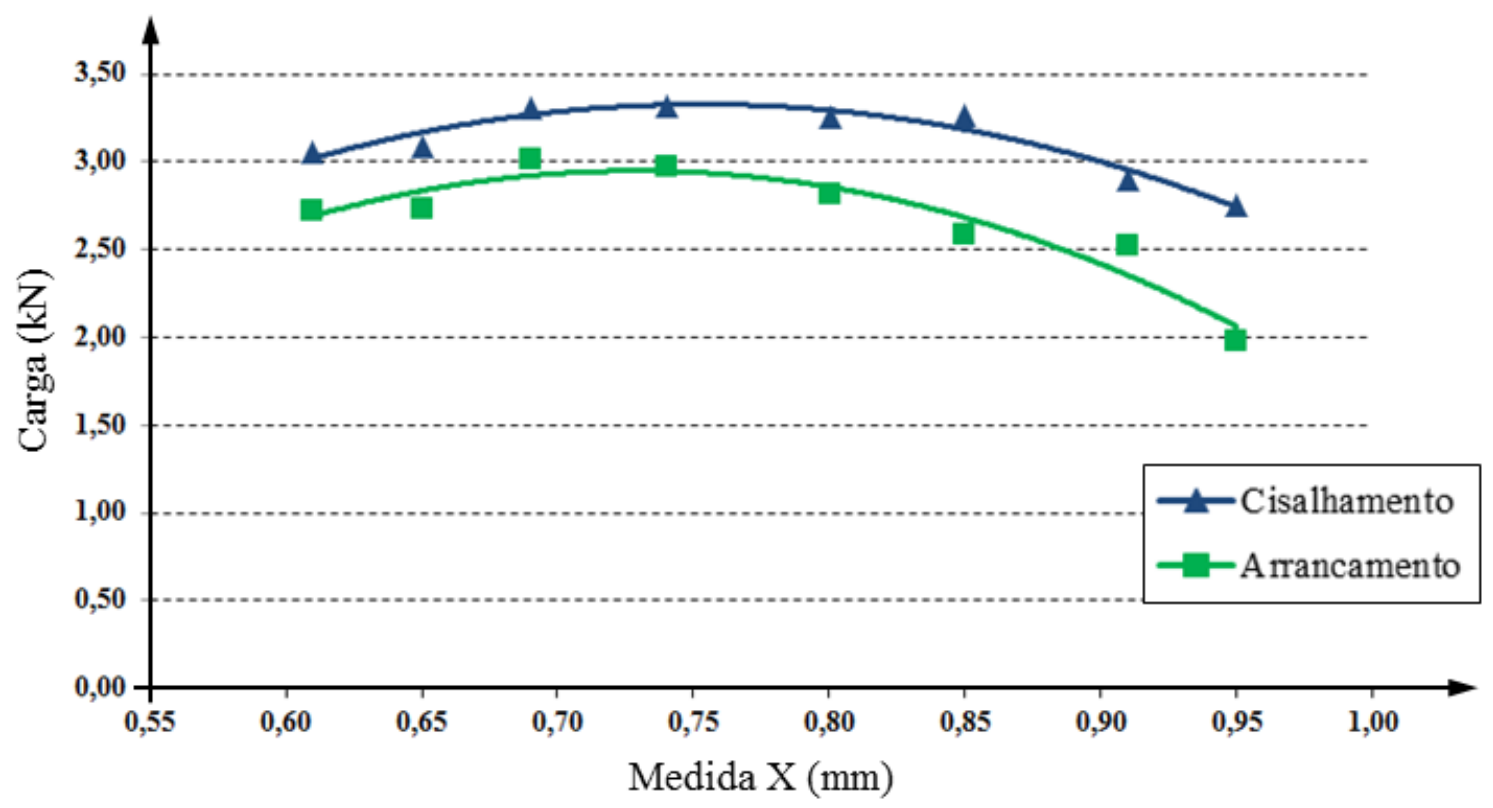

Figura 62 - Gráfico de resistência do ponto de $8 \mathrm{~mm}$ para a chapa de 1,2mm 
3.1.3.1 Análises dos resultados

O ponto de $8 \mathrm{~mm}$ demonstrou maior resistência tanto aos esforços de cisalhamento quanto aos esforços de arrancamento, portanto apenas os gráficos referentes à Figura $60 \mathrm{e}$ Figura 62 serão analisados para determinação da medida " $X$ " ideal.

A escolha da medida " $X$ " ideal passará por uma média ponderada dos valores de " $X$ " dos corpos de prova que obtiveram maior resistência ao cisalhamento e ao arrancamento, conforme equação abaixo:

$X_{\text {ideal }}=\frac{1}{2}\left(X_{c}+X_{a}\right)$

Onde $\mathrm{X}_{\text {ideal }}$ é a medida "X" que será utilizada nos corpos de prova para o ensaio multiaxial: $X_{c}$ é a medida " $X$ " dos corpos de prova que mais resistiram aos esforços de cisalhamento e o $X_{a}$ é medida " $X$ " aos esforços de arrancamento.

Para a união 1 de chapas de $0,8 \mathrm{~mm}$ é possível determinar o $\mathrm{X}_{\text {ideal } 0,8}$ analisando o gráfico da Figura 63. Os pontos A e B representam a medida " $\mathrm{X}$ " dos corpos de prova de maior resistência ao cisalhamento e ao arrancamento respectivamente. Projetando os pontos no eixo da abcissa é possível encontrar os valores abaixo:

$$
\begin{gathered}
X_{\mathrm{c} 0,8}=0,43 \mathrm{~mm} \\
X_{\mathrm{a} 0,8}=0,47 \mathrm{~mm} \\
X_{\text {ideal } 0,8}=\frac{1}{2}(0,43+0,47)=0,45 \\
\text { Portanto, } X_{\text {ideal } 0,8}=0,45 \mathrm{~mm}
\end{gathered}
$$




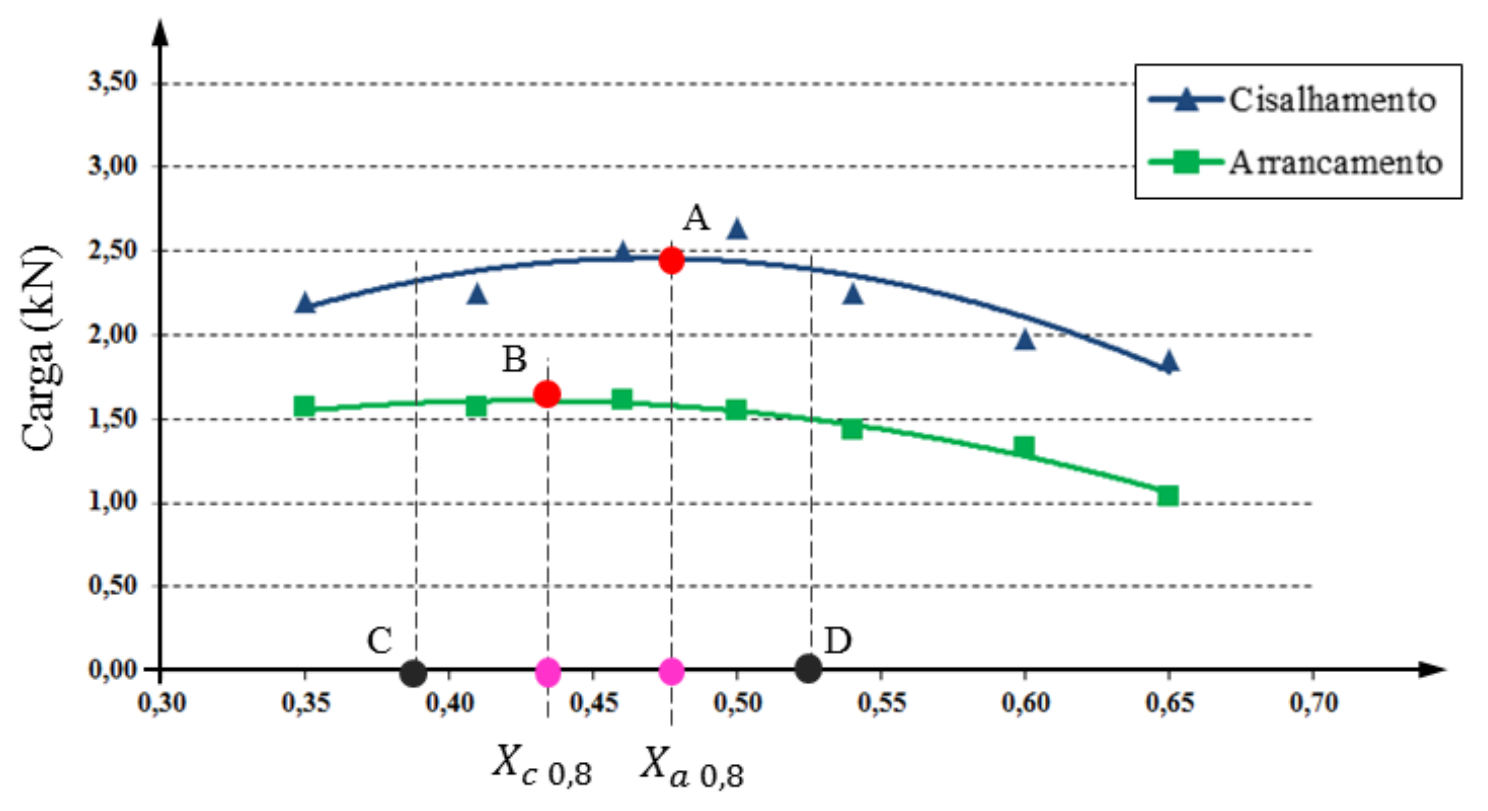

Medida X (mm)

Figura 63 - Gráfico para determinação da medida Xideal do ponto de $8 \mathrm{~mm}$ para chapa de $0,8 \mathrm{~mm}$

Segundo Haller apud Varis (2006), no processo produtivo, a medida "X" pode variar em $15 \%$ tanto para mais quanto para menos devido à variação de resistência mecânica das chapas. Tal informação também se confirmou em visita técnica (informação verbal) ${ }^{2}$. Sendo assim, uma verificação desses limites deve ser feita no gráfico para garantir que as medidas extremas não coloquem em risco a integridade do produto e até mesmo do consumidor. Sendo assim, a medida $X_{\text {ideal } 0,8}$ pode variar, no processo produtivo, de $0,38 \mathrm{~mm}$ a $0,52 \mathrm{~mm}$, conforme pontos C e D respectivamente do gráfico da Figura 63. Esses valores estão aprovados, pois os valores de resistência não foram reduzidos significativamente.

$\mathrm{O}$ mesmo procedimento foi realizado para determinação do $\mathrm{X}_{\text {ideal 1,2. }}$ Os pontos $\mathrm{E}$ e $\mathrm{F}$ do gráfico da Figura 64 representam as medidas "X" do corpos de prova de maior resistência dos corpos de prova ao cisalhamento e ao arrancamento respectivamente. Projetando os pontos no eixo da abcissa é possível encontrar os valores abaixo:

$$
\begin{gathered}
\mathrm{X}_{\mathrm{c} 1,2}=0,73 \mathrm{~mm} \\
\mathrm{X}_{\mathrm{a} 1,2}=0,77 \mathrm{~mm} \\
X_{\text {ideal } 1,2}=\frac{1}{2}(0,73+0,77)=0,75
\end{gathered}
$$

$$
\text { Portanto, } X_{\text {ideal 1,2 }}=0,75 \mathrm{~mm}
$$

\footnotetext{
${ }^{2}$ Informação fornecida pelo Engenheiro Leandro de Lemos em visita técnica feita à TOX® , Joinville-SC em 25 de Outubro de 2011.
} 


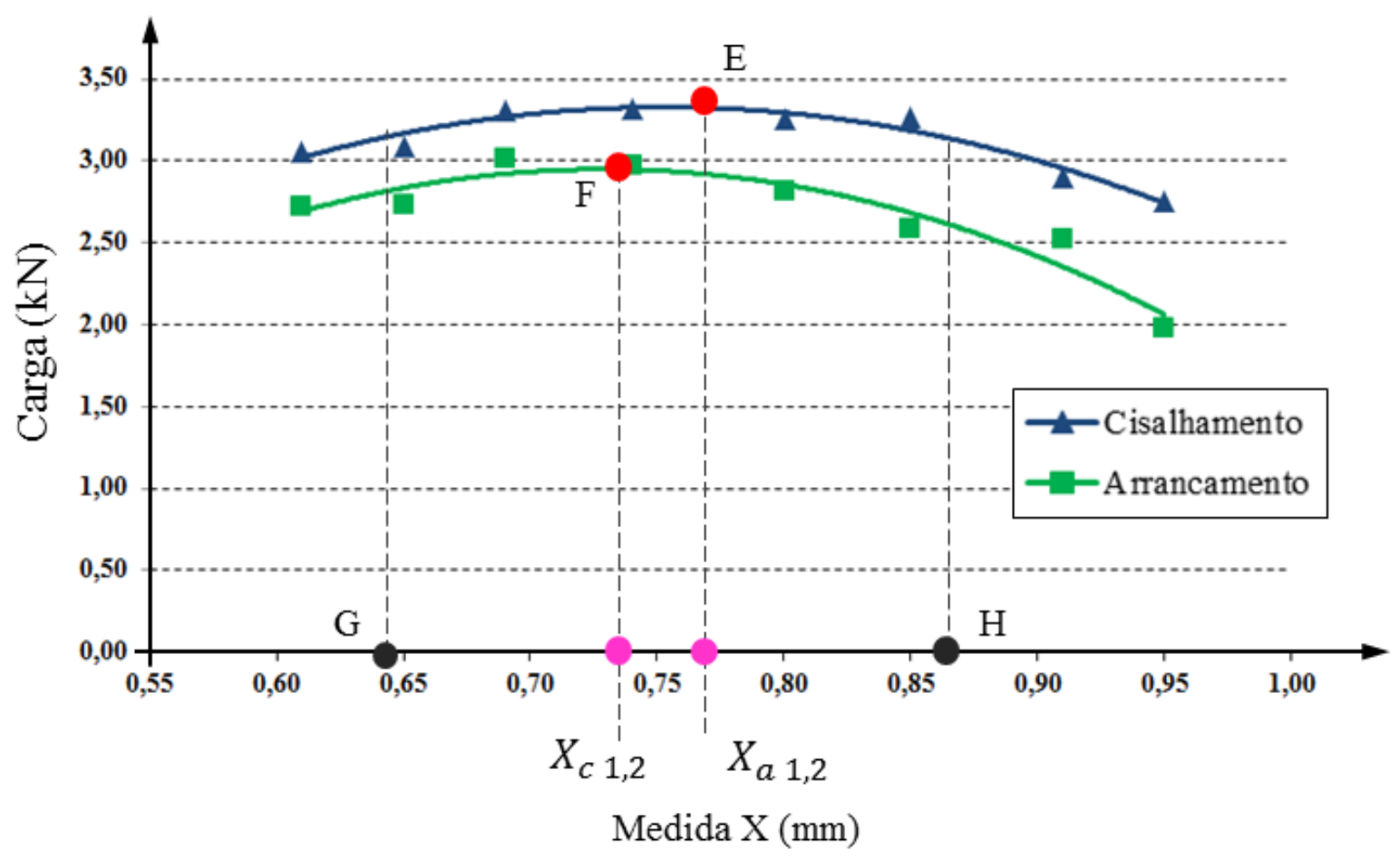

Figura 64 - Gráfico para determinação da medida Xideal do ponto de 8mm para chapa de 1,2mm

O critério da variação de $15 \%$ da medida $X_{\text {ideal } 1,2}$ também será aplicado. Para a chapa com espessura de $1,2 \mathrm{~mm}$, a medida $X_{\text {ideal } 1,2}$ pode variar, no processo produtivo, de $0,64 \mathrm{~mm}$ a $0,86 \mathrm{~mm}$, conforme pontos $\mathrm{G}$ e $\mathrm{H}$ respectivamente do gráfico da Figura 64. Esses valores estão aprovados, pois estão dentro de valores de resistência aceitáveis.

\subsubsection{Equivalência do elemento de fixação}

É necessário estabelecer um parâmetro de equivalência quando se compara dois processos de junção diferentes. No caso da UCCF e SPRE essa equivalência pode ser facilmente determinada haja vista que ambos os elementos tem características semelhantes. O tipo de união escolhido para ser utilizado na análise é a UCCF sem material auxiliar denominado Round (elemento cilíndrico da Figura 7).

Estudos foram feitos por Ruiz (2005) para relacionar características visuais do SPRE com a qualidade da união. A Tabela 9 mostra os valores encontrados para o diâmetro mínimo aceitável para a união de chapas de $0,8 \mathrm{~mm}$ e $1,2 \mathrm{~mm}$ por SPRE. 
Tabela 9 - Diâmetros reais dos pontos de solda

\begin{tabular}{ccccc}
\hline \multicolumn{5}{c}{$\begin{array}{c}\text { Diâmetro Mínimo } \\
\text { do Botão }\end{array}$} \\
\hline $\begin{array}{c}\text { Espessura } \\
(\mathrm{mm})\end{array}$ & $\begin{array}{c}\text { Corpo } \\
\mathrm{N}^{\circ}\end{array}$ & $\begin{array}{c}\text { Teórico } \\
(\mathrm{mm})\end{array}$ & $\begin{array}{c}\text { Real } \\
(\mathrm{mm})\end{array}$ & $\begin{array}{c}\text { Diâmetro } \\
\text { Mínimo Médio } \\
(\mathrm{mm})\end{array}$ \\
\hline & 1 & 4,40 & 5,53 & \\
& 2 & 4,40 & 7,05 & \\
$0,80 \times 0,80$ & 3 & 4,40 & 6,86 & 6,36 \\
& 4 & 4,40 & 6,32 & \\
& 5 & 4,40 & 6,03 & \\
\hline \multirow{3}{*}{$1,20 \times 1,20$} & 22 & 5,00 & 6,85 & \\
& 23 & 5,00 & 6,80 & \\
& 24 & 5,00 & 6,60 & 6,85 \\
& 25 & 5,00 & 6,86 & \\
\hline
\end{tabular}

Fonte: Ruiz (2005)

Na SPRE o diâmetro mínimo é uma consequência dos parâmetros da máquina de solda e principalmente da espessura das chapas envolvida na união.

Para a UCCF será adotado o critério da resistência do ponto, já que, neste caso, o diâmetro do ponto é um dado de entrada. Sendo assim, o ponto com diâmetro de $8 \mathrm{~mm}$ foi o escolhido por resistir às maiores cargas de cisalhamento e arrancamento.

\subsection{ANÁLISE DA RESISTÊNCIA MECÂNICA DA UCCF SOB CARGA MULTIAXIAL}

\subsubsection{Diagrama de causa e efeito (Ishikawa)}

O diagrama de espinha de peixe é um instrumento gráfico para identificar, organizar e apresentar de modo estruturado as causas de problemas em processos. É também frequentemente designado por diagrama de causa-efeito ou diagrama de Ishikawa. 
Quando os problemas são de natureza industrial, é comum designar as causas principais por Materiais - Métodos - Homens, juntamente com o Dinheiro. Esses fatores determinam o termos em inglês 5 Ms: Materials - Machines - Methods - Manpower Money.

No ensaio comparativo experimental entre a UCCF e a SPRE serão utilizados os dados previamente levantados por Kawamura (2007) referente à SPRE. O método de Ishikawa representado pela Figura 65 foi utilizado para levantar possíveis problemas que possam influenciar na correlação do experimento. Todas as possíveis causas foram estudadas e eliminadas para que o ensaio possa fornecer resultados mais precisos.

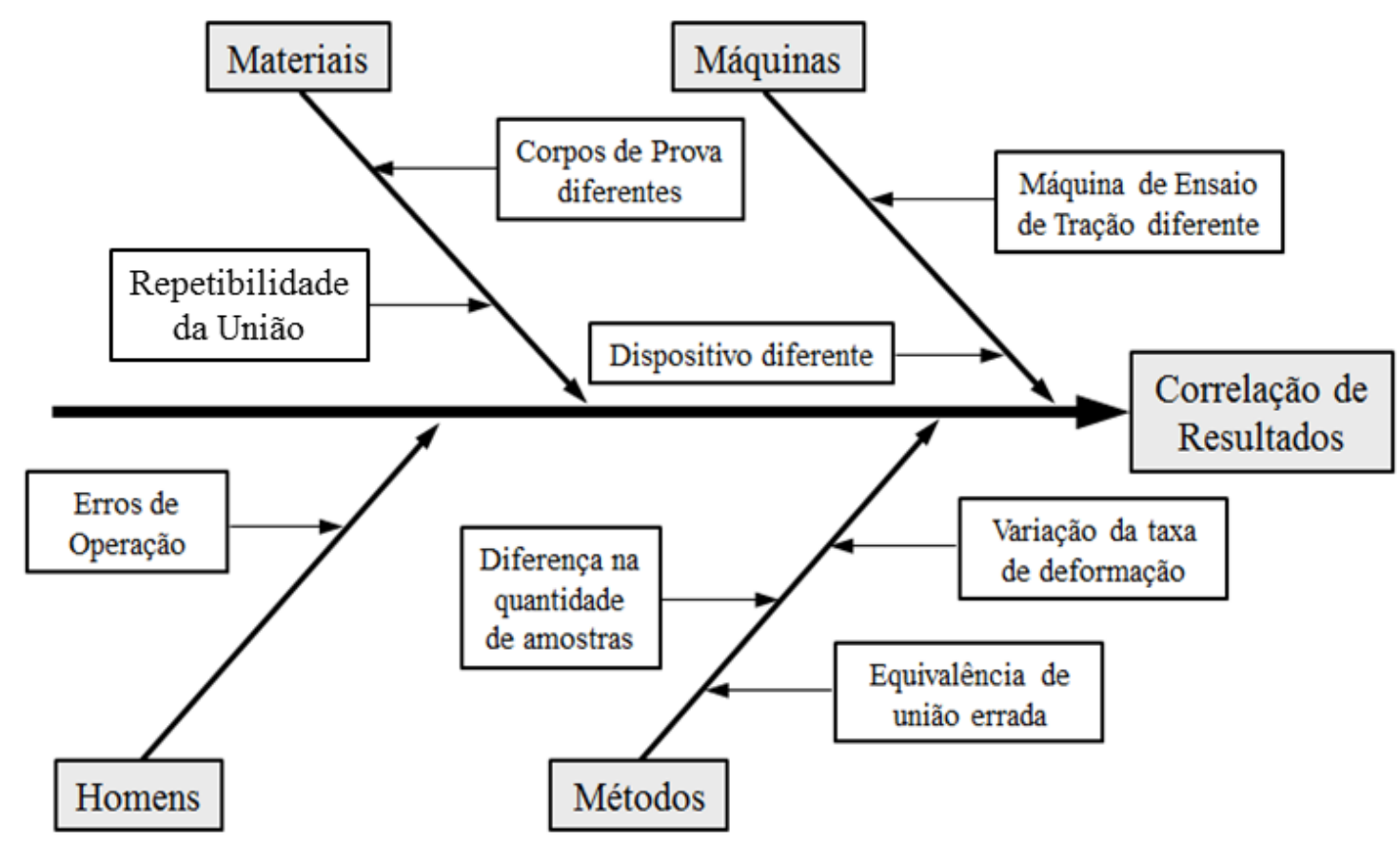

Figura 65 - Espinha de peixe do ensaio de tração

\subsubsection{Condições gerais de ensaio para análise da UCCF sob carga multiaxial}

O corpo de prova possui um formato "U" e configuração e dimensões conforme Figura 66. Para a formação da junta metálica foram utilizados 2 corpos de prova.

O modelo de Zhou et al. (1999) foi utilizado para determinação da largura crítica dos corpos de prova. As espessuras a serem usadas são $0,8 \mathrm{~mm}$ e 1,2mm. Utilizando-se a equação (1) as seguintes larguras críticas serão encontradas: 


$$
\begin{aligned}
& \text { Para } \mathrm{t}=0,8, L_{\text {CRÍTICA }}=28,28 \mathrm{~mm} \\
& \text { Para } \mathrm{t}=1,2, L_{\text {CRÍTICA }}=35,72 \mathrm{~mm}
\end{aligned}
$$

Os valores calculados acima são mínimos, portanto será estabelecido o valor de largura de $55 \mathrm{~mm}$ para satisfazer todas as configurações de espessuras. O comprimento do corpo de prova será utilizado $90 \mathrm{~mm}$. O comprimento é a dimensão que menos influi no ensaio, mas construtivamente ela é importante porque o formato de "U", caso seja estabelecido um comprimento relativamente pequeno, o mesmo poderá impossibilitar o acesso ao UCCF.

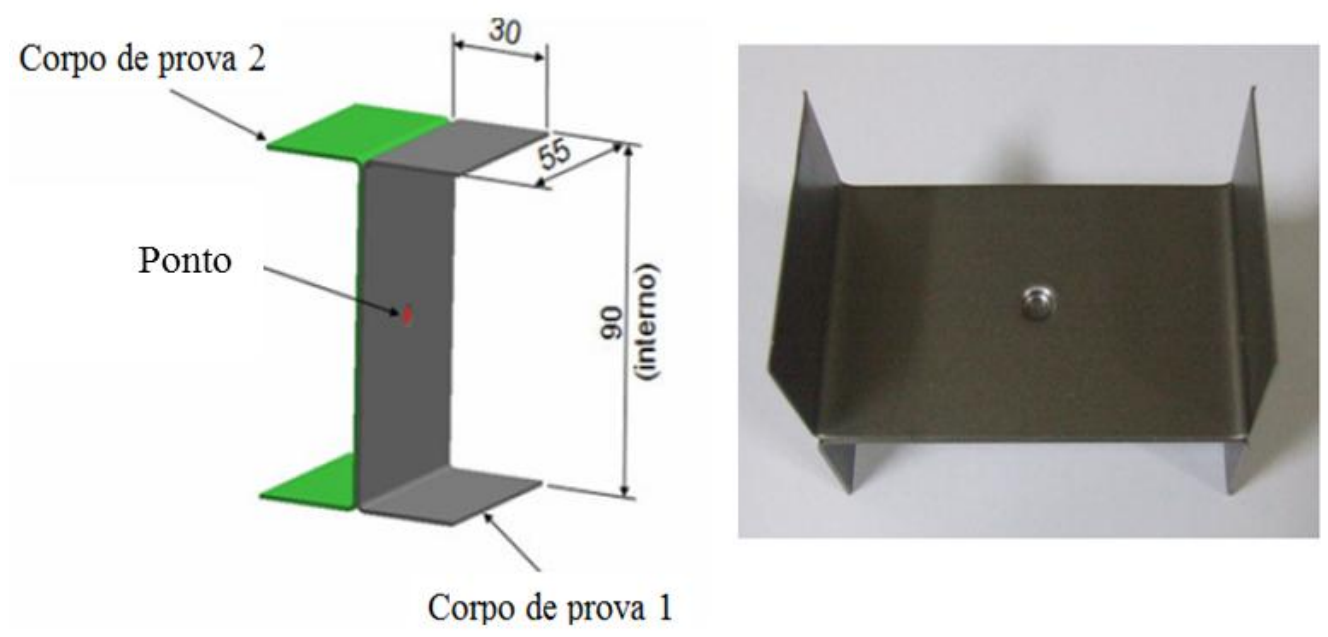

Figura 66 - Junta metálica de ensaio

O material utilizado é o Aço comum EMS.ME.1508 BFF EEP (EMS.ME.1508, 1996), sem revestimento, utilizado na indústria automotiva, com as espessuras de $0,80 \mathrm{~mm}$ e $1,20 \mathrm{~mm}$. A especificação completa do material pode ser vista no Anexo B.

A escolha da geometria do corpo de prova, bem como o material se justifica para ser possível a comparação dos resultados com os ensaios feitos por Kavamura (2007) para SPRE.

Foi utilizado uma prensa TOX $^{\circledR}$ Modelo CEU de $150 \mathrm{kN}$ (Figura 56a); máquina de tração EMIC modelo DL10000 de 100kN (Figura 67). Instrumento de medição da marca Kroeplin Modelo CMT85, escala de 0-17mm, com resolução de 0,01mm (Figura 56c). Um torquímetro de relógio da marca Gedore $100 \mathrm{Nm}$ foi utilizado para apertar os parafusos do dispositivo de Arcan, evitando assim o deslizamento do corpo de prova durante o ensaio. 
Todos os ensaios forma realizados no laboratório do departamento de engenharia civil da Escola Politécnica da Universidade de São Paulo.

Para que o ensaio seja bem sucedido foi utilizado o mesmo dispositivo usado por Kavamura (2007), projetado para acomodar os corpos de prova, resistir às solicitações e prover flexibilidade para a combinação de ângulos. $\mathrm{O}$ dispositivo proposto foi baseado nos ensaios de Lee et al. (1998), ver Figura 27.

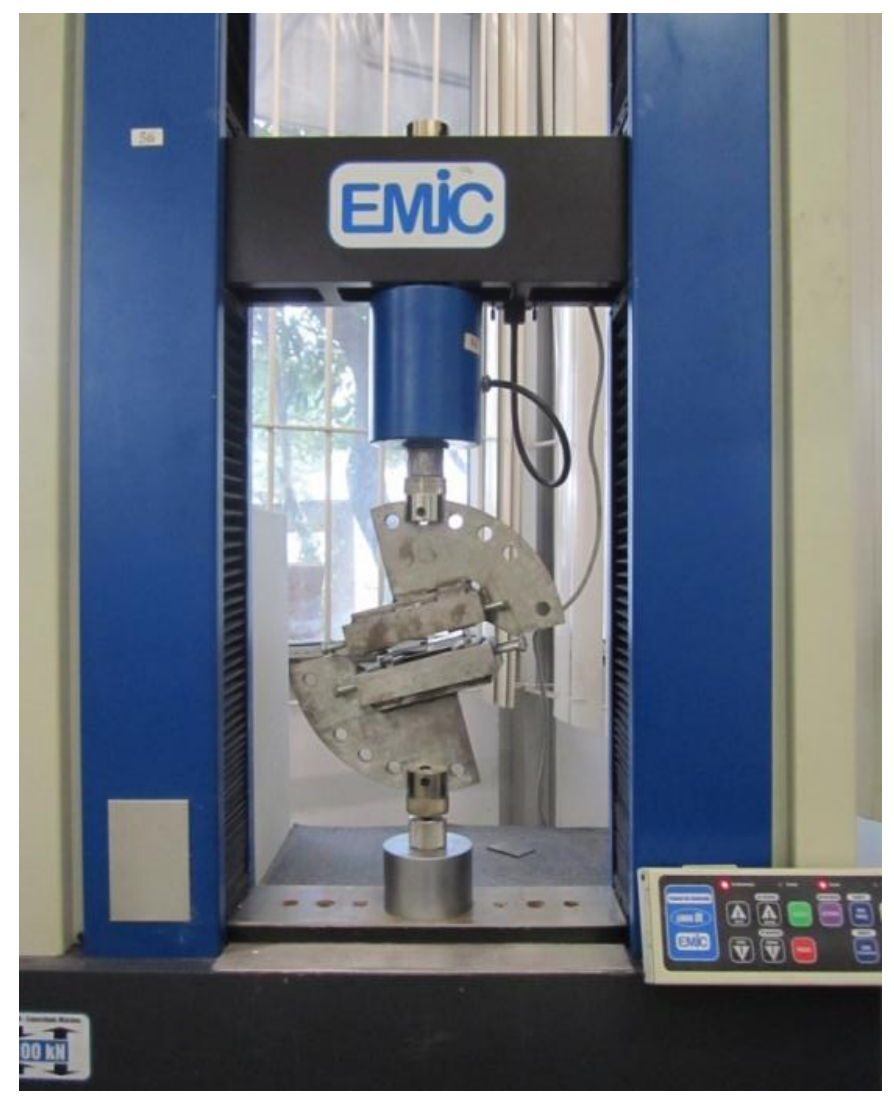

Figura 67 - Máquina de tração EMIC DL10000

Kavamura (2007) também realizou análise de elementos finitos para se certificar de que a rigidez do dispositivo suporta as cargas aplicadas no ensaio sem se deformar elasticamente. No modelo, o ângulo de aplicação crítico foi de $0^{\circ}$ e a força aplicada foi de $20 \mathrm{kN}$, onde a tensão máxima chegou a $111 \mathrm{MPa}$ em uma pequena região localizada. Como o limite de escoamento do material é de $210 \mathrm{MPa}$, concluiu-se que o dispositivo satisfaz as condições do ensaio, já que a força máxima esperada no ensaio é de $10 \mathrm{kN}$. Verificou-se que os ensaios a $90^{\circ}$ foram os que exigiram maior carga de aplicação, uma vez que o mesmo exige apenas cisalhamento do ensaio. Isso reforça a afirmação que o dispositivo atende sem 
problemas o ensaio, pois na configuração de $90^{\circ}$ é onde obtemos a maior rigidez estrutural do dispositivo.

O dispositivo de Arcan foi construído na Engenharia Experimental da General Motors do Brasil, localizada em São Caetano do Sul. A Figura 68 mostra fotos do dispositivo físico construído para os ensaios. A Tabela 10 mostra os parâmetros definidos e utilizados paraa a UCCF.

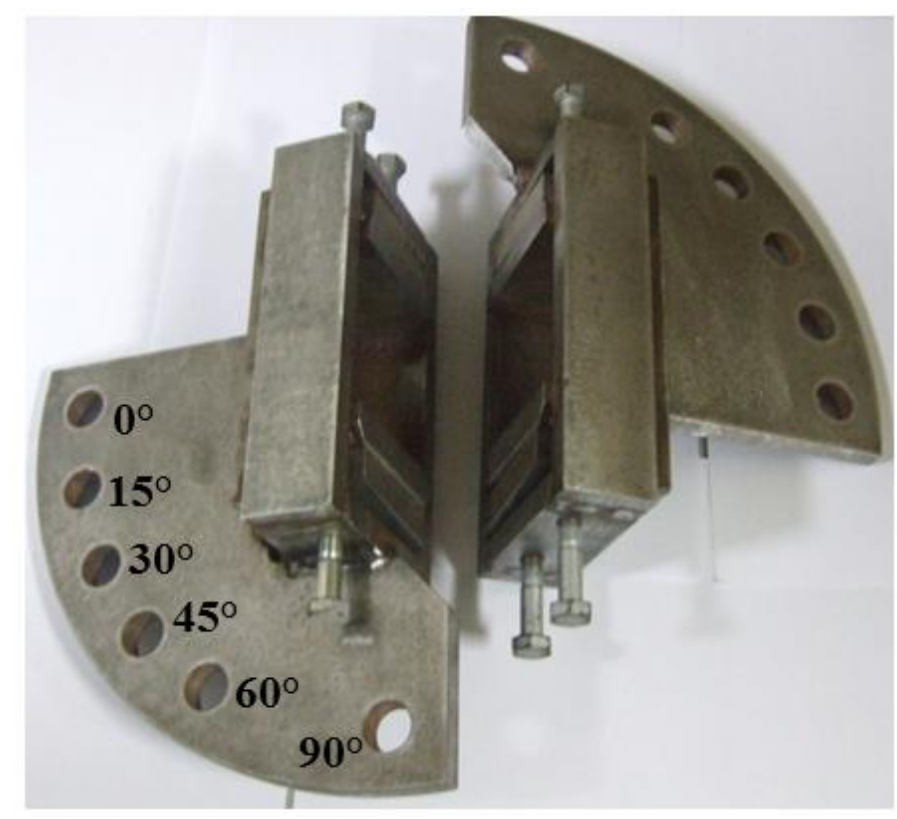

Figura 68 - Fotos do dispositivo de Arcan.

Tabela 10 - Parâmetros utilizados para a UCCF

\begin{tabular}{|c|c|c|c|c|c|c|c|}
\hline União & 1 & $\begin{array}{c}\text { Espessura da } \\
\text { Chapa } 1 \\
\text { (mm) }\end{array}$ & $\begin{array}{c}\text { Espessura da } \\
\text { Chapa } 2 \\
\text { (mm) }\end{array}$ & $\begin{array}{l}\text { Medida } \\
\text { "X" } \\
(\mathrm{mm})\end{array}$ & $\begin{array}{c}\text { Punção } \\
\left(\emptyset_{\mathrm{p}} / \mathrm{L}_{\mathrm{p}}\right) \\
\text { mm }\end{array}$ & $\begin{array}{c}\text { Matriz } \\
\left(\emptyset_{\mathrm{m}} / \mathrm{P}_{\mathrm{m}}\right) \\
\mathrm{mm}\end{array}$ & $\begin{array}{c}\text { Força de } \\
\text { Prensagem } \\
(\mathrm{kN})\end{array}$ \\
\hline 1 & \multirow{2}{*}{$\begin{array}{c}\text { Aço EMS.ME. } 1508 \\
\text { BFF EEP }\end{array}$} & & & 0,45 & $5,6 / 100$ & $8,0 / 1,6$ & 53 \\
\hline 2 & & 1,20 & 1,20 & 0,75 & $5,2 / 100$ & $8,0 / 1,6$ & 51 \\
\hline
\end{tabular}

\subsubsection{Quantidade de amostras}

A quantidade de amostras segue a distribuição mostrada na Tabela 11. A definição do numero de combinações nas análises seguiu o plano de ensaios feito por Kavamura (2007). 
Tabela 11 - Matriz de ensaios de comparação entre UCCF e SPRE

\begin{tabular}{ccccccccc}
\hline $\begin{array}{c}\text { Confirguração } \\
\text { Número }\end{array}$ & Tipo de & União & Espessura & \multicolumn{7}{c}{ Ângulo de Ensaio $\left(^{\circ}\right)$} \\
1 & 1 & 1 & A,B,C & A,B,C & A,B,C & A,B,C & A,B,C & A,B,C \\
2 & 1 & 2 & A,B,C & A,B,C & A,B,C & A,B,C & A,B,C & A,B,C \\
3 & 2 & 1 & A,B,C & A,B,C & A,B,C & A,B,C & A,B,C & A,B,C \\
4 & 2 & 2 & A,B,C & A,B,C & A,B,C & A,B,C & A,B,C & A,B,C \\
\hline
\end{tabular}

Fonte adaptada de: Kavamura (2007)

Para o tipo de união se terá:

$1=\mathrm{UCCF}$

$2=$ SPRE.

Nas espessuras:

$1=0,80 \mathrm{~mm}$

$2=1,20 \mathrm{~mm}$.

A matriz resultou em quatro combinações de corpos de prova com seis configurações de ângulos de ensaios $\left(0^{\circ}, 15^{\circ}, 30^{\circ}, 45^{\circ}, 60^{\circ}\right.$ e $\left.90^{\circ}\right)$. Para cada combinação de corpo de prova e uma configuração de ensaio temos três repetições representadas pelas letras "A", "B" e "C" que foram usadas no ensaio físico, para se certificar que problemas relativos ao processo de junção não foram incluídos na coleta de dados. No total serão 36 ensaios.

\subsubsection{Procedimento para o ensaio de cargas multiaxiais de Arcan}

O ensaio de Arcan permite submeter os corpos de prova a cargas axiais partindo do puro cisalhamento até o puro arrancamento, utilizando uma máquina de tração comum. Os 6 estágios do ensaio podem ser observados na Figura 69.

Foi mantida uma velocidade de $5 \mathrm{~mm} /$ minuto para obedecer o critério de "condição quase estática" recomendado por Lin et al. (2003) e Lee et al. (1998). O ensaio finaliza assim que ocorre a falha da união, que se caracteriza pela diminuição repentina da carga. Logo após 
a falha, os corpos de prova podem separar-se por inteiro ou permanecer ainda unidas por uma junção com ruptura.

$0^{\circ}$
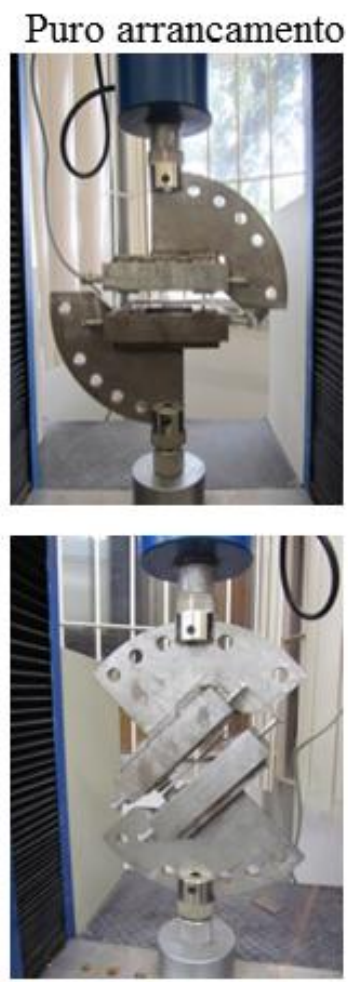

$45^{\circ}$ $15^{\circ}$
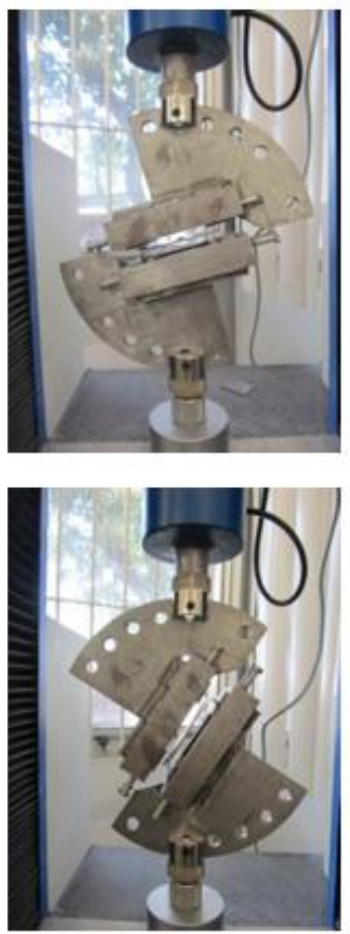

$60^{\circ}$ $30^{\circ}$
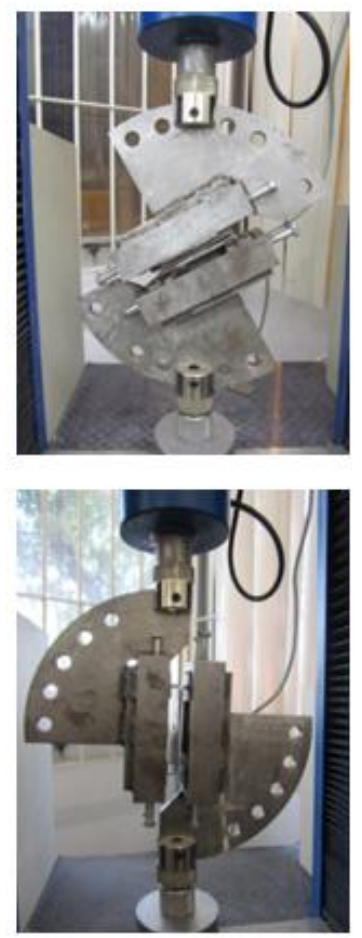

$90^{\circ}$

Puro cisalhamento

Figura 69 - Etapas do ensaio de tração multiaxial

Os corpos de prova devem ser cuidadosamente instalados no dispositivo para evitar danos antes do ensaio. Uma das bases do dispositivo de Arcan deve ser presa a uma morsa, o corpo de prova deve ser instalado entre os mordentes. Um torque de $10 \mathrm{Nm}$ deve ser aplicado em cruz aos quatro parafusos, para que assim seja garantida a condição de fixação. $\mathrm{O}$ resultado dessa primeira etapa pode ser visto na Figura 70a. A base superior deve ser inserida já com os parafusos dos mordentes devidamente soltos de modo a não danificar o corpo de prova. Um pré-troque é inserido nos parafusos superiores apenas para encostar os mordentes no corpo de prova. O dispositivo é rotacionado e a base superior é presa na morsa, conforme Figura 70b. O mesmo torque dados aos parafusos anteriores deve ser dado aos faltantes. 


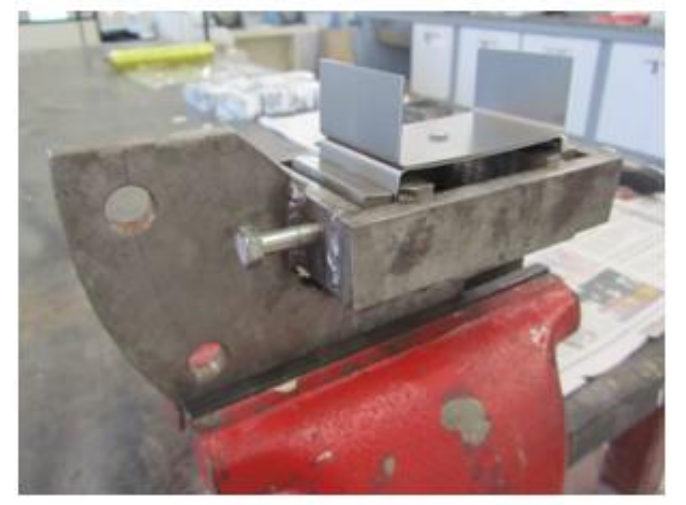

(a)

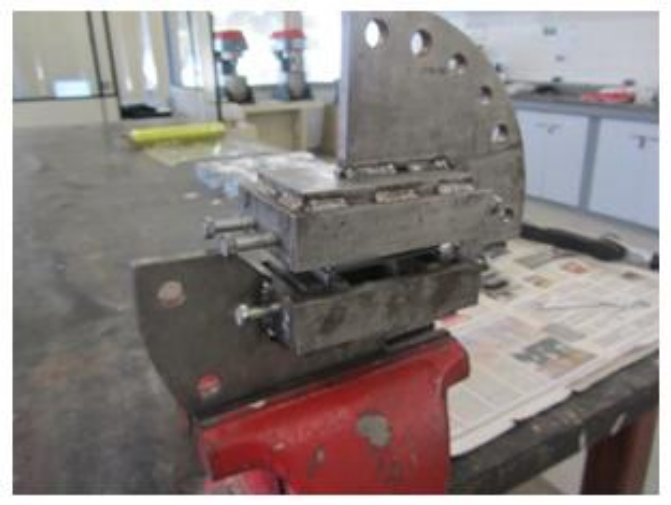

(b)

Figura 70 - Procedimento para fixação do corpo de prova no dispositivo de Arcan 


\section{RESULTADOS E DISCUSSÕES}

\subsection{RESULTADO DO ENSAIO DE ARCAN PARA UCCF}

Os resultados gráficos dos ensaios físicos de Arcan para chapas de 0,80mm e 1,20mm para UCCF são mostrados na Figura 71 e na Figura 72, que, confrontadas com a Figura 23, comprova a importância de se considerar a rigidez da junção, uma função da espessura da chapa e diâmetro do ponto, em cada direção da aplicação das cargas solicitantes. Foram feitas três repetições para cada configuração, porém o gráfico mostra apenas uma das curvas para facilitar a visualização. O relatório com os gráficos dos resultados completos pode ser visto no Apêndice B - Resultados dos ensaios físicos de Arcan. Os valores de cada ensaio podem ser encontrados nas Tabela 12 e Tabela 13. Pode-se notar claramente que a maior carga foi a do ângulo de $90^{\circ}$ (puro cisalhamento). Os valores de resistência foram reduzindo com o incremento das cargas de arrancamento. O comportamento entre as chapas de $0,8 \mathrm{~mm}$ e $1,2 \mathrm{~mm}$ foi muito semelhante, apesar da maior resistência da chapa de $1,2 \mathrm{~mm}$.

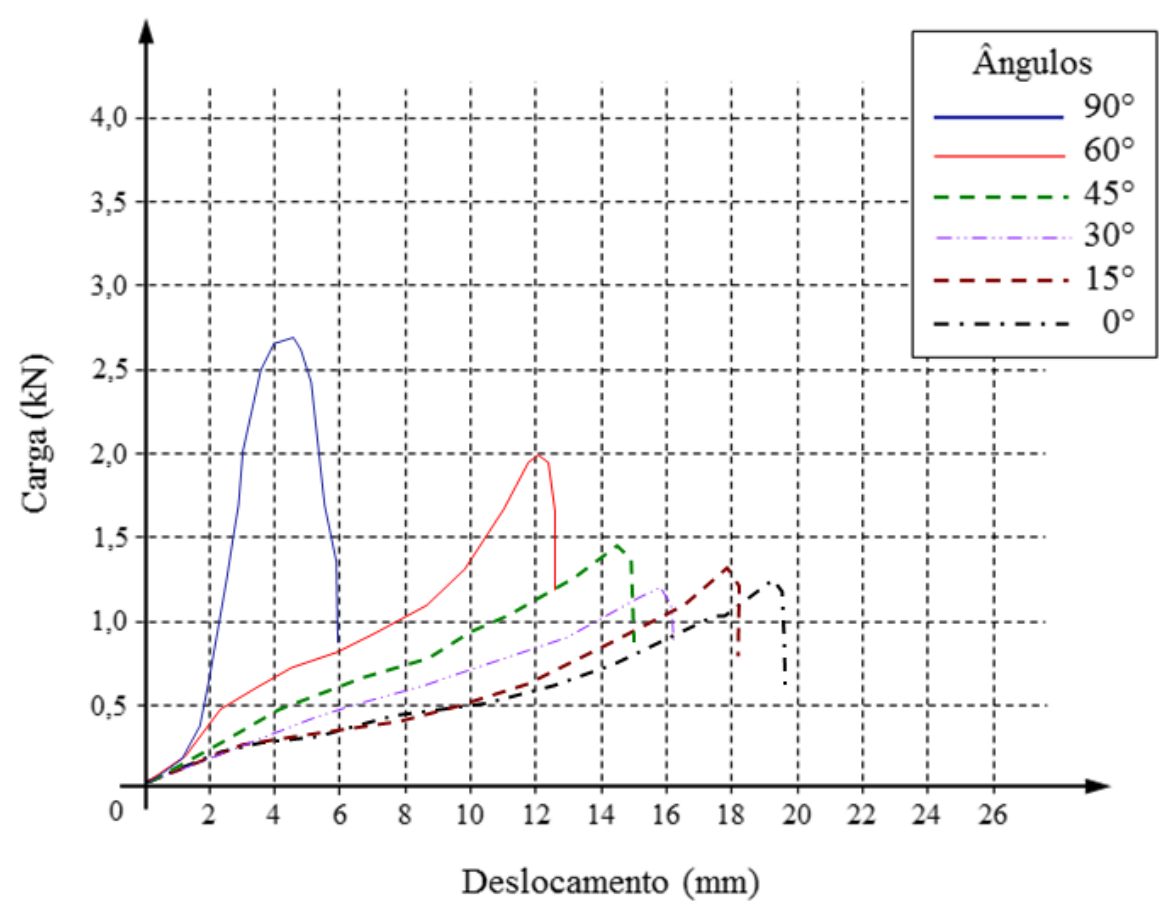

Figura 71 - Resultado do ensaio de Arcan para chapa de 0,8mm unido pelo processo de UCCF 


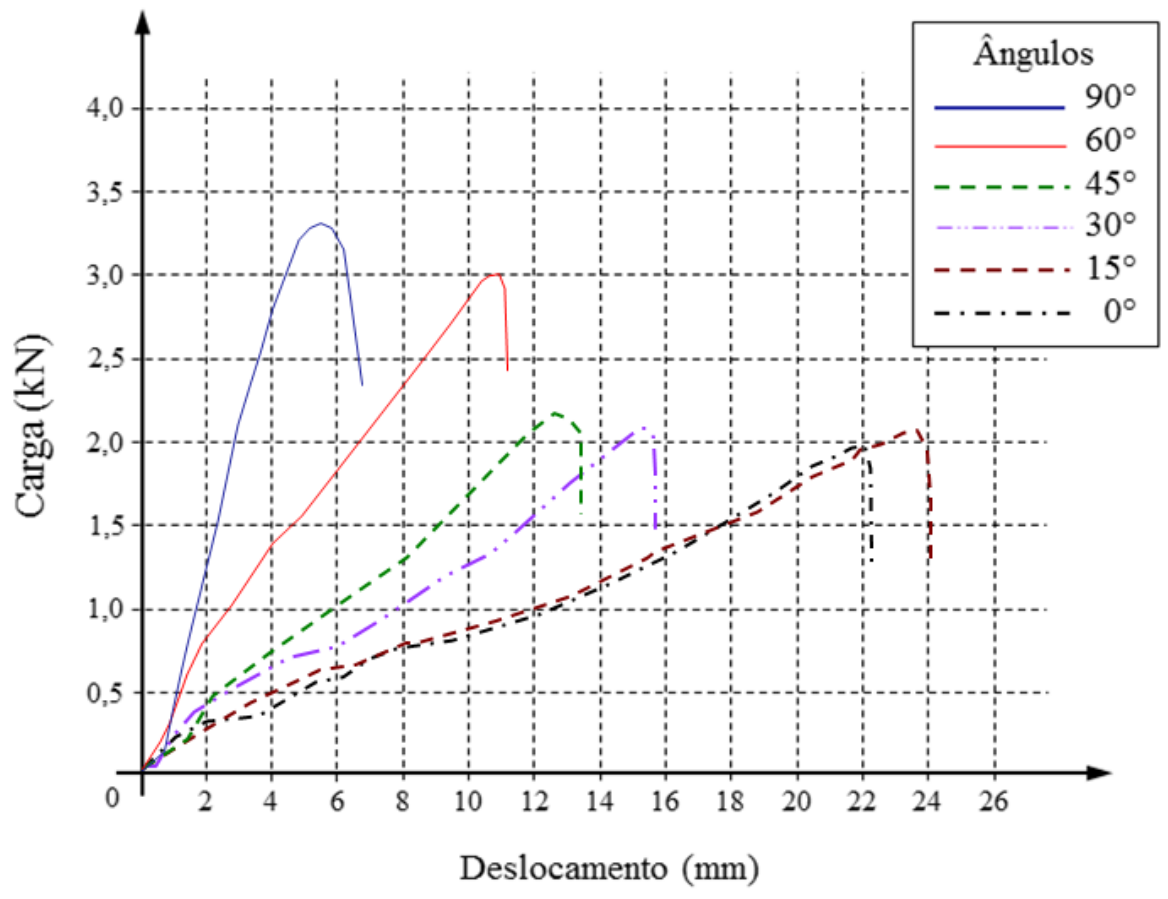

Figura 72 - Resultado do ensaio de Arcan para chapa de 1,2 unido pelo processo de UCCF

Tabela 12 - Valores dos ensaios da Figura 71

\begin{tabular}{ccccccc}
\hline \multicolumn{7}{c}{ UCCF - Chapa de 0,80mm } \\
\hline Ânetição \\
\hline $0^{\circ}$ & 1,08 & 1,13 & 1,18 & 1,13 & 0,05 & $1,13 \pm 0,08$ \\
\hline $15^{\circ}$ & 1,29 & 1,21 & 1,12 & 1,20 & 0,08 & $1,20 \pm 0,14$ \\
\hline $30^{\circ}$ & 1,22 & 1,20 & 1,17 & 1,20 & 0,03 & $1,20 \pm 0,04$ \\
\hline $45^{\circ}$ & 1,20 & 1,48 & 1,25 & 1,31 & 0,15 & $1,31 \pm 0,26$ \\
\hline $60^{\circ}$ & 1,75 & 1,81 & 2,02 & 1,86 & 0,14 & $1,86 \pm 0,23$ \\
\hline $90^{\circ}$ & 2,48 & 2,69 & 2,49 & 2,56 & 0,12 & $2,56 \pm 0,20$ \\
\hline
\end{tabular}

Tabela 13 - Valores dos ensaios da Figura 72

\begin{tabular}{|c|c|c|c|c|c|c|}
\hline \multicolumn{7}{|c|}{ UCCF - Chapa de $1,20 \mathrm{~mm}$} \\
\hline \multicolumn{7}{|c|}{ Repetição } \\
\hline Ângulo & $\begin{array}{c}\mathrm{A} \\
(\mathrm{kN})\end{array}$ & $\begin{array}{c}\text { B } \\
(\mathrm{kN})\end{array}$ & $\begin{array}{c}\mathrm{C} \\
(\mathrm{kN})\end{array}$ & $\begin{array}{c}\text { Média } \\
(\mathrm{kN})\end{array}$ & $\begin{array}{c}\text { Desvio } \\
\text { Padrão } \\
(\mathrm{mm})\end{array}$ & $\begin{array}{c}\text { Correção } \\
\text { (t-student 95\%) } \\
\text { (N) }\end{array}$ \\
\hline $0^{\circ}$ & 1,95 & 1,89 & 1,84 & 1,89 & 0,05 & $1,89 \pm 0,09$ \\
\hline $15^{\circ}$ & 2,04 & 1,91 & 1,92 & 1,96 & 0,07 & $1,96 \pm 0,12$ \\
\hline $30^{\circ}$ & 1,96 & 1,71 & 1,76 & 1,81 & 0,13 & $1,81 \pm 0,22$ \\
\hline $45^{\circ}$ & 1,86 & 1,98 & 2,06 & 1,97 & 0,10 & $1,97 \pm 0,16$ \\
\hline $60^{\circ}$ & 2,67 & 2,60 & 2,89 & 2,72 & 0,15 & $2,72 \pm 0,26$ \\
\hline $90^{\circ}$ & 3,21 & 3,07 & 3,26 & 3,18 & 0,10 & $3,18 \pm 0,16$ \\
\hline
\end{tabular}




\subsubsection{Análise de falha dos corpos de prova}

Observou-se basicamente 3 tipos de falha nos corpos de prova:

A. Cisalhamento da parte interna do ponto sem separação total do corpo de prova (Figura 73). É possível observar que a parte inferior do ponto não sofre danos visíveis.

B. Cisalhamento da parte interna do ponto com separação total do corpo de prova (Figura 74). Neste caso ocorreu o cisalhamento e o destacamento do ponto. Houve uma pequena deformação na parte inferior do ponto.

C. Destacamento do ponto sem cisalhamento (Figura 75). O ponto é deformado plasticamente e ranhuras são formadas ao redor da parte interna do ponto devido aos esforços de atrito envolvidos durante o processo de separação.

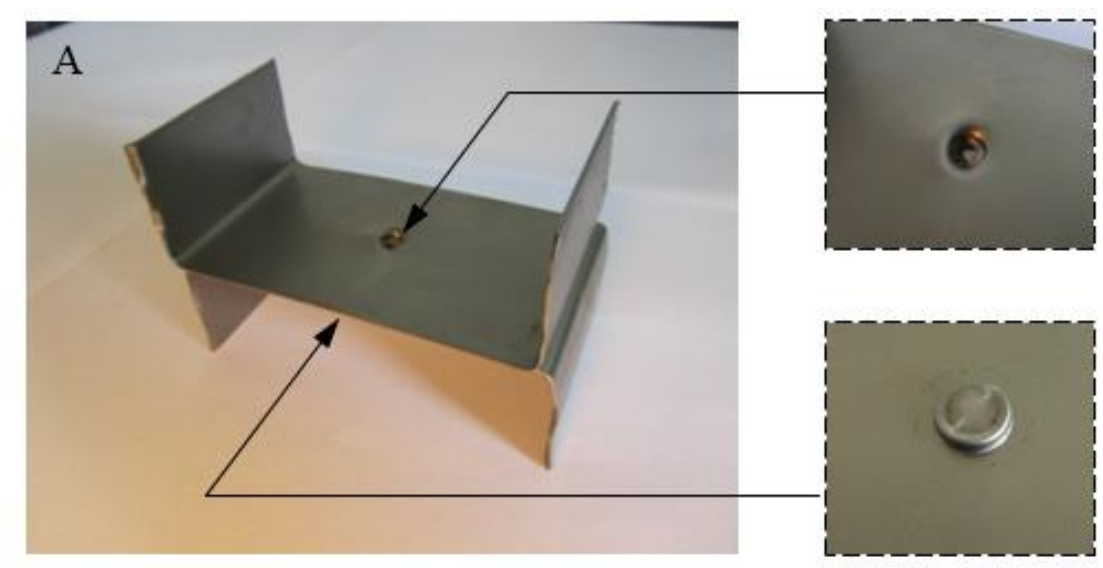

Figura 73 - Cisalhamento da parte interna do ponto sem separação total do corpo de prova

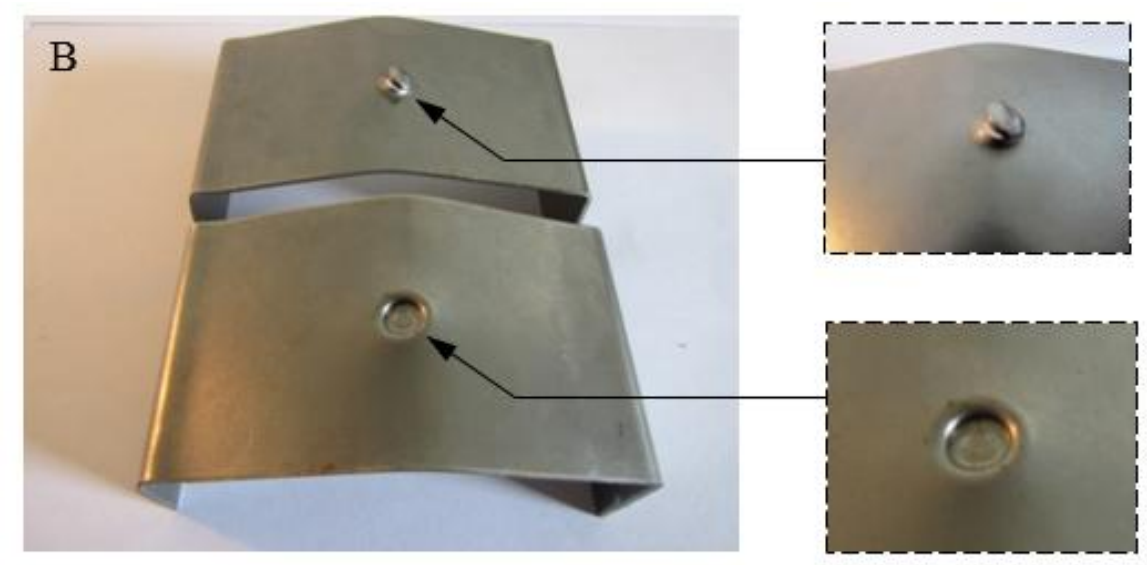

Figura 74 - Cisalhamento da parte interna do ponto com separação total do corpo de prova 


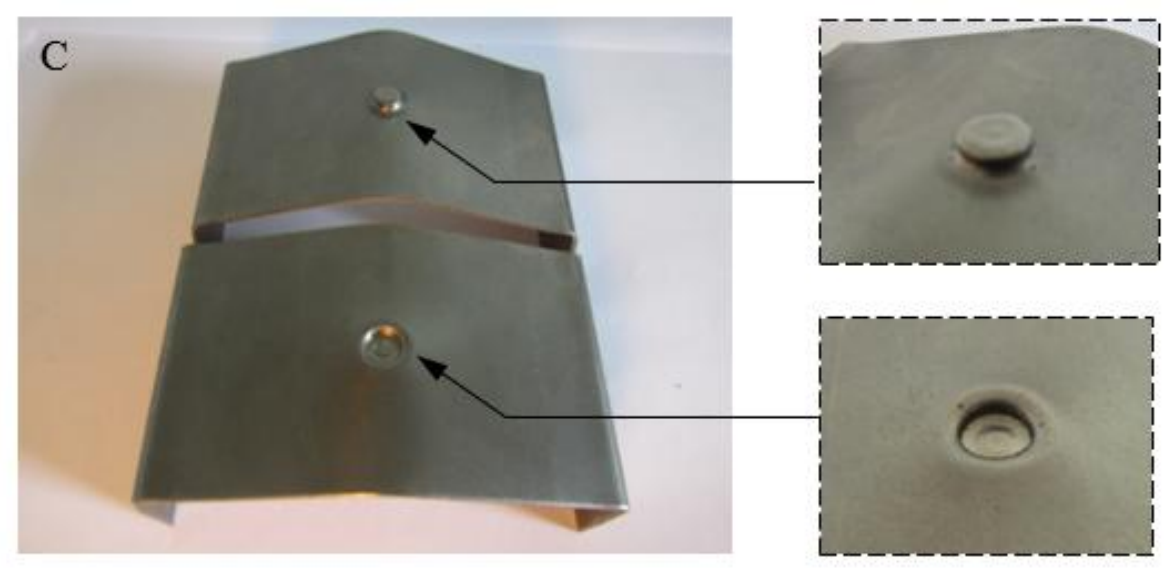

Figura 75 - Destacamento do ponto sem cisalhamento

É possível estabelecer uma relação entre a configuração da carga da união e o modo de falha (Figura 76). O cisalhamento do ponto (falhas A e B) ocorreu nas configurações angulares de ensaio onde a carga de cisalhamento foi predominante (ângulos de $60^{\circ}$ e $90^{\circ}$ ). A direção da carga para condição de ângulo de $90^{\circ}$ pode ser observada na Figura 77a.

$\mathrm{O}$ destacamento do ponto (falha $\mathrm{C}$ ) ocorreu para as configurações angulares entre $0^{\circ} \mathrm{e}$ $45^{\circ}$. A direção da carga de arrancamento puro $\left(0^{\circ}\right)$ está representada na Figura $77 \mathrm{~b}$.

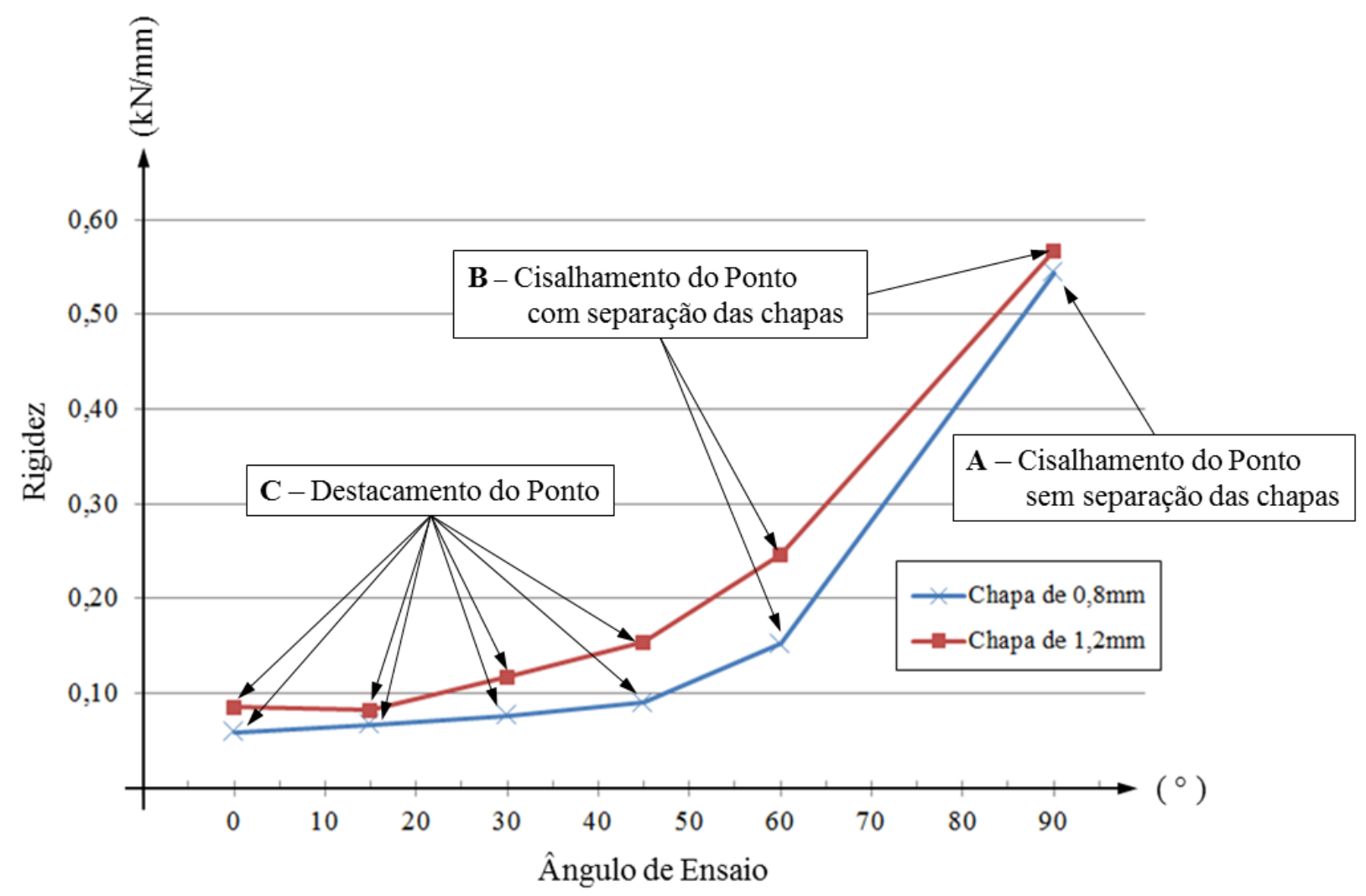

Figura 76 - Rigidez do ponto em diferentes configurações angulares de ensaio 
A explicação para os valores de resistência e rigidez do ponto serem maiores nas configurações onde a carga de cisalhamento é predominante, também pode ser encontrada na Figura 77. Em uma análise simplificada, nota-se que no caso (a), para ocorrer a falha, a tensão na região do pescoço deve chegar à ruptura. No caso (b), até mesmo a deformação elástica do ponto pode permitir o deslizamento e a separação das chapas. Tal análise serve de base para compreensão das cargas obtidas nos ensaios anteriores.

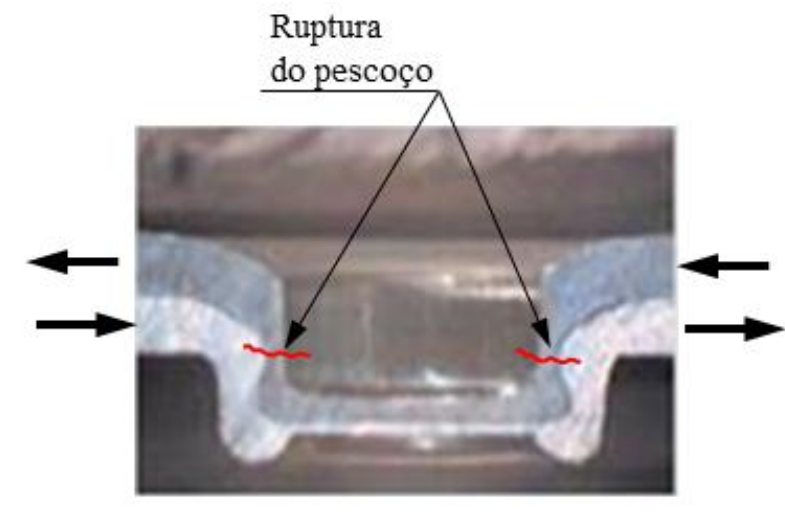

(a)

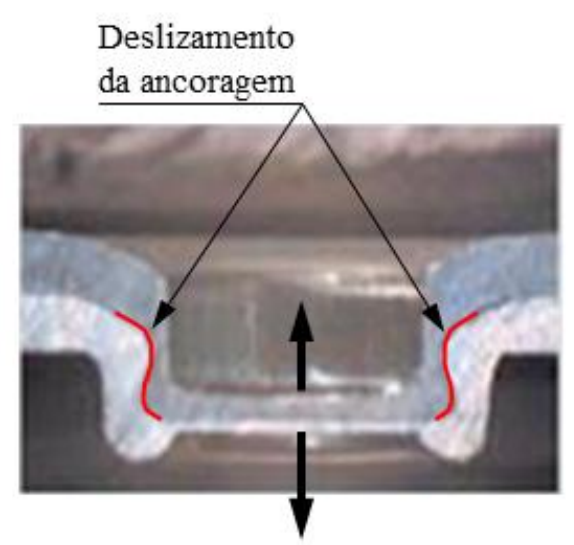

(b)

Figura 77 - Relação do tipo de falha com a configuração da carga na UCCF (TOX, 2011a - Modificado)

\subsection{ANÁLISE COMPARATIVA DA RESISTÊNCIA MECÂNICA DA UCCF VERSUS SPRE}

\subsubsection{Condições gerais de ensaio realizado para SPRE}

O corpo de prova utilizado por Kavamura (2007) segue o mesmo padrão do utilizado para os ensaios de UCCF (Figura 66). O material utilizado é o Aço comum EMS.ME.1508 BFF EEP (EMS.ME.1508, 1996), sem revestimento, utilizado na indústria automotiva, com as espessuras de $0,80 \mathrm{~mm}$ e $1,20 \mathrm{~mm}$. A especificação completa do material pode ser visto no Anexo B.

Para SPRE foi utilizada uma MSPP tipo “C”, ver Figura 78, instalada em um TSP Roman de 170 kVA de potência. A Tabela 14 mostra os parâmetros utilizados na SPRE. 

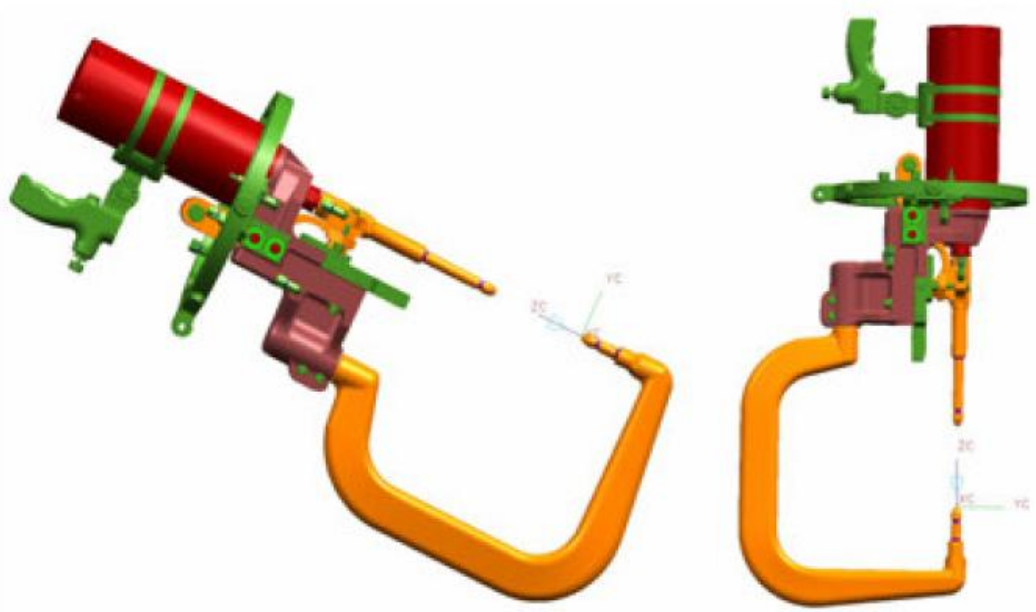

Figura 78 - MSPP tipo "C" (RUIZ, 2005)

Tabela 14 - Parâmetros da SPRE

\begin{tabular}{ccccccccc}
\hline $\begin{array}{c}\text { Corpo de } \\
\text { Prova } \\
(\mathrm{mm})\end{array}$ & $\begin{array}{c}\text { Corrente } \\
(\mathrm{kA})\end{array}$ & $\begin{array}{c}\text { Tempo } \\
(\mathrm{ms})\end{array}$ & $\begin{array}{c}\text { Corrente } \\
(\mathrm{kA})\end{array}$ & $\begin{array}{c}\text { Tempo } \\
(\mathrm{ms})\end{array}$ & $\begin{array}{c}\text { Corrente } \\
(\mathrm{kA})\end{array}$ & $\begin{array}{c}\text { Tempo } \\
(\mathrm{ms})\end{array}$ & Retenção & $\begin{array}{c}\text { Força dos } \\
\text { Eletrodos } \\
(\mathrm{kN})\end{array}$ \\
\hline 0,80 & 2,90 & 20 & 8,70 & 161 & 0 & 0 & 133 & 2,3 \\
1,20 & 3,00 & 20 & 9,00 & 220 & 0 & 0 & 167 & 2,3 \\
\hline
\end{tabular}

Fonte: Kavamura (2007)

\subsubsection{Resultados obtidos para a SPRE}

Os resultados gráficos dos ensaios físicos de Arcan para chapas de 0,80mm e 1,20mm para SPRE são mostrados na Figura 79, comparando-se os diferentes ângulos de ensaio. Foram feitas três repetições para cada configuração, porém o gráfico mostra apenas uma das curvas para facilitar a visualização. Os valores de cada ensaio podem ser encontrados no Anexo D. 


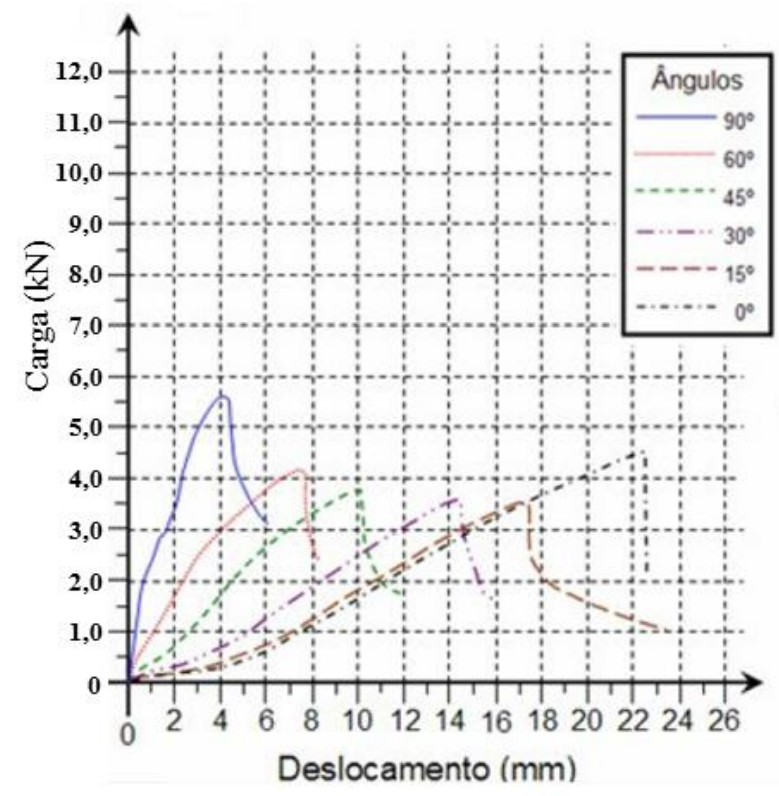

(a)

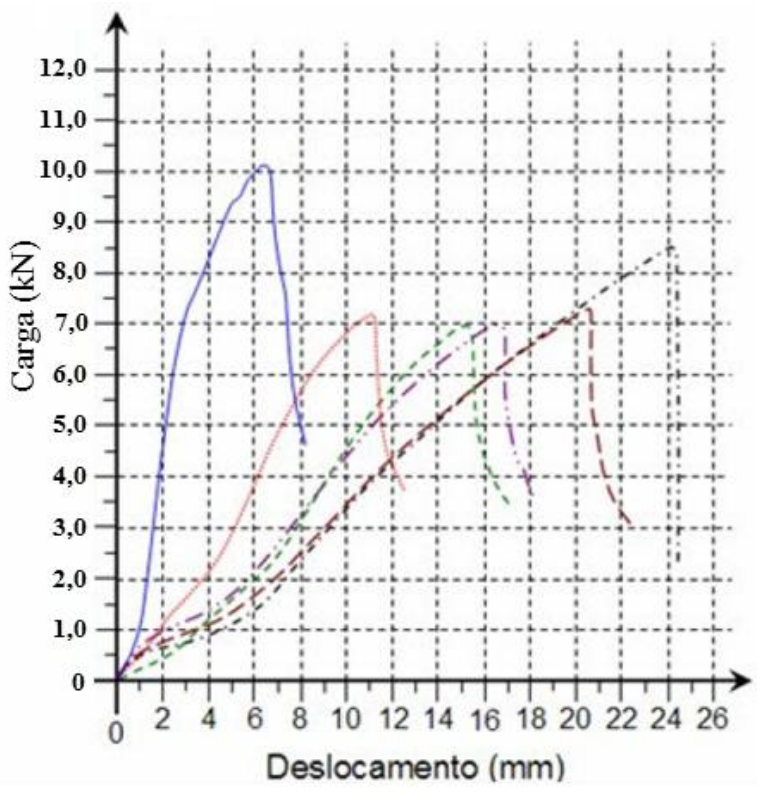

(b)

Figura 79- Comparação dos resultados das diferentes configurações angulares em relação à espessura e tipo de processo de solda: (a) SPRE espessura 0,80 mm (b) SPRE espessura 1,20 mm (KAVAMURA, 2007)

\subsubsection{Comparação dos Resultados}

As curvas obtidas anteriormente para a UCCF foram transferidas para uma escala vertical de 0 a $12,0 \mathrm{kN}$ para permitir a comparação gráfica de resistência entre as duas tecnologias (Figura 80).

As chapas unidas pelo processo de conformação a frio apresentaram menor resistência tanto ao esforço de cisalhamento quanto arrancamento. Os valores médios de carga máxima dos corpos de prova para os dois ensaios são mostrados na Tabela 15. 


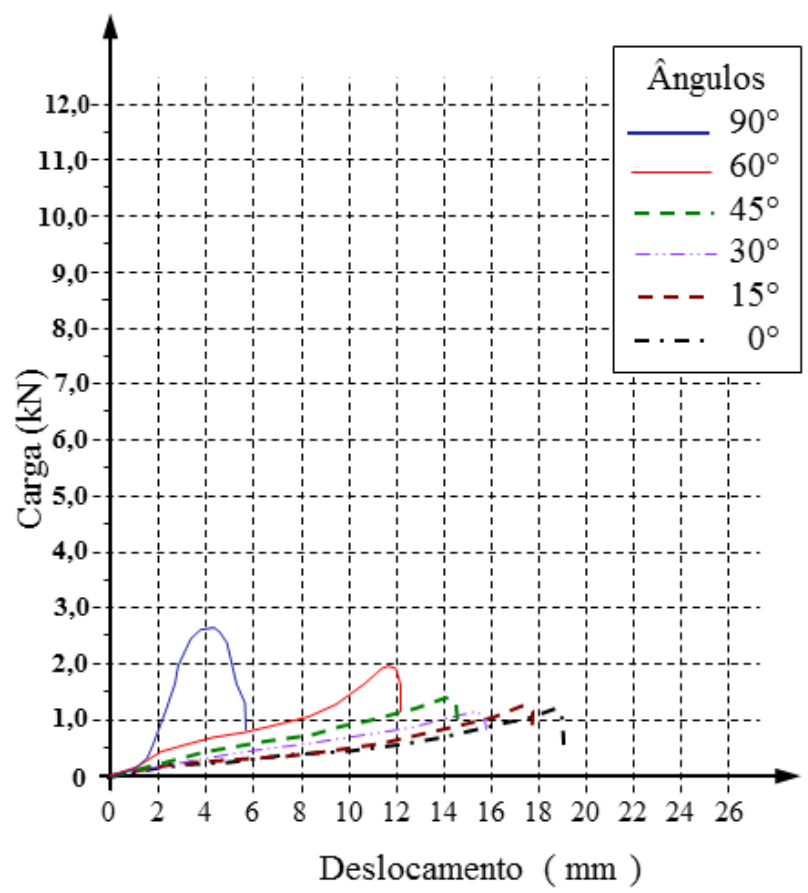

(a)

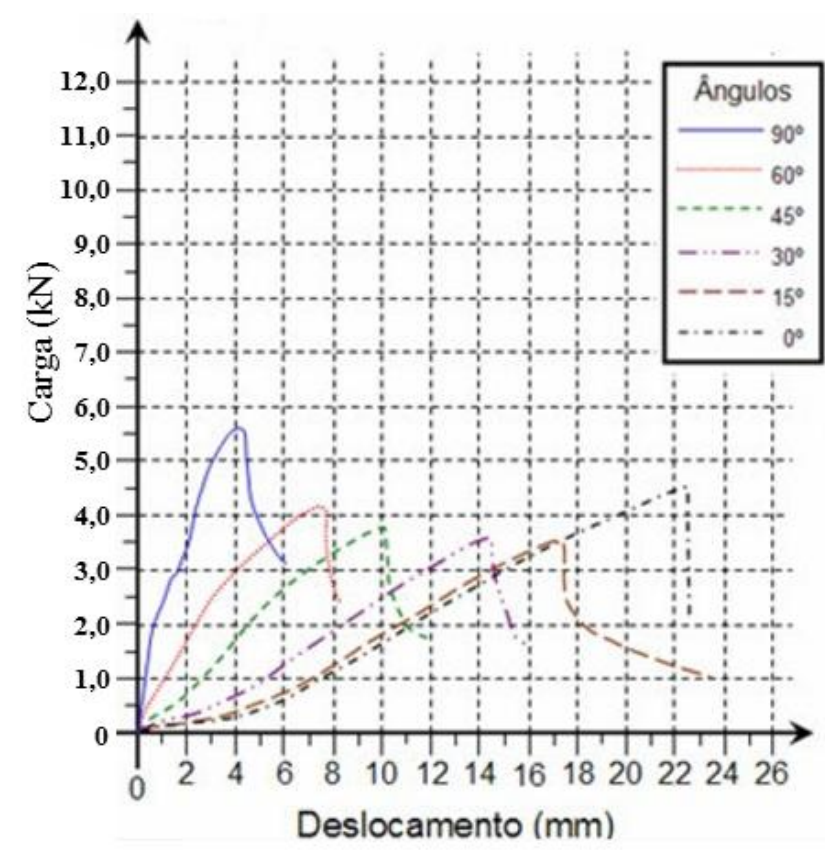

(c)

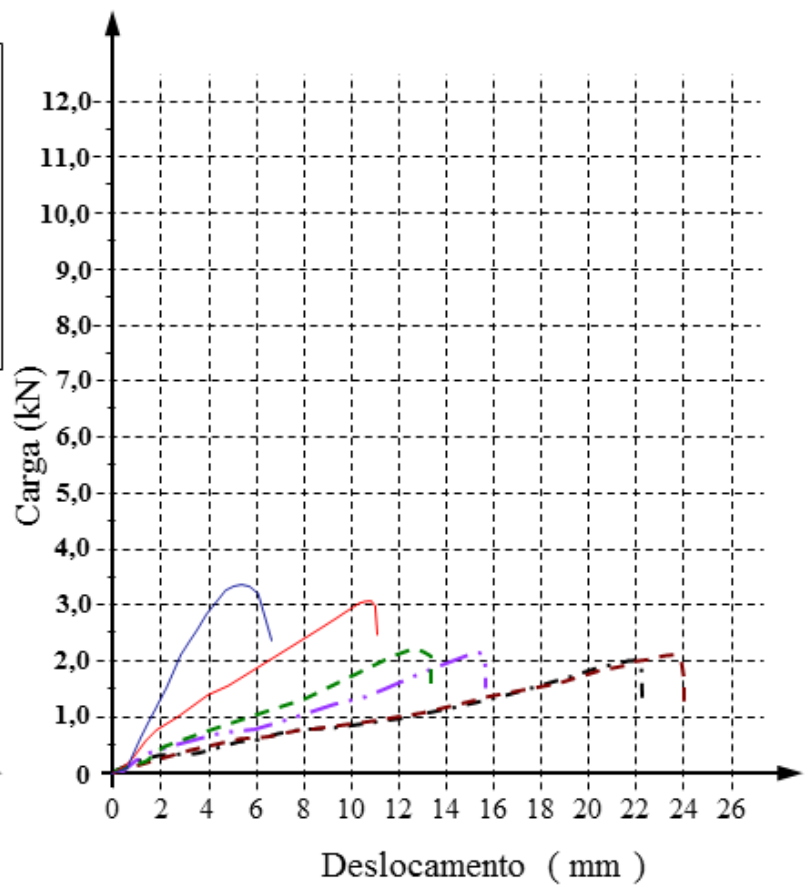

(b)

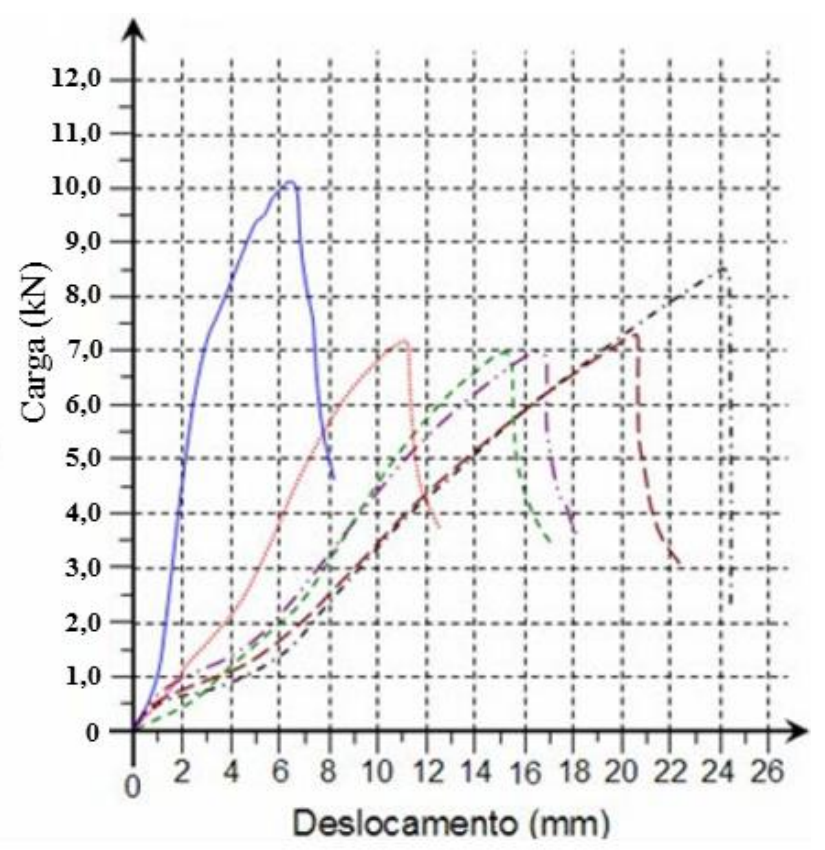

(d)

Figura 80 - Comparação dos resultados das diferentes configurações angulares em relação à espessura e tipo de processo de união: (a)UCCF espessura 0,8mm; (b) UCCF espessura 1,2mm; (c) SPRE espessura 0,8mm;

(d) SPRE espessura $1,2 \mathrm{~mm}$ 
Tabela 15 - Valores médios de carga máxima das diferentes configurações angulares em relação à espessura e tipo de união

\begin{tabular}{|c|c|c|c|c|}
\hline & \multicolumn{2}{|c|}{$\mathrm{UCCF}$} & \multicolumn{2}{|c|}{ SPRE } \\
\hline & Chapa de $0,8 \mathrm{~mm}$ & Chapa de $1,2 \mathrm{~mm}$ & Chapa de $0,8 \mathrm{~mm}$ & Chapa de $1,2 \mathrm{~mm}$ \\
\hline Ângulo & $\begin{array}{c}\text { Força de } \\
\text { Ruptura } \\
(\mathrm{kN})\end{array}$ & $\begin{array}{c}\text { Força de } \\
\text { Ruptura } \\
(\mathrm{kN})\end{array}$ & $\begin{array}{c}\text { Força de } \\
\text { Ruptura } \\
(\mathrm{kN})\end{array}$ & $\begin{array}{c}\text { Força de } \\
\text { Ruptura } \\
(\mathrm{kN})\end{array}$ \\
\hline $0^{\circ}$ & 1,13 & 1,89 & 4,50 & 8,29 \\
\hline $15^{\circ}$ & 1,20 & 1,96 & 3,82 & 7,39 \\
\hline $30^{\circ}$ & 1,20 & 1,81 & 3,60 & 6,81 \\
\hline $45^{\circ}$ & 1,31 & 1,97 & 3,72 & 6,78 \\
\hline $60^{\circ}$ & 1,86 & 2,72 & 3,90 & 7,20 \\
\hline $90^{\circ}$ & 2,56 & 3,18 & 5,55 & 10,14 \\
\hline
\end{tabular}

O gráfico em 3D mostrado na Figura 81 facilita a comparação das cargas de ruptura das tecnologias em relação aos ângulos de ensaio e espessura de chapa. Uma parábola pode ser observada na tecnologia SPRE para as cargas de ruptura, sendo mais frágil quando solicitado a $30^{\circ}$ e mais resistente às cargas de cisalhamento $\left(90^{\circ}\right)$.

A tecnologia UCCF também resistiu mais às cargas de cisalhamento, porém a resistência à ruptura seguiu uma tendência mais linear tendo como ponto mínimo as cargas de arrancamento.

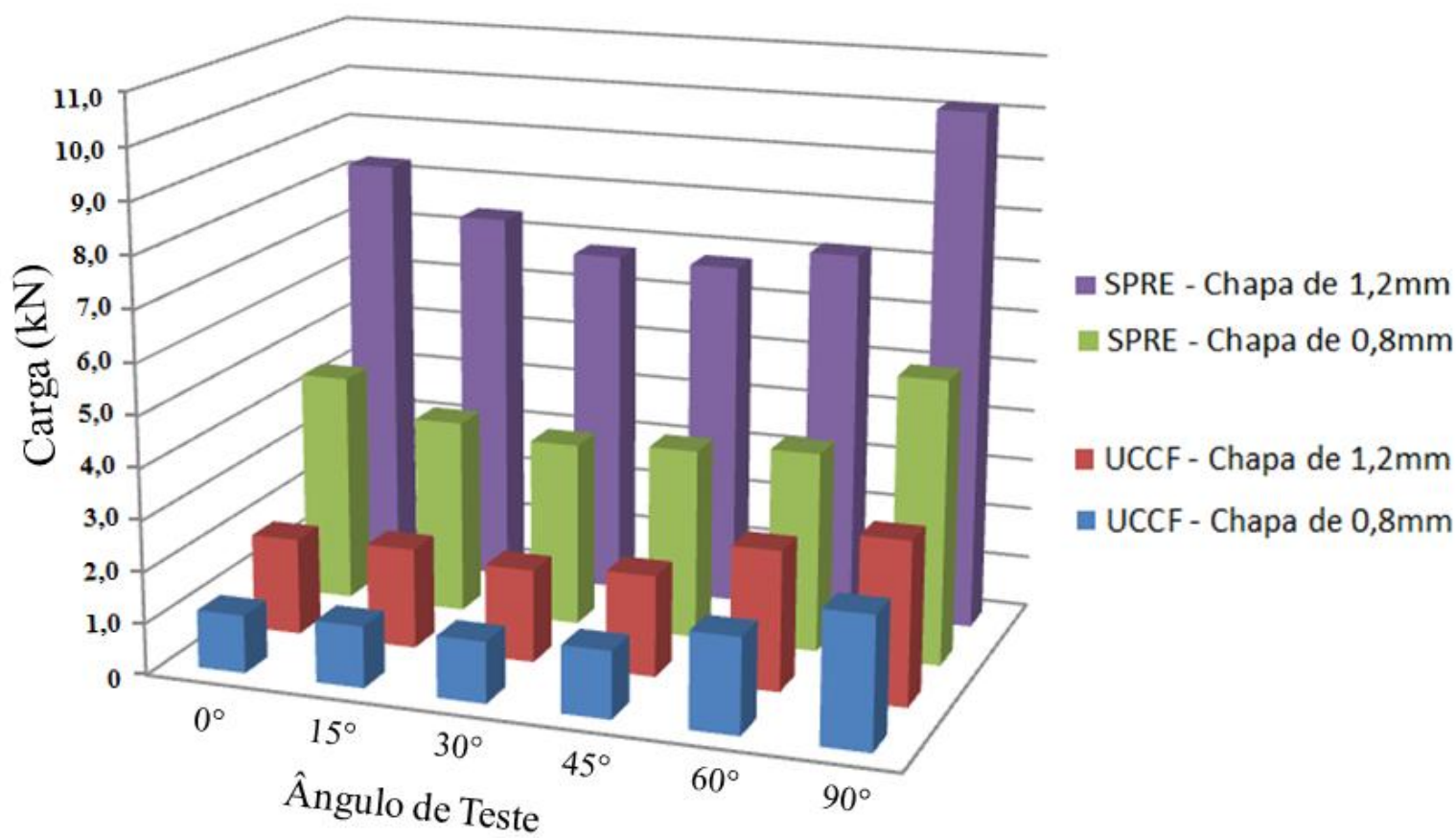

Figura 81 - Comparação dos valores de resistência entre UCCF e SPRE 
$\mathrm{O}$ fator $\mathrm{R}_{\mathrm{R}}$ (Equação 21) foi estabelecido para facilitar a comparação entre as tecnologias, onde $\mathrm{R}_{\mathrm{U}}$ é a força de resistência do corpo de prova unido por UCCF e $\mathrm{R}_{\mathrm{S}}$ unido por solda a ponto. Nota-se, no gráfico da Figura 82, que a resistência da UCCF ao cisalhamento alcançou bons resultados, chegando a 47,68 \% dos valores obtidos para a SPRE para chapa com espessura de $0,8 \mathrm{~mm}$ e $37,78 \%$ para chapas de $1,2 \mathrm{~mm}$.

$R_{R}=\frac{R_{U}}{R_{S}} \times 100$

Os menores valores do fator $\mathrm{R}_{\mathrm{R}}$ foram observados para as cargas de arrancamento. Valores de $25,17 \%$ e $22,84 \%$ foram encontrados para as chapas de $0,8 \mathrm{~mm}$ e $1,2 \mathrm{~mm}$ respectivamente. É importante observar que a valor de $R_{R}$ foi maior para as chapas de $0,8 \mathrm{~mm}$ do que para as chapas de $1,2 \mathrm{~mm}$, apesar dos valores de resistência obtidos para a tecnologia UCCF serem maiores para a chapa de 1,2mm. Uma possível explicação para esse fenômeno é a sensibilidade das chapas mais finas à zona termicamente afetada (ZTA), que é a região da solda em torno do ponto que não se fundiu durante o processo, tendo, como consequência, a microestrutura e propriedades alteradas pelo calor induzido pela soldagem.

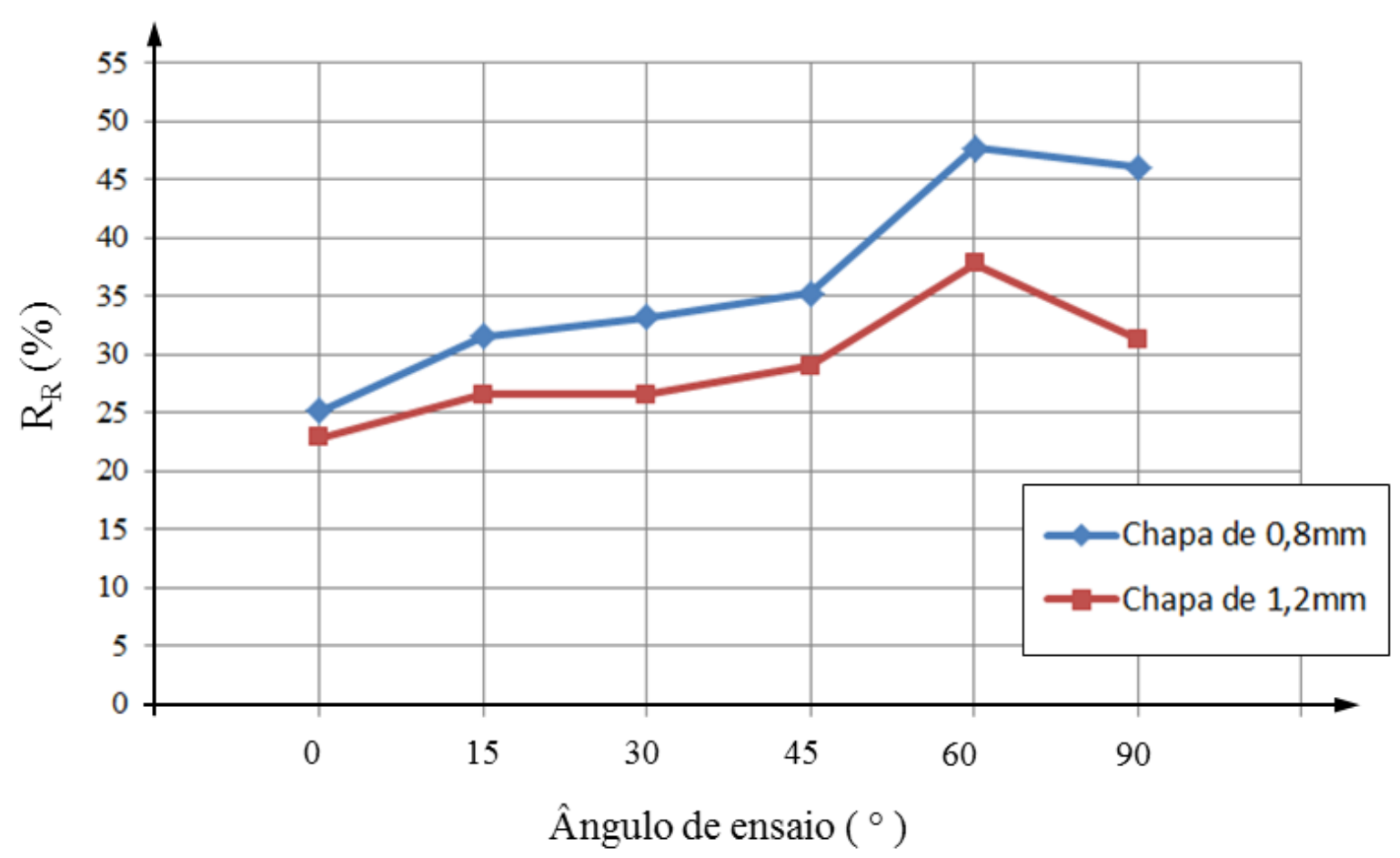

Figura 82 - Relação de resistência entre as tecnologias de UCCF e SPRE em função dos ângulos de ensaio e espessura de chapa. 
A Tabela 16 mostra os valores de $\mathrm{R}_{\mathrm{R}}$ plotados no gráfico da Figura 82.

Tabela 16 - Valores de $\mathrm{R}_{\mathrm{R}}$ utilizados na Figura 82

\begin{tabular}{ccc}
\hline \multicolumn{3}{c}{$\begin{array}{c}\mathrm{R}_{\mathrm{R}}=\text { Relação de Resistência } \\
(\text { UCCF / SPRE ) }\end{array}$} \\
\hline Ângulo & $\begin{array}{c}\text { Chapa de 0,8mm Chapa de } 1,2 \mathrm{~mm} \\
(\%)\end{array}$ \\
\hline $0^{\circ}$ & 25,17 & 22,84 \\
\hline $15^{\circ}$ & 31,55 & 26,52 \\
\hline $30^{\circ}$ & 33,20 & 26,59 \\
\hline $45^{\circ}$ & 35,20 & 29,02 \\
\hline $60^{\circ}$ & 47,68 & 37,78 \\
\hline $90^{\circ}$ & 46,05 & 31,35 \\
\hline
\end{tabular}

Apesar da tecnologia de união a frio apresentar valores menores de resistência quando comparado a SPRE, estudos de substituição são interessantes já que a UCCF possui vantagens tais como: preservação do meio ambiente, melhoria das condições de trabalho para o operador por não emitir gases e faísca, além de não alterar as propriedades químicas da união por não haver troca térmica envolvida no processo. Outros fatores organizacionais devem também ser avaliados na escolha da tecnologia de junção. 


\section{CONCLUSÕES}

O presente trabalho possibilitou as seguintes conclusões:

1. A resistência da junção da chapa confeccionada pelo processo de UCCF varia em função da medida " $X$ " do elemento de união, portanto é um parâmetro que deve ser controlado no processo produtivo para garantir o desempenho do produto fabricado às solicitações consideradas no projeto.

2. Os valores de resistência mecânica encontrados para um único elemento de UCCF foram de $1,13 \mathrm{kN}$ (mínimo) a 2,55kN (máximo) para as chapas de aço com espessura de $0,8 \mathrm{~mm}$ e de $1,89 \mathrm{kN}$ (mínimo) e 3,18kN (máximo) para as chapas de 1,2mm.

3. A resistência da UCCF à carga multiaxial segue uma tendência linear, sendo mais resistente à condição de cisalhamento $\left(90^{\circ}\right)$ e menos resistente ao arrancamento $\left(0^{\circ}\right)$.

4. Os fatores mais importantes no processo de UCCF são: medida "X", espessura das chapas relacionadas à união, propriedades mecânicas do material a ser unido e relação punção/matriz.

5. Em comparação à SPRE, comumente utilizado na indústria, a UCCF, alcançou $47,68 \%$ dos valores de resistência obtidos para a SPRE para chapa com espessura de $0,8 \mathrm{~mm}$ e 37,78\% para chapas de 1,2mm. Logo, a substituição de tecnologia de SPRE por UCCF, em termos de resistência mecânica, é mais conveniente para as chapas de menor espessura. 


\section{TRABALHOS FUTUROS}

1. Uma análise de correlação de resultados utilizando o método de elementos finitos deve ser realizada, sendo assim possível prever, de forma mais rápida e menos onerosa o comportamento de outras junções de diferentes materiais e espessuras.

2. Novos estudos com o ensaio de Arcan devem ser feitos combinando outras espessuras, processos de junções e avaliando os efeitos de diferentes materiais.

3. Estudar os aspectos de mecânica da fratura e fadiga de junções de chapas unidas pelo processo de conformação a frio com cargas multiaxiais. 


\section{REFERÊNCIAS BIBLIOGRÁFICAS}

ALI, M.S. A support system for evaluating a suitable joining method in the production of sheet metal goods. 2005. 95p. Master Thesis - Lappeenranta University of Technology. Lappeenranta, 2005.

BATALHA, G. F. PMR 2202 Introdução a Manufatura Mecânica - Processos de Fabricação: Junção, Soldagem e Brasagem, EPUSP, São Paulo, p. 1-54, 2003. Disponível em: < http://sites.poli.usp.br/d/pmr2202/arquivos/soldagem brasagem.pdf> Acesso em: 15 fev. 2011.

BERTO, R.M.V.S.; NAKANO, D.N. A produção científica nos anais do encontro nacional de engenharia de produção: um levantamento de métodos e tipos de pesquisa. Produção, São Paulo, v. 9, n. 2, p. 65-75, jul. 2000.

BRYMAN, A. Research methods and organization studies. London: Uniwin Hyman Ltd, 1989.

CARBONI, M.; BERETTA, S.; MONNO, M. Fatigue behaviour of tensile-shear loaded clinched joints. Engineering Fracture Mechanics, Milano, v. 73, n. 2, p. 178 - 190, 2006.

CARTER, J.T. Method of friction-assisted clinching. US 2010/0083480 A1. Apr. 8, 2010.

CHAO, Y. J. Ultimate Strength and Failure Mechanism of Resistance Spot Weld Subjected to Tensile, Shear, or Combined Tensile/Shear Loads. Journal of Engineering Materials and Technology, v. 125, p. 125 - 132, Apr. 2003.

COPPIETERS, S.; LAVA, P.; BAES, S.; HOUTTE, V.P.; Debruyne, D. Analytical method to predict the pull-out strength of clinched connections. International Paper. Belgium Research group Mechanics of Materials, Products and Processes. Disponível em: <http://matchid.org/index.php?option=com_content\&view=article\&id=3\&Itemid=4>.

Acesso em 02 fev. 2012.

DEUTSCHES INSTITUT FÜR NORMUNG. DIN 8593-5: Manufacturing processes joining Part 5: Joining by forming processes; Classification, subdivision, terms and definitions. Sept. 2003.

ENGINEERING MATERIAL SPECIFICATION PRODUCT ENGINEERING. EMS.ME.1508: Cold Rolled Carbon Steel Sheets, Coated or Uncoated, for Drawing. GM Brazil, p. 1-28, May 1996. 
FERNANDES, F.C.F. A pesquisa em Gestão da Produção: evolução e tendências. XIX Encontro Nacional de Engenharia de Produção (ENEGEP) e V International Congress of Industrial Engineering (ICIE), Rio de Janeiro, RJ, UFRJ/ABEPRO, nov. 1999. CD-ROM

FILIPPINE, R. Operations management research: some reflections on evolution, models and empirical studies in OM. International Journal of Operations and Production Management, v.17, n.7, p.650-670, 1997.

FREIJE, J.L.P.; JAHN, T.; HEIM, G. The New Opel Meriva. In: EUROCARBODY, $12^{\text {th }}$ Edition. 2010 Bad Nauheim, Germany. Opel - the new Meriva. Disponível em: <http://www.automotive-circle.com/delegates/ecb10/index.cfm?lg=e>. Acesso em: $10 \mathrm{mar}$. 2011. Informação disponível apenas para congressistas.

GAO, S.; BUDDE, L. Mechanism of mechanical press joining. International Journal of Machine Tools and Manufacture. Paderborn: Elsevier Science. v. 34, n. 5, p. 641-657. 1994.

IWU (INSTITUTE WERKZEUGMASKHINEN UMFORMTEKHNIK). Annual Report from Fraunhofer Institute, 2003. Chemnitz, Germany. Technologien für Fahrzeugkomponenten: Joining by forming - an overview. p. 36 - 37. Disponível em:

< http://www.iwu.fraunhofer.de>. Acesso em: 5 set. 2010.

KAVAMURA, H. A. Aplicação de solda laser em carrocerias automotivas: estudo comparativo entre a solda laser e a solda ponto por resistência. 2007. 108p. Dissertação (Mestrado) - Escola Politécnica, Universidade de São Paulo. São Paulo, 2007.

LANGRAND, B.; COMBESCURE, A. Non-linear and failure behavior of spot welds: a "global" finite element and experiment in pure and mixed modes I/II. International Journal of Solids and Structures, p. 6631 - 6646, June 2004.

LEE, Y. L.; WEHNER, T. J.; Lu, M. W.; MORRISETT, T. W.; PAKALNINS, E. Ultimate Strength of Resistance Spot Weld Subject to Combined Tension and Shear. Journal of Testing and Evaluation, v. 26, p. 213 - 219, May 1998.

LIN, S. H.; PAN, J.; TYAN, T.; WUNG, P. Failure loads of spot weld under combined opening and shear static loading conditions. International Journal of Solids and Structures, v. 39, p. 19-39, 2002. 
LIN, S. H.; PAN, J.; TYAN, T.; PRASAD, P. A general failure criteria for spot welds under combined loading conditions. International Journal of Solids and Structures, v. 40, p. 5539-5564, 2003.

MINAYO, M. C. S. O desafio do conhecimento. São Paulo: Hucitec, 1993.

MUCHA, J. The analysis of lock forming mechanism in the clinching joint. Materials and Design v. 32, n. 10, p. 4943-4954, Dec 2011.

PORTER, M. E. Estratégia Competitiva. Ed. Campus, Rio Janeiro, 1991.

RUIZ, D. Contribuição ao Desenvolvimento de Processos de Montagem e Soldagem de Carrocerias Automotivas. 2005. 107p. Dissertação (Mestrado) - Escola Politécnica, Universidade de São Paulo. São Paulo, 2005.

TOX $^{\circledR}$ PRESSOTECHNIK GmbH \& Co. KG, Training TOX - Technology, SU 80.0804.01, p. 1-44, [entre 2000 e 2011].

TOX $^{\circledR}$ PRESSOTECHNIK GmbH \& Co. KG, TOX - Joining-Systems, Brochure, 80.200901.en. p. 1-12, Feb. 2011a. Disponível em: <http://www.toxbr.com/pt/downloads/material-impresso.html> Acesso em: 26 out. 2011.

TOX $^{\circledR}$ PRESSOTECHNIK GmbH \& Co. KG, Overview of the TOX - Clinching Technology, TOX - Joining-Systems, DS 80.100 Clinching Technology, Round Joint tool selection list. p. 2-5, Sept. 2011b. Disponível em: <http://www.tox-br.com/pt/downloads/materialimpresso.html> Acesso em: 26 out. 2011.

VANDENBOSSCHE, D. J. Ultimate strength and failure mode of spotweld in high strength steels. SAE Technical Paper n. 770214, Society of Automotive Engineers, Warrendale, PA, EUA. 1977.

VARIS, J.P. The suitability of round clinching tools for high strength structural steel. International paper. Thin-Walled Structures 2002 v. 40, p. 225-238, 2001.

VARIS, J.P.; LEPISTÖ, J. A simple testing-based procedure and simulation of the clinching process using finite element analysis for establishing clinching parameters. Thin-Walled Struct, 2003. v. 41, n 8, p. 691-709, 2003. 
VARIS, J.P. Ensuring the integrity in clinching process. International paper. Journal of Materials Processing Technology. v. 174, n. 1-3, p. 277-285, 2006.

ZHOU, M.; HU, S. J.; ZHANG, H. Critical Specimen Sizes for Tensile-Shear Testing of Steel Sheets. Welding Research Supplement, p. 305 - 312, Sept. 1999. 


\section{APÊNDICE A}

Valores de resistência de cada corpo de prova no ensaio de cisalhamento e arrancamento para determinação da Medida " $X$ " ideal

\begin{tabular}{|c|c|c|c|c|c|}
\hline \multicolumn{7}{|c|}{ União de Chapas 0,8 x 0,8 - Diâmetro do Ponto: 6mm dos Corpos de Prova } \\
\hline Amostra & $\begin{array}{c}\text { Corpo de Prova } \\
\text { A } \\
(\mathrm{mm})\end{array}$ & $\begin{array}{c}\text { Corpo de Prova } \\
\text { B } \\
(\mathrm{mm})\end{array}$ & $\begin{array}{c}\text { Corpo de Prova } \\
\text { C } \\
(\mathrm{mm})\end{array}$ & $\begin{array}{c}\text { Média } \\
(\mathrm{mm})\end{array}$ & $\begin{array}{c}\text { Desvio Padrão } \\
(\mathrm{mm})\end{array}$ \\
\hline 1 & 0,25 & 0,27 & 0,26 & 0,26 & 0,01 \\
\hline 2 & 0,31 & 0,31 & 0,30 & 0,31 & 0,01 \\
\hline 3 & 0,35 & 0,35 & 0,36 & 0,35 & 0,01 \\
\hline 4 & 0,40 & 0,41 & 0,40 & 0,40 & 0,01 \\
\hline 5 & 0,44 & 0,45 & 0,45 & 0,45 & 0,01 \\
\hline 6 & 0,50 & 0,50 & 0,50 & 0,50 & 0,00 \\
\hline 7 & 0,55 & 0,57 & 0,56 & 0,56 & 0,01 \\
\hline 8 & 0,60 & 0,61 & 0,62 & 0,61 & 0,01 \\
\hline 9 & 0,66 & 0,65 & 0,66 & 0,66 & 0,01 \\
\hline
\end{tabular}

\begin{tabular}{|c|c|c|c|c|c|c|}
\hline \multicolumn{7}{|c|}{ União de Chapas 0,8 x 0,8 - Diâmetro do Ponto: $6 \mathrm{~mm}$} \\
\hline \multicolumn{7}{|c|}{ Ensaio de Cisalhamento } \\
\hline $\begin{array}{l}\text { Medida X } \\
\quad(\mathrm{mm})\end{array}$ & $\begin{array}{c}\text { Força de } \\
\text { Estampagem } \\
(\mathrm{N})\end{array}$ & $\begin{array}{c}\text { Corpo de Prova } \\
\text { A } \\
(\mathrm{N}) \\
\end{array}$ & $\begin{array}{c}\text { Corpo de Prova } \\
\text { B } \\
(\mathrm{N}) \\
\end{array}$ & $\begin{array}{c}\text { Corpo de Prova } \\
\mathrm{C} \\
(\mathrm{N}) \\
\end{array}$ & $\begin{array}{c}\text { Valor Médio de } \\
\text { Resistência } \\
(\mathrm{N}) \\
\end{array}$ & $\begin{array}{l}\text { Desvio Padrão } \\
(\mathrm{mm})\end{array}$ \\
\hline 0,26 & $51.000,00$ & $1.780,90$ & $1.836,40$ & $1.883,30$ & $1.833,53$ & 51,26 \\
\hline 0,31 & $40.000,00$ & $1.988,90$ & $2.106,00$ & $2.006,80$ & $2.033,90$ & 63,08 \\
\hline 0,35 & $34.000,00$ & $2.098,90$ & $2.193,50$ & $2.084,00$ & $2.125,47$ & 59,39 \\
\hline 0,40 & $28.000,00$ & $2.007,70$ & $2.088,20$ & $2.097,30$ & $2.064,40$ & 49,31 \\
\hline 0,45 & $26.000,00$ & $1.990,10$ & $2.040,10$ & $2.110,10$ & $2.046,77$ & 60,28 \\
\hline 0,50 & $23.000,00$ & $1.782,90$ & $1.809,50$ & $1.973,70$ & $1.855,37$ & 103,34 \\
\hline 0,56 & $21.000,00$ & $1.913,10$ & $1.946,60$ & $1.708,60$ & $1.856,10$ & 128,83 \\
\hline 0,61 & $19.000,00$ & $1.580,00$ & $1.598,00$ & $1.800,90$ & $1.659,63$ & 122,67 \\
\hline 0,66 & $17.000,00$ & $1.569,70$ & $1.521,30$ & $1.204,80$ & $1.431,93$ & 198,19 \\
\hline
\end{tabular}

\begin{tabular}{|c|c|c|c|c|c|c|}
\hline \multicolumn{7}{|c|}{ União de Chapas 0,8 x 0,8 - Diâmetro do Ponto: 6mm } \\
\hline $\begin{array}{c}\text { Medida X } \\
(\mathrm{mm})\end{array}$ & $\begin{array}{c}\text { Força de } \\
\text { Estampagem } \\
(\mathrm{N})\end{array}$ & $\begin{array}{c}\text { Corpo de Prova A } \\
(\mathrm{N})\end{array}$ & $\begin{array}{c}\text { Corpo de Prova B } \\
(\mathrm{N})\end{array}$ & $\begin{array}{c}\text { Corpo de Prova C } \\
(\mathrm{N})\end{array}$ & $\begin{array}{c}\text { Valor Médio de } \\
\text { Resistência } \\
(\mathrm{N})\end{array}$ & $\begin{array}{c}\text { Desvio Padrão } \\
(\mathrm{mm})\end{array}$ \\
\hline 0,25 & $51.000,00$ & $1.054,50$ & $1.120,00$ & $1.201,50$ & $1.125,33$ & 73,64 \\
\hline 0,30 & $40.000,00$ & $1.101,00$ & $1.124,60$ & $1.181,00$ & $1.135,53$ & 41,11 \\
\hline 0,35 & $34.000,00$ & $1.145,60$ & $1.123,40$ & $1.156,90$ & $1.141,97$ & 17,04 \\
\hline 0,40 & $28.000,00$ & $1.089,50$ & $1.091,80$ & $1.055,50$ & $1.078,93$ & 20,33 \\
\hline 0,45 & $26.000,00$ & 998,00 & $1.079,90$ & $1.165,30$ & $1.081,07$ & 83,66 \\
\hline 0,50 & $23.000,00$ & $1.039,10$ & $1.126,50$ & 930,40 & $1.032,00$ & 98,24 \\
\hline 0,55 & $21.000,00$ & $1.038,40$ & 905,60 & $1.092,20$ & $1.012,07$ & 96,05 \\
\hline 0,60 & $19.000,00$ & 985,30 & $1.057,50$ & 868,60 & 970,47 & 95,32 \\
\hline 0,66 & $17.000,00$ & 874,40 & 743,50 & 564,90 & 727,60 & 155,36 \\
\hline
\end{tabular}




\begin{tabular}{|c|c|c|c|c|c|}
\hline \multicolumn{7}{|c|}{ União de Chapas 0,8 x 0,8 - Diâmetro do Ponto: 8mm } \\
\hline Amostra & $\begin{array}{c}\text { Corpo de Prova } \\
\text { A } \\
(\mathrm{mm})\end{array}$ & $\begin{array}{c}\text { Corpo de Prova } \\
\text { B } \\
(\mathrm{mm})\end{array}$ & $\begin{array}{c}\text { Corpo de Prova } \\
\text { C } \\
(\mathrm{mm})\end{array}$ & $\begin{array}{c}\text { Média } \\
(\mathrm{mm})\end{array}$ & $\begin{array}{c}\text { Desvio Padrão } \\
(\mathrm{mm})\end{array}$ \\
\hline 1 & 0,35 & 0,35 & 0,35 & 0,35 & 0,00 \\
\hline 2 & 0,40 & 0,41 & 0,42 & 0,41 & 0,01 \\
\hline 3 & 0,46 & 0,46 & 0,45 & 0,46 & 0,01 \\
\hline 4 & 0,50 & 0,50 & 0,50 & 0,50 & 0,00 \\
\hline 5 & 0,54 & 0,54 & 0,54 & 0,54 & 0,00 \\
\hline 6 & 0,60 & 0,60 & 0,61 & 0,60 & 0,01 \\
\hline 7 & 0,63 & 0,65 & 0,65 & 0,64 & 0,01 \\
\hline
\end{tabular}

\begin{tabular}{|c|c|c|c|c|c|c|}
\hline \multicolumn{7}{|c|}{ União de Chapas 0,8 x 0,8 - Diâmetro do Ponto: 8mm } \\
\hline \multicolumn{7}{|c|}{ Ensaio de Cisalhamento } \\
\hline $\begin{array}{c}\text { Medida X } \\
(\mathrm{mm})\end{array}$ & $\begin{array}{c}\text { Força de } \\
\text { Estampagem } \\
(\mathrm{N})\end{array}$ & $\begin{array}{c}\text { Corpo de Prova } \\
\mathrm{A}\end{array}$ & $\begin{array}{c}\text { Corpo de Prova } \\
\mathrm{N})\end{array}$ & $\begin{array}{c}\text { Corpo de Prova } \\
\mathrm{C}\end{array}$ & $\begin{array}{c}\text { Valor Médio de } \\
\text { Resistência } \\
(\mathrm{N})\end{array}$ & $\begin{array}{c}\text { Desvio Padrão } \\
(\mathrm{mm})\end{array}$ \\
\hline 0,35 & $73.000,00$ & $2.201,10$ & $2.108,90$ & $2.279,00$ & $2.196,33$ & 85,15 \\
\hline 0,41 & $69.000,00$ & $2.335,70$ & $2.220,70$ & $2.187,50$ & $2.247,97$ & 77,77 \\
\hline 0,46 & $53.000,00$ & $2.518,70$ & $2.443,30$ & $2.558,50$ & $2.506,83$ & 58,51 \\
\hline 0,50 & $47.000,00$ & $2.654,40$ & $2.570,80$ & $2.691,90$ & $2.639,03$ & 62,00 \\
\hline 0,54 & $44.000,00$ & $2.277,80$ & $2.302,70$ & $2.184,80$ & $2.255,10$ & 62,14 \\
\hline 0,60 & $42.000,00$ & $2.029,80$ & $2.036,50$ & $1.887,50$ & $1.984,60$ & 84,16 \\
\hline 0,65 & $38.000,00$ & $1.930,00$ & $1.910,00$ & $1.733,00$ & $1.857,67$ & 108,43 \\
\hline
\end{tabular}

\begin{tabular}{|c|c|c|c|c|c|c|}
\hline \multicolumn{7}{|c|}{ União de Chapas 0,8 x 0,8 - Diâmetro do Ponto: 8mm } \\
\hline $\begin{array}{c}\text { Medida X } \\
(\mathrm{mm})\end{array}$ & $\begin{array}{c}\text { Força de } \\
\text { Estampagem } \\
(\mathrm{N})\end{array}$ & $\begin{array}{c}\text { Corpo de Prova A } \\
(\mathrm{N})\end{array}$ & $\begin{array}{c}\text { Corpo de Prova B } \\
(\mathrm{N})\end{array}$ & $\begin{array}{c}\text { Corpo de Prova C C } \\
(\mathrm{N})\end{array}$ & $\begin{array}{c}\text { Valor Médio de } \\
\text { Resistência } \\
(\mathrm{N})\end{array}$ & $\begin{array}{c}\text { Desvio Padrão } \\
(\mathrm{mm})\end{array}$ \\
\hline 0,35 & $73.000,00$ & $1.611,70$ & $1.503,20$ & $1.587,90$ & $1.567,60$ & 57,03 \\
\hline 0,41 & $69.000,00$ & $1.601,80$ & $1.548,80$ & $1.559,90$ & $1.570,17$ & 27,95 \\
\hline 0,46 & $53.000,00$ & $1.536,20$ & $1.643,40$ & $1.655,50$ & $1.611,70$ & 65,66 \\
\hline 0,50 & $47.000,00$ & $1.509,90$ & $1.659,90$ & $1.488,80$ & $1.552,87$ & 93,29 \\
\hline 0,54 & $44.000,00$ & $1.419,70$ & $1.339,30$ & $1.543,40$ & $1.434,13$ & 102,81 \\
\hline 0,60 & $42.000,00$ & $1.402,70$ & $1.385,90$ & $1.216,10$ & $1.334,90$ & 103,23 \\
\hline 0,65 & $38.000,00$ & $1.101,00$ & $1.103,00$ & 898,00 & $1.034,00$ & 117,78 \\
\hline
\end{tabular}




\begin{tabular}{|c|c|c|c|c|c|}
\hline \multicolumn{7}{|c|}{ União de Chapas 1,2 x 1,2 - Diâmetro do Ponto: 6mm } \\
\hline Amostra ḑão dos Corpos de Prova \\
\hline & $\begin{array}{c}\text { Corpo de Prova } \\
\text { A } \\
(\mathrm{mm})\end{array}$ & $\begin{array}{c}\text { Corpo de Prova } \\
\text { B } \\
(\mathrm{mm})\end{array}$ & $\begin{array}{c}\text { Corpo de Prova } \\
\text { C } \\
(\mathrm{mm})\end{array}$ & $\begin{array}{c}\text { Média } \\
(\mathrm{mm})\end{array}$ & $\begin{array}{c}\text { Desvio Padrão } \\
(\mathrm{mm})\end{array}$ \\
\hline 1 & 0,45 & 0,44 & 0,44 & 0,44 & 0,01 \\
\hline 2 & 0,50 & 0,51 & 0,49 & 0,50 & 0,01 \\
\hline 3 & 0,55 & 0,54 & 0,54 & 0,54 & 0,01 \\
\hline 4 & 0,60 & 0,61 & 0,60 & 0,60 & 0,01 \\
\hline 5 & 0,65 & 0,66 & 0,66 & 0,66 & 0,01 \\
\hline 6 & 0,70 & 0,69 & 0,69 & 0,69 & 0,01 \\
\hline 7 & 0,75 & 0,75 & 0,75 & 0,75 & 0,00 \\
\hline
\end{tabular}

\begin{tabular}{|c|c|c|c|c|c|c|}
\hline \multicolumn{7}{|c|}{ União de Chapas 1,2 x 1,2 - Diâmetro do Ponto: 6mm } \\
\hline \multicolumn{7}{|c|}{ Ensaio de Cisalhamento } \\
\hline $\begin{array}{c}\text { Medida X } \\
(\mathrm{mm})\end{array}$ & $\begin{array}{c}\text { Força de } \\
\text { Estampagem } \\
(\mathrm{N})\end{array}$ & $\begin{array}{c}\text { Corpo de Prova } \\
\mathrm{A}\end{array}$ & $\begin{array}{c}\text { Corpo de Prova } \\
\mathrm{N})\end{array}$ & $\begin{array}{c}\text { Corpo de Prova } \\
\mathrm{C}\end{array}$ & $\begin{array}{c}\text { Valor Médio de } \\
\text { Resistência } \\
(\mathrm{N})\end{array}$ & $\begin{array}{c}\text { Desvio Padrão } \\
(\mathrm{mm})\end{array}$ \\
\hline 0,44 & $47.000,00$ & $2.523,00$ & $2.317,00$ & $2.448,00$ & $2.429,33$ & 104,26 \\
\hline 0,50 & $44.000,00$ & $2.469,00$ & $2.411,00$ & $2.356,00$ & $2.412,00$ & 56,51 \\
\hline 0,54 & $42.000,00$ & $2.392,00$ & $2.350,00$ & $2.490,00$ & $2.410,67$ & 71,84 \\
\hline 0,60 & $39.000,00$ & $2.405,00$ & $2.390,00$ & $2.428,00$ & $2.407,67$ & 19,14 \\
\hline 0,66 & $32.000,00$ & $2.309,00$ & $2.437,00$ & $2.350,00$ & $2.365,33$ & 65,36 \\
\hline 0,69 & $29.000,00$ & $2.319,00$ & $2.225,00$ & $2.470,00$ & $2.338,00$ & 123,60 \\
\hline 0,75 & $22.000,00$ & $1.980,00$ & $2.032,00$ & $1.715,00$ & $1.909,00$ & 170,01 \\
\hline
\end{tabular}

\begin{tabular}{|c|c|c|c|c|c|c|}
\hline \multicolumn{7}{|c|}{ União de Chapas 1,2 x 1,2 - Diâmetro do Ponto: 6mm } \\
\hline \multicolumn{7}{|c|}{ Ensaio de Destacamento } \\
\hline $\begin{array}{c}\text { Medida X } \\
(\mathrm{mm})\end{array}$ & $\begin{array}{c}\text { Força de } \\
\text { Estampagem } \\
(\mathrm{N})\end{array}$ & $\begin{array}{c}\text { Corpo de Prova } \\
\mathrm{A}\end{array}$ & $\begin{array}{c}\text { Corpo de Prova } \\
\mathrm{N})\end{array}$ & $\begin{array}{c}\text { Corpo de Prova } \\
\mathrm{C}\end{array}$ & $\begin{array}{c}\text { Valor Médio de } \\
\text { Resistência } \\
(\mathrm{N})\end{array}$ & $\begin{array}{c}\text { Desvio Padrão } \\
(\mathrm{Nm})\end{array}$ \\
\hline 0,44 & $47.000,00$ & $2.040,00$ & $2.109,00$ & $1.925,00$ & $2.024,67$ & 92,95 \\
\hline 0,50 & $44.000,00$ & $2.080,00$ & $1.962,00$ & $2.115,00$ & $2.052,33$ & 80,16 \\
\hline 0,54 & $42.000,00$ & $1.830,00$ & $1.913,00$ & $1.935,00$ & $1.892,67$ & 55,37 \\
\hline 0,60 & $39.000,00$ & $1.780,00$ & $1.822,00$ & $1.707,00$ & $1.769,67$ & 58,19 \\
\hline 0,66 & $32.000,00$ & $1.693,00$ & $1.899,00$ & $1.785,00$ & $1.792,33$ & 103,20 \\
\hline 0,69 & $29.000,00$ & $1.760,00$ & $1.801,00$ & $1.548,00$ & $1.703,00$ & 135,79 \\
\hline 0,75 & $22.000,00$ & $1.680,00$ & $1.458,00$ & $1.391,00$ & $1.509,67$ & 151,27 \\
\hline
\end{tabular}




\begin{tabular}{|c|c|c|c|c|c|}
\hline \multicolumn{7}{|c|}{ União de Chapas 1,2 x 1,2 - Diâmetro do Ponto: 8mm } \\
\hline Amostra & $\begin{array}{c}\text { Corpo de Prova } \\
\text { A } \\
(\mathrm{mm})\end{array}$ & $\begin{array}{c}\text { Corpo de Prova } \\
\text { B } \\
(\mathrm{mm})\end{array}$ & $\begin{array}{c}\text { Corpo de Prova } \\
\text { C } \\
(\mathrm{mm})\end{array}$ & $\begin{array}{c}\text { Média } \\
(\mathrm{mm})\end{array}$ & $\begin{array}{c}\text { Desvio Padrão } \\
(\mathrm{mm})\end{array}$ \\
\hline 1 & 0,60 & 0,60 & 0,61 & 0,60 & 0,01 \\
\hline 2 & 0,65 & 0,64 & 0,66 & 0,65 & 0,01 \\
\hline 3 & 0,69 & 0,69 & 0,70 & 0,69 & 0,01 \\
\hline 4 & 0,74 & 0,74 & 0,75 & 0,74 & 0,01 \\
\hline 5 & 0,80 & 0,80 & 0,80 & 0,80 & 0,00 \\
\hline 6 & 0,85 & 0,86 & 0,85 & 0,85 & 0,01 \\
\hline 7 & 0,90 & 0,91 & 0,91 & 0,91 & 0,01 \\
\hline 8 & 0,95 & 0,95 & 0,95 & 0,95 & 0,00 \\
\hline
\end{tabular}

\begin{tabular}{|c|c|c|c|c|c|c|}
\hline \multicolumn{7}{|c|}{ União de Chapas 1,2 x 1,2 - Diâmetro do Ponto: 8mm } \\
\hline \multicolumn{7}{|c|}{ Ensaio de Cisalhamento } \\
\hline $\begin{array}{c}\text { Medida X } \\
(\mathrm{mm})\end{array}$ & $\begin{array}{c}\text { Força de } \\
\text { Estampagem } \\
(\mathrm{N})\end{array}$ & $\begin{array}{c}\text { Corpo de Prova } \\
\mathrm{A}\end{array}$ & $\begin{array}{c}\text { Corpo de Prova } \\
\mathrm{N})\end{array}$ & $\begin{array}{c}\text { Corpo de Prova } \\
\mathrm{B}\end{array}$ & $\begin{array}{c}\text { Valor Médio de } \\
\text { Resistência } \\
(\mathrm{N})\end{array}$ & $\begin{array}{c}\text { Desvio Padrão } \\
(\mathrm{mm})\end{array}$ \\
\hline 0,61 & $62.000,00$ & $3.177,00$ & $2.981,20$ & $3.019,20$ & $3.059,13$ & 103,83 \\
\hline 0,65 & $56.000,00$ & $3.102,20$ & $3.126,80$ & $3.041,00$ & $3.090,00$ & 44,18 \\
\hline 0,69 & $53.000,00$ & $3.266,30$ & $3.269,50$ & $3.399,60$ & $3.311,80$ & 76,05 \\
\hline 0,74 & $51.000,00$ & $3.384,40$ & $3.295,20$ & $3.288,70$ & $3.322,77$ & 53,47 \\
\hline 0,80 & $48.000,00$ & $3.199,70$ & $3.220,20$ & $3.335,40$ & $3.251,77$ & 73,15 \\
\hline 0,85 & $46.000,00$ & $3.192,20$ & $3.258,10$ & $3.361,80$ & $3.270,70$ & 85,50 \\
\hline 0,91 & $43.000,00$ & $2.972,20$ & $2.979,80$ & $2.734,40$ & $2.895,47$ & 139,54 \\
\hline 0,95 & $38.000,00$ & $2.925,30$ & $2.770,70$ & $2.574,10$ & $2.756,70$ & 176,02 \\
\hline
\end{tabular}

\begin{tabular}{|c|c|c|c|c|c|c|}
\hline \multicolumn{7}{|c|}{ União de Chapas 1,2 x 1,2 - Diâmetro do Ponto: 8mm } \\
\hline $\begin{array}{c}\text { Medida X } \\
(\mathrm{mm})\end{array}$ & $\begin{array}{c}\text { Força de } \\
\text { Estampagem } \\
(\mathrm{N})\end{array}$ & $\begin{array}{c}\text { Corpo de Prova A A } \\
(\mathrm{N})\end{array}$ & $\begin{array}{c}\text { Corpo de Prova B } \\
(\mathrm{N})\end{array}$ & $\begin{array}{c}\text { Corpo de Prova C } \\
(\mathrm{N})\end{array}$ & $\begin{array}{c}\text { Valor Médio de } \\
\text { Resistência } \\
(\mathrm{N})\end{array}$ & $\begin{array}{c}\text { Desvio Padrão } \\
(\mathrm{mm})\end{array}$ \\
\hline 0,60 & $62.000,00$ & $2.587,40$ & $2.829,80$ & $2.747,60$ & $2.721,60$ & 123,27 \\
\hline 0,65 & $56.000,00$ & $2.774,70$ & $2.700,60$ & $2.719,00$ & $2.731,43$ & 38,58 \\
\hline 0,69 & $53.000,00$ & $2.981,60$ & $2.965,70$ & $3.094,20$ & $3.013,83$ & 70,05 \\
\hline 0,74 & $51.000,00$ & $3.012,40$ & $2.980,00$ & $2.934,70$ & $2.975,70$ & 39,03 \\
\hline 0,80 & $48.000,00$ & $2.714,70$ & $2.891,00$ & $2.846,70$ & $2.817,47$ & 91,71 \\
\hline 0,85 & $46.000,00$ & $2.640,00$ & $2.423,80$ & $2.691,00$ & $2.584,93$ & 141,86 \\
\hline 0,91 & $43.000,00$ & $2.346,10$ & $2.552,50$ & $2.665,40$ & $2.521,33$ & 161,92 \\
\hline 0,95 & $38.000,00$ & $2.185,00$ & $1.977,40$ & $1.790,00$ & $1.984,13$ & 197,59 \\
\hline
\end{tabular}




\section{APÊNDICE B}

Curvas de todos os corpos de prova obtidas no ensaio de Arcan para UCCF.
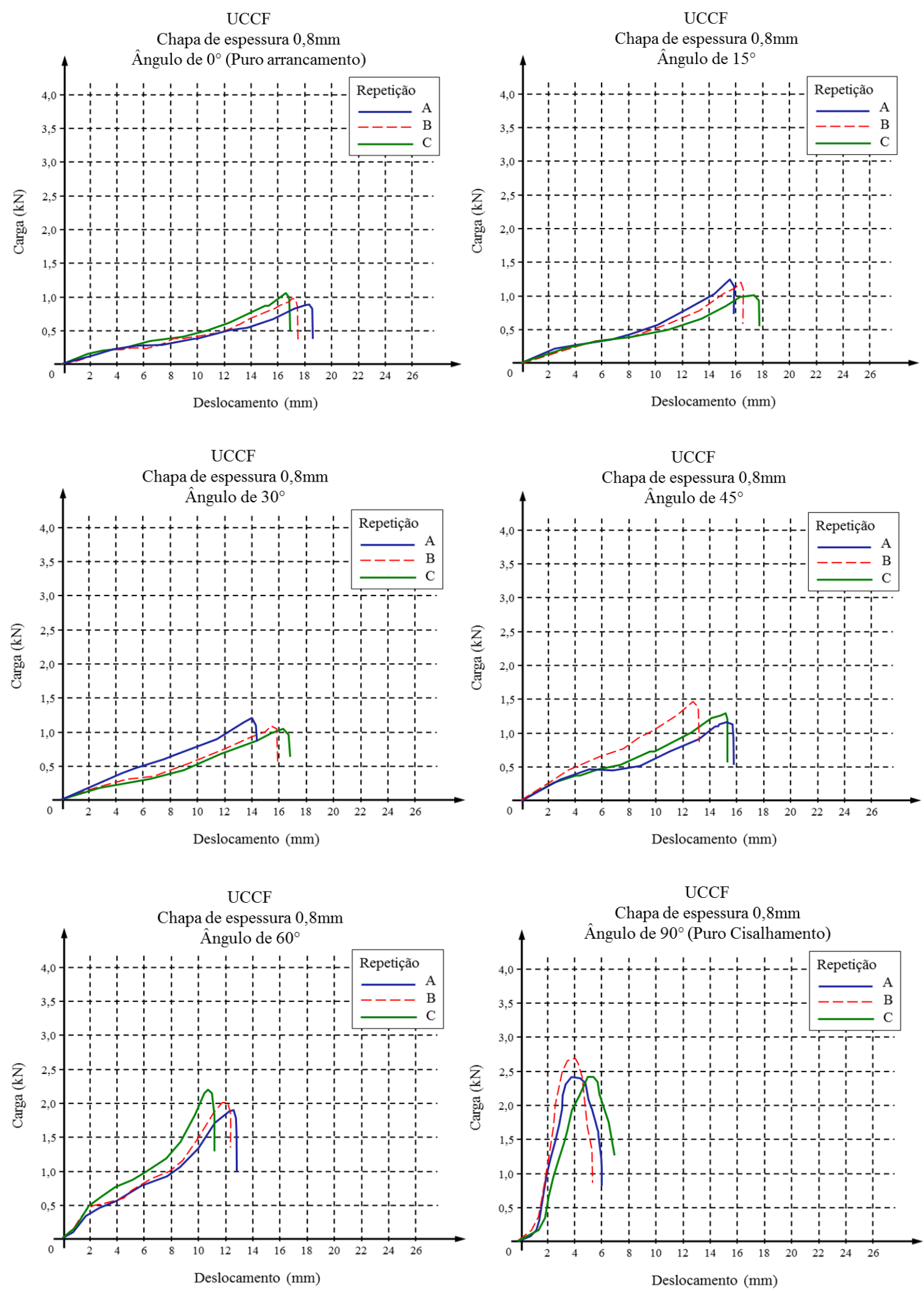
UCCF

Chapa de espessura $1,2 \mathrm{~mm}$

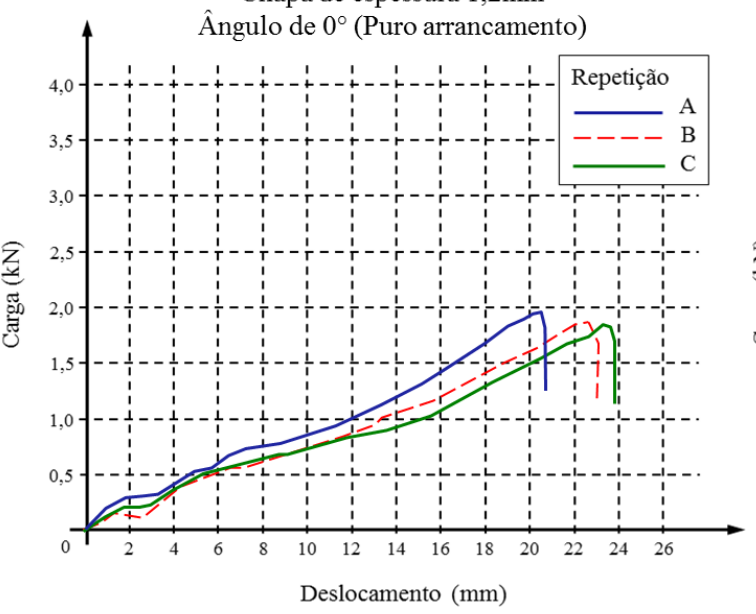

Clinching

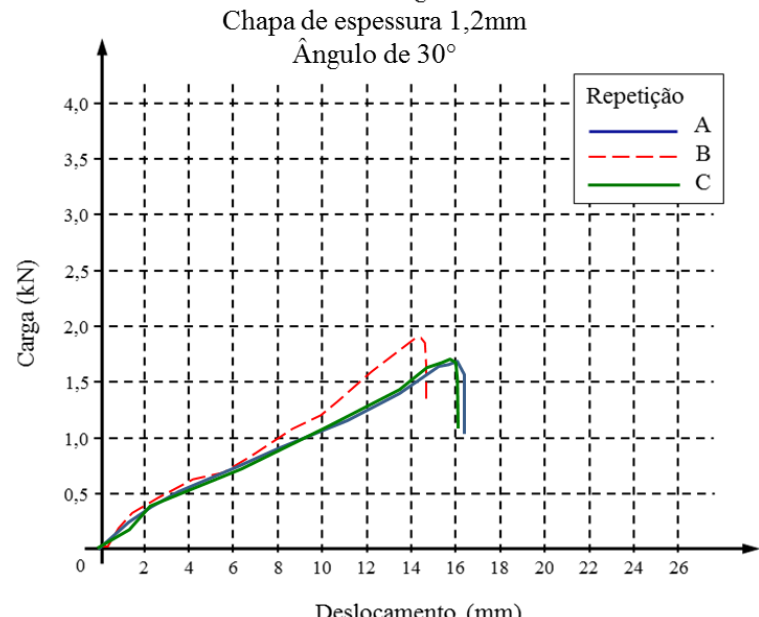

UCCF

Chapa de espessura 1,2mm

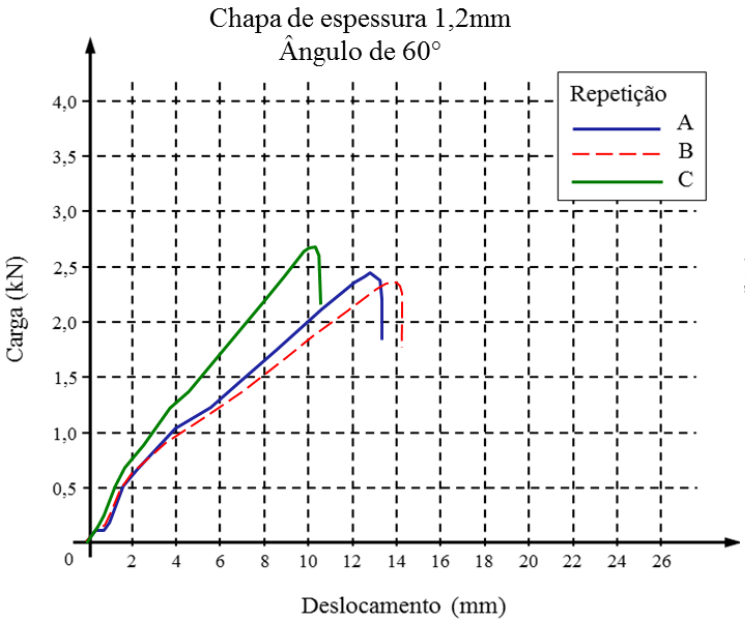

UCCF

Chapa de espessura $1,2 \mathrm{~mm}$

Ângulo de $15^{\circ}$

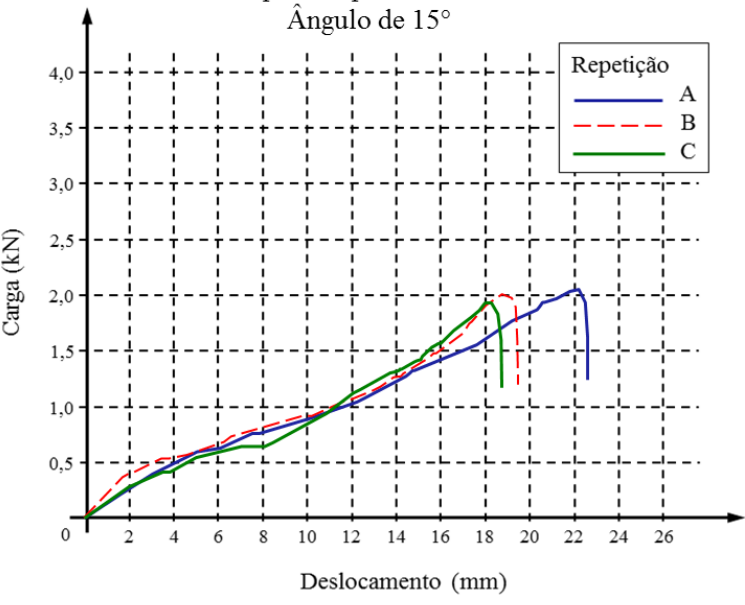

UCCF

Chapa de espessura 1,2mm

Ângulo de $45^{\circ}$

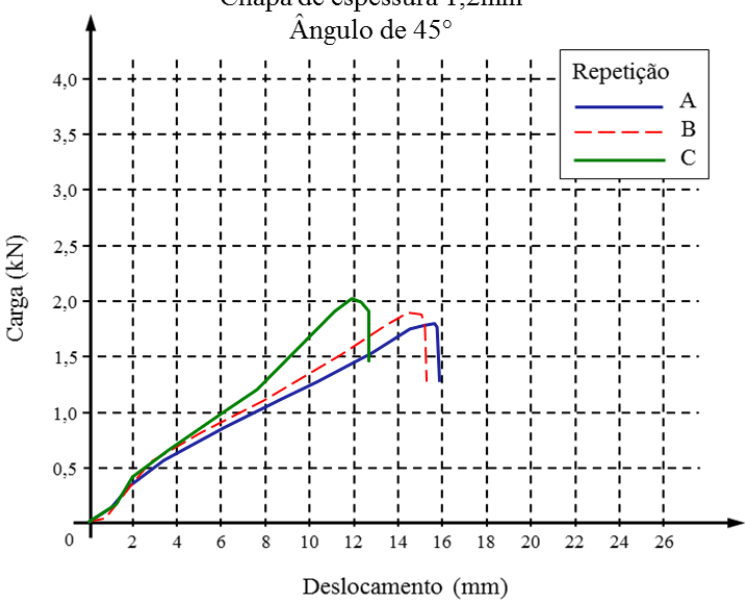

UCCF

Chapa de espessura $1,2 \mathrm{~mm}$

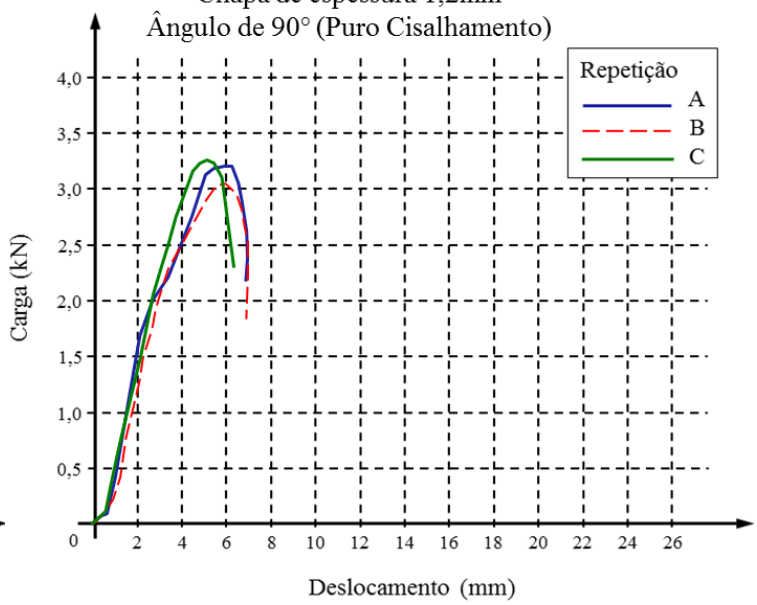




\section{ANEXOA}

Análise de custo de processo e investimento de oito processos de junção

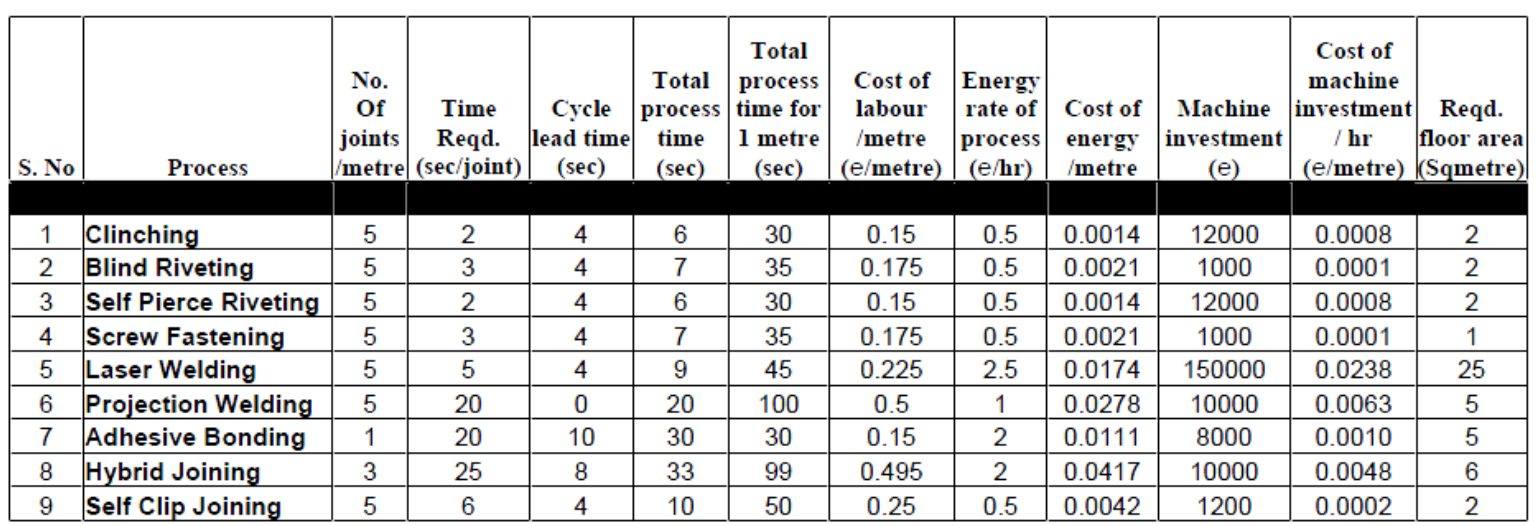

\begin{tabular}{|c|c|c|c|c|c|c|c|c|c|}
\hline S. No & Process & $\begin{array}{c}\text { Cost of unit } \\
\text { floor } \\
\text { area/metre } \\
\text { (e/metre) }\end{array}$ & $\begin{array}{c}\text { Tools and } \\
\text { Addnl. } \\
\text { elements } \\
\text { cost /metre } \\
(\mathrm{e} / \mathrm{mtr})\end{array}$ & $\begin{array}{c}\text { Monthly } \\
\text { Interest } \\
\text { (e) }\end{array}$ & $\begin{array}{c}\text { Working } \\
\text { Hour } \\
\text { interest } \\
(\mathrm{e} / \mathrm{hr})\end{array}$ & $\begin{array}{c}\text { Interest } \\
\text { per } \\
\text { metre } \\
\text { (e/metre) }\end{array}$ & $\begin{array}{c}\text { Compensation } \\
/ \mathrm{hr}(\mathrm{e} / \mathrm{hr})\end{array}$ & $\begin{array}{c}\text { Compensation } \\
\text { per metre } \\
(\mathrm{e} / \mathrm{metre})\end{array}$ & $\begin{array}{c}\text { Unit cost of process } \\
(\mathrm{e} / \text { metre })\end{array}$ \\
\hline 1 & Clinching & 0.000027 & 0.0250 & 200 & 0.581 & 0.005 & 0.00015 & 0.000001 & 0.1820 \\
\hline 2 & Blind Riveting & 0.000040 & 0.1000 & 16.67 & 0.048 & 0.001 & 0.00002 & 0.000000 & 0.2777 \\
\hline 3 & Self Pierce Riveting & 0.000027 & 0.0475 & 200 & 0.581 & 0.005 & 0.00015 & 0.000001 & 0.2045 \\
\hline 4 & Screw Fastening & 0.000020 & 0.0625 & 16.67 & 0.048 & 0.000 & 0.00002 & 0.000000 & 0.2402 \\
\hline 5 & Laser Welding & 0.000832 & 0.8350 & 2500 & 7.267 & 0.091 & 0.00476 & 0.000059 & 1.1929 \\
\hline 6 & Projection Welding & 0.000666 & 0.0500 & 167.7 & 0.488 & 0.014 & 0.00127 & 0.000035 & 0.5984 \\
\hline 7 & Adhesive Bonding & 0.000133 & 0.0500 & 133.34 & 0.388 & 0.003 & 0.00020 & 0.000002 & 0.2155 \\
\hline 8 & Hybrid Joining & 0.000599 & 0.0300 & 166.7 & 0.485 & 0.014 & 0.00095 & 0.000026 & 0.5854 \\
\hline 9 & Self Clip Joining & 0.000080 & 0.0750 & 25 & 0.073 & 0.001 & 0.00005 & 0.000001 & 0.3305 \\
\hline
\end{tabular}

Fonte: (ALI, 2005). 


\section{ANEXO B}

Características principais do Aço EMS.ME.1508 BFF EEP

GM BRASIL
ENGINEERING MATERIAL SPECIFICATION PRODUCT ENGINEERING

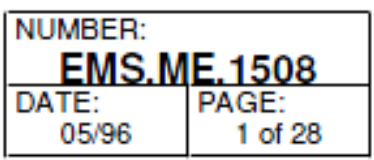

Cold Rolled Carbon Steel Sheets, Coated or Uncoated, for Drawing.

Chapas de Aço-Carbono, Laminadas a Frio, Revestidas ou Não - Revestidas, para Estampagem.

\subsection{Chemical Composition}

4.3 Composição Química

\begin{tabular}{|c|c|c|c|c|c|c|c|}
\hline $\begin{array}{l}\text { GRADE } \\
\text { GRAU }\end{array}$ & $\begin{array}{c}\% \\
\text { CARBON/ } \\
\text { CARBONO } \\
\text { MAX. }\end{array}$ & $\begin{array}{c}\% \\
\text { MANGANESE } \\
\text { MANGANES } \\
\text { MAX. }\end{array}$ & $\begin{array}{c}\% \\
\text { PHOSPHORUS/ } \\
\text { FOSFORO } \\
\text { MAX. }\end{array}$ & $\begin{array}{c}\% \\
\text { SULFUR/ } \\
\text { ENXOFRE } \\
\text { MAX. }\end{array}$ & $\begin{array}{c}\% \\
\text { ALUMINUM } \\
\text { ALUMINIO } \\
\text { MIN. }\end{array}$ & $\begin{array}{c}\text { \% } \\
\text { TITANIUM/ } \\
\text { TITÂNIO } \\
\text { MAX. }\end{array}$ & $\begin{array}{c}\% \\
\text { BORON } \\
\text { BORO } \\
\text { MAX }\end{array}$ \\
\hline EM & $0,007-0,100$ & 0,50 & 0,040 & 0,040 & $-X-$ & \multirow{2}{*}{$\begin{array}{l}-X- \\
-X-\end{array}$} & 0,0005 \\
\hline EP & $0,007-0,080$ & 0,45 & 0,030 & 0,030 & 0,015 & & 0,0005 \\
\hline EEP & $0,001-0,080$ & 0,45 & 0,020 & 0,020 & 0,015 & $0,010-0,20$ & 0,0005 \\
\hline EEP-PC & $0,001-0,060$ & 0,35 & 0,020 & 0,020 & 0,015 & $0,010-0,20$ & 0,0005 \\
\hline CSC & $0,001-0,007$ & 0,35 & 0,020 & 0,020 & 0,015 & $0,010-0,20$ & 0,0005 \\
\hline $180 \mathrm{BH}$ & 0,05 & 0,70 & 0,06 & 0,030 & 0,015 & \multirow{6}{*}{$\begin{array}{l}-X- \\
-X- \\
-X- \\
-X- \\
-X- \\
-X-\end{array}$} & 0,0025 \\
\hline $210 \mathrm{BH}$ & 0,07 & 0,70 & 0,08 & 0,030 & 0,015 & & 0,0025 \\
\hline $240 \mathrm{BH}$ & 0,08 & 0,80 & 0,10 & 0,030 & 0,015 & & 0,0025 \\
\hline $270 \mathrm{BH}$ & 0,09 & 1,00 & 0,11 & 0,030 & 0,015 & & 0,0025 \\
\hline $300 \mathrm{BH}$ & 0,10 & 1,30 & 0,12 & 0,030 & 0,015 & & 0,0025 \\
\hline $340 \mathrm{BH}$ & 0,12 & 1.50 & 0,12 & 0,030 & 0,015 & & 0,0025 \\
\hline
\end{tabular}

\subsection{Mechanical Properties}

\subsection{Propriedades Mecânicas}

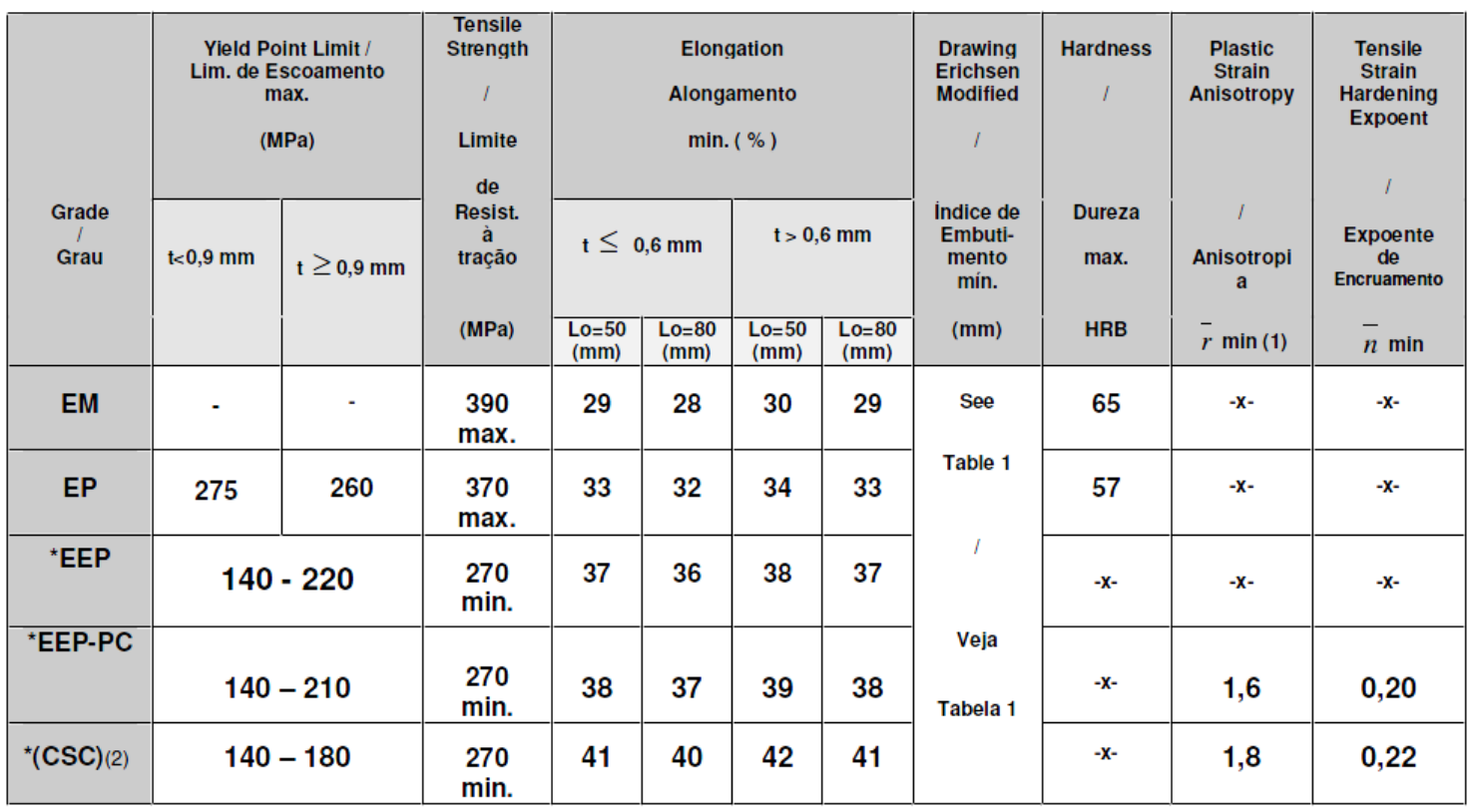




\section{ANEXO C}

Catálogo TOX ${ }^{\circledR}$ para seleção de diâmetro de ponto

TOX point $\oslash 6 \mathrm{~mm}$

total sheet thickness $1,0-3,0 \mathrm{~mm}$

\begin{tabular}{|c|c|c|c|c|c|c|c|}
\hline $\begin{array}{l}\text { sheet th } \\
\text { punch } \\
\text { side }\end{array}$ & $\begin{array}{l}\text { ness }(\mathrm{mm}) \\
\text { die } \\
\text { side }\end{array}$ & $\begin{array}{l}\text { material/coatin } \\
\text { punch side }\end{array}$ & g die side & $\begin{array}{l}\text { shear } \\
\text { strength } \\
\text { (N) }\end{array}$ & $\begin{array}{l}\text { tensile } \\
\text { strength } \\
\text { (N) }\end{array}$ & $\begin{array}{l}\text { pressing } \\
\text { force } \\
(\mathrm{kN})\end{array}$ & $\begin{array}{l}\text { TOX }^{\circledR} \text { test } \\
\text { report } \\
\text { number * }\end{array}$ \\
\hline \multicolumn{8}{|c|}{ steel uncoated } \\
\hline 0,60 & 0,60 & ZStE $180 \mathrm{BH}$ & ZStE $180 \mathrm{BH}$ & 1300 & 650 & 27 & 570021.2 \\
\hline 0,75 & 1,00 & St 1203 & St 1203 & 1400 & 1200 & 36 & 1.0001 .00 \\
\hline 1,00 & 0,75 & St 1203 & St 1203 & 2000 & 1000 & 36 & 1.0004 .00 \\
\hline 1,00 & 1,00 & St 1203 & St 1203 & 1800 & 1400 & 33 & 1.0007 .00 \\
\hline 1,00 & 1,50 & St 1203 & St 1203 & 1500 & 2100 & 40 & 1.0016 .00 \\
\hline 1,50 & 1,00 & St 1203 & St 1203 & 2100 & 1800 & 28 & 1.0019 .00 \\
\hline
\end{tabular}

TOX ${ }^{\circledast}$ point $\oslash 8 \mathrm{~mm}$

total sheet thickness $1,6-6,0 \mathrm{~mm}$

\begin{tabular}{|c|c|c|c|c|c|c|c|}
\hline $\begin{array}{l}\text { sheet thi } \\
\text { punch- } \\
\text { side }\end{array}$ & $\begin{array}{l}\text { ness }(\mathrm{mm}) \\
\text { die } \\
\text { side }\end{array}$ & $\begin{array}{l}\text { material/coat } \\
\text { punch side }\end{array}$ & die side & $\begin{array}{l}\text { shear } \\
\text { strength } \\
\text { (N) }\end{array}$ & $\begin{array}{l}\text { tensile } \\
\text { strength } \\
\text { (N) }\end{array}$ & $\begin{array}{l}\text { pressing } \\
\text { force } \\
(\mathrm{kN})\end{array}$ & $\begin{array}{l}\text { TOX test } \\
\text { report } \\
\text { number * }\end{array}$ \\
\hline \multicolumn{8}{|c|}{ steel uncoated } \\
\hline 0,75 & 1,00 & St 1203 & St 1203 & 2000 & 1200 & 51 & 1.0002 .00 \\
\hline 0,75 & 1,25 & ZStE 220 & ZStE 220 & 1850 & 1600 & 45 & 465019.0 \\
\hline 1,00 & 1,00 & ZStE 420 & ZStE 420 & 4000 & 2200 & 52 & 570021.0 \\
\hline 1,00 & 1,00 & St 1203 & St 1203 & 2700 & 1400 & 49 & 1.0008 .00 \\
\hline 1,00 & 1,50 & St 1203 & St 1203 & 2400 & 2700 & 54 & 1.0017 .00 \\
\hline 1,00 & 2,00 & St 1203 & St 1203 & 2500 & 2400 & 55 & 469603.0 \\
\hline 1,50 & 1,50 & ZStE 340 & ZStE 340 & 3600 & 2000 & 50 & 562607.5 \\
\hline 1,50 & 1,00 & St 1203 & St 1203 & 3800 & 1900 & 60 & 1.0020 .00 \\
\hline 2,00 & 2,00 & QStE 420 & QStE 420 & 3600 & 2600 & 55 & 364015.01 \\
\hline 3,00 & 1,50 & QStE 420 & QStE 420 & 6200 & 4400 & 50 & 370024.2 \\
\hline
\end{tabular}




\section{ANEXO D}

Resultados dos Ensaios Físicos de Arcan para SPRE

\begin{tabular}{|c|c|c|c|c|c|c|}
\hline \multicolumn{7}{|c|}{ Solda Ponto por Resistência - Chapa de $0,80 \mathrm{~mm}$} \\
\hline Ângulo & $\stackrel{\mathrm{A}}{\mathrm{A}}$ & $\begin{array}{l}\mathrm{B} \\
(\mathrm{kN})\end{array}$ & $\stackrel{\mathrm{C}}{\mathrm{C}}$ & $\begin{array}{l}\text { Média } \\
(\mathrm{kN})\end{array}$ & $\begin{array}{c}\text { Desvio } \\
\text { Padräo } \\
\text { (kN) }\end{array}$ & $\begin{array}{c}\text { Correção (t-student 95\%) } \\
\qquad(\mathrm{kN})\end{array}$ \\
\hline $0^{\circ}$ & $4,486,00$ & $4.497,00$ & $4.510,00$ & $4.497,67$ & 12.01 & $\pm 20,25$ \\
\hline $15^{\circ}$ & $4.011,00$ & $3.882,00$ & $3.557,00$ & 3.816 .67 & 233,95 & $3.816,67 \pm 394,40$ \\
\hline $30^{\circ}$ & 3.544 .00 & 3.579 .00 & 3.678 .00 & $3.600,33$ & 69.50 & $3.600,33 \pm 117,17$ \\
\hline $45^{\circ}$ & $3.734,00$ & $3.683,00$ & $3.742,00$ & $3.719,67$ & 32.01 & $\pm 53,96$ \\
\hline $60^{\circ}$ & $4.003,00$ & $3.581,00$ & $4.129,00$ & $3.904,33$ & 287.01 & $3.904,33 \pm 483,87$ \\
\hline $90^{\circ}$ & 5.549 .00 & 5.538 .00 & 5.557 .00 & 5.548 .00 & 9,54 & $5.548 .00 \pm 16.08$ \\
\hline
\end{tabular}

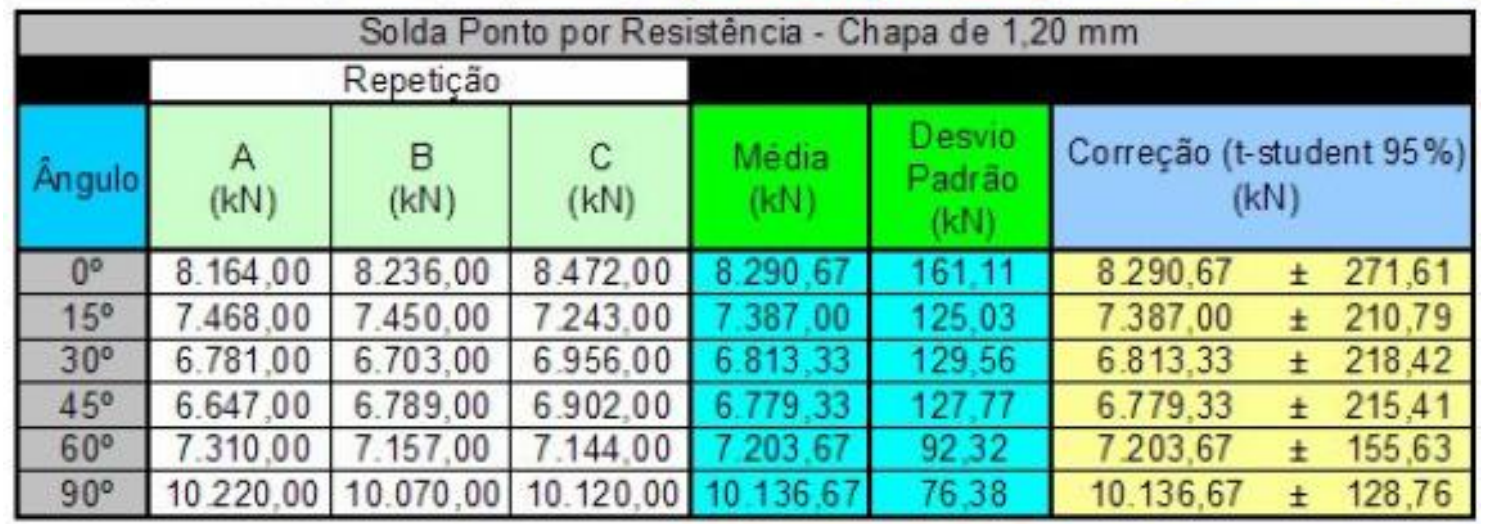

Fonte: Kavamura (2007) 